Espaço incremental para a mineração visual de conjuntos dinâmicos de documentos 



\title{
Espaço incremental para a mineração visual de conjuntos dinâmicos de documentos
}

\author{
Roberto Dantas de Pinho \\ Orientadora: Profa. Dra. Maria Cristina Ferreira de Oliveira \\ Co-orientadora: Profa. Dra. Rosane Minghim
}

Tese apresentada ao Instituto de Ciências Matemáticas e de Computação - ICMC-USP, como parte dos requisitos para obtenção do título de Doutor em Ciências - Ciências de Computação e Matemática Computacional.

"Versão apresentada para defesa"

Data da Defesa:

Visto da Orientadora:

USP - São Carlos

Abril/2009 

PINHO, R. Espaço incremental para a mineração visual de conjuntos dinâmicos de documentos. Tese de Doutoramento, Instituto de Ciências Matemáticas e de Computação, Universidade de São Paulo, 2009.

Representações visuais têm sido adotadas na exploração de conjuntos de documentos, auxiliando a extração de conhecimento sem que seja necessária a análise individual de milhares de textos. Mapas de documentos, em particular, apresentam documentos individualmente representados espalhados em um espaço visual, refletindo suas relações de similaridade ou conexões. A construção destes mapas de documentos inclui, entre outras tarefas, o posicionamento dos textos e a identificação automática de áreas temáticas. Um desafio é a visualização de conjuntos dinâmicos de documentos. Na visualização de informação, é comum que alterações no conjunto de dados tenham um forte impacto na organização do espaço visual, dificultando a manutenção, por parte do usuário, de um mapa mental que o auxilie na interpretação dos dados apresentados e no acompanhamento das mudanças sofridas pelo conjunto de dados. Esta tese introduz um algoritmo para a construção dinâmica de mapas de documentos, capaz de manter uma disposição coerente à medida que elementos são adicionados ou removidos. O processo, inerentemente incremental e de baixa complexidade, utiliza um espaço bidimensional dividido em células, análogo a um tabuleiro de xadrez. Resultados consistentes foram alcançados em comparação com técnicas não incrementais de projeção de dados multidimensionais, tendo sido a técnica aplicada também em outros domínios, além de conjuntos de documentos. A visualização resultante não está sujeita a problemas de oclusão. A identificação de áreas temáticas é alcançada com técnicas de extração de regras de associação representativas para a identificação automática de tópicos. A combinação da extração de tópicos com a projeção incremental de dados em um processo integrado de mineração visual de textos compõe um espaço visual em que tópicos e áreas de interesse são destacados e atualizados à medida que o conjunto de dados é modificado. 
PINHO, R. An incremental space for visual mining of dynamic document collections. Ph.D. Thesis, Instituto de Ciências Matemáticas e de Computação, University of São Paulo, 2009.

Visual representations are often adopted to explore document collections, assisting in knowledge extraction, and avoiding the thorough analysis of thousands of documents. Document maps present individual documents in visual spaces in such a way that their placement reflects similarity relations or connections between them. Building these maps requires, among other tasks, placing each document and identifying interesting areas or subsets. A current challenge is to visualize dynamic data sets. In Information Visualization, adding and removing data elements can strongly impact the underlying visual space. That can prevent a user from preserving a mental map that could assist her/him on understanding the content of a growing collection of documents or tracking changes on the underlying data set. This thesis presents a novel algorithm to create dynamic document maps, capable of maintaining a coherent disposition of elements, even for completely renewed sets. The process is inherently incremental, has low complexity and places elements on a 2D grid, analogous to a chess board. Consistent results were obtained as compared to (non-incremental) multidimensional scaling solutions, even when applied to visualizing domains other than document collections. Moreover, the corresponding visualization is not susceptible to occlusion. To assist users in indentifying interesting subsets, a topic extraction technique based on association rule mining was also developed. Together, they create a visual space where topics and interesting subsets are highlighted and constantly updated as the data set changes. 


\section{Agradecimentos}

Agradeço, antes de tudo, à professora Cristina, exemplo de profissional. Não existe problema que não seja recebido por ela com tranquilidade, atenção, e, sobretudo, com um sorriso no rosto. Agradeço as sábias palavras, os momentos agradáveis e o cuidado constante.

À professora Rosane, por sua dedicação, pela troca de ideias, por sua contribuição para a concretização deste trabalho, pelas risadas, e pela oportunidade de trabalhar em seu grupo de pesquisa e desenvolver trabalhos conjuntos.

Ao professor Alneu, pelos momentos de amizade e de trabalho. Levo comigo a imagem de incontáveis tardes no ICMC: tomar um café na cantina e correr para um dos quadros do corredor para testar fórmulas e ideias. A técnica de extração de tópicos foi essencialmente desenvolvida a quatro mãos. Levo também um sentimento de identificação e admiração.

A Vivi. Eu não teria finalizado este trabalho sem você. Em todas as dimensões, todas as coisas e todos os sentidos.

Aos amigos desde sempre e para sempre: Sérgio, Neca, Pontual, Clarice, Beto, Domingos, Joni, W. e os dvorakos.

Aos amigos paulistanos e neopaulistanos, que fizeram de Sampa um agradável refúgio de fim de semana, quase um lar: Doda e Panhoca [e grande família], Abreu, Erica, W. [de novo], Otávio e Teresa.

Ao Dr. Panhoca, pela tranquilidade para finalizar este texto.

À [também minha] família Malheiros pela acolhida, pela atenção e por todo suporte técnicooperacional.

Aos meus pais por se fazerem presentes, mesmo à distância. E, por terem plantado o que hoje posso colher. 
À minha família pela admiração e incentivo, concretizados em telefonemas, mensagens, curry, cartas, visitas e [longos] DVDs.

Aos colegas e amigos professor Manoel Mendonça e Daniela, por continuarem presentes, mesmo quando em hemisférios distintos, o que é bem comum.

Ao incansável Camilo, pelo outro lado da notícia, pelo outro lado da ideia, e for keeping me on my toes, always.

Aos colegas do LCAD. Cláudio, Fernando e Wagner pelas discussões e troca de experiências. A Kemelli, pelos eventos. Ao Renato Rodrigues, pela implementação da Topic Tree e respectivas visualizações. Ao Márcio, em especial, pela amizade, convivência e valiosa consultoria.

Ao meus professores no ICMC, pelas disposição e disponibilidade: Gustavo, Castelo, Graça Pimentel e Haim.

To Dr. Chen, who received me at Drexel university, for openning his research group to me, for creating an environment of knowledge creation, sharing and transfer.

To my friends Fidélia, Don, Xiaojun and Jian (James) at Drexel. I thank for their valuable contributions, and for making my period in the US full of rich work developments and joy.

À Ana Paula, Laura, Beth e todo pessoal do ICMC pela atenção e prestatividade.

À cidade de São Carlos, e, em especial, a dois de seus moradores: Cida e Seu Mário.

À UNIFACS, CAPES, CNPQ e FAPESP pelo apoio financeiro ao doutorado.

À musica do The Doors, Cowboy Junkies, Baden Powell, U2 e de Nina Simone, responsáveis pelos momentos de maior produtividade durante a escrita deste texto. 
Para os meus professores, aqueles cuja marca pode ser sentida ao longo deste trabalho e da minha vida. Relaciono aqui alguns, exemplos de dedicação:

Aderbal, Anice, Bass, Celina, Claudete, Cristina, Deida, Diva, Euclério, Iami, Isaac, Itamar, Jurema, Lisete, Lucinha, Mgmn, Mr. Straub, Rui, Sérgio Brito, Silveira, Tereza, Tia Augusta, Zilton, ... 
Toda a nossa ciência, comparada com a realidade, é primitiva e infantil - e, no entanto, é a coisa mais preciosa que temos.

Albert Einstein (1879-1955) 
Resumo

Abstract iii

\begin{tabular}{|ll}
\hline Lista de Figuras & xviii \\
\hline
\end{tabular}

\begin{tabular}{ll}
\hline Lista de Tabelas & xix \\
\hline
\end{tabular}

Lista de Símbolos $\quad$ xxii

$\begin{array}{lll}1 & \text { Introdução } & 1\end{array}$

1.1 Motivação . . . . . . . . . . . . . . . . . . . . . . . 1

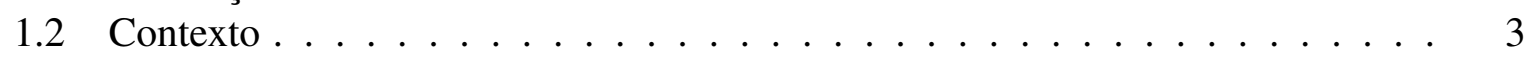

1.3 Identificação do problema . . . . . . . . . . . . . . . . . 5

1.4 Relevância e aplicabilidade das contribuições . . . . . . . . . . . . . . 5

1.4.1 Problemas em aberto . . . . . . . . . . . . . . . . 6

1.5 Objetivos e metodologia $\ldots \ldots \ldots \ldots \ldots \ldots$

1.5 .1 Resultados diretos . . . . . . . . . . . . . . . 8

1.6 Terminologia $\ldots \ldots \ldots \ldots \ldots \ldots \ldots$

1.7 Organização da tese . . . . . . . . . . . . . . . . . . . . . 9

\begin{tabular}{|lll}
2 & Visualização de domínios de conhecimento & 11
\end{tabular}

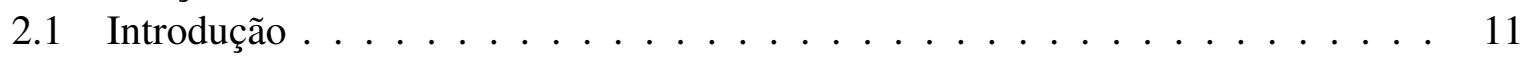

2.2 Processo de visualização de domínios de informação $\ldots$. . . . . . . . . . . . 13

2.3 Medidas de similaridade $\ldots \ldots \ldots \ldots \ldots \ldots \ldots$

2.3.1 Relação com a recuperação de informação . . . . . . . . . . . . . . . 16

2.3.1.1 Modelo vetorial . . . . . . . . . . . . . . . . . 17

2.3.1.2 Modelo Booleano . . . . . . . . . . . . . . . . . 19

2.3.1.3 Modelo Probabilístico . . . . . . . . . . . . . . 21

2.3 .2 Distância entre textos por complexidade de Kolmogorov . . . . . . . . 22

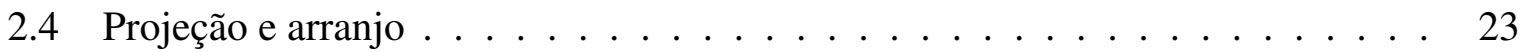

$2.4 .1 \quad$ Pathfinder network scaling (PFNET) . . . . . . . . . . . . . . 24 
$2.4 .2 \quad$ Self-Organizing Maps (SOMs) . . . . . . . . . . . . . . . 25

$2.4 .3 \quad$ Multi-Dimensional Scaling . . . . . . . . . . . . . . . . 26

$2.4 .4 \quad$ Layout de rede no Prefuse . . . . . . . . . . . . . . . . . . . . . . . . . . . 27

$2.4 .5 \quad$ Latent Semantic Analysis (LSA) . . . . . . . . . . . . . . . . . . . . . . . . 28

$2.4 .6 \quad$ Análise de Componentes Principais (PCA) . . . . . . . . . . . . . 29

2.4 .7 Fastmap . . . . . . . . . . . . . . . . . . 30

$2.4 .8 \quad$ Nearest-neighbor projection (NNP) . . . . . . . . . . . . . . . . . . . . . 31

2.4 .9 Projeção de agrupamentos (ProjClus) . . . . . . . . . . . . . . . . . 32

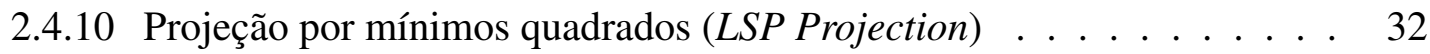

2.4 .11 Mapas em árvore . . . . . . . . . . . . . . . 33

2.4 .12 Soluções incrementais de projeção e arranjo . . . . . . . . . . . . . . 35

2.5 Visualização e interação . . . . . . . . . . . . . . . . 36

2.6 Soluções em visualização de domínios de conhecimento . . . . . . . . . . . . 39

$2.6 .1 \quad$ Self-Organization Maps (SOMs) cartográficos . . . . . . . . . . . . . . 39

2.6 .2 CiteSpace II . . . . . . . . . . . . . . . . . . 40

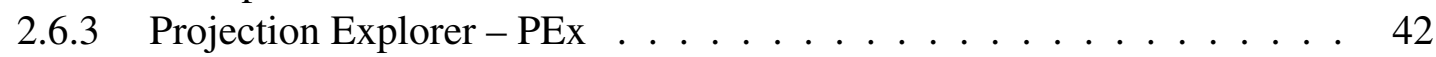

2.6 .4 IN-SPIRE . . . . . . . . . . . . . . . . . . . . . . . . . . . 44

2.7 Considerações finais $\ldots \ldots \ldots$. . . . . . . . . . . . . . . . . . . . . . 49

3 Extração de tópicos e mineração visual de textos 51

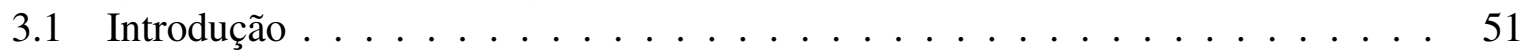

3.2 Mineração de dados . . . . . . . . . . . . . . . . . . . . . 51

3.3 Mineração e visualização . . . . . . . . . . . . . . . . . . . . 52

3.4 Mineração de textos . . . . . . . . . . . . . . . . . . . . . 54

3.4 .1 Regras de associação e mineração de textos . . . . . . . . . . . . . . . 55

3.5 Extração de Tópicos $\ldots \ldots \ldots \ldots \ldots \ldots \ldots$

$3.5 .1 \quad$ Identificação de temas de pesquisa por agrupamento de locuções . . . . 59

3.5 .2 Detecção de Burst . . . . . . . . . . . . . . . . . 61

3.5.3 Classificação e agrupamento de resultados de consultas . . . . . . . . . . 63

3.6 Tópicos e Visualização $\ldots \ldots \ldots \ldots \ldots \ldots$. . . . . . . . . . . . . . . . . 64

3.6.1 Mapas de tópicos . . . . . . . . . . . . . . . . . . . 65

3.6.2 Tópicos e sistemas de visualização . . . . . . . . . . . . . . . . . 65

3.7 Considerações finais $\ldots \ldots \ldots \ldots \ldots$. . . . . . . . . . . . 67

4 Posicionamento incremental de elementos no plano 69

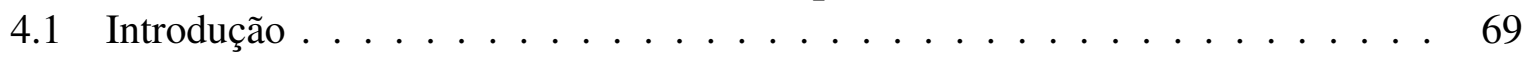

4.2 Trabalhos relacionados $\ldots \ldots \ldots \ldots \ldots \ldots$. . . . . . . . . . . . . . . . . . . . . . . . . . . .

4.3 O espaço incremental . . . . . . . . . . . . . . . . . . . . . . . . 74

4.3 .1 Construção dinâmica . . . . . . . . . . . . . . . . . . . 76

4.3.2 Complexidade algorítmica . . . . . . . . . . . . . . . . 79

4.4 Visualização incremental . . . . . . . . . . . . . . . . . . . . 81

4.5 Estudos de caso . . . . . . . . . . . . . . . . . . . . . . . . . . . . 82

$4.5 .1 \quad$ Comparação com técnicas de MDS . . . . . . . . . . . . . 82

4.5 .2 Cenários potenciais de uso do algoritmo . . . . . . . . . . . . . . . . 87

4.6 Considerações finais $\ldots \ldots \ldots$. . . . . . . . . . . . . . . . . 89 
5 Regras de associação com peso local para identificar tópicos em mapas de documentos $\quad 99$

$5.1 \quad$ Introdução . . . . . . . . . . . . . . . . . . . . . . . . . . . . 99

5.2 Visualização e regras de associação com peso local para extração de tópicos . . 101

5.2 .1 Extração de tópicos em áreas selecionadas pelo usuário . . . . . . . . . . 101

5.2.2 Extração de tópicos representativos do corpus . . . . . . . . . . . . . . . . 104

5.3 Exploração de mapas com base em tópicos . . . . . . . . . . . . . . . . . . . . 109

5.4 Estudos de caso . . . . . . . . . . . . . . . . . . . . . . . . . . . . 112

5.5 Mineração visual e identificação de tópicos em mapas dinâmicos de documentos 118

$5.5 .1 \quad$ Estratégia de atualização incremental de agrupamentos . . . . . . . . 118

5.5 .2 Estratégia de atualização incremental de tópicos . . . . . . . . . . . . . . 122

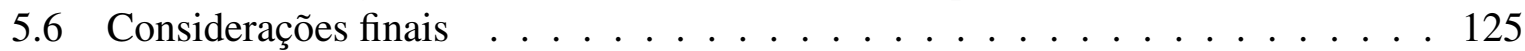

$\begin{array}{llr}6 & \text { Conclusão } & 129\end{array}$

6.1 Contribuições . . . . . . . . . . . . . . . . . . . . . . . . . . 129

$6.1 .1 \quad$ Contribuições principais . . . . . . . . . . . . . . . . . . . . . . 129

6.1.2 Outras contribuições . . . . . . . . . . . . . . . . . . . 131

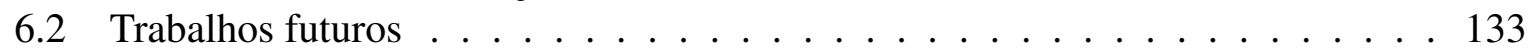

\begin{tabular}{ll}
\hline Referências Bibliográficas & 135
\end{tabular}

\begin{tabular}{ll}
\hline Apêndice A Trabalhos associados & 150
\end{tabular} 


\section{Lista de Figuras}

2.1 Porção de um Mapa Cartográfico com milhares de artigos, gerado por SOM. Extraído de Skupin e Fabrikant (2003) . . . . . . . . . . . . . . . . . . 12

2.2 Processo de produção de mapas de domínio. Adaptado de Börner et al.[(2003)] 13

2.3 Etapas para construção de um espaço vetorial de um corpus de documentos. . . 18

2.4 Exemplo de aplicação do algoritmo PFNET. Números indicam pesos associados

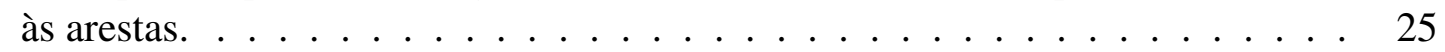

2.5 No topo, decomposição de uma matriz $M$ de termos $\times$ documentos em matrizes de autovalores e autovetores. Abaixo, seleção dos $k$ primeiros autovalores, na matriz $S$, e seleção de autovetores correspondentes para formar a matriz $M^{*}$. Adaptado de Chen(2004). . . . . . . . . . . . . . . . . . . 29

2.6 Casos de interseção para NNP (a) Círculos intersectam. (b) Não há interseção, um círculo interno. (c) Não há interseção ou inclusão. Adaptado de Tejada et

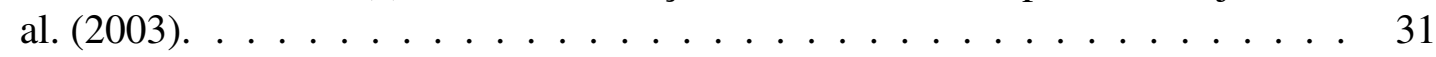

2.7 Mapa em árvore da população dos Estados Unidos Continentais em 2006. Tamanho e cor das regiões representam população total e mudança populacional, respectivamente. As linhas com início no centro de cada região mostram o seu deslocamento em relação à posição geográfica de cada estado em mapa de mesmas dimensões. Extraído de Wood e Dykes (2008). . . . . . . . . . . . . . 34

$2.8 \quad$ IDMAP com cursor aranha. Extraído de Minghim et al.(2006). . . . . . . . . . 38

2.9 Visão por períodos da pesquisa em extinções em massa, mostrando três subareas distintas da pesquisa. O segundo (de baixo para cima) e maior agrupamento trata da extinção K-T, quando pereceram os dinossauros, inicia com artigo de Alvarez et al. (1980), bastante citado, que propõe a queda de asteróide como causa do evento. A pesquisa acerca do assunto praticamente desaparece na década de 1990, após a descoberta de uma cratera, o que fortalece a hipótese de Alvarez et al.[(1980). Os demais agrupamentos tratam de extinções ocorridas em outros períodos. Extraído de Chen (2006). . . . . . . . . . . . . . . . 41

2.10 Author Co-citation Analysis, com 380 autores com 9 ou mais citações. Extraído de Börner et al. (2003). . . . . . . . . . . . . . . . . . . 42

\begin{tabular}{|l|l|l|l|l|l|}
\hline 2.11 Visão do mapa Author Co-citation Analysis visto na Figura & 2.10 & com barra de
\end{tabular} citação. A cor indica a data da citação. Extraído de Börner et al.(2003)] . . . . 43 
2.12 Mapa Document Co-citation Analysis de 394 artigos com barra de citação associada a cada documento. Exibidos os artigos com 10 ou mais citações. Extraído de Börner et al. (2003). . . . . . . . . . . . . . . . . . . . . 44

2.13 Opções de configuração para visualização em uma da versões da PEx. . . . . . 45

2.14 Ferramenta de seleção de termos na PEx. . . . . . . . . . . . . . . . 45

2.15 Galaxy View no IN-SPIRE. Extraído de Pacific Northwest National Laboratory

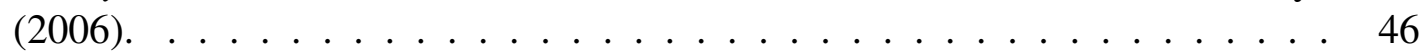

2.16 ThemeView no IN-SPIRE. Extraído de Pacific Northwest National Laboratory

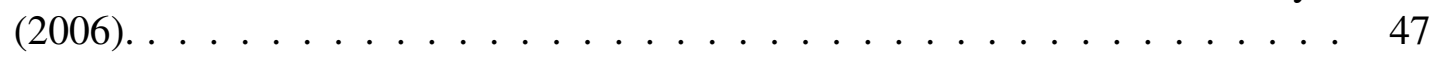

$3.1 \quad$ Visualização de regras de associação. Extraído de Wong et al. [1999). . . . . . 53

3.2 Interface da ferramenta I2E : visualização de conjuntos de itens (a) e controles para a exploração de regras (b). Extraído de Yamamoto et al.(2008). . . . . . . 54

3.3 Combinação de medidas de qualidade proposta por Cherfi et al. (2004). No diagrama, uma medida alta implica a classificação da regra entre os $k$ maiores valores encontrados para a dada medida. Analogamente, uma medida baixa indica que a regra foi classificada entre os $k$ menores valores encontrados. $\mathrm{O}$ conjunto resultado é dado por $I \cup I I \cup I I I . ~ \ldots \ldots \ldots \ldots . \ldots \ldots 7$

3.4 Visualização de um mapa de tópicos no Topic Navigator. Extraído de Baudon

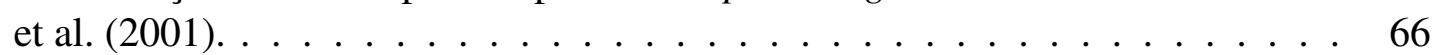

4.1 Diferentes versões, correspondentes a instantes distintos, de um mapa de documentos hipotético para um corpus de notícias. . . . . . . . . . . . . . . 71

4.2 Comparação entre medidas de distância entre células vizinhas computadas segundo fórmulas de distância Manhattan (a) e de Chebyschev (b), equações (4.1) e (4.2), respectivamente. . . . . . . . . . . . . . . 75

4.3 Número médio de movimentos necessários para estabilizar o tabuleiro após a adição de um novo documento, versus número de documentos no tabuleiro $(V)$ quando projetando um corpus de 675 artigos científicos (corpus CBR-ILP-IR-SON, apresentado em estudo de caso na Seção 4.5.1). . . . . . . . . . . . . . . . . . 80

4.4 Visualização de 1109 imagens etiquetadas manualmente. A similaridade entre imagens é determinada pela comparação entre etiquetas manualmente atribuídas às imagens. Mapa completo (a) e detalhe (b). . . . . . . . . . . . . . . . . 91

4.5 Parte de um mapa com 675 artigos científicos. Versões com bordas simples (a), bordas destacando a similaridade entre pares (b), cores representando classes manualmente atribuídas (c). Bordas mais finas denotam maior similaridade. Artigos classificados como Case-Based Reasoning (CBR), Inductive Logic Programming (ILP) e Sonification (SON) são mostrados em azul, vermelho e verde, respectivamente, em (c). . . . . . . . . . . . . . 92

4.6 Três momentos na construção incremental de um mapa do corpus CBR-ILP-IR-SON. A cor denota classes manualmente atribuídas aos elementos. . . . . . . . . . . 93

4.7 Três momentos da visualização do corpus CBR-ILP-IR-SON em que no máximo 300 documentos são mantidos no tabuleiro. A cor dos elementos denota classes manualmente atribuídas. . . . . . . . . . . . . . . . . . . . . . 94

4.8 A ferramenta de visualização incBoard, exibindo 493 documentos do corpus

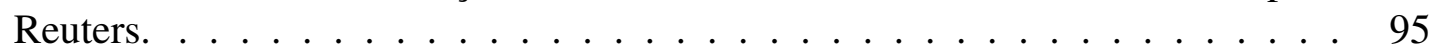


4.9 Visualização de 500 documentos do corpus Reuters, tendo 'Brazil Chrysler' como consulta ativa. Aproximadamente mil documentos adicionados desde o início do processo $\ldots \ldots \ldots \ldots \ldots \ldots$. . . . . . . . . . . . . . 96

4.10 Visualização de 500 documentos do corpus Reuters, tendo 'Brazil Chrysler' como consulta ativa. Aproximadamente 1.800 documentos adicionados desde o início do processo. . . . . . . . . . . . . . . . . .

5.1 Mapa de 574 artigos científicos. Glifos vermelhos, verdes e azuis representam artigos em raciocínio baseado em casos (Case based reasoning - CBR), Programação Lógica Indutiva (Inductive logic programming - ILP) e recuperação de informação (Information retrieval - IR), respectivamente. Bordas em cinza delimitam áreas demarcadas automaticamente para extração de tópicos. . . . . . 102

5.2 Exemplo da árvore de navegação por tópicos - Topic Tree Control. Os números que acompanham cada tópico indicam suporte e confiança, respectivamente para a regra de associação que deu origem ao tópico. O suporte é expresso em número de documentos que suportam a regra e a confiança em expressa em valores percentuais. O primeiro termo de um tópico é a cabeça (consequente)

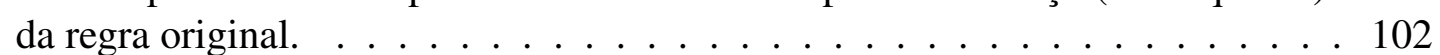

5.3 Visão parcial de um mapa de documentos para o corpus RSS, gerado no Projection Explorer e exibindo etiquetas com termos descritivos de tópicos. . . . . . 108

5.4 (a) Quantidade acumulada de regras $\times$ percentual de documentos cobertos para 3 iterações do Algoritmo 2 com 10, 60 e 110 agrupamentos. Marcadores foram adicionados no início e final de cada iteração. (b) Quantidade de regras induzidas $\times$ percentual de documentos cobertos na indução de 9.108 .828 regras (2.028.917 conjuntos distintos de termos frequentes) com diferentes valores de suporte mínimo usando o algoritmo Apriori sem modificações e confiança mínima fixada em $80 \%$. Marcadores indicam resultados para diferentes valores de suporte mínimo. . . . . . . . . . . . . . . . . . . . . . 110

5.5 Visualização de similaridade entre tópicos para os tópicos [bird, flu] até [moussaoui, zacarias] da Figura 5.7 . Cores mais escuras denotam maiores coeficientes de similaridade, e, portanto, maior compartilhamento de documentos entre tó-

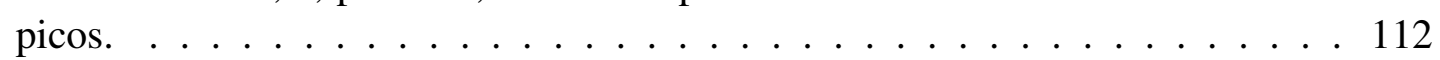

5.6 Visualização de similaridade por documentos para os tópicos [bird, flu] até [moussaoui, zacarias] exibidos na árvore da Figura 5.7] Cores mais escuras denotam maior similaridade entre documentos. . . . . . . . . . . . . . . . 113

5.7 Visão parcial da árvore de tópicos do corpus RSS, ordenada por suporte. Os primeiros elementos são mostrados. . . . . . . . . . . . . . . . . . . 114

5.8 Comparação entre os tópicos [baghdad, mosque], [moussaoui, zacarias] e [dead,

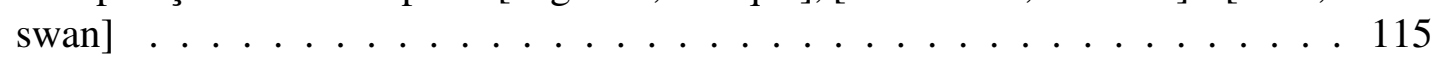

5.9 Exemplo de construção de novo mapa com documentos remanescentes após a exploração com base em tópicos. Mapa original incluindo apenas os documentos remanescentes (a) e novo mapa, gerado com o esse mesmo conjunto de documentos (b). As areas destacadas em vermelho contêm notícias relacionadas com o tópico $[$ bird,$f l u] . \ldots \ldots \ldots \ldots \ldots 117$ 
5.10 Exemplo de resultado de atualização incremental de agrupamentos para o corpus CBR-ILP-IR-SON. O triângulo colorido no interior de cada célula denota o resultado do agrupamento. Agrupamento inicial, obtido por k-means sobre 207 documentos (a) e mapa final com 675 (b). . . . . . . . . . . . . . . . . . 120

5.11 Exemplo de resultado de atualização incremental de agrupamentos para o corpus CBR-ILP-IR-SON. A cor de fundo de cada célula denota classes manualmente atribuídas aos elementos. O triângulo colorido no interior de cada célula denota o resultado do agrupamento. Agrupamento inicial, obtido por k-means sobre 340 documentos (a) e mapa final com 675 (b). . . . . . . . . . . . . . 121

5.12 Árvores de tópicos - (a) e (b) - e respectivos mapas - (c) e (d) - para os primeiros documentos de um subconjunto do corpus Reuters. Os documentos relacionados aos tópicos selecionados em (a) e (b), são destacados em amarelo nos mapas (c) e (d), respectivamente. 


\section{Lista de Tabelas}

$2.1 \quad$ Medidas bibliométricas de similaridade . . . . . . . . . . . . . . . . . . 15

2.2 Medidas usuais de distância (dissimilaridade) no modelo de espaço vetorial. . . 19

2.3 Técnicas de redução de dimensionalidade, abordagem e possibilidade de aplicação direta sobre matrizes de distância. . . . . . . . . . . . . . . . . . . . 24

3.1 Variantes léxico-sintáticas adotadas na identificação de temas de pesquisas. Exemplos extraídos de Ibekwe-SanJuan e SanJuan[(2002). . . . . . . . . . . . 60

4.1 Exemplo de ordenação por posição relativa. $d_{c}\left(E_{1}, E_{j}\right)$ é a distância computada no espaço $2 \mathrm{D}, R_{c}\left(E_{1}, E_{j}\right)$ é a classificação no espaço $2 \mathrm{D}$ do elemento $E_{j} \mathrm{em}$ relação ao elemento $E_{1}, \delta\left(E_{1}, E_{j}\right)$ é a dissimilaridade entre $E_{1}$ e $E_{j}$ computada no espaço $\mathrm{mD}$, e $R_{m}\left(E_{1}, E_{j}\right)$ é a classificação relativa em $\mathrm{mD}$ do elemento $E_{j}$

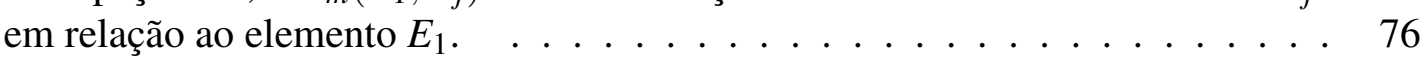

4.2 Resultados para diferentes técnicas de projeção usando o corpus CBR-ILP-IR-SON. Nearest Neighbor Precision (nnp) computada para os 8 primeiros vizinhos. Melhores resultados em negrito. . . . . . . . . . . . . . . . . . . . 84

4.3 Medidas de estresse e Nearest Neighbor Precision (nnp) computadas ao adicionar gradualmente documentos do corpus CBR-ILP-IR-SON em um tabuleiro usando incBoard, até um número total de 675 documentos. . . . . . . . . . . . 85

4.4 Medidas de estresse e Nearest Neighbor Precision (nnp) computadas ao substituir documentos do corpus CBR-ILP-IR-SON usando o incBoard em um tabuleiro com 300 células. . . . . . . . . . . . . . . . . 86

4.5 Resultados para diferentes técnicas de projeção com o conjunto de dados Iris. Nearest Neighbor Precision (nnp) computada para os 8 primeiros vizinhos. Melhores resultados em negrito. . . . . . . . . . . . . . 87

5.1 Tamanho, termos distintos, cobertura e suporte mínimo para conjuntos de regras extraídos do corpus RSS. . . . . . . . . . . . . . . . . . . . . . . . . 109 
$N$ tamanho do conjunto de dados ou corpus;

$E_{i}$ elemento $i$ de um conjunto de dados;

$t_{j}$ um termo;

$t f_{t_{j} D_{i}}$ Frequência de um termo $t_{j}$ em um documento $D_{i}$;

$i d f_{t_{j}}$ Inverso da quantidade de documentos que contêm o termo $t_{j}$;

$D_{i}$ documento $i$ de um corpus;

$w_{D_{i} t_{k}}$ peso atribuído ao termo $t_{j}$ no documento $D_{i}$;

$d f_{t_{j}}$ quantidade de documentos que contêm o termo $t_{j}$;

$\hat{w}_{D_{i} t_{j}}$ peso normalizado atribuído ao termo $t_{j}$ no documento $D_{i}$;

T. conjunto de termos de uma regra de associação, tópico ou corpus;

$C$ um corpus, conjunto de dados composto por documentos;

$L$ conjunto de elementos;

$d_{e}\left(E_{i}, E_{j}\right)$ distância euclidiana entre os elementos $E_{i}$ e $E_{j}$;

$d_{m}\left(E_{i}, E_{j}\right)$ distância Manhattan entre os elementos $E_{i}$ e $E_{j}$;

$d_{c o s}\left(E_{i}, E_{j}\right)$ distância por cosseno entre os elementos $E_{i}$ e $E_{j}$;

$m$ dimensionalidade de um conjunto de elementos;

$\mu_{i, k}$ função de pertinência de um documentos $D_{i}$ a um conjunto difuso, dado um termo $t_{k}$;

$c_{j, k}$ correlação entre termos $t_{j}$ e $t_{k}$;

$A T_{i}$ atributo de um conjunto de dados; 
$a t_{i j}$ valor do atributo $A T_{i}$ para o elemento $E_{j}$;

$q, r$ cadeias de caracteres;

$d_{k}\left(E_{i}, E_{j}\right)$ distância por complexidade de Kolmogorov entre os elementos $E_{i}$ e $E_{j}$;

$C(q)$ tamanho da cadeia resultante da compressão de $q$;

$m_{r}$ dimensionalidade de um conjunto após redução, $m_{r} \ll m$;

$L N_{E_{i}}$ conjunto de elementos próximos a $E_{i}$;

$L A_{E_{i}}$ conjunto de elementos aleatórios de E_i;

$\delta\left(E_{i}, E_{j}\right)$ dissimilaridade entre os elementos $E_{i}$ e $E_{j}$

$p_{i}$ ponto em um espaço que representa o elemento $E_{i}$;

$p_{i}^{\prime}$ projeção do ponto $p_{i}$;

$S_{k}$ um subconjunto de elementos de um conjunto de dados;

$T p_{i}$ um tópico;

$V$ quantidade de células em um mapa ou grade, ou número de elementos no tabuleiro;

$d_{c}\left(E_{i}, E_{j}\right)$ distância Chebyshev entre os elementos $E_{i}$ e $E_{j}$;

$m D$ espaço com dimensionalidade $m$;

$R_{c}\left(E_{i}, E_{j}\right)$ classificação no espaço $2 \mathrm{D}$ do elemento $E_{j}$ em relação ao elemento $E_{i}$;

$R_{m}\left(E_{i}, E_{j}\right)$ classificação em $m D$ do elemento $E_{j}$ em relação ao elemento $E_{i}$;

$w_{\text {err }}\left(E_{i}, L\right)$ erro ponderado para $E_{i}$ dado $L$;

$B$ conjunto de elementos no tabuleiro;

$\hat{d}\left(E_{i}, E_{j}\right)$ distância ajustada entre $E_{i}$ e $E_{j}$;

$P S_{i}$ um conjunto de pontos;

$N_{k}$ número de elementos de uma seleção $S_{k}$;

$T f_{t_{j} A}$ Frequência total de um termo $t_{j}$ no conjunto $A$;

$A R S$ conjunto agregado de regras;

$D S_{A}$ conjunto de documentos que suportam a regra de associação ou tópico $A$; 


\section{Introdução}

\subsection{Motivação}

Mapas geográficos fazem parte da história da humanidade e pode-se especular que os padrões utilizados na sua construção são mais difundidos do que qualquer outra forma de comunicação no mundo. No Brasil, o seu uso e interpretação fazem parte dos primeiros ciclos do ensino fundamental como ferramenta básica do estudo da geografia (Secretaria de Educação Fundamental, Brasi1, 1997).

Simultaneamente, é patente o grande volume e a crescente disponibilidade de informação em meio digital, ainda que não estruturada. Uma estimativa difundida aponta que aproximadamente $80 \%$ de toda informação corporativa está disponível exclusivamente em forma não estruturada (Bess et al., 2003; Grimes, 2008). Ela encontrar-se-ia espalhada em cartas, relatórios, apresentações, mensagens de correio eletrônico, planilhas, intranets, blogs e páginas em servidores Web e outros documentos eletrônicos, criados e atualizados a todo momento. Ainda que este valor seja questionado e oriundo de fontes não bem estabelecidas, são inúmeros os eventos que atestam a importância destas fontes de informação (Grimes, 2008). A crescente disponibilidade de conteúdo multimídia digital é outro desafio a ser considerado. Videoblogs 1 e Podcasts ${ }^{2}$ são cada vez mais comuns (Dean, 2005). O tratamento de objetos multimídia

\footnotetext{
${ }^{1}$ blogs ou weblogs cujo conteúdo principal são vídeos.

${ }^{2}$ Fontes de conteúdo digital (áudio, vídeo, etc) em formato RSS que permitem o acompanhemanto de atualizações.
} 
geralmente envolve a extração de características (features) (Baeza-Yates e Ribeiro-Neto, 1999). Estas características, estando no formato texto, permitiriam a utilização de técnicas específicas para texto sobre estes documentos multimídia. Um exemplo seria a transcrição, manual ou automática, de um arquivo de voz digital (ligação telefônica, notícia de rádio, etc.) e a aplicação de uma busca por termos sobre a transcrição.

Alguns esforços têm sido empreendidos para estruturar documentos, a fim de facilitar a sua recuperação e permitir que computadores e pessoas trabalhem em cooperação (Berners-Lee et al., 2001), como é o caso da Web Semântica (World Wide Web Consortium, 2005). No entanto, ainda que se assuma que todo documento encontrado esteja minimamente estruturado, o volume de documentos é, por si só, justificativa para a adoção de novas estratégias para a sua exploração.

Técnicas de mineração de dados e de visualização de informação têm sido adotadas no tratamento de conjuntos de dados não-estruturados, seja isoladamente ou em conjunto, no que denomina-se mineração visual de dados (ver Capítulo 3) e também na visualização de domínios de conhecimento (ver Capítulo2), cuja fonte primária de informação são artigos científicos, em formato estruturado ou semi-estruturado. Um exemplo da utilização de técnicas de visualização para a análise de dados não estruturados é a construção de mapas para representar espaços abstratos nos quais são posicionados documentos textuais. Estes mapas de documentos aproveitam a relativa familiaridade dos usuários com mapas geográficos e a grande capacidade dos mapas de transmitir informação.

Chen (2004) sugere que a navegação em um espaço de informação visual passa pela construção de um mapa cognitivo, tal como na navegação por um espaço real. O desafio é, neste caso, a construção de visualizações que permitam ao usuário manter uma conexão com o seu mapa cognitivo interior, sem que a complexidade do espaço de informação, representado e disponibilizado por meio do computador, torne-se um obstáculo.

Um caso particular da visualização de conjuntos de documentos apresentados como mapas é a apresentação de conjuntos dinâmicos. Quando se visualiza informação desprovida de parâmetros espaciais definidos, alterações nos dados podem impactar a representação visual substancialmente. Por exemplo, a visualização de uma série temporal de dados de países quando sobrepostos a um mapa mundi é mais estável do que observar estes mesmos dados em um espaço conceitual no qual os países estejam agrupados conforme o nível de renda ou forma de governo, sendo estas informações sujeitas a alterações significativas ao longo do tempo.

Neste contexto, Hetzler et al. (2005), a fim de possibilitar a visualização de conjuntos dinâmicos de documentos, fixaram como objetivos para o sistema que desenvolveram: (i) possibilitar aos usuários monitorar a visualização e identificar mudanças sempre que novos dados forem adicionados; (ii) minimizar perturbações no processo de análise e interação; (iii) prover 
um amplo espectro de ferramentas auxiliares - busca, marcação de conjuntos de interesse, etc e (iv) manter pesquisas e agrupamentos atualizados à medida que o conjunto sofre alterações.

No entanto, a solução adotada por Hetzler et al.(2005), e também por outros, para posicionar um conjunto no qual elementos são constantemente adicionados ou removidos toma como base um posicionamento inicial. Essa solução seria incapaz de refletir grandes mudanças no conjunto de dados, sendo necessário, de tempos em tempos, refazer todo o mapa, que, neste caso, guardaria pouca ou nenhuma semelhança com o mapa original. Propõe-se nesta tese uma terceira estratégia que incrementalmente posiciona e re-posiciona elementos de dados em um espaço que se assemelha a um tabuleiro de xadrez à medida que elementos são adicionados ou removidos, buscando minimizar as alterações no mapa.

Nesta tese é apresentado um processo integrado de visualização de conjuntos dinâmicos de documentos que visa facilitar a manutenção de um mapa cognitivo por parte do usuário em face a mudanças nos dados. Para isto, são adotadas duas estratégias: (i) a aplicação de um novo algoritmo para o posicionamento dinâmico e incremental de dados no plano e (ii) a identificação de subconjuntos e tópicos à medida que um mapa de documentos evolui. A identificação de tópicos se dá com a aplicação de um algoritmo seletivo de indução de regras de associação sobre o mapa. As soluções desenvolvidas abrangem os domínios da mineração visual de textos, da visualização de domínios de conhecimento e da projeção de dados multidimensionais.

\subsection{Contexto}

Conjuntos de documentos, notadamente artigos científicos, oferecem a base para a visualização de domínios de conhecimento, um dos campos de estudo em visualização de informação. A visualização de domínios de conhecimento (Knowledge Domain Visualization - KDViz) aborda não apenas a localização de um documento relevante para uma dada consulta, mas como identificar tendências, grupos, eventos e atores relevantes a partir do contexto determinado por um conjunto de documentos em análise. Seu objetivo é fornecer ao usuário uma visão abrangente do domínio representado por este conjunto de documentos. As técnicas de KDViz compreendem a criação de visualizações (usualmente representações por superfícies e grafos) para conjuntos de documentos, autores e conceitos, por meio de técnicas variadas de: (i) determinação de similaridade entre documentos, (ii) redução de dimensionalidade em conjuntos de dados, (iii) posicionamento espacial de elementos e, (iv) agrupamento (clustering).

No Capítulo 2, são apresentadas técnicas de visualização de conjuntos de documentos. O capítulo é organizado de acordo com uma descrição do processo de visualização, partindo do preprocessamento dos dados até a interação com usuários. Técnicas integrantes do processo e relevantes a esta tese são também detalhadas nesse capítulo. 
A visualização de domínios de conhecimento possui forte relação com as técnicas de recuperação de informação, no entanto, possuem objetivos diversos. Na recuperação de informação, conjuntos de documentos são comparados com uma consulta que representa uma necessidade de informação, para selecionar os documentos considerados relevantes. Os objetivos são diferentes na visualização de domínios de conhecimento, que prioriza a análise global de uma coleção, ou na mineração de textos, usualmente voltada à extração de padrões considerados interessantes. Pode-se também vincular a recuperação de informação ao atendimento a necessidades específicas, conquanto as demais proveriam respostas a necessidades mais amplas, como, por exemplo, entender como evolui a pesquisa em determinada área do conhecimento, ou ainda na descoberta de informação saliente, porém previamente desconhecida.

Apesar dessas divergências, a determinação de similaridade por conteúdo, a classificação e o agrupamento também assumem papel de destaque na recuperação de informação. Ademais, técnicas de visualização de domínios de conhecimento ou de mineração podem se mostrar adequadas para a análise de resultados de consultas. Sob uma outra ótica, técnicas de recuperação de informação podem se prestar às etapas de extração ou de preprocessamento de documentos, que integram a visualização de domínios de conhecimento ou a mineração de dados, respectivamente. Técnicas e conceitos da recuperação de informação considerados relevantes para os objetivos deste trabalho são brevemente abordados nos Capítulos $2 \mathrm{e} 3$.

Outro paradigma para abordar a análise exploratória de conjuntos de documentos é enxergá-la como um processo de mineração de textos. A mineração de textos (text mining) ou mineração de dados textuais (text data mining), ou ainda a descoberta de conhecimento em bases de dados textuais (knowledge discovery from textual databases), tem como objetivo a descoberta de padrões ou conhecimento não trivial a partir de documentos textuais não estruturados (Tan, 1999). Neste contexto, técnicas de visualização de informação podem ser vistas como um componente adicional no processo de mineração de um conjunto de documentos. A sinergia entre a mineração de dados e a visualização é explorada de forma mais abrangente na linha de pesquisa conhecida como mineração visual de dados (visual data mining) (Oliveira e Levkowitz, 2003). Na mineração visual, processos de análise de dados e visualização estão fortemente integrados. Quando aplicada a fontes de dados textuais, têm-se a mineração visual de textos ou visual text mining. Para este trabalho, são especialmente relacionadas as técnicas de extração de tópicos, sendo este o foco do Capítulo 3. Também nesse capítulo, é feita uma introdução ao uso de regras de associação na mineração de textos. Regras de associação possuem uma longa história na representação de conhecimento (Hand et al., 2001), tendo sido aplicadas no contexto de mineração de textos (Cherfi et al., 2004) e formam a base para a estratégia utilizada neste trabalho para a identificação de temas de interesse em grupos e subgrupos de documentos em um mapa visual (Capítulo 5). 


\subsection{Identificação do problema}

Mapas de documentos são capazes de representar áreas do conhecimento, destacar características e relações entre documentos, auxiliar no processo de exploração de grandes volumes de texto, e, em alguns casos, mostrar a evolução de um determinado assunto ou área do conhecimento.

A manutenção, por parte dos usuários, de um mapa cognitivo que lhes permita compreender a informação apresentada, relacionando adequadamente as imagens exibidas com a informação que lhes deu origem é fundamental para as tarefas de exploração em espaços conceituais (Chen, 2004). Quando se trata de um conjunto de dados que sofre constante atualização, é importante preservar o contexto dos usuários, que eles possam acompanhar alterações à medida que novos dados são acrescentados e que a representação sofra um mínimo de perturbação por parte do sistema (Hetzler et al., 2005).

As soluções correntes para a criação de mapas de conjuntos dinâmicos de documentos adotam duas estratégias: (i) soluções iniciais para a disposição de elementos no mapa são adotadas para o posicionamento de novos dados, ou (ii) novos mapas são gerados com o novo conjunto, contemplando tanto os dados originais quanto os dados adicionados. No primeiro caso, a solução é vulnerável a alterações significativas no conjunto de dados, deixando de representá-lo. No segundo, o contexto do usuário é abruptamente alterado, exigindo a reconstrução do seu mapa cognitivo.

Assim, procura-se uma solução que permita a construção de mapas de conjuntos dinâmicos de documentos capaz de representar adequadamente esse conjunto à medida que elementos são acrescentados ou retirados, minimizando as alterações necessárias, e assim facilitando a manutenção de um mapa cognitivo, pelos usuários, que os auxilie na compreensão da informação apresentada.

Entende-se que tal solução requer uma técnica incremental para o posicionamento de elementos no mapa, bem como uma estratégia, também incremental, para a identificação de documentos relacionados no mapa, documentos que, por exemplo, abordam temas em comum.

\subsection{Relevância e aplicabilidade das contribuições}

Thomas e Cook (2006) defendem que o estabelecimento da análise visual (visual analytics) como ciência foi motivado pela necessidade de integrar esforços nas áreas de visualização científica e de informação; análise estatística; representação de dados e conhecimento e das ciências cognitivas, tendo como objetivo atender as necessidades de especialistas que lidam com grande quantidade de dados dinâmicos em ambientes de alta demanda. Segundo esses 
autores, esforços neste sentido possuem ampla aplicabilidade, sendo potencialmente valiosos em situações em que a sobrecarga de informações e sua complexidade prejudicam a análise efetiva e a comunicação de resultados. Para Wong et al. (2003), tem especial importância a análise de fluxos de dados (data streams) que requerem tratamento imediato.

Para Wong e Thomas (2004), visual analytics é definida pela formação de metáforas visuais em conjunto com a interação, a fim de permitir a detecção do esperado e a descoberta do inesperado, em ambientes dinâmicos e volumosos de informação. O conjunto de tecnologias em visual analytics pode ser aplicado em diversos campos. O processo de análise e seus objetivos dominam, sendo suportados pelo alto poder informativo das técnicas de visualização e modelos dinâmicos de interação. Ainda segundo Wong e Thomas (2004), a visual analytics é um desenvolvimento das pesquisas em visualização científica e de informação, porém incluindo gestão do conhecimento, análise estatística, ciência cognitiva, apoio à decisão (decision science) e outras.

Neste trabalho, parte-se da premissa de que a integração de avanços em diversas áreas pode ser valiosa para o processo de análise de dados volumosos e complexos, capaz de trazer benefícios efetivos maiores do que avanços isolados, ainda que substanciais, em algoritmos ou técnicas específicas. Esta busca de sinergia se dá no processo interativo e iterativo de extração de tópicos apresentado no Capítulo 5, que combina visualização, tópicos automaticamente extraídos e intervenções feitas pelos usuários para extrair conhecimento.

No processo de integração de técnicas de visualização e mineração de conjuntos de documentos surgem contribuições importantes, mas também lacunas que suscitam o desenvolvimento de novas técnicas e soluções. Este caminho culminou no desenvolvimento da estratégia incremental de projeção descrita no Capítulo 4. O trabalho foi direcionado ao tratamento de conjuntos dinâmicos de documentos em formato texto. No entanto, a estratégia incremental de projeção tem aplicação para quaisquer conjuntos dinâmicos de dados em que se possa estabelecer uma medida de similaridade entre elementos. A aplicação em outros domínios da estratégia de posicionamento também é demonstrada no Capítulo 4.

\subsubsection{Problemas em aberto}

Chen (2005) identificou os dez principais problemas não resolvidos em visualização de informação:

1. Usabilidade;

2. Compreensão das tarefas elementares de percepção e cognição;

3. Necessidade de conhecimento prévio de ferramentas e convenções; 
4. Formação e treinamento;

5. Medidas intrínsecas de qualidade;

6. Escalabilidade;

7. Estética;

8. Mudança de paradigma: da visualização da estrutura para visualização da dinâmica de dados abstratos;

9. Causalidade, inferência visual e predições;

10. Visualização de domínios de conhecimento.

O trabalho aqui apresentado relaciona-se diretamente a três deles: (i) Mudança de paradigma: da visualização da estrutura para visualização da dinâmica de dados abstratos (problema 8), (ii) Causalidade, inferência visual e predições (problema 9) e (iii) Visualização de domínios de conhecimento (problema 10).

Ao possibilitar a projeção incremental de dados complexos, esta tese pode contribuir para tornar explícita a dinâmica da evolução de um conjunto de dados, especialmente se os mesmos são adicionados em ordem cronológica. Persegue-se, assim a mudança de foco sugerida no problema 8 .

No contexto do problema 9, Chen (2005) destaca o papel da visualização de informação para a descoberta de relações da causalidade, formação de hipóteses e avaliação das evidências disponíveis. Para isto, os usuários devem interagir livremente com dados e visualizações, com o auxílio de algoritmos complexos, o que se propõe neste trabalho.

Ainda para Chen (2005), a visualização de domínios de conhecimento compreende ou enfrenta elementos dos demais nove problemas apresentados, sendo por isso uma relevante área de pesquisa. $\mathrm{O}$ foco no tratamento de conjuntos dinâmicos de documentos em formato texto dado a esta tese é compatível com os trabalhos em visualização de domínios de conhecimento, que, via de regra, têm conjuntos de artigos como fonte primária de dados.

\subsection{Objetivos e metodologia}

O objetivo geral deste trabalho é o desenvolver um processo integrado de mineração e visualização de conjuntos dinâmicos de documentos, tendo como base a construção incremental de mapas de documentos e a identificação de subconjuntos de interesse.

São objetivos específicos deste projeto: 
- Desenvolver ou melhorar técnicas para a geração incremental de mapas de conjuntos dinâmicos de documentos, permitindo também a sua aplicação em um processo integrado de análise associado à mineração de texto com regras de associação;

- Identificar formas de seleção de regras de associação que permitam a delimitação de fronteiras temáticas, auxiliem na visualização de agrupamentos e de relações de relevância e na extração de conhecimento útil e previamente desconhecido a partir de um conjunto de documentos;

- Propor formas de identificação e caracterização de subconjuntos de interesse associados a temas ou tópicos;

- Permitir a exploração de conjuntos dinâmicos de documentos em um ambiente integrado de visualização/mineração.

\subsubsection{Resultados diretos}

São resultados diretos deste trabalho:

1. Uma interface para a aplicação do processo integrado de mineração e visualização de conjuntos de documentos, disponível como parte do projeto InfoVis 2 - A Repository of Visual Mining and Information Visualization and Sonification Techniques;

2. Um algoritmo, disponível no repositório de técnicas do projeto InfoVis2, que suporta a extração de regras de associação a partir de conjuntos de documentos;

3. Um algoritmo, disponível no repositório de técnicas do projeto InfoVis2, para a projeção incremental de dados multidimensionais;

Todo software desenvolvido está disponível para acesso livre, segundo a licença GPL.

\subsection{Terminologia}

Nesta monografia, o termo documento é utilizado para designar documentos eletrônicos em formato texto ou documentos que produziram informação em forma de texto (por exemplo, a transcrição de uma conversa telefônica ou uma descrição de uma imagem obtida por técnicas de visão computacional).

As expressões "visual analysis" e "visual analytics" têm tradução idêntica em português: análise visual. Assim, a expressão "análise visual" virá sempre acompanhada do original, entre parênteses, a fim de indicar o sentido desejado. 
$\mathrm{Na}$ literatura analisada para a elaboração deste trabalho, não foram encontradas definições consistentes para termo, conceito, tema e tópico. São adotadas as seguintes convenções:

termo vocábulo (palavra) ou locução ( $n$-gram), sem a restrição de definição prévia dada em de Holanda Ferreira (2004): 10.E. Ling. Vocábulo ou locução que denomina conceito, prévia e rigorosamente definido, peculiar a uma ciência, arte, profissão, ofício;

conceito conjunto de termos representativos de uma ideia, próximo ao sentido de "2.Ação de formular uma ideia por meio de palavras; definição, caracterização: O professor deu-nos um conceito de beleza absolutamente subjetivo. "(de Holanda Ferreira, 2004);

tema sinônimo de assunto, i.e., 1.Aquilo de que se trata, que é objeto ou matéria de observação, consideração, atenção, interesse, etc. (de Holanda Ferreira, 2004).

Na literatura específica de recuperação de informação e da extração de informação, "topic" - tópico - pode assumir significados diversos:

- uma necessidade de informação - materializada como uma descrição, lista de termos ou como uma consulta a ser apresentada a uma ferramenta de recuperação de informação;

- um conjunto de documentos relativos a um mesmo assunto ou que atendem a uma necessidade de informação;

- lista de termos descritivos de um assunto ou conjunto de documentos.

Nesta tese, adota-se tópico como a descrição dada a um conjunto de documentos, usualmente relacionados entre si, tipicamente representada por uma lista de termos e ao qual corresponde um conjunto de documentos por ele cobertos, i.e., que abordam o tema em questão, o que é, em geral, verificado pela presença da lista de termos nos documentos.

\subsection{Organização da tese}

O restante desta tese está assim organizado:

- No Capítulo 2, é apresentada uma revisão bibliográfica de técnicas de visualização de domínios de conhecimento, assim como uma descrição das principais tecnologias necessárias para a sua aplicação. Um processo de construção de visualizações de domínios de conhecimento proposto por Börner et al. (2003) é utilizado como referência para a organização do capítulo; 
- No Capítulo 3 é abordada a extração de tópicos, descrevendo-se também a mineração de dados, a mineração de textos, e as suas relações com a visualização de informação. É dado especial destaque à aplicação de regras de associação para a mineração de textos;

- No Capítulo 4é apresentado o algoritmo incremental de posicionamento de elementos de conjuntos dinâmicos de dados multidimensionais no plano, incremental Board - incBoard.

- A utilização de regras de associação para a identificação de tópicos e subconjuntos de interesse como base para um processo iterativo e interativo de mineração visual de textos é objeto do Capítulo 5. Nele, também é apresentado o espaço incremental e processo integrado de mineração visual de textos, fruto da união das contribuições para a identificação de tópicos e para a visualização incremental de conjuntos de documentos;

- Conclusões, contribuições e propostas de trabalhos futuros encontram-se no Capítulo 6 . 


\section{Visualização de domínios de conhecimento}

\subsection{Introdução}

As técnicas de visualização de domínios de conhecimento buscam oferecer a potenciais usuários uma visão geral acerca de um domínio de conhecimento específico. Elas buscam complementar abordagens tradicionais, como a elaboração de surveys, que exigem grandes esforços de mão de obra altamente qualificada, demandam tempo, são difíceis de reproduzir e são, além de tudo, subjetivas. Oferecem uma alternativa interessante porque, dependendo da técnica utilizada, ajudam o usuário a gradualmente assimilar a informação necessária à geração destes surveys. Neste caso, o foco sai da busca de documentos relevantes a uma consulta para a percepção da movimentação de agrupamentos intelectuais entre documentos em um contexto mais amplo e ao longo de um extenso período de tempo (Chen, 2004).

Na Figura 2.1. por exemplo, documentos são dispostos em um mapa, no qual as relações conceituais entre grupos de documentos são evidenciadas com a utilização de convenções adotadas em mapas cartográficos convencionais, que destacam zonas temáticas, identificando-as e separando-as, tal como é feito com estados e países (Skupin, 2002).

Técnicas de visualização de domínios de conhecimento podem também apoiar a recuperação de informação e a sua classificação (Börner et al., 2003). No entanto, Spence (Spence, 2000) 


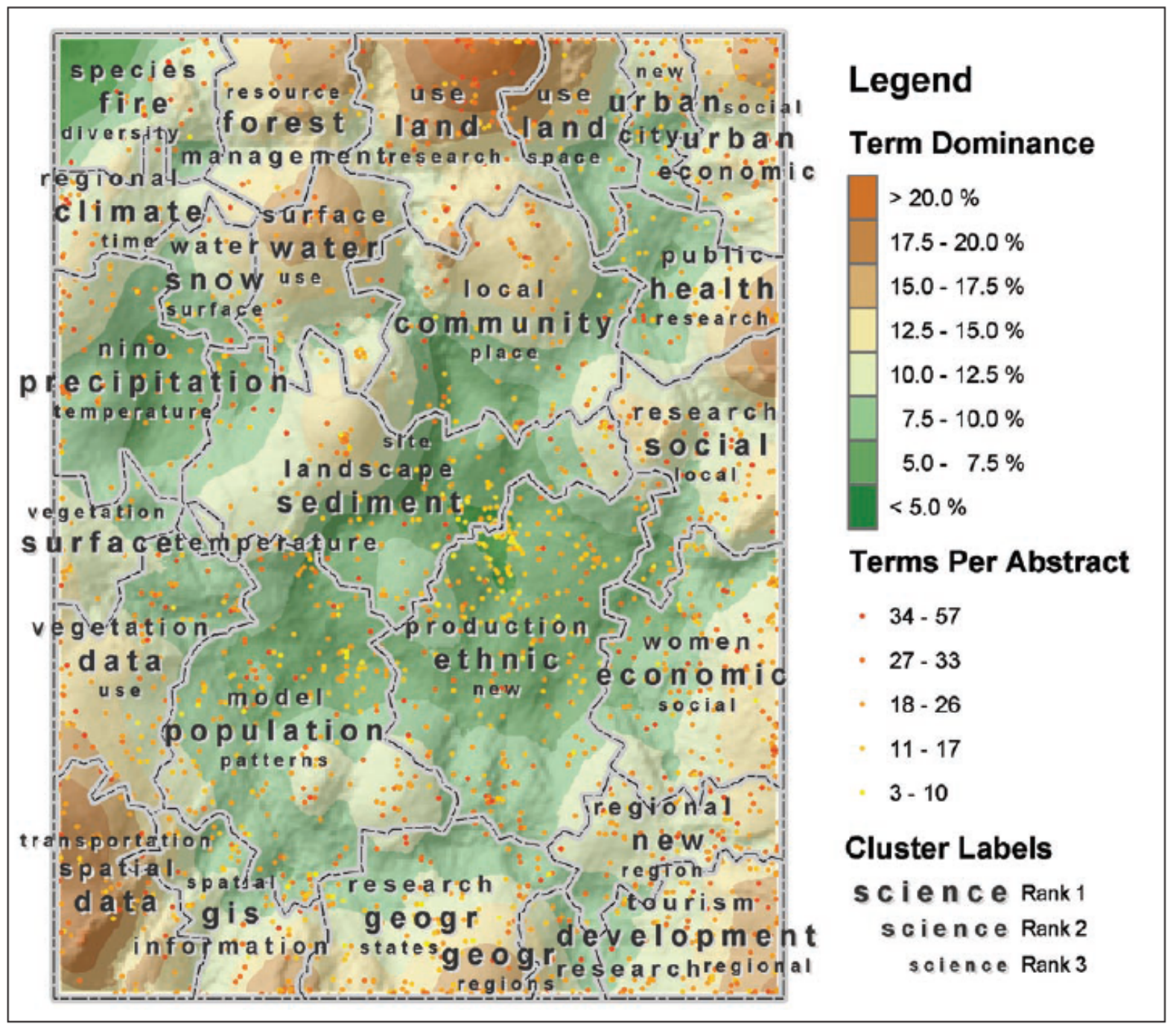

Figura 2.1: Porção de um Mapa Cartográfico com milhares de artigos, gerado por SOM. Extraído de Skupin e Fabrikant (2003)

ressalta que a visualização de documentos não é o mesmo que recuperação de informação, uma vez que o usuário talvez não saiba a priori o que está procurando, desejando obter inicialmente uma visão global, mesmo que imprecisa, possivelmente como forma de apoiar a formulação de consultas mais precisas para tarefas de recuperação de informação. Por analogia, pode-se afirmar o mesmo acerca da visualização de domínios de conhecimento.

Documentos disponíveis e as relações entre autores e citações neles encontradas são a fonte primária de dados para a visualização de domínios de conhecimento. A utilização simultânea de diversas técnicas sobre um mesmo conjunto de dados produz visualizações alternativas do domínio com diferentes perspectivas, possibilitando assim um maior entendimento do domínio do que se fosse utilizada uma única técnica. A análise visual (visual analytics) pode trazer 
novas perspectivas para a exploração de grandes volumes de textos não estruturados (Wong e Thomas, 2004).

Este capítulo descreve um processo de produção de mapas de domínios de informação (Seção 2.2) e detalha técnicas e algoritmos necessários ao processo (Seções 2.3, 2.4 e 2.5). Especial atenção é dada às soluções incrementais de projeção e arranjo (Seção 2.4.12), diretamente relacionadas ao algoritmo introduzido no Capítulo 4. Por fim, são apresentados alguns exemplos de soluções em visualização de domínios de conhecimento (Seção 2.6), seguidos das considerações finais (Seção 2.7).

\subsection{Processo de visualização de domínios de informa- ção}

O processo de produção de mapas de domínios de informação, como definido por Börner et al. (2003) é apresentado na Figura 2.2. Este processo prevê a realização de etapas sequenciais, em que a saída de uma etapa é a entrada da etapa subsequente, no entanto, nem todas as etapas são necessárias em todos os casos.

\begin{tabular}{|c|c|c|c|c|c|}
\hline $\begin{array}{l}\text { Extração } \\
\text { de } \\
\text { Dados }\end{array}$ & $\begin{array}{l}\text { Definição } \\
\text { da unidade } \\
\text { de análise }\end{array}$ & $\begin{array}{l}\text { Seleção } \\
\text { de } \\
\text { medidas }\end{array}$ & $\begin{array}{l}\text { Cálculo } \\
\text { de } \\
\text { Similarida }\end{array}$ & $\begin{array}{c}\text { Projeção } \\
- \\
\text { Arranjo }\end{array}$ & Interação \\
\hline
\end{tabular}

Figura 2.2: Processo de produção de mapas de domínio. Adaptado de Börner et al. (2003)

A “extração de dados" consiste na obtenção dos documentos e o seu preprocessamento, para viabilizar as etapas seguintes. Tipicamente, nesta etapa são eliminadas quaisquer marcações de formatação, como elementos HTML, produzindo documentos que contêm apenas texto.

Na etapa de "definição da unidade de análise", é identificada a unidade fundamental sobre a qual os mapas serão construídos. Unidades típicas são: autor, publicação, termo e documento. Dentre estas, a unidade mais comum é documento. Dentre os exemplos apresentados neste capítulo, as Figuras 2.1, 2.8, 2.12, 2.15 e 2.16 têm documentos como unidade de análise. Já as Figuras 2.10 e 2.11 usam autores como unidade de análise. Chen (2006) trabalha também com soluções híbridas em que unidades distintas fazem parte de um mesmo mapa ou rede, combinando, por exemplo, elementos que representam artigos e termos relevantes (Figura 2.9).

A escolha da unidade de análise é dependente do uso que se deseja para os mapas. Mapas que têm como unidade de análise o autor denotam a estrutura de um campo de pesquisa, ou as 
suas relações sociais, como na Figura 2.11. Mapas de publicações, por sua vez, são aplicados quando se busca uma visão de alto nível sobre determinado ramo do conhecimento, ou ainda das suas relações com outros ramos. Mapas semânticos, cuja unidade de análise são os termos encontrados nos documentos, são aplicados quando se quer obter uma visão da estrutura cognitiva de uma área. Mapas de documentos podem ser utilizados para diversas tarefas, incluindo a recuperação de documentos, análise de domínios, determinação de desempenho e produtividade em pesquisa, gerenciamento de ciência e tecnologia e inteligência competitiva (Börner et al. 2003).

Durante a "seleção de medidas", são feitos cálculos de frequência e contagens de cocitação, coautoria e presença de termos nos documentos, de acordo com o cálculo de similaridade, a ser feito na próxima etapa. Neste ponto, é comum eliminar documentos que não atendem a determinado limiar mínimo, como, por exemplo, ter sido citado por pelo menos 5 outros documentos.

Para o "cálculo de similaridade", a etapa seguinte, busca-se estabelecer relações entre os elementos analisados que deverão ser traduzidas como relações de distância durante a montagem dos mapas. Relações de similaridade comuns são: (i) ligações por citação; (ii) coocorrência e; (iii) distâncias medidas em um espaço vetorial de representação. Pesquisadores do ICMC adotaram um novo método para o cálculo de similaridade com base na complexidade de Kolmogorov (Telles et al., 2007). Esse e outros métodos serão tratados na Seção 2.3.

O resultado da etapa do cálculo de similaridade é, usualmente, uma matriz de distâncias, ou ainda uma representação em um espaço vetorial, ambas com alta dimensionalidade. Assim, na etapa de "projeção e arranjo" - Ordination, as medidas disponíveis são organizadas de maneira a gerar os mapas. Diversas técnicas de redução de dimensionalidade podem ser aplicadas para permitir que uma representação n-dimensional seja apresentada no espaço $2 D$ da tela. As técnicas usuais de projeção serão detalhadas na Seção 2.4. Ainda na etapa de "projeção e arranjo", deve ser feito o mapeamento de atributos dos dados, como, por exemplo, data de publicação ou número de citações, para atributos visuais dos mapas, como cor e altura de superfícies.

Por fim, técnicas convencionais de interação podem ser aplicadas sobre a visualização para a manipulação e exploração dos mapas criados.

Spence (2000) define um processo mais simples para visualização de documentos que pode ser relacionado ao processo descrito acima. O processo de Spence prevê apenas as etapas de (i) Análise; (ii) Algoritmos e; (iii) Visualização. A etapa de Análise corresponde às etapas de extração de dados, definição da unidade de análise, seleção de medidas e cálculo de similaridade, conforme o processo de Börner et al. (2003). Já as duas últimas etapas, Algoritmos e Visualização, estão englobadas na etapa de projeção e arranjo, na qual é feita a redução de 
dimensionalidade (etapa de aplicação de Algoritmos) e o mapeamento de atributos (etapa de Visualização).

\subsection{Medidas de similaridade}

A escolha de medidas de similaridade é crucial para a construção de mapas de documentos e de outras formas de visualizar domínios de conhecimento. Ela determinará o tipo de relação a ser denotada pela distribuição espacial dos elementos nos mapas gerados.

Em corpora de artigos científicos, é frequente a adoção de medidas derivadas de relações bibliográficas, como, por exemplo, coautoria ou cocitação para a determinação de similaridade. Alternativamente, adota-se também a comparação entre conteúdo dos documentos, sobretudo se informação bibliométrica não está disponível, ou em domínios em que tal informação não se aplique, como na visualização de conjuntos de notícias, em que relações de cocitação não são relevantes ou mesmo disponíveis, por exemplo. A determinação de similaridade por conteúdo na visualização de domínios de conhecimento tipicamente adota modelos desenvolvidos para a recuperação de informação. $\mathrm{Na}$ Seção 2.3.1. esta relação é brevemente explorada, sendo descritos alguns modelos clássicos da recuperação de informação.

É descrito também o computo da distância entre textos por complexidade de Kolmogorov (Seção 2.3.2), que tem sido adotado na visualização de conjuntos de documentos (Telles et al., 2007).

A Tabela 2.1 traz uma descrição sucinta de diversas medidas bibliométricas de similaridade.

Tabela 2.1: Medidas bibliométricas de similaridade.

\begin{tabular}{|l|l|}
\hline \multicolumn{2}{|c|}{ Ligações por citação } \\
\hline Variação & Descrição \\
\hline cocitação & $\begin{array}{l}\text { os dois elementos, sejam eles autores, documentos ou periódicos, } \\
\text { são citados por um terceiro elemento }\end{array}$ \\
\hline citação direta & um dos elementos contém citação ao outro elemento \\
\hline acoplamento bibliográfico & $\begin{array}{l}\text { quando dois documentos citam um } \\
\text { terceiro documento (Egghe e Rousseau. 2002) }\end{array}$ \\
\hline ligação combinada & $\begin{array}{l}\text { proposta por Small } \\
\text { citação direta e indireta }\end{array}$ \\
\hline \hline & \multicolumn{1}{|c|}{ Ligações por coocorrência } \\
\hline Variação & Descrição \\
\hline termos comuns & presença de termos comuns (co-term) nos documentos \\
\hline classificação comum & documentos pertencem a uma mesma classe(coclassification) \\
\hline cocitação de autores & quando dois documentos citam um mesmo autor \\
\hline cocitação de documentos & o mesmo que acoplamento bibliográfico \\
\hline
\end{tabular}


A diferença entre a similaridade determinada pela cocitação de documentos no contexto de ligações por coocorrência e a similaridade derivada da cocitação no contexto das ligações por cocitação, é que, no primeiro caso, são considerados similares (próximos) documentos que citam um terceiro documento, enquanto que no segundo caso são considerados similares os documentos que são citados em um outro documento. Considere, por exemplo, quatro documentos A, B, C e D. Se A e B citam C e D, A e B são julgados similares se considerada a co-ocorrência da citação de $\mathrm{C}$ (e também de $\mathrm{D}$ ). Por outro lado, se a análise de similaridade for feita por cocitação, C e D são considerados similares, pois ambos são citados em A (e, adicionalmente, em B).

\subsubsection{Relação com a recuperação de informação}

A recuperação de informação aborda a representação, o armazenamento, a organização e o acesso a itens de informação. A organização e o armazenamento destes itens devem prover fácil acesso dos usuários a itens de interesse (Baeza-Yates e Ribeiro-Neto, 1999). Ela usualmente envolve a codificação da necessidade de informação apresentada pelo usuário na forma de uma consulta, e a subsequente indicação de todos os documentos considerados relevantes para esta consulta, evitando a indicação de documentos não relevantes.

Parte importante do processo de recuperação de informação é a ordenação (ranking) dos resultados de uma consulta. A ordenação pode ser vista como a determinação de um grau de similaridade entre documentos e uma consulta do usuário, tal como é necessário ao processo de visualização de domínios de conhecimento. No entanto, a visualização de domínios de conhecimento requer uma medida de similaridade computada para cada par de documentos, enquanto que na recuperação de informação a comparação do conjunto de documentos é feita apenas em relação à consulta apresentada. Afora a maior complexidade inerente ao processo, que pode chegar a $O\left(n^{2}\right)$, se a construção de um mapa de documentos demandar a comparação entre todos os pares de documentos, outras questões se apresentam ao tratar as relações de similaridade entre todo um conjunto de documentos, como, por exemplo, qual o vocabulário a ser considerado na construção de um modelo de espaço vetorial.

Não obstante, estratégias adotadas para a recuperação de informação podem vir a ser transpostas, com algum esforço, para o problema, assim como aconteceu com o modelo de espaço vetorial, proposto por Salton et al. (1975) originalmente para a recuperação de documentos.

Nesta seção, são descritos os modelos booleano (teoria dos conjuntos), vetorial e probabilístico de recuperação de informação, considerados clássicos por Baeza-Yates e Ribeiro-Neto (1999). O modelo vetorial é enfatizado, devido à sua ampla aplicação na visualização de domínios de conhecimento. 


\subsubsection{Modelo vetorial}

No modelo vetorial ou modelo de espaço vetorial, Vector Space Model - VSM (Salton et al., 1975), para a recuperação de informação, consultas são definidas por um pequeno conjunto de termos dados pelo usuário. Tanto as consultas quanto os documentos são representados como vetores em um espaço n-dimensional. Cada uma das dimensões destes vetores representa a presença ou a frequência de cada termo encontrado no documento em questão. A similaridade entre o vetor da consulta e os vetores dos documentos é avaliada e são recuperados os documentos cuja similaridade é superior a um dado limiar (threshold), que são tipicamente listados em ordem decrescente de similaridade.

No momento em que apenas um pequeno conjunto de termos deve ser comparado com documentos completos, algumas escolhas na aplicação do modelo têm impacto diferente do que quando documentos completos são comparados entre si. Por exemplo, a eliminação de palavras comuns (stopwords) é uma estratégia bastante adotada para reduzir o número de termos a serem indexados. Estas palavras, por estarem presentes na maior parte do documentos, podem não servir para diferenciá-los. No entanto, para consultas específicas, a eliminação de qualquer palavra pode tornar o modelo incapaz de produzir resultados apropriados. Por exemplo, a eliminação da palavra 'água' em um corpus pode transformar a consulta por 'água pesada'1 na consulta por 'pesada' ou mesmo em uma consulta nula, caso o termo 'pesada' também tenha sido eliminado do índice. Este tipo de problema justifica a adoção de índices contendo todos os termos encontrados (full text index) pelas ferramentas de busca na Internet (Baeza-Yates e Ribeiro-Neto, 1999).

Apesar de trazer graves consequências para o tratamento de consultas curtas, a eliminação de termos, em geral, tem impacto reduzido quando adotada para a comparação de documentos inteiros. Intuitivamente, é possível perceber que outros termos conseguem substituir aqueles eliminados no estabelecimento de relações entre dois documentos. No exemplo acima, o termo 'deutério' talvez seja encontrado com frequência em documentos que se refiram a 'água pesada' ${ }^{1}$.

A seleção de termos a serem indexados também é influenciada pelo contexto. Termos irrelevantes em um contexto podem vir a ser importantes em outros. A título de ilustração, o termo 'deputado' pode ser irrelevante entre os artigos do Jornal da Câmara, mas pode determinar contexto em artigos de uma agência de notícias. A relevância de um termo em uma coleção específica pode ser avaliada automaticamente com base na sua distribuição (Bookstein et al., 1998). Para a recuperação de informação, termos considerados relevantes poderiam receber maior peso, enquanto para a comparação de documentos, termos pouco relevantes

\footnotetext{
${ }^{1}$ Água pesada. 1. Quím. Óxido de deutério, ou solução aquosa deste óxido, líquida, incolor (de Holanda Ferreira, 2004).
} 
seriam simplesmente eliminados. Foi também proposta a combinação de medidas, computadas sobre conjuntos distintos de termos e agregadas com pesos distintos (Zhou et al., 2007).

No modelo vetorial, assume-se que os termos são mutuamente independentes. Para a recuperação de informação, esta característica é interessante, uma vez que a correlação entre termos é também dependente de contexto. Ou seja, a adoção de alguma medida fixa de correlação entre termos pode prejudicar o resultado de uma consulta. No entanto, na análise de conjuntos de documentos, medidas de correlação podem ser úteis. Uma forma de prever a correlação entre termos no modelo vetorial é trocar o índice de termos por um índice de conceitos. Assim, cada dimensão no espaço representaria um conjunto de termos. Um thesaurus permitiria associar um conjunto de termos a uma dimensão. Esta operação equivaleria a substituir todas as variações de termos encontradas nos documentos por uma forma comum, indicativa de um conceito (Cherfi et al., 2004). Outra forma seria a aplicação da técnica LSA (ver Seção 2.4.5). Outras possibilidades incluem a utilização de matrizes de associação entre termos (Wise, 1999).

As etapas gerais do processo de construção de um espaço vetorial, como adotadas neste trabalho, estão ilustradas na Figura 2.3 .

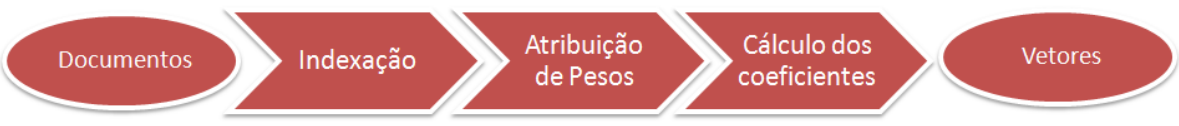

Figura 2.3: Etapas para construção de um espaço vetorial de um corpus de documentos.

Durante a etapa de indexação, é montado um vetor a partir da análise dos termos encontrados em cada documento. Termos com frequência muito alta são eliminados. Muitas vezes isto é feito utilizando stopwords, i.e., uma relação de palavras comuns que devem ser eliminadas, que inclui palavras como os artigos definidos e indefinidos. Termos muito pouco frequentes também podem ser eliminados, pois considera-se que eles não ajudam a discriminar entre documentos diferentes. A seleção de termos por frequência é conhecida como cortes de Luhn (Luhn) (1957) apud Bookstein et al. (1998)). Outra técnica comum é a redução de termos ao seu radical (stemming). Não obstante, os vetores formados após esta etapa possuem, ainda assim, uma dimensionalidade da ordem de milhares, o que dificultará a etapa seguinte da construção da visualização, que deverá reduzir ou projetar este espaço de alta dimensionalidade para uma representação em apenas duas ou três dimensões.

$\mathrm{Na}$ atribuição de pesos, a cada termo é atribuída uma importância na representação dos documentos. Um modelo bastante utilizado é o modelo $t f \times i d f$ que considera a frequência do termo no documento $(t f)$ e o inverso da frequência do termo no corpus (idf). O peso de um termo $t_{k}$ em um documento $D_{i}$ específico é dado pela fórmula abaixo: 


$$
w_{i k}=t f_{i k} \times \log \left(\frac{N}{d f_{k}}\right)
$$

onde $t f_{i k}$ é a frequência do termo $t_{k}$ no documento $D_{i}, N$ é o total de documentos no corpus e $d f_{k}$ é o número de documentos da coleção que contêm o termo.

Ainda nesta etapa, é comum considerar a normalização dos valores encontrados em função do tamanho dos documentos, uma vez que documentos longos terão, naturalmente, uma maior ocorrência dos termos. Esta normalização pode ser dada pela fórmula (Salton e Buckley,, 1988):

$$
\hat{w}_{i k}=\frac{w_{i k}}{\sum_{j=1}^{\left|T_{C}\right|} w_{i j}}
$$

onde $\left|T_{C}\right|$ é o número de termos no corpus $C$.

De posse dos pesos para cada documento, que representariam as suas posições nos eixos coordenados definidos por cada termo, e consequentemente a sua posição em um espaço n-dimensional, as métricas de similaridade são determinadas computando a distância dos vetores neste espaço. O cálculo da distância considera, normalmente, a distância euclidiana, a distância Manhattan e também o cosseno do ângulo formado pelos vetores associados a dois documentos, dado pelo produto escalar de ambos, conforme a Tabela 2.2 .

Tabela 2.2: Medidas usuais de distância (dissimilaridade) no modelo de espaço vetorial.

\begin{tabular}{|l|l|}
\hline Variação & Descrição \\
\hline distância euclidiana & $d_{e}\left(E_{i}, E_{j}\right)=\sqrt{\left(w_{i, 1}-w_{j, 1}\right)^{2}+\ldots+\left(w_{i, m}-w_{j, m}\right)^{2}}$ \\
\hline distância manhattan & $d_{m}\left(E_{i}, E_{j}\right)=\left|w_{i, 1}-w_{j, 1}\right|+\ldots+\left|w_{i, m}-w_{j, m}\right|$ \\
\hline distância por cossenos & $d_{c o s}\left(E_{i}, E_{j}\right)=1-\frac{\left(w_{i, 1} \times w_{j, 1}\right)+\ldots+\left(w_{i, m} \times w_{j, m}\right)}{\left(w_{i, 1}^{2}+\ldots+w_{i, m}^{2}\right) \times\left(w_{j, 1}^{2}+\ldots+w_{j, m}^{2}\right)}$ \\
\hline \multicolumn{2}{|l|}{ em que $w_{i, k}$ é o peso do termo $t_{k}$ no documento $i$ e $m$ é número de termos no espaço. } \\
\hline
\end{tabular}

\subsubsection{Modelo Booleano}

O modelo booleano une a teoria dos conjuntos e a álgebra booleana. Neste modelo, uma consulta é especificada por um conjunto de termos combinados em expressões booleanas. Cada termo da consulta é avaliado quanto à sua presença nos documentos e é formado um subconjunto com os documentos encontrados. Os subconjuntos de documentos são, então, combinados de acordo com os operadores lógicos, produzindo o conjunto dos documentos que compõe o resultado final.

Apesar de aparentemente simples, usuários geralmente encontram dificuldade para formular consultas como requerido pelo modelo. Por exemplo, a consulta 'cães e gatos' pode implicar, 
para usuários não-experientes, a recuperação de documentos sobre cães em conjunto com documentos sobre gatos e não apenas os que contenham simultaneamente os dois termos, como preconiza a álgebra booleana (Hearst, 1999).

Outro problema do modelo é que o resultado a uma consulta é sempre um conjunto de documentos considerados relevantes, sem qualquer noção de ordem entre eles. Também não há o conceito de aderência parcial à consulta. Desta forma, uma extensão para a sua aplicação como medida de similaridade entre documentos não é viável.

Uma solução para este problema é oferecida pelo modelo de conjuntos difusos (Fuzzy Set Model) (Ogawa et al., 1991). Neste modelo, um conjunto difuso $A$, associado a um termo $t_{k}$ da consulta, é definido por uma função de pertinência $\mu_{A}: \rightarrow[0,1]$ que associa cada documento $D_{i}$ do universo de documentos $C$ à sua pertinência $\mu_{i, k}$ ao subconjunto $A$. A relação $\mu_{i, k}$ é então definida pela presença do termo $t_{k}$ no documento $D_{i}$ e também pela presença de termos relacionados a $t_{k}$. Assim, termos similares ou relacionados contribuiriam com valores intermediários ] $0,1\left[\right.$ para $\mu_{i, k}$.

A similaridade entre termos pode ser obtida a partir de um thesaurus estático, ou ainda de uma matriz dinâmica ou semiestática de correlação de termos, em que um fator de correlação $c_{j, k}$ entre dois termos $t_{j}$ e $t_{k}$ seria dado por

$$
c_{j, k}=\frac{d f_{j, k}}{d f_{j}+d f_{k}-d f_{j, k}}
$$

onde $d f_{j}$ e $d f_{k}$ são o número de documentos que contêm os termos $t_{j}$ e $t_{k}$, respectivamente, e $d f_{j, k}$ é o número de documentos que contêm ambos os termos. Em seguida, os coeficientes de correlação para todos os termos $t_{k}$ pertences à $D_{i}$ são agregados para computar o grau de similaridade do documento para o termo $t_{j}$ :

$$
\mu_{i, j}=1-\prod_{t_{l} \in D_{i}}\left(1-c_{j, l}\right)
$$

Por fim, as operações booleanas são aplicadas sobre os valores computados para cada termo conforme a teoria de conjuntos difusos. Assim, por exemplo, a união (ou, or) de dois conjuntos de resultados é dada pelo maior valor encontrado para o documento nos dois conjuntos:

$$
\mu_{i, j} \cap \mu_{i, l}=\max \left\{\mu_{i, j}, \mu_{i, l}\right\}
$$

O resultado final é uma lista de documentos associados ao seu grau de similaridade em relação à consulta, tipicamente apresentada em ordem decrescente de grau de similaridade, que pode ser filtrada com base em um limiar. 
Ogawa et al. (1991) definem ainda um método para o refinamento de consultas que envolve a calibração da matriz de correlação com base em documentos apontados como relevantes pelo usuário. Segundo Baeza-Yates e Ribeiro-Neto (1999), o modelo booleano não foi amplamente adotado pela comunidade de recuperação de informação.

\subsubsection{Modelo Probabilístico}

O modelo probabilístico de Jones et al. (2000) tenta calcular a probabilidade $P\left(L \mid D_{i}\right)$ de que um documento $D_{i}$ pertença ao conjunto $L$ de documentos relevantes dada a sua descrição. Com base no teorema de Bayes, esta probabilidade é expressa em termos da probabilidade $P\left(D_{j} \mid L\right)$ de encontrar o documento $D_{i}$ entre os documentos considerados relevantes $L$ :

$$
\log \frac{P\left(L \mid D_{i}\right)}{P\left(\bar{L} \mid D_{i}\right)}=\log \frac{P\left(D_{i} \mid L\right)}{P\left(D_{i} \mid \bar{L}\right)}+\frac{P(L)}{P(\bar{L})} \propto \log \frac{P\left(D_{i} \mid L\right)}{P\left(D_{i} \mid \bar{L}\right)}
$$

onde $\bar{L}$ indica o conjunto dos documentos considerados não relevantes.

O próximo passo é definir $P\left(D_{i} \mid L\right)$ e $P\left(D_{i} \mid \bar{L}\right)$ em função dos atributos de $D_{i}$, desta forma:

$$
\begin{aligned}
& P\left(D_{i} \mid L\right)=\prod_{j} P\left(A T_{j}=a t_{i j} \mid L\right) \\
& P\left(D_{i} \mid \bar{L}\right)=\prod_{j} P\left(A T_{j}=a t_{i j} \mid \bar{L}\right)
\end{aligned}
$$

onde $A T_{j}$ é um atributo e $a t_{i j}$ o seu valor para o documento $D_{i}$.

A partir destas fórmulas, Jones et al. (2000) chegam a uma medida de relevância que considera a presença ou ausência de termos $t_{j}$ como atributos de $D_{i}$ e da consulta $Q$. Nesta fórmula, eles garantem também que termos ausentes contribuirão com zero para a medida final de relevância:

$$
r e l=\sum_{t_{j} \in D_{i}, t_{j} \in Q} \log \frac{P\left(t_{j} \mid L\right) \times\left(1-P\left(t_{j} \mid \bar{L}\right)\right)}{P\left(t_{j} \mid \bar{L}\right) \times\left(1-P\left(t_{j} \mid L\right)\right)}
$$

Neste ponto, é preciso determinar os valores para $P\left(t_{j} \mid L\right)$ e $P\left(t_{j} \mid \bar{L}\right)$. Como $L$ não é conhecido, a priori, assume-se que $P\left(t_{j} \mid L\right)$ é constante e que $P\left(t_{j} \mid \bar{L}\right)$ segue a distribuição do termo na coleção:

$$
P\left(t_{j} \mid \bar{L}\right)=\frac{d f_{j}}{N}
$$


onde $d f_{j}$ é o número de documentos que contêm o termo na coleção e $N$ é o número total de documentos.

Com estes valores iniciais, é possível recuperar um conjunto $A$ contendo os $|A|$ documentos mais relevantes. Considerando-se que este conjunto $A$ inicial aproxima o conjunto $L$ de documentos relevantes, $A$ pode ser usado, de forma recursiva, para melhorar $P\left(t_{j} \mid L\right)$ e $P\left(t_{j} \mid \bar{L}\right)$ :

$$
\begin{gathered}
P\left(t_{j} \mid L\right)=\frac{d f_{A, j}}{V} \\
P\left(t_{j} \mid \bar{L}\right)=\frac{d f_{j}-d f_{A, j}}{N-|A|}
\end{gathered}
$$

onde $d f_{A, j}$ é o número de documentos em $A$ que possuem o termo $t_{j}$.

Este modelo é particularmente apropriado para a aplicação de estratégias de obtenção de feedback de relevância, na qual o usuário seleciona, a partir de resultados preliminares, documentos que de fato atendem às suas necessidades. Neste caso, o conjunto de documentos selecionados pelo usuário será adotado como o conjunto inicial $A$ que aproxima o conjunto $L$.

\subsubsection{Distância entre textos por complexidade de Kolmogorov}

Uma técnica de comparação direta entre documentos para obtenção de uma medida de similaridade fundamentada em uma aproximação da complexidade de Kolmogorov foi adotada por pesquisadores do ICMC (Telles et al., 2007) na exploração visual de conjuntos de documentos. A complexidade Kolmogorov é base para a Normalized Compression Distance - NCD, aplicada para a formação de agrupamentos em Cilibrasi e Vitani (2005).

A complexidade de Kolmogorov, $K(q)$, de uma cadeia de caracteres $q$ é o tamanho do menor algoritmo capaz de produzir esta cadeia. Intuitivamente, ela representa a quantidade de informação presente na cadeia. A complexidade de Kolmogorov condicional, $K(q \mid r)$, é o tamanho do menor algoritmo que produz a cadeia $q$ quando recebe como entrada a cadeia $r$. Neste caso, pode-se entender a complexidade condicional como a quantidade de informação em $q$ que não está presente em $r$.

No trabalho de Li et al. (2001), é definida uma medida de distância entre sequências de caracteres que tem como base a complexidade de Kolmogorov:

$$
d_{k}(x, y)=1-\frac{K(q)-K(q \mid r)}{K(q r)}
$$

onde $K(q r)$ é complexidade de Kolmogorov da cadeia $q$ concatenada à cadeia $r$.

Uma vez que complexidade de Kolmogorov não é computável, utiliza-se o tamanho do resultado da compressão de uma cadeia como uma aproximação da sua complexidade. Consi- 
derando documentos como longas sequências, Telles et al. (2007) adotam uma variação NCDs da fórmula $N C D$ de Cilibrasi e Vitani (2005) para aproximar a distância $d_{k}(x, y)$ que utiliza compressão para calcular cada um dos termos desta aproximação, dada pela fórmula:

$$
\begin{gathered}
N C D(q, r)=\frac{C(q r)-\min \{C(q), C(r)\}}{\max \{C(q), C(r)\}} \\
N C D s(q, r)=N C D(q, r)-\frac{N C D(q, q)+N C D(r, r)}{2}
\end{gathered}
$$

onde $C(q)$ é o tamanho da cadeia $q$ após compressão. Para $C(q r)$, é adotado o tamanho da cadeia resultante da compressão de $q$ e $r$ concatenados.

$\mathrm{Na}$ exploração visual de um corpus, esta técnica seria aplicada na geração de uma matriz de distâncias entre os documentos. No processo de compressão, elementos muito frequentes, que equivaleriam às stopwords, tendem a ter pouca representatividade nas sequencias comprimidas. Isto eliminaria a etapa de preprocessamento dos textos, o que é imprescindível e determinante para o resultado em outras técnicas. O preprocessamento tipicamente requer ajuste manual e conhecimento do domínio, por isso, a sua eliminação é bastante desejável.

Os resultados reportados por Telles et al.(2007) foram positivos, se considerada a separação dos documentos analisados em mapas, o que depende também da técnica usada na geração dos mapas. A técnica apresenta um alto custo computacional, no entanto, ela é naturalmente incremental, pois a chegada de um novo documento não têm impacto nas distâncias já calculadas. Neste caso, basta calcular a distância do novo documento para aqueles que já pertencem ao conjunto. Uma versão paralela do algoritmo foi desenvolvida por Almeida et al. (2008), obtendo, com o uso de dezesseis processadores, uma performance oito vezes mais rápida que a versão sequencial.

\subsection{Projeção e arranjo}

Uma vez definido como deve ser o cálculo de similaridade para um conjunto de dados, a etapa de projeção e arranjo tem como principal objetivo permitir a exibição destes dados em um ambiente 2D ou 3D. Também nesta etapa, técnicas de aglomeração (clustering) são aplicadas para identificar grupos de objetos similares, desenhar fronteiras ou associar rótulos ou legendas a grupos.

O posicionamento de elementos de um conjunto de dados em ambientes de baixa dimensionalidade (2 ou 3D) pode ser obtido aplicando-se: (i) multi-dimensional scaling - MDS, (ii) projeção, (iii) mapas auto organizáveis (self-organizing maps - SOM), (iv) abordagens por componentes principais e, (v) abordagens baseadas em grafos. 
Nesta seção, são descritas algumas das técnicas disponíveis, em particular, foram escolhidas aquelas usualmente aplicadas na visualização de conjuntos de documentos. A Tabela 2.3 fornece uma lista das técnicas apresentadas, sua abordagem, e seu suporte à utilização de matrizes de distância. A utilização direta de matrizes de distância é desejável, pois permite a adoção de medidas de similaridade que não dependem da formação de um espaço, contando apenas com a definição de similaridade entre pares de elementos, como na aproximação da complexidade de Kolmogorov.

Algumas das técnicas descritas adotam heurísticas que evitam o cálculo da distância de cada elemento para todos os demais, um processo que, por si só, tem complexidade $O\left(N^{2}\right)$. Chalmers (1996), por exemplo, adota listas aleatórias e de elementos próximos para calcular o deslocamento de elementos durante o processo de projeção, potencialmente evitando o cômputo da distância de todos para todos os elementos (Seção 2.4.3).

\begin{tabular}{|c|c|c|}
\hline Técnica & Abordagem & Matriz de Distância \\
\hline \hline SOM & self-organizing maps & Não \\
\hline PFNET & grafos & Sim \\
\hline PCA & análise de componentes & Não \\
\hline LSA & análise de componentes & Não \\
\hline FastMap & projeção & Sim \\
\hline NNP & projeção & Sim \\
\hline MDS & preservação de distâncias & Sim \\
\hline Prefuse & aplicação de forças & Sim \\
\hline NNP & projeção & Sim \\
\hline ProjClus & projeção/agrupamento & Sim \\
\hline LSP & interpolação de malhas & Sim \\
\hline Mapas em árvore & divisão do espaço / dados hierárquicos & Não se aplica \\
\hline
\end{tabular}

Tabela 2.3: Técnicas de redução de dimensionalidade, abordagem e possibilidade de aplicação direta sobre matrizes de distância.

\subsubsection{Pathfinder network scaling (PFNET)}

A aplicação do algoritmo Pathfinder network scaling - PFNET (Schvaneveldt, 1990; Cooke et al., 1996) para redução de dimensionalidade considera as relações de proximidade entre elementos de um conjunto para a construção de um grafo. Neste grafo, os itens do conjunto original são nós e o peso ou comprimento associado a cada aresta é inversamente proporcional à similaridade entre dois documentos. Com a aplicação do algoritmo, grande parte das arestas é eliminada. São mantidas apenas as arestas entre documentos cuja distância seja menor que o caminho mínimo encontrado para conectar indiretamente os documentos. Ou seja, as arestas mantidas denotam as relações mais importantes entre documentos. Ajustes no algoritmo 
incluem a seleção de métodos para determinar o caminho mínimo e do tamanho máximo do caminho indireto a ser considerado na eliminação de uma aresta. No exemplo da Figura 2.4, a aresta que liga o nó $E_{1}$ ao nó $E_{4}$ é eliminada, pois existe um caminho mais curto entre $E_{1}$ e $E_{4}$, ainda que indireto $\left(E_{1}-E_{2}-E_{3}-E_{4}\right)$.

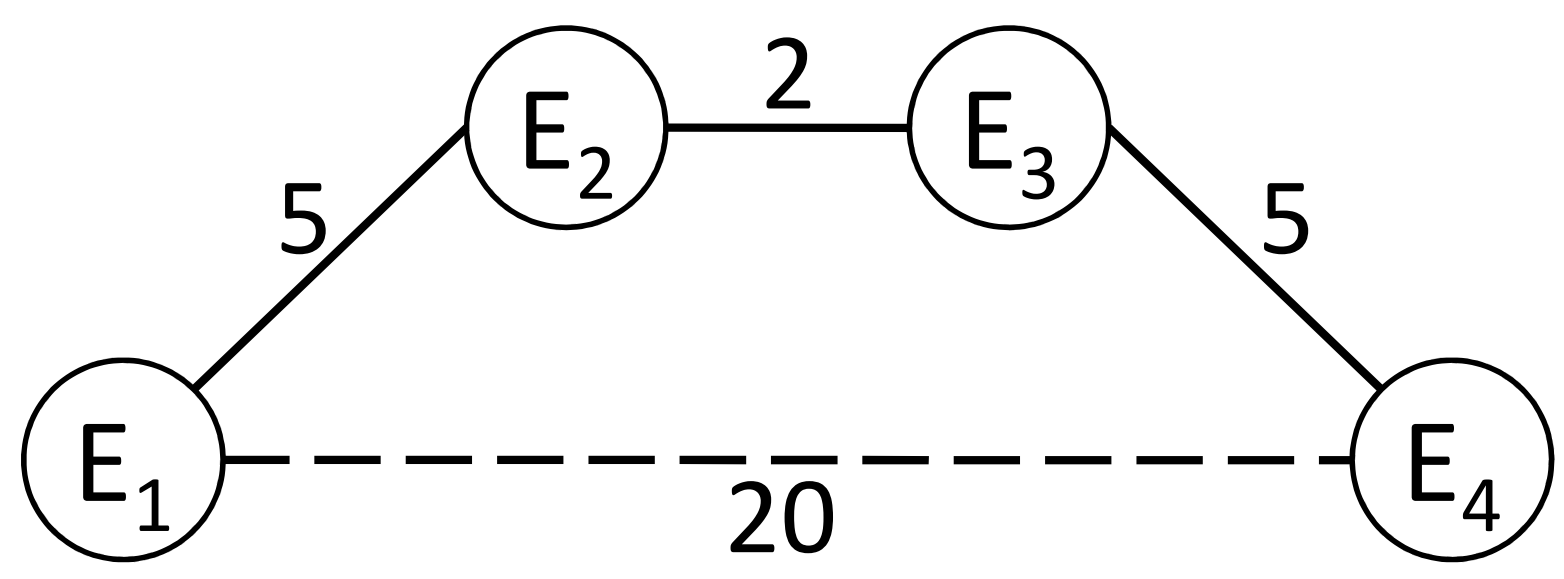

Figura 2.4: Exemplo de aplicação do algoritmo PFNET. Números indicam pesos associados às arestas.

A visualização da rede final pode ser feita por algoritmos convencionais de visualização de grafos, com o benefício de que apenas um pequeno número de arestas será mantido. Redes PFNETS têm sido aplicadas em estudos de análises de cocitação (Chen, 2004). Entres as desvantagens do métodos, está o seu alto custo computacional $\left(O\left(N^{4}\right)\right)$, embora tenha uma variante tenha sido proposta com custo computacional na ordem de $O\left(N^{3}\right)$ (Quirin et al., 2008).

\subsubsection{Self-Organizing Maps (SOMs)}

Self-Organizing Maps - SOMs (Kohonen, 1997, 1990) são redes neurais artificiais competitivas capazes de formar mapas que buscam preservar a distribuição de elementos entre os espaços de entrada e de saída, conseguindo, com isto, representar vetores n-dimensionais numa grade 2D.

$\mathrm{Na}$ execução do algoritmo, uma grade de nós é formada. A cada nó é associado um conjunto de pesos. O conjunto de pesos é inicialmente preenchido com valores aleatórios, tendo a dimensionalidade igual a do conjunto de dados a ser representado. A cada passo do algoritmo, cada um dos elementos do conjunto é comparado, usualmente por meio do computo da distância euclidiana, com os nós da grade, sendo atribuído ao nó que lhe é mais próximo. Após a atribuição de um elemento a um nó, os pesos deste nó, e também o de seus vizinhos, são 
atualizados, aproximando-os do elemento recém associado. O processo é repetido até que um limite de tempo seja atingido.

Uma vez que a associação de um elemento a um nó tem repercussão nos nós vizinhos, ainda que em menor escala, o sistema tende a formar regiões de nós com elementos similares ou relacionados. O impacto de um elemento na alteração do peso nos vizinhos é governado por uma função de vizinhança, por exemplo, uma função gaussiana. A região de impacto do elemento é também ajustada ao longo da execução do algoritmo, sendo maior no início e gradualmente reduzida.

Uma desvantagem desta técnica é a necessidade de estabelecer previamente as dimensões da grade. Grades de tamanho reduzido se prestam a tarefas de agrupamento. Por exemplo, uma grade de tamanho $3 \times 3$ produz 9 agrupamentos. Se grades maiores forem utilizadas, um $\mathrm{SOM}$ pode projetar, em um espaço $2 \mathrm{D}$, relações de vizinhança entre um grande número de elementos (Skupin, 2004). Em ambos os casos, não há quaisquer restrições quanto ao número de elementos atribuídos a cada célula da grade. Algumas células podem terminar contendo diversos elementos, enquanto outras podem permanecer vazias.

Um vez que a quantidade de elementos atribuídos a cada célula da grade não é fixa, pode-se subdividir uma célula com muitos elementos em novas células e aplicar a técnica sobre os seus elementos (Kaski et al., 1998).

Algumas versões incrementais da técnica foram propostas. Estas versões são descritas em conjunto com outras soluções incrementais de projeção e arranjo na Seção 2.4 .12 .

\subsubsection{Multi-Dimensional Scaling}

Técnicas de Multi-Dimensional Scaling - MDS, ou escalonamento multidimensional, buscam preservar relações de distância encontradas em um espaço de $m$ dimensões em um espaço reduzido com $m_{r}$ dimensões. Nem sempre tais relações são perfeitamente representáveis em espaços reduzidos, sendo possível obter apenas aproximações. Nestes casos, múltiplas soluções são possíveis, em função do viés introduzido por diferentes algoritmos. No escalonamento multidimensional não métrico (nonmetric multidimensional scaling), o objetivo é obter uma relação monotônica entre dissimilaridades ou similaridades e as distâncias no espaço reduzido Kruskal, 1964b).

Em modelos baseados na aplicação de forças (force-directed placement - FDP), cada elemento é associado aos demais por uma força proporcional à sua distância no espaço n-dimensional original. Em um tempo proporcional a $O\left(N^{3}\right)$, uma representação estável, em 2D ou 3D, pode ser encontrada. 
Chalmers (1996) propôs o uso de amostragem estocástica para métodos de FDP. Nesta abordagem, dois subconjuntos são considerados para determinar a força atuando em cada elemento $E_{i}$ : (i) um subconjunto aleatório com $\left|L A_{E_{i}}\right|$ elementos, e (ii) um subconjunto com os $\left|L N_{E_{i}}\right|$ elementos mais próximos. O subconjunto de elementos aleatórios $L A_{E_{i}}$ é completamente renovado a cada iteração do algoritmo, enquanto o subconjunto $L N_{E_{i}}$ de elementos mais próximos é apenas atualizado. $L N_{E_{i}}$ é composto por candidatos originalmente selecionados para formar $L A_{E_{i}}$. A adoção de um número fixo $\left(\left|L A_{E_{i}}\right|+\left|L N_{E_{i}}\right|\right) \ll N$ de elementos na determinação de forças reduz a complexidade do cálculo de forças em cada iteração sobre o conjunto de $O\left(N^{2}\right)$ para $O\left(N \times\left(\left|L A_{E_{i}}\right|+\left|L N_{E_{i}}\right|\right)\right)$.

Morrison et al. (2002) desenvolveram uma solução híbrida de MDS que combina amostragem estocástica, estratégias baseadas na aplicação de forças e interpolação. Além da amostragem estocástica tal qual introduzida por Chalmers (1996), a abordagem híbrida aplica a interpolação de posições de elementos desta maneira:

1. Um pequena amostra é extraída do conjunto, com tamanho $\sqrt{N}$;

2. A amostra é posicionada no espaço reduzido pela aplicação do algoritmo estocástico;

3. Os itens remanescentes são posicionados em um ponto ao longo de um círculo, em torno do elemento mais próximo que é parte da amostra inicial;

4. A posição dos itens interpolados é refinada pelo algoritmo de FDP estocástico, e, finalmente;

5. O conjunto completo é submetido a algumas interações do algoritmo de FDP estocástico.

Uma melhoria adicional neste sistema foi obtida pela utilização de pivôs na busca pelo elemento mais próximo no espaço m-dimensional, como é requerido no item 3 acima. Com a abordagem híbrida, a complexidade total do algoritmo foi reduzida para $O\left(N^{5 / 4}\right)$.

\subsubsection{Layout de rede no Prefuse}

O Prefuse é um conjunto de ferramentas (toolkit) para a visualização interativa de informação (Heer et al., 2005). A biblioteca do Prefuse inclui componentes para: (i) layout de elementos, em grades, em mapas em árvore (treemaps) e em gráficos de dispersão (scatterplots), entre outros; (ii) distorção do espaço visualizado, incluindo visão olho-de-peixe e distorção bifocal; (iii) controle interativo da visualização, incluindo controle de zoom e deslocamento; (iv) atribuição de cores para a elementos, de acordo com valores de atributos, utilizando mapas de cores da biblioteca; (v) busca de elementos por palavras e; (vi) registro de eventos. 
Ele inclui também um módulo de layout de redes, em tempo-real, com base na aplicação de forças, que pode adotar múltiplos modelos para a simulação como: (i) força gravitacional (problema dos n-corpos), (ii) tensão em molas e, (iii) arrasto (drag). Além da sua evidente aplicação para a visualização de relações que são naturalmente representadas por grafos, como, por exemplo, relações de cocitação, a similaridade entre pares de documentos pode ser usada para determinar o tamanho de arestas entre documentos. Neste caso, como há, apriori, $N^{2}$ arestas em um grafo assim constituído, recomenda-se a eliminação de arestas, seja pela remoção daquelas não alcancem um limiar mínimo, ou pela aplicação de um algoritmo como o PFNET (Seção 2.4.1).

\subsubsection{Latent Semantic Analysis (LSA)}

A técnica Latent Semantic Analysis foi desenvolvida para resolver problemas em recuperação de textos que são decorrentes do uso de termos distintos para descrever um mesmo objeto (sinonímia). Assume-se que exista uma estrutura semântica "latente" nos documentos, que seria disfarçada pela escolha de palavras. Nesta técnica, métodos estatísticos são aplicados para eliminar o "ruído" provocado pela variação na escolha de palavras e estimar a estrutura latente (Dumais et al., 1988).

Partindo de uma matriz $M$ de termos $\times$ documentos, a extração de termos latentes se dá pela aplicação da técnica de Decomposição de Valores Singulares (Singular Value Decomposition - SVD). A matriz $M$ é decomposta em três matrizes de autovetores e autovalores conforme ilustrado na Figura 2.5 .

Um autovalor (eingenvalue) ein de $M$ é um valor capaz de transformar $M$ em uma matriz singular aplicando-se a operação $M-e i n \times I$, sendo $I$ uma matriz identidade. Um autovetor ou eingenvector einV de $M$ é um vetor coluna tal que $(M-e i n \times I) \times e i n V=0$. Em SVD, a matriz diagonal $S$ contém os autovalores de $M$ em sua diagonal, ordenados de forma decrescente. Neste contexto, eles recebem o nome de valores singulares de $M$. Os $k$ maiores valores de $S$ apontam para os autovetores de maior impacto na formação de $M$. A nova matriz $M^{*}$ (ver figura 2.5 obtida por $M^{*}=U^{*} \times S^{*} \times W^{t *}$ aproxima $M$, porém sem "ruído" de autovetores de baixo impacto. Um ótimo tutorial sobre SVD pode ser encontrado em Garcia (2006).

Uma característica da LSA, especialmente interessante para a recuperação de informação, é que termos sinônimos tendem a se agrupar em uma mesma dimensão. Desta forma, é possível, com esta técnica, que uma consulta retorne documentos com os quais ela não compartilhe nenhum termo. Para KDViz, a seleção das duas ou três primeira dimensões da matriz $M^{*}$ que aproxima $M$ permite que um conjunto de documentos possa ser projetado num espaço euclidiano para a visualização. No entanto, nem sempre a projeção reflete adequadamente o espaço original, quando as três dimensões latentes não capturam a diversidade do conjunto (Chen, 

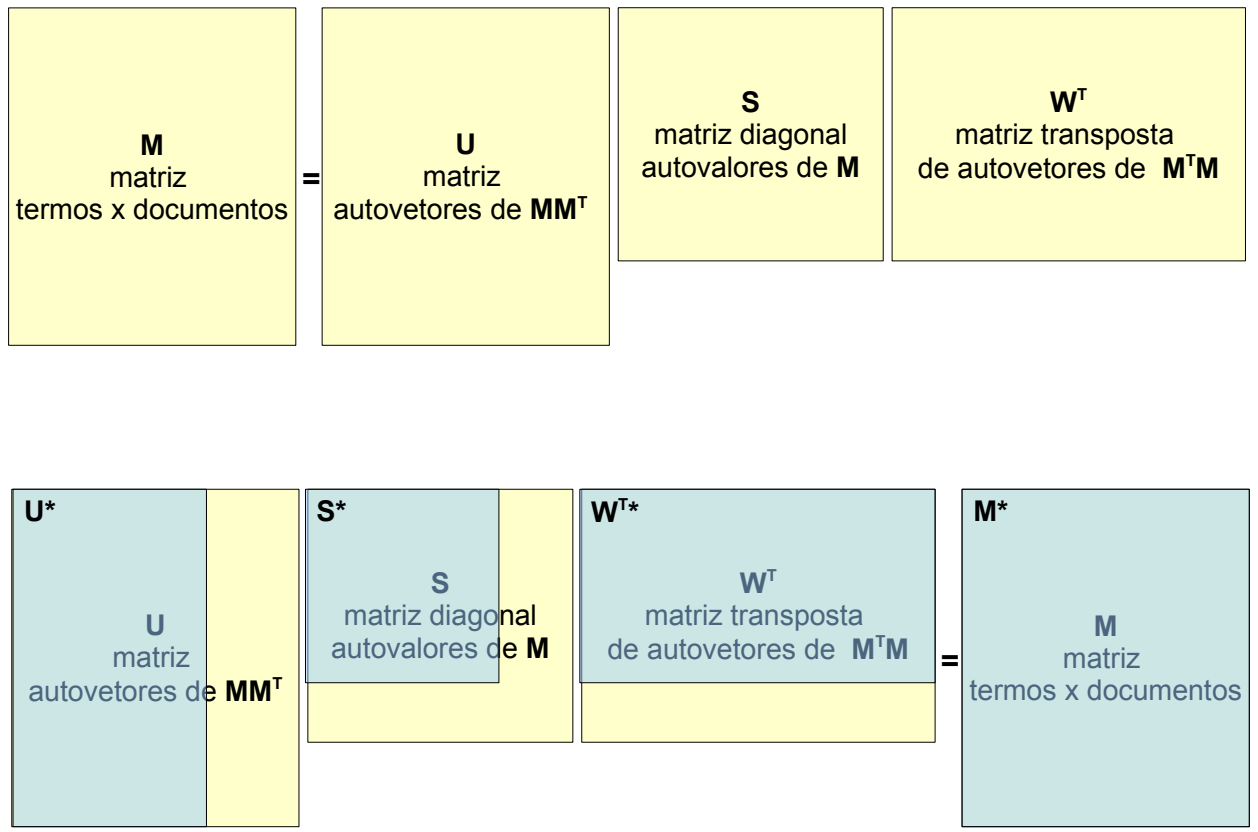

Figura 2.5: No topo, decomposição de uma matriz $M$ de termos $\times$ documentos em matrizes de autovalores e autovetores. Abaixo, seleção dos $k$ primeiros autovalores, na matriz $S$, e seleção de autovetores correspondentes para formar a matriz $M^{*}$. Adaptado de Chen (2004).

2004). Tal situação é observável na visualização de um conjunto de dados que contenha cinco ou mais agrupamentos bem distintos. A visualização resultante potencialmente será capaz de efetivamente separar espacialmente apenas três dos cinco agrupamentos, mesclando os demais entre si.

LSA é um técnica computacionalmente cara $\left(O\left(\min \left\{N m^{2}, m N^{2}\right\}\right)\right.$, sendo $N$ e $m$ o número de documentos e de dimensões, respectivamente), seu custo computacional cresce juntamente com o tamanho das coleções, não sendo uma solução prática para grande coleções.

\subsubsection{Análise de Componentes Principais (PCA)}

A análise de componentes principais (Principal Component Analysis - PCA) objetiva reduzir o número de variáveis na descrição de um conjunto de dados. A PCA transforma um conjunto de variáveis correlacionadas em um conjunto menor de variáveis não correlacionadas chamadas de componentes principais. O primeiro componente identificado busca preservar o máximo possível de variância dos dados originais. Os componentes subsequentes são, então, organizados em ordem de variabilidade decrescente. Assim, é possível selecionar os $k$ primeiros componentes 
conforme a necessidade, como é feito também com LSI (ver Seção 2.4.5). Por exemplo, para uma projeção tridimensional, seriam selecionados os três primeiros componentes.

Documentos com coeficientes altos para um determinado componente podem ser considerados como representativos deste componente e similares sob este aspecto. Chen (2004) descreve uma visualização na qual os três componentes principais de um conjunto de dados determinam a cor de esferas que representatam documentos. Por exemplo, esferas vermelhas representam documentos com forte identificação com o primeiro componente, verdes com o segundo, e azuis com o terceiro. A cor branca, neste exemplo, apareceria em documentos que são igualmente relacionados aos três fatores selecionados. Documentos associados com cada um destes componentes são minerados para a extração de palavras que servirão de legenda para as cores no gráfico. Na visualização proposta por Chen, o posicionamento destas esferas se dá por outro método.

Assim como acontece com LSA, as duas ou três primeiras dimensões, definidas pela técnica PCA, podem não capturar uma boa representação do espaço original. A técnica tem forte base matemática e tem sido usada na detecção de grupos de documentos. A sua complexidade algortimica é da ordem de $O\left(N^{3}\right)$. Uma evolução recente do algoritmo reduziu a sua complexidade para $O\left(N^{2}\right)$ (Sharma e Paliwal, 2007).

\subsubsection{Fastmap}

A técnica Fastmap projeta objetos de um espaço m-dimensional em um espaço $m_{r}$-dimensional reduzido, buscando preservar as relações de distância existentes no espaço original (Faloutsos e Lin, 1995). São selecionados inicialmente dois objetos, preferencialmente os mais distantes entre si. Estes objetos determinam então uma reta no espaço m-dimensional e um hiperplano de dimensionalidade $m-1$ perpendicular à reta. Cada um dos demais objetos é projetado neste hiperplano. O processo é repetido até que $m-1$ atinja o valor desejado, $m_{r}$.

Fastmap, assim como qualquer outra técnica de projeção, produz uma visão distorcida dos dados, uma vez que a perda de informação é intrínseca ao processo de projeção. Paulovich (2008) sugere ainda que a técnica não é indicada para conjuntos de dados não-lineares ou com alta dimensionalidade, desaconselhando o seu uso nestes casos, apesar da sua baixa complexidade $(O(N))$. Platt (2005) sugere a adoção de técnicas correlatas, que teriam melhor precisão, com custo computacional ligeiramente maior. Para o autor, a perda de precisão poderia ser resultado da abordagem sequencial do Fastmap, que trata uma dimensão por vez. Tejada et al. (2003) sugerem a aplicação de uma técnica simplificada de posicionamento baseado em forças após a aplicação de técnicas de projeção, como a Fastmap e a NNP, discutida a seguir. 


\subsubsection{Nearest-neighbor projection (NNP)}

Esta técnica, desenvolvida por pesquisadores do ICMC, projeta rapidamente objetos definidos um espaço n-dimensional em um espaço bidimensional, sem necessidade de construir um espaço vetorial (Tejada et al., 2003). Assim, ela pode ser aplicada quando a distância ou similaridade entre objetos é conhecida, sem que, no entanto, tenham sido obtidos vetores representativos de cada um deles no espaço. Esta característica é importante, pois permite a utilização direta sobre uma matriz de distâncias, gerada, por exemplo, pela aplicação da complexidade de Kolmogorov, descrita na Seção 2.3.2.

Para cada novo ponto a ser projetado são selecionados os dois pontos mais próximos já projetados, considerando-se as distâncias no espaço m-dimensional, para estabelecer a posição do novo ponto. A posição de um novo ponto $p_{1}^{\prime}$ no espaço projetado encontra-se na interseção entre os dois círculos com centro nos pontos projetados $p_{2}^{\prime}$ e $p_{3}^{\prime}$, e cujos raios são dados pela distância (dissimilaridade $\delta\left(p_{i}, p_{j}\right)$ ) entre o ponto $p_{1}$ e os pontos $p_{2}$ e $p_{3}$ no espaço m-dimensional. Quando não há interseção entre os círculos, o ponto $p_{1}^{\prime}$ é localizado em um ponto médio entre os círculos determinados. Quando há interseção, mas os círculos não são tangentes, duas soluções são possíveis, sendo escolhida uma delas, ao acaso. Estes casos são mostrados na Figura 2.6 .

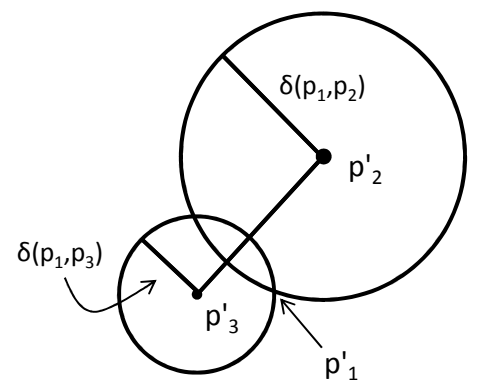

(a)

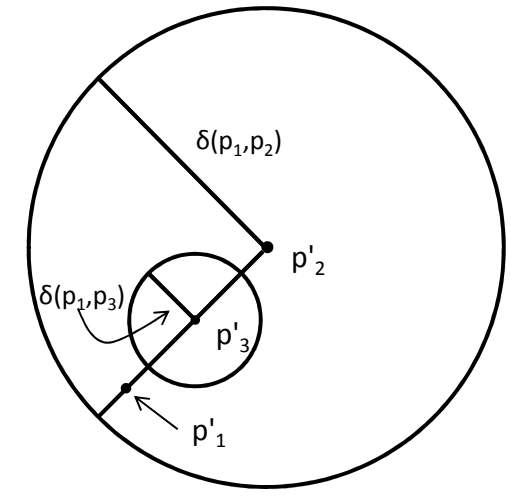

(b)

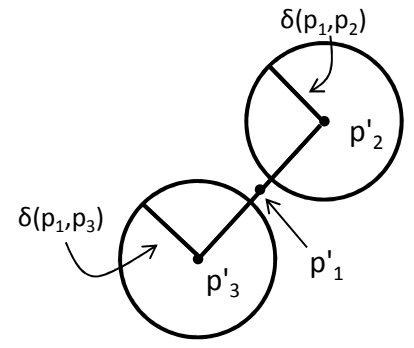

(c)

Figura 2.6: Casos de interseção para NNP (a) Círculos intersectam. (b) Não há interseção, um círculo interno. (c) Não há interseção ou inclusão. Adaptado de Tejada et al. (2003).

Tejada et al. (2003) desenvolveram e adotam, em conjunto com a NNP, um algoritmo para a melhoria de projeções a que deram o nome de Force. A cada interação do algoritmo, são computadas forças atuantes entre cada par de elementos com intensidade proporcional a uma 
fração da diferença entre a distância normalizada observada no espaço original (m-dimensional) e a distância observada no espaço projetado. Tomando um elemento $E_{i}$ como referência, os demais elementos $E_{j, j \neq i}$ são deslocados na direção do vetor $\overrightarrow{E_{i} E_{j}}$ de acordo com as forças computadas. O somatório das diferenças computadas a cada iteração constitui um indicador da qualidade da projeção. São executadas diversas iterações do algoritmo para que tal indicador convirja a um valor. O custo computacional do algoritmo é de $O\left(N^{2}\right)$ por iteração.

\subsubsection{Projeção de agrupamentos (ProjClus)}

A projeção de agrupamentos (Projection of Clusters - ProjClus) (Paulovich e Minghim, 2006a, Paulovich, 2008) inicialmente separa os $N$ documentos em $\sqrt{N}$ agrupamentos com a técnica de bisseção com k-médias (Tan et al., 2006). Em seguida, os centróides de cada um dos agrupamentos são projetados com a técnica Fastmap (Seção 2.4.7) associada à técnica Force.

Os pontos de cada agrupamento são projetados em um espaço normalizado contendo apenas os elementos do seu agrupamento. Por fim, os agrupamentos já projetados são posicionados no espaço comum de acordo com a posição dos seus centróides. O processo de normalização das projeções individuais de cada agrupamento requer um parâmetro $f$ que determina a densidade de cada agrupamento no espaço reduzido.

Além de baixa complexidade, da ordem de $O\left(N^{\frac{3}{2}}\right)$, esta técnica tem o benefício de preservar a proximidade de elementos pertecentes a agrupamentos construídos ainda no espaço n-dimensional original. No entanto, o posicionamento de cada subespaço não é consistente com o posicionamento do conjunto de centróides ou mesmo entre si. Tal distorção pode, eventualmente, ser corrigida na aplicação do algoritmo Force, de complexidade $O\left(k N^{2}\right)$.

Uma técnica análoga foi desenvolvida por Janjusevic e Izquierdo (2008) para o posicionamento de uma coleção de imagens. Após o posicionamento de centróides computados para classes de imagens utilizando uma técnica de MDS, as imagens são posicionadas em pontos aleatórios ao redor dos respectivos centróides. Os autores justificam o posicionamento aleatório de elementos como uma estratégia para reduzir a complexidade algorítmica, que seria da ordem de $O\left(k^{3} \cdot N\right)$, para $k$ classes de imagens. No entanto, não foram apresentados estudos do impacto da solução no posicionamento dos elementos, seja pela comparação com outras técnicas medidas objetivas, seja por meio de estudos com usuários.

\subsubsection{Projeção por mínimos quadrados (LSP Projection)}

Uma malha pode ser descrita em termos da conectividade entre os seus nós e da posição dos mesmos. Pode-se imaginar que, mesmo que a informação geométrica relativa a alguns nós seja ignorada, a posição dos nós restantes e a conectividade da malha podem ser utilizadas 
para aproximar a posição dos nós de localização desconhecida. Least-Square Meshes (Sorkine e Cohen-Or, 2004) são malhas que mantém informação geométrica de apenas um conjunto esparso de pontos de controle $C T$, além da sua conectividade (Sorkine e Cohen-Or, 2004). A geometria da malha é reconstruída por meio da solução de um sistema linear, que tenta aproximar, por mínimos quadrados, uma solução que respeite os pontos de controle e posicione os pontos para os quais não há informação geométrica próximo ao centro de gravidade de seus vizinhos imediatos. Uma das potenciais aplicações desta técnica é a compressão na representação de malhas.

A partir desta ideia, a LSP Projection seleciona um subconjunto $S$ de elementos em uma coleção e os projeta com alguma técnica convencional de projeção (Paulovich et al., 2008a, Paulovich, 2008). Considerando-se as relações de vizinhança no espaço n-dimensional como a conectividade de uma malha, e as posições dos elementos de $S$ no espaço reduzido como os pontos de controle $C T$, os demais elementos da coleção podem ser projetados com a técnica descrita para a reconstrução de Least-Square Meshes. Para selecionar os pontos de controle, a opção adotada por Paulovich et al. (2008a) foi utilizar o algoritmo de agrupamento k-medoids, e tomar o elemento de cada agrupamento mais próximo ao seu centróide como referência. Esta abordagem foi capaz de, efetivamente, segmentar e agrupar documentos, embora questões como a escolha do conjunto de pontos de controle possam ter impacto negativo na projeção resultante.

\subsubsection{Mapas em árvore}

Um caso particular para a projeção e arranjo de dados é a visualização de conjuntos associados a estruturas hierárquicas. Uma das técnicas mais populares é a dos mapas em árvores (treemaps), proposta por Shneiderman (1992). Nela, o espaço visual disponível é dividido em regiões retangulares associadas aos elementos encontrados no primeiro nível da hierarquia. O espaço atribuído a cada elemento é então dividido entre os seus filhos. Este processo é repetido recursivamente até que sejam representados os nós folha da árvore formada pela hierarquia. As principais vantagens da técnica são: (i) a capacidade de mostrar diversos níveis de uma hierarquia em um única visualização e (ii) o total aproveitamento da área de exibição disponível. Adicionalmente, o tamanho e a cor de cada região podem ser alterados para representar atributos do conjunto de dados. A técnica tem ampla utilização, tendo sido aplicada na visualização de diversos tipos de dados, entre eles, conjuntos de imagens e de documentos (Bederson, 2001; Almeida, 2003).

Diversas extensões foram desenvolvidas para a treemap. A técnica Voronoi Treemaps, por exemplo, utiliza polígonos (células de Voronoi) no lugar de regiões retangulares, evitando a formação de regiões muito finas ou muito compridas (Balzer e Deussen, 2005). 
Wood e Dykes (2008) propõem um algoritmo alternativo para a divisão do espaço em treemaps que tenta respeitar a posição dos elementos do conjunto de dados em um espaço bidimensional tomado como referência. Os autores aplicam a técnica na construção de treemaps para conjuntos de dados georeferenciados. O treemap da Figura 2.7 apresenta a população e mudança populacional, representados respectivamente pelo tamanho e cor das regiões, relativos aos 48 estados dos Estados Unidos Continentais e Distrito de Columbia. As linhas sobrepostas ao mapa denotam o deslocamento verificado entre cada região do treemap e a posição do centróide da região geográfica representada, caso o mapa original fosse sobreposto ao treemap. Observa-se que à leste há uma razoável compatibilidade entre o posicionamento no treemap e o real posicionamento dos estados no mapa. Nesta região, não há grande disparidade entre o tamanho das populações e há estados com formato retangular ou próximo, como Colorado e Utah. Já na costa oeste há uma maior distorção no mapa.

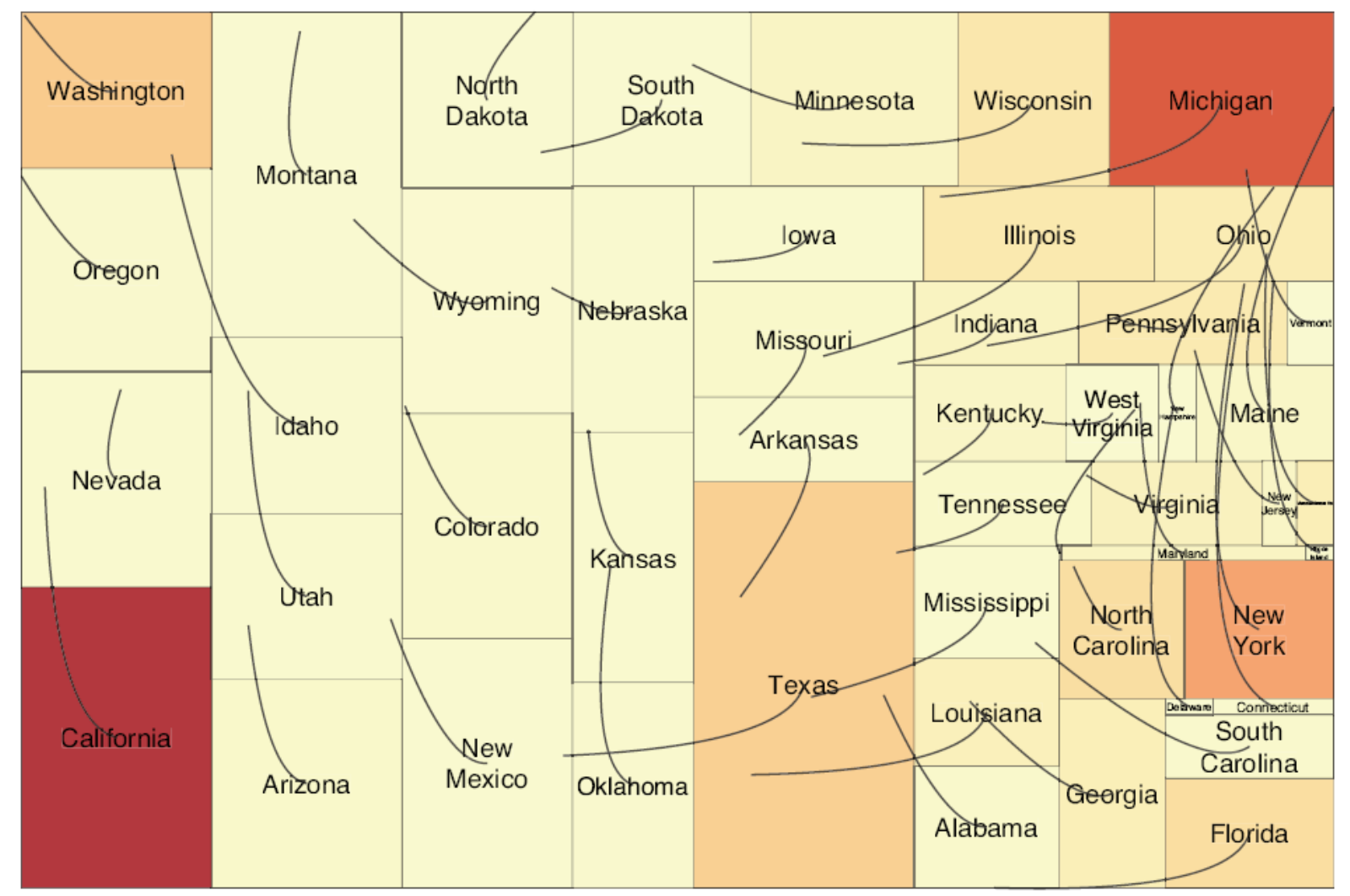

Figura 2.7: Mapa em árvore da população dos Estados Unidos Continentais em 2006. Tamanho e cor das regiões representam população total e mudança populacional, respectivamente. As linhas com início no centro de cada região mostram o seu deslocamento em relação à posição geográfica de cada estado em mapa de mesmas dimensões. Extraído de Wood e Dykes (2008). 


\subsubsection{Soluções incrementais de projeção e arranjo}

Tipicamente, a visualização de mudanças em conjuntos de dados requer a construção de novos mapas, ou, em alguns casos, a utilização de dimensões visuais estabelecidas com um subconjunto inicial dos dados, que talvez não reflitam adequadamente estados posteriores do conjunto analisado. Um solução alternativa é proposta no Capítulo 4. Nesta seção são apresentadas soluções prévias para a projeção e arranjo de conjuntos dinâmicos de dados.

Algumas soluções de visualização de documentos explicitamente associam dimensões ou atributos do espaço de dados original a dimensões no espaço visual apresentado ao usuário. Isto acontece nos diagramas de correlação ou dispersão (scatterplots), em representações temporais com a associação da variável tempo a um dos eixos, como ocorre no sistema ThemeRiver ( $\mathrm{Ha}-$ vre et al. 2000), ou ainda em alguns sistemas que apresentam dados sobre superfícies, cuja elevação é determinada por uma variável específica (Lopes et al., 2006), por exemplo, utilizam uma superfície inserida em um espaço 3D, em que altura é atribuída a pontos na superfície para apresentar conjuntos de documentos. Outros sistemas, como o IN-SPIRE (Wise, 1999), aplicam técnicas centradas na extração de fatores, como a análise de componentes principais Principal Component Analysis (PCA), Seção 2.4.6 - e a análise de semântica latente - Latent Semantic Analysis (LSA), Seção 2.4.5 - para posicionar os documentos. É possível adicionar elementos a mapas assim construídos. No entanto, além dos limites inerentes a estas técnicas, os pontos adicionados são posicionados de acordo com a representação visual construída com os elementos previamente disponíveis. À medida que o conjunto de dados distancia-se do conjunto de dados original, é necessário refazer todo o mapa, como propõem Wong et al. (2003).

Uma solução para visualizar a evolução de um conjunto de documentos, utilizada por Chen (2006) em seu sistema CiteSpace II, é construir o mapa usando todo o conjunto de dados e então manipular atributos visuais, como, por exemplo, a transparência de elementos, para adicionar ou remover elementos da visualização de modo a refletir a sua evolução. Embora esta solução possa gradualmente apresentar a evolução do conjunto de dados ao mesmo tempo em que mantém uma disposição consistente dos elementos ao longo do processo, ela não pode ser considerada como uma técnica verdadeiramente incremental ou dinâmica. O conjunto completo a ser analisado deve estar disponível para que a representação visual inicial possa ser construída. O mapa não é construído gradualmente à medida que novos documentos são adicionados ou que documentos existentes são removidos, apenas a apresentação de elementos, já posicionados, é alterada ao longo do processo.

Versões dinâmicas do algoritmo SOM (Seção 2.4.2) foram propostas, como, o Incremental Grid Growing (IGG) (Blackmore e Miikkulainen, 1995), e o growing self-organizing map (GSOM) e suas subsequentes versões (Alahakoon et al., 2000; Amarasiri et al., 2005). Elas não exigem a definição prévia de dimensões da grade como no SOM original, mantendo, no entanto 
a possibilidade de que diversos elementos sejam agrupados em uma única célula (neurônio), enquanto outras permanecem vazias. Esta possibilidade é útil para prover visões de alto nível de um conjunto de dados ou para construir soluções hierárquicas, ao custo de não apresentar elementos individualmente. Um característica indesejável de ambos, IGG e GSOM, também indicada por Nurnberger e Detyniecki (2002), é que os mapas crescem apenas a partir das bordas, criando áreas de alta densidade (muitos elementos por célula) ao centro. A técnica GSOM parece degradar quando ramos ou braços encontram-se e unem-se. Versões recentes da técnica tentam tratar este problema com uma fase de atenuação (smoothing) que tem impacto na complexidade algorítmica da solução. Não foi encontrada, até este momento, descrição de um processo para a remoção de elementos da visualização, seja para a técnica IGG ou a GSOM.

Chalmers (1996) menciona brevemente que novos elementos podem ser adicionados enquanto sua técnica de escalonamento multidimensional - multidimensional scaling (MDS) converge para uma solução, no entanto, esta possibilidade não é explorada. Um vez que esteja trabalhando com um conjunto estável de dados, ele espera encontrar uma solução em algumas poucas iterações do seu procedimento estocástico de posicionamento baseado em forças. Melhorias posteriores do algoritmo utilizam-se de fases de ajuste fino para atingir uma solução definitiva (Morrison e Chalmers, 2004). Em ambos os casos, a complexidade algorítmica situaria-se muito acima de $O\left(N^{2}\right)$ quando aplicados de forma incremental.

Uma solução mais robusta é o algortimo ISOMAP incremental apresentado por Law e Jain (2006). No entanto, as coordenadas de todos os elementos existentes são atualizadas e podem mudar drasticamente a cada novo elemento adicionado ao conjunto (Law et al., 2004). Além de implicar processamento adicional para atualizar todo o conjunto de dados, um rearranjo global das coordenadas, como batizado por Law e Jain (2006), não é desejável para os nossos objetivos. Em contraposição, o posicionamento incremental proposto no Capítulo 4 requer poucas modificações nas coordenadas dos elementos a cada elemento adicionado ou removido.

A tese de Basalaj (2000) introduz um algoritmo incremental de escalonamento multidimensional. No entanto, sua abordagem requer uma árvore geradora mínima computada apriori para o conjunto de dados analisado, impedindo a sua aplicação a conjuntos dinâmicos de dados.

\subsection{Visualização e interação}

Uma vez que o conjunto de elementos a serem analisados está distribuído em um espaço de duas ou três dimensões, é preciso especificar a sua aparência, definindo como cada atributo dos dados será mapeado em atributos visuais.

Segundo Börner et al. (2003), uma boa visualização deve: 
- Permitir a compreensão de grande quantidades de dados, seja por meio de visões gerais (overviews), seja pela análise de detalhes;

- Reduzir o tempo de busca, aproveitando, por exemplo, a percepção visual de baixo nível;

- Prover um melhor entendimento acerca de dados complexos;

- Revelar relações não identificáveis de outra forma;

- Permitir a visão do conjunto de dados sob diversas perspectivas simultaneamente;

- Facilitar a formulação de hipóteses;

- Servir como meio eficiente de comunicação.

Um bom exemplo daquilo que compreende a etapa de visualização e interação pode ser encontrado em Minghim et al. (2006). O Interactive Document Map - IDMAP é um conjunto de técnicas combinadas para a geração de mapas interativos de documentos. Nele, após a etapa de projeção e arranjo, é construída uma superfície por triangulação de Delaunay a partir dos pontos que representam os documentos projetados. Em seguida, atributos adicionais dos documentos, como relevância, número de citações, e ano de publicação são mapeados em altura e cor (Figura 2.8). Adicionalmente, a solução permite mapear para cor e/ou altura o nível de uma hierarquia de agrupamento obtida por um método de agrupamento hierárquico, a fim de denotar subareas de interesse no mapa. O agrupamento hierárquico gera um dendograma, em que o nível em que se encontra um documento denota em que ponto do processo ele foi incluído em um agrupamento. Assim, considerando que esta informação seja mapeada em altura, documentos que guardam uma forte relação entre si concentrar-se-iam no topo das "montanhas".

Outra opção para visualizar conjuntos de dados usando superfícies é a divisão do espaço por um diagrama de Voronoi (Pinho et al., 2006). Após o posicionamento de elementos em um espaço, diagramas de Voronoi representam cada um deles por um polígono. Qualquer posição no interior de um polígono está mais próxima do elemento representado do de quaisquer dos demais elementos do conjunto. A comparação entre uma visualização de conjuntos de documentos na qual o espaço é divido em células de Voronoi e a visualização do IDMAP, que adota uma divisão do espaço por triangulação, mostrou alguma evidencia de que a utilização de diagramas de Voronoi facilita a interação dos usuários. A solução apresentada no Capítulo 4 também trabalha com uma visualização em que o espaço é dividido em polígonos associados a elementos do conjunto de dados.

Ainda como parte da abordagem IDMAP, a interação com o mapa gerado é apoiada pelo cursor aranha (Spider Cursor) (Minghim et al., 2005), uma ferramenta de interação que mostra 


\section{Visualization Toolkit - Win320penGL $\# 1$}

RI-finat-webslog-papsr.ps.txt

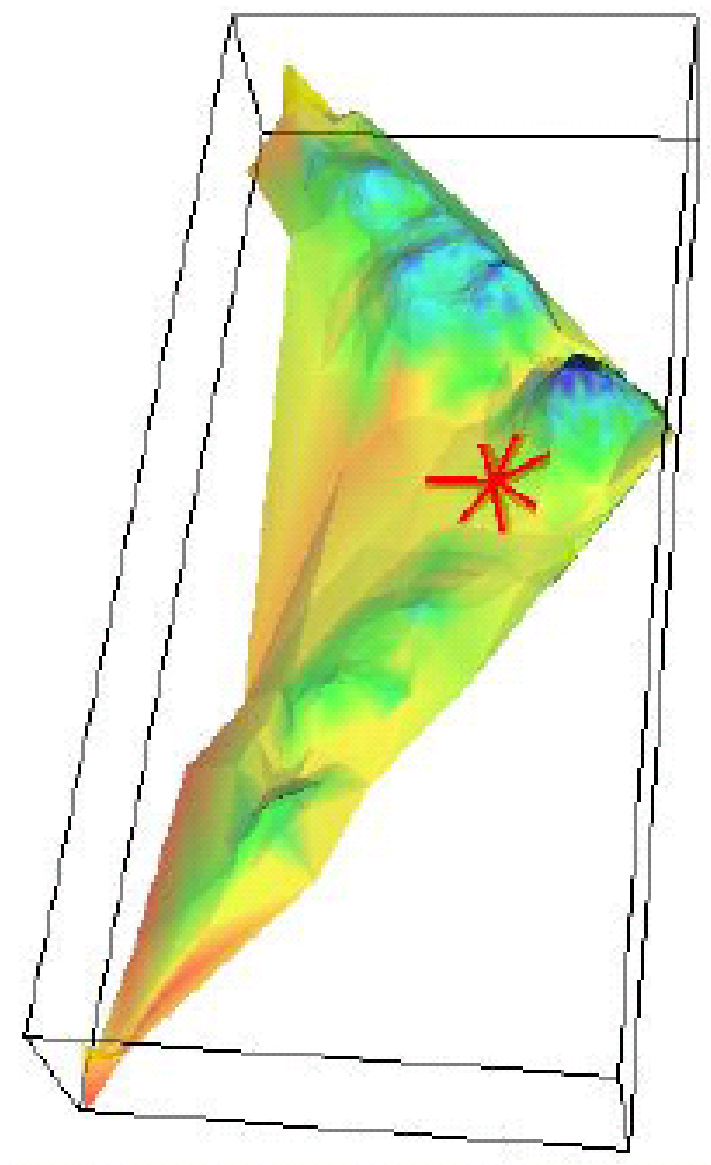

Figura 2.8: IDMAP com cursor aranha. Extraído de Minghim et al. (2006).

o deslocamento de um cursor sobre a superfície formada pela triangulação à medida que o usuário move o mouse (Figura 2.8). A partir do documento que está sob o cursor, as arestas dos triângulos que ligam o documento corrente aos seus vizinhos são realçadas, dando a impressão de pernas de aranha. O Spider Cursor foi estendido para a representação de dados utilizando atributos aurais (sonificação) (Franchin, 2007; Franchin et al., 2009).

O cursor aranha permite a navegação espacial, conforme classificação de Dourish e Chalmers (1994). Essa navegação tenta imitar a nossa navegação no mundo real. Os autores defininem também a navegação semântica, comandada por relações semânticas ou lógicas presentes no conjunto de documentos, e a navegação social, seguindo ações de outros usuários, em um ambiente colaborativo. 
Técnicas de interação baseadas em "foco+contexto" permitem examinar detalhes locais sem perder a noção da estrutura global. Algumas delas são recorrentes na visualização de domínios de conhecimento (Börner et al., 2003):

- Árvores hiperbólicas, que montam a visualização num espaço hiperbólico, reservando maior espaço de tela para o foco de interesse, mantendo uma visão distorcida do contexto;

- Visões olho-de-peixe simulam o funcionamento de uma lente grande angular, porém com maior ampliação no centro da imagem;

- Zoom semântico, que apresenta diferentes visões de acordo com o nível de zoom selecionado. Assim, numa visão geral, os elementos apresentados podem ser publicações, porém, ao aproximar a visão, os artigos de cada uma das publicações podem se tornar visíveis.

\subsection{Soluções em visualização de domínios de conhe- cimento}

Nesta seção, apresenta-se uma visão geral de algumas ferramentas e técnicas utilizadas em Visualização de Domínios de Conhecimento, a partir de alguns exemplos.

\subsubsection{Self-Organization Maps (SOMs) cartográficos}

Self-Organization Maps - SOMs (ver seção 2.4.2) utilizam algoritmos de redes neurais para gerar mapas auto-organizáveis de visualização de informação adequados para organizar grandes volumes de informação, de forma que documentos similares são alocados em posições próximas em uma malha bidimensional (Seção 2.4.2).

No exemplo da Figura 2.1, um SOM Cartográfico foi construído por meio da aplicação de agrupamento (clustering) hierárquico baseado em palavras-chave encontradas em documentos previamente organizados por meio de um SOM (Börner et al., 2003). O resultado deste agrupamento é interpretado como altura em uma superfície. Assim, o relevo associado expressa quão organizada, focalizada e coerente é uma porção dos dados. O mapa é apresentado conforme os padrões utilizados para a construção de mapas geográficos convencionais (Skupin, 2002). Na Figura 2.1, a altura está representada por cores e as fronteiras entre agrupamentos são desenhadas como linhas de fronteira entre regiões ou países. 


\subsubsection{CiteSpace II}

O sistema CiteSpace II, desenvolvido por Chen (2006), tem como objetivo facilitar a análise e detecção de tendências emergentes em domínios de conhecimento. Para Chen, uma especialidade (specialty), ou área de pesquisa, materializa-se como uma função que relaciona uma fronteira de pesquisa e sua base intelectual. Ele então trabalha com redes híbridas de artigos científicos e termos. Os artigos são conectados por relações de cocitação e representam a base intelectual de um domínio. Já os termos são extraídos de artigos recentes por uma técnica de detecção de termos emergentes, derivada de Kleinberg (2002) e representam as fronteiras da pesquisa (research fronts) ou o estado da arte do domínio. Um termo é ligado a um artigo se um ou mais artigos em que é encontrado citam o referido artigo. Tais termos seriam melhor adequados a capturar evoluções recentes em uma area de pesquisa, dado que não espera-se encontrar muitas citações a artigos recentes, ainda que relevantes.

A visualizações produzidas no CiteSpace II apresentam artigos e termos como nós de uma rede (Figura 2.9]. Os artigos são obtidos de fontes de dados bibliográficos como a Web of Science e o PubMed e filtrados por número de citação, cocitação e coeficiente de cocitação. A quantidade de arestas nas redes apresentadas é usualmente reduzida com a técnica PFNET (Seção 2.4.1). Para facilitar o processamento, especialmente do algoritmo PFNET, e permitir a aplicação de limiares distintos para os filtros aplicados aos artigos recuperados, os artigos são separados por data de publicação, em períodos de extensão determinada pelos usuários. Uma das visualizações disponíveis, como a apresentada na Figura 2.9, utiliza tais períodos para separar a tela em faixas horizontais. Nesta visualização, os artigos têm liberdade de movimento vertical, porém são mantidos dentro das suas respectivas faixas temporais. Na outra opção de visualização, o posicionamento segue exclusivamento o layout de rede, de maneira análoga ao descrito na Seção 2.4 .4 .

Além dos termos emergentes, são destacados também artigos julgados como pontos de inflexão (pivotal points) na pesquisa e aqueles com grande número de citações. São considerados como pontos de inflexão aqueles artigos que estabelecem a ligação entre agrupamentos distintos no grafo. No sistema, são destacados aqueles artigos com alto grau de intermediação (betweenness centrality).

$\mathrm{O}$ artigo de Chen traz dois estudos de caso em que o impacto de mudanças em um domínio é observado com o sistema, quer tenham estas mudanças origem na própria pesquisa, como, por exemplo, uma nova descoberta, quer tenham origem no ambiente externo. Autores de artigos considerados como pontos de inflexão na pesquisa foram entrevistados e corroboraram ou explicaram as observações feitas por Chen, com base nas visualizações produzidas.

As figuras a seguir apresentam versões anteriores do CiteSpace e são exemplos do uso de diferentes unidades de análise na visualização de domínios de informação. Nas Figuras 2.10 


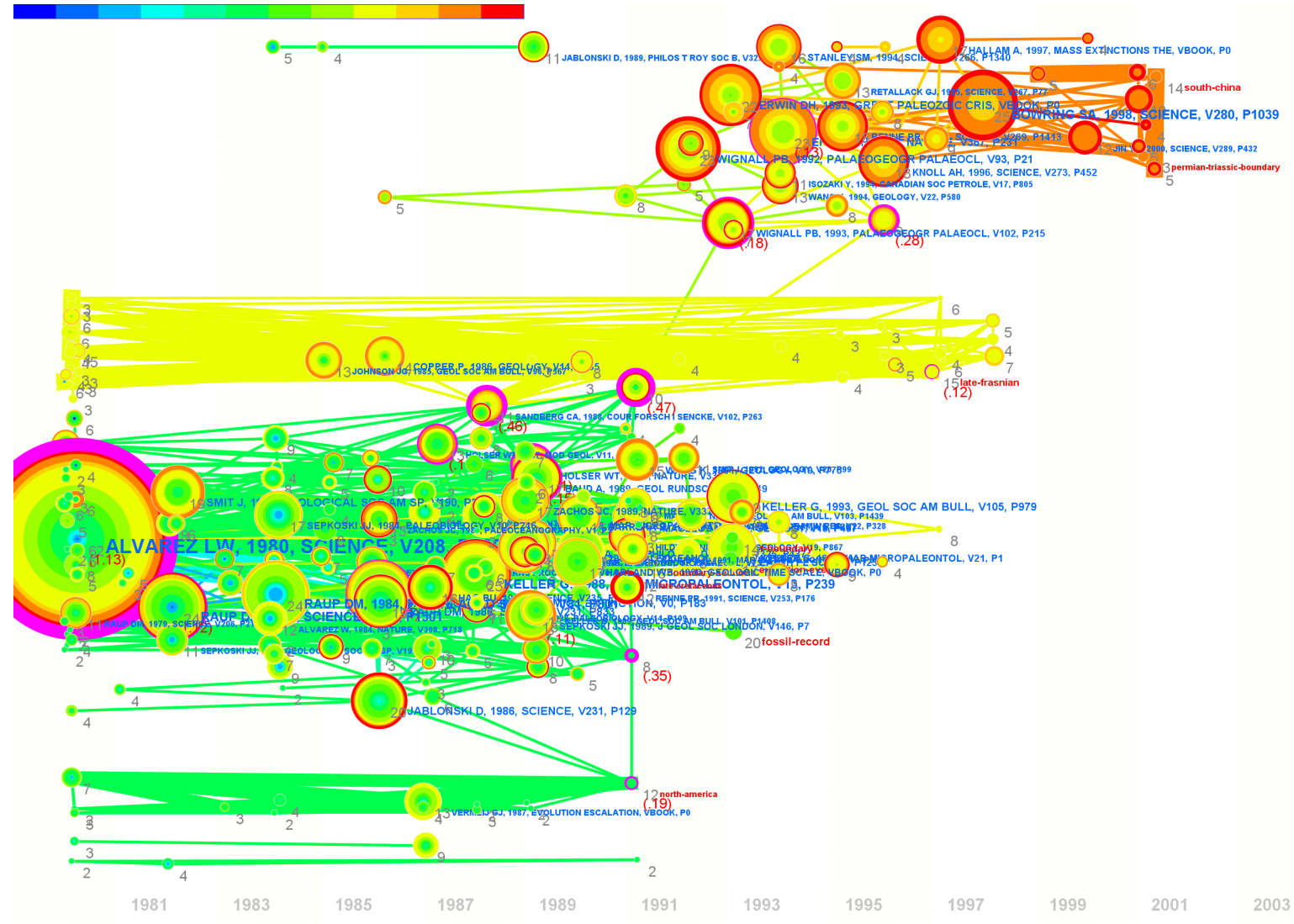

Figura 2.9: Visão por períodos da pesquisa em extinções em massa, mostrando três subareas distintas da pesquisa. O segundo (de baixo para cima) e maior agrupamento trata da extinção K-T, quando pereceram os dinossauros, inicia com artigo de Alvarez et al. (1980), bastante citado, que propõe a queda de asteróide como causa do evento. A pesquisa acerca do assunto praticamente desaparece na década de 1990, após a descoberta de uma cratera, o que fortalece a hipótese de Alvarez et al. (1980). Os demais agrupamentos tratam de extinções ocorridas em outros períodos. Extraído de Chen (2006).

e 2.11, os nós representam autores distribuídos de acordo com as relações de cocitação destes autores em trabalhos de terceiros (ver Seção 2.3). Esta abordagem é chamada de análise de autores por cocitação (Author Co-citation Analysis - ACA). A Figura 2.11 apresenta o mesmo mapa da Figura 2.10, porém com uma barra de citação associada a cada nó, a qual indica o número de citações de cada autor e reflete o impacto de cada um na área apresentada.

Na Figura 2.12, os nós da rede representam documentos. Neste exemplo, a similaridade entre os documentos foi determinada pela coocorrência de citações destes documentos em trabalhos mais recentes (ver Seção 2.3). Esta abordagem é chamada de análise de documentos por cocitação (Document Co-citation Analysis - DCA). 


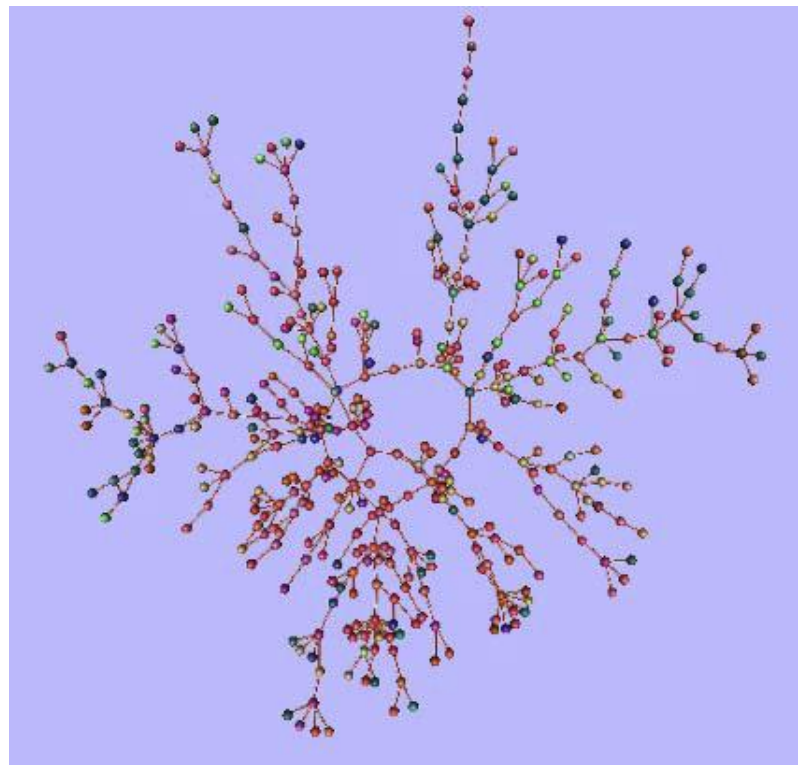

Figura 2.10: Author Co-citation Analysis, com 380 autores com 9 ou mais citações. Extraído de Börner et al. (2003).

\subsubsection{Projection Explorer - PEx}

A Projection Explorer (PEx) (Paulovich et al., 2007) é uma ferramenta de mineração visual de dados baseada no posicionamento no plano de dados multidimensionais por similaridade. Ela tornou-se uma plataforma de trabalho e experimentação, recebendo contribuições de diversos membros do grupo de pesquisa em visualização do ICMC. O sistema realiza também tarefas auxiliares, como a obtenção de dados a partir de consultas na Web e o preprocessamento de conjuntos de documentos. A PEx é uma evolução do Text Map Explorer (Paulovich e Minghim, 2006a). A ferramenta está disponível com licença GNU GPL. A Figura 5.1 traz um exemplo de um mapa de documentos gerado com a PEx.

Por ser uma ferramenta que se presta à experimentação, a PEx suporta múltiplas opções para as etapas de projeção, preprocessamento e visualização. Também permite a manipulação de diversos parâmetros, que, em um produto destinado a usuários finais, seriam fixos ou definidos por alguma heurística, ainda que imperfeita. Ela suporta não só a exploração de conjuntos de documentos, aceitando como entrada vetores de pontos ou matrizes de distância que podem ser obtidas a partir de conjuntos quaisquer. Ela também importa conjuntos de documentos no formato Portable Documento Format - PDF e resultados de consultas do Google, conforme descrito em Pinho (2006).

A PEx permite controle de diversos parâmetros de visualização. A Figura 2.13 mostra o painel de configuração da visualização em uma das versões da PEx. Adotando-se os parâmetros padrão, cada documento é um círculo colorido ligado a seus vizinhos por arestas. As arestas 


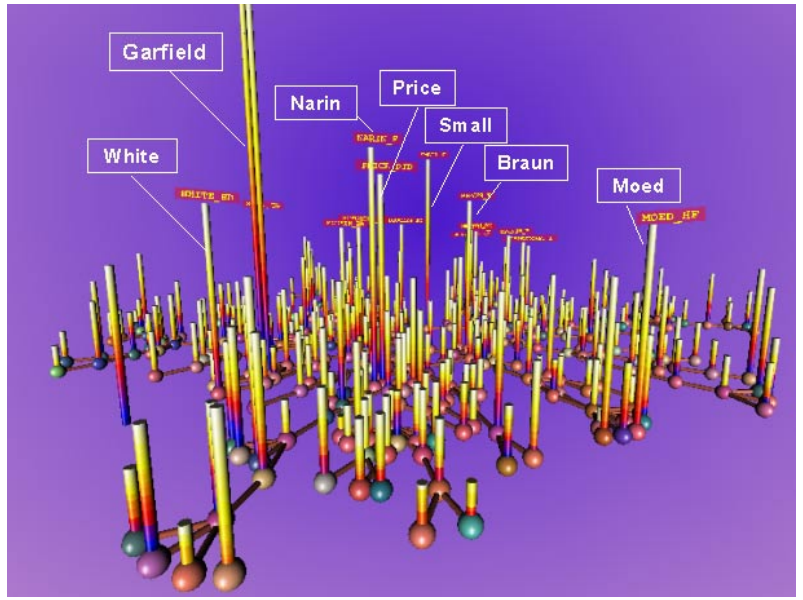

Figura 2.11: Visão do mapa Author Co-citation Analysis visto na Figura 2.10 com barra de citação. A cor indica a data da citação. Extraído de Börner et al. (2003)

podem ser determinadas por uma triangulação de Delaunay, pela indicação dos $k$ vizinhos mais próximos no espaço antes da projeção (K Nearest Neighbors $-K N N)$, os vizinhos no espaço projetado, ou por informações importadas de outras fontes.

Assim como as arestas transmitem informação, a cor e tamanho dos elementos (círculos) podem indicar o resultado de uma consulta, ou ainda conjuntos de valores escalares associados a cada elemento. A consulta disponível na PEx é uma variação da pesquisa booleana (Seção 2.3.1.2) com pesos, sendo aplicada sobre o texto completo dos documentos analisados.

Na PEx, diversas opções estão disponíveis para a projeção de dados, entre elas: ProjClus, FastMap e LSP. Estão disponíveis também técnicas de redução de dimensionalidade e a técnica Force de melhoria de projeções (Seção 2.4.8).

As medidas de distâncias sobre espaços vetoriais disponíveis são euclidiana, Manhattan e cosseno. Também está disponível o NCDs. No preprocessamento de documentos, a PEx aplica stemming e fornece uma ferramenta para a seleção de cortes de Luhn e inclusão de stop words (ver Figura 2.14 e Seção 2.3.1.1).

É possível selecionar subconjuntos de interesse e eliminar elementos indesejados. Também é possível ver o texto de cada documento. Como suporte à experimentação, o texto visualizado pode ser diferente do texto de origem do mapa. Assim, um mapa pode ser gerado apenas com títulos e resumos de artigos, por exemplo, mas ter o seu texto completo apresentado aos usuários.

A PEx apresenta ainda uma relação de completa de itens da coleção, para seleção direta, e também uma lista com os $k$ vizinhos de cada item. Outras funcionalidades presentes são: (i) a adição de etiquetas para uma área selecionada pelo usuário, (ii) a aplicação de um algoritmo baseado em força para reposicionamento dos documentos com base nas arestas visualizadas, 


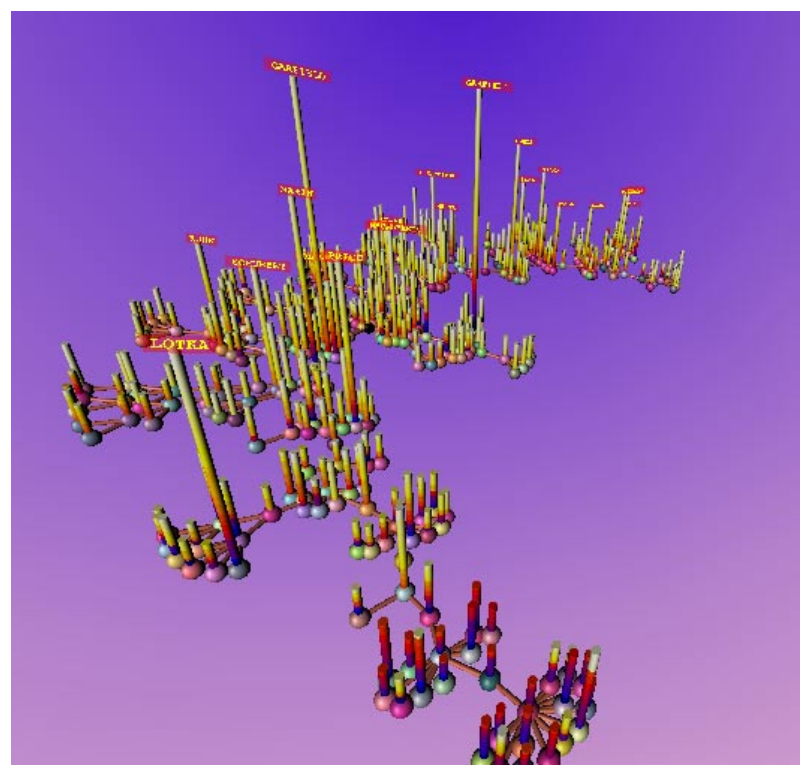

Figura 2.12: Mapa Document Co-citation Analysis de 394 artigos com barra de citação associada a cada documento. Exibidos os artigos com 10 ou mais citações. Extraído de Börner et al. (2003).

similar ao algoritmo à técnica de layout de rede do Prefuse (Seção 2.4.4), e (iii) a coordenação entre múltiplas visões.

Algumas versões especializadas da PEx foram desenvolvidas, resultado da adaptação da ferramenta para diferentes tarefas e o suporte a diferentes algoritmos, fruto do trabalho de múltiplos pesquisadores: (i) TopicPEx (Capítulo 5), (ii) PEx-image (Eler et al., 2008), (iii) PEx-web (Paulovich et al., 2008b) e (iv) Temporal-PEx (Alencar et al., 2008).

\subsubsection{IN-SPIRE}

O software IN-SPIRE (http://in-spire.pnl.gov/), que é uma evolução do SPIRE (Wise, 1999), tem como objetivo criar rapidamente visualizações significativas de coleções de textos, possibilitando a exploração e a compreensão de grandes coleções de documentos sem a necessidade de ler cada um deles (Pacific Northwest National Laboratory, 2006).

O IN-SPIRE gera duas visões de uma coleção de documentos: Galaxy View e ThemeView. Na Galaxy View, cada documento é apresentado como um ponto, ou estrela. Agrupamentos são destacados com o desenho de nuvens, áreas em azul na Figura 2.15. Para cada nuvem é atribuída uma etiqueta com os termos predominantes nos documentos associados. Já a ThemeView (ver Figura 2.16, apresenta o mesmo conjunto de documentos, porém formando uma superfície em um ambiente 3D. Nesta visão, os documentos não são individualizados. A altura da superfície é dada pela ocorrência de termos selecionados nos documentos distribuídos ao longo do mapa. $\mathrm{O}$ mapa é separado em regiões e, para cada região, é verificada a ocorrência de termos selecionados 


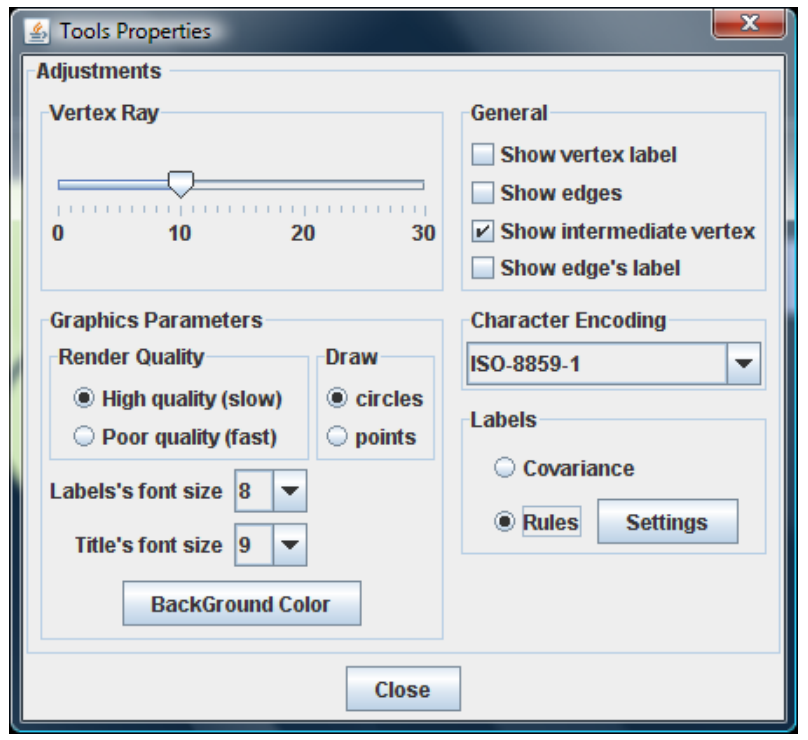

Figura 2.13: Opções de configuração para visualização em uma da versões da PEx.

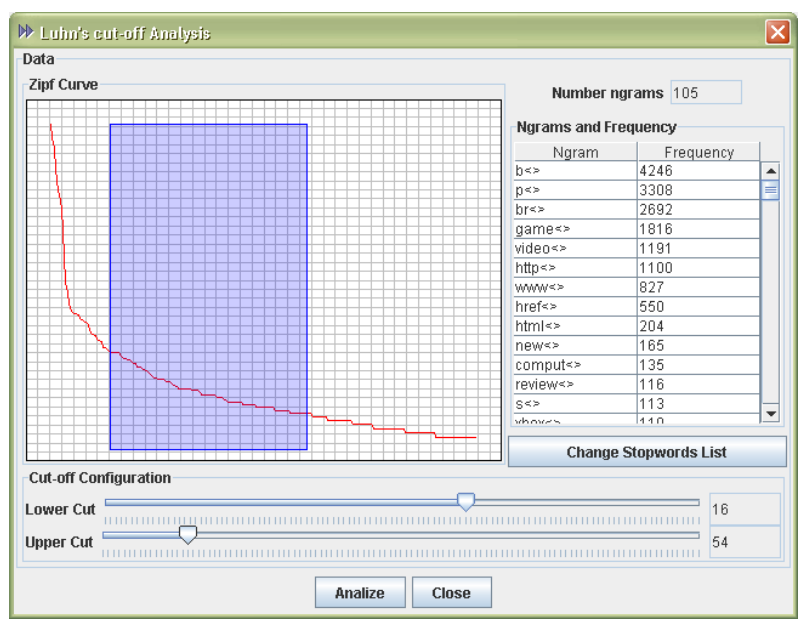

Figura 2.14: Ferramenta de seleção de termos na PEx. 
nos documentos da região. Regiões mais altas indicam um maior número de documentos e tópicos mais coesos.

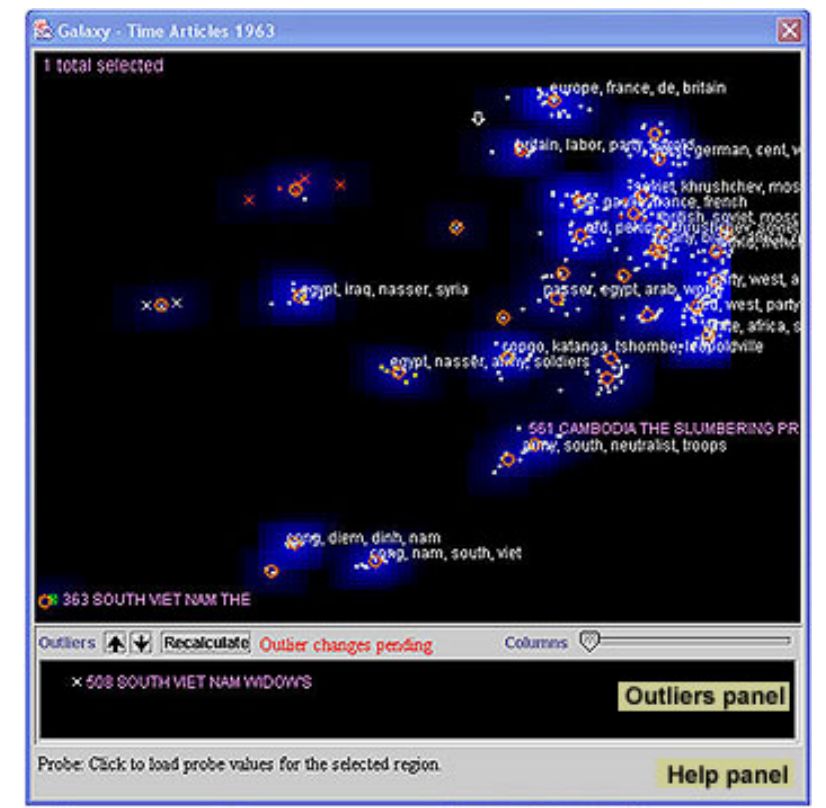

Figura 2.15: Galaxy View no IN-SPIRE. Extraído de Pacific Northwest National Laboratory (2006).

O IN-SPIRE suporta, além da busca booleana, uma busca por similaridade, que considera a correlação entre os termos, determinada para o conjunto de documentos em análise. O sistema implementa uma única técnica de projeção de centróides de agrupamentos denominada Anchored Least Stress - ALS (Wise, 1999), semelhante à técnica ProjClus (Paulovich e Minghim, 2006a), apresentada na Seção 2.4.9, para posicionamento de agrupamentos. Utilizando, no entanto, uma técnica de extração de fatores, inspirada na LSA (Seção 2.4.5), para a projeção dos centróides.

A seleção de termos é feita automaticamente. A seleção automática é feita por meio de stemming e remoção de stop words, seguida de filtros por frequência, como na PEx. Os termos mais significativos são mantidos com base na sua distribuição, de forma análoga ao proposto por Bookstein et al. (1998), e com base em uma análise de correlação com os demais termos da extraídos da coleção. No máximo trezentos termos ou dimensões no espaço vetorial são mantidos. Durante a interação com o sistema, é possível excluir termos não relevantes, o que provoca a reconstrução da visualização.

Os agrupamentos formados durante a projeção são aproveitados na seleção do termos que contribuirão para o cálculo de altura da ThemeView. Um variante da medida $t f \times i d f$ é calculada, que considera a frequência de cada termo $t_{j}$ em um agrupamento $S_{k}$ em relação à sua frequência nos demais agrupamentos: 


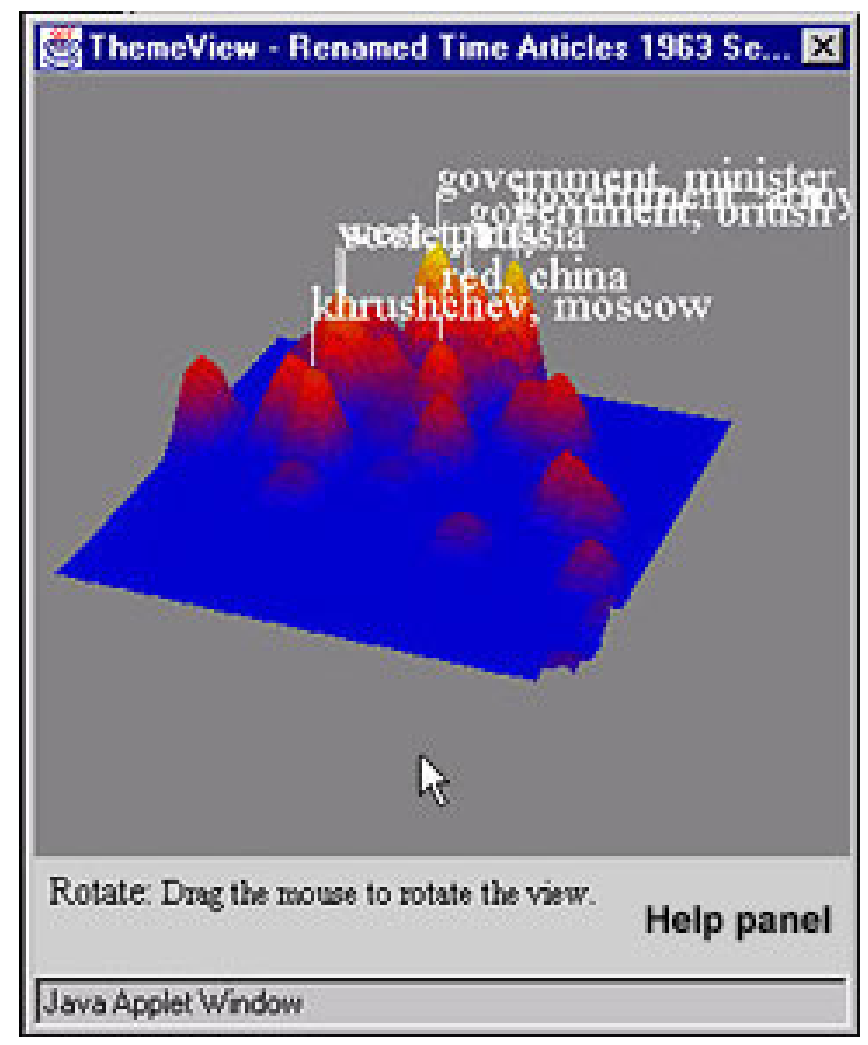

Figura 2.16: ThemeView no IN-SPIRE. Extraído de Pacific Northwest National Laboratory (2006). 


$$
w_{t_{j} S_{k}}=\frac{\sum_{D_{i} \in S_{k}} t f_{t_{j} D_{i}}}{\sum_{D_{i} \notin S_{k}} t f_{t_{j} D_{i}}}
$$

Tal medida é análoga ao peso adotado na Seção 5.2.1 para a avaliação de regras de associação. Para cada agrupamento, é escolhido um número fixo de termos entre aqueles de maior peso, sendo 150 a 300 a quantidade de termos tipicamente adotada

É possível selecionar documentos que contêm termos de uma consulta e que, simultaneamente, encontram-se em uma área determinada pelo mouse. Também estão disponíveis ferramentas para selecionar subconjuntos, eliminar elementos indesejados e para inspecionar o conteúdo de cada documento. No momento da leitura dos dados, os documentos podem ser separados em campos, que podem integrar ou não o processo de projeção.

Outras funcionalidades do IN-SPIRE são: (i) criação e manutenção de grupos de documentos por seleção de área ou consulta por termos, (ii) interface para visualização da distribuição de documentos ao longo do tempo (time slicer), (iii) interface para visualização da correlação de termos dada pela sua freqüência em grupos de documentos, (iv) visualização da frequência de termos em uma área do mapa, e (v) registro e visualização do suporte a hipóteses. Documentos podem ser marcados como a favor ou contrários a uma hipótese, cuja visualização apresenta um resumo da quantidade de documentos contrários e a favoráveis.

Wong et al. (2003) introduzem duas técnicas de visualização para a análise de conjuntos dinâmicos de dados, considerando a necessidade da análise imediata de fluxos de dados capturados em tempo real.

A primeira técnica consiste de uma abordagem adaptativa para garantir o processamento em tempo real, reduzindo, conforme a necessidade, a dimensionalidade dos dados tratados, ou mesmo processando apenas parte dos dados recebidos, selecionados por amostragem.

A segunda consiste na utilização de uma janela deslizante para projeção dos dados. Uma porção inicial do conjunto é projetada normalmente, porém, a projeção de um número predeterminado de novos elementos reutiliza os autovetores computados para o subconjunto inicial. Após a inclusão destes novos elementos, a projeção é refeita com todos os elementos a serem visualizados. Como trata-se da visualização de fluxos de dados, entende-se que a projeção completa se dá sempre com um número constante de elementos, já que elementos mais antigos são descartados.

Os autores propõem a combinação destas abordagens considerando a capacidade de processamento do sistema, seguindo os seguintes passos:

1. Quando o fluxo é inferior à capacidade de processamento, o conjunto de dados é reprojetado sempre que nova informação é obtida; 
2. Caso contrário, usar a última projeção como base para a inclusão de um número predeterminado de novos elementos;

3. Adotar a redução de dimensionalidade e/ou a amostragem para prover uma visão geral do conjunto de dados;

4. Computar o erro entre as duas projeções usando análise de Procrustes (Borg e Groenen, 2005);

5. Caso o erro seja superior a um limite estabelecido, refazer a projeção, caso contrário voltar a atualizar a projeção com base nos autovetores correntes para um número predeterminado de novos elementos.

Hetzler et al. (2005) apresentam uma versão adaptada do IN-SPIRE para a visualização de conjuntos dinâmicos de documentos. Nela, a visualização é atualizada com base na projeção de elementos anteriores, como proposto por Wong et al. (2003). Além disto, foram feitas intervenções na interface para destacar os novos documentos, remover documentos antigos e manter consultas atualizadas. Foram feitas duas avaliações do sistema com usuários, primeiro usando uma versão preliminar na qual a visualização era sempre refeita e depois com uma versão beta do sistema completo. A versão inicial demonstrou que o sistema era capaz de destacar novos elementos e apoior os usuários no reconhecimento e caracterização dos novos elementos. Estes experimentos suscitaram o desenvolvimento de ferramentas disponíveis na versão final, como o controle de pausa, que interrompe momentaneamente a adição de novos elementos. A segunda avaliação confirmou a expectativa dos autores da necessidade da manutenção de estado para o apoio aos usuários em uma tarefa de acompanhamento de um tema ao longo do tempo, o que foi conseguido pelos usuários.

\subsection{Considerações finais}

Neste capítulo foi descrito o processo de visualização de domínios de conhecimento, que serviu de fio condutor a descrição de diversas técnicas necessárias para o desenvolvimento do trabalho apresentado nesta tese. Ênfase foi atribuída aos sistemas que produzem mapas de documentos, tendo sido apresentados alguns exemplos.

Pelos exemplos de técnicas e sistemas apresentados, percebe-se que é comum o aproveitamento de técnicas desenvolvidas originalmente com outros propósitos na composição de soluções de visualização de domínios de conhecimento e de visualização de informação. Não descarta-se tampouco o aproveitamento de técnicas desenvolvidas para a visualização de informação ou para um domínio específico no tratamento de problemas em outros domínios. 
Diferentes técnicas estão disponíveis para cada etapa do processo. A escolha entre as muitas variações possíveis vai depender da aplicação e da natureza dos dados, assim como de limites apresentados pelas técnicas existentes. A técnica incremental de posicionamento de elementos de conjuntos dinâmicos de dados no plano introduzida no Capítulo 4 pode ampliar o leque de soluções possíveis na visualização de informação, ao tratar eficientemente conjuntos dinâmicos de dados. 


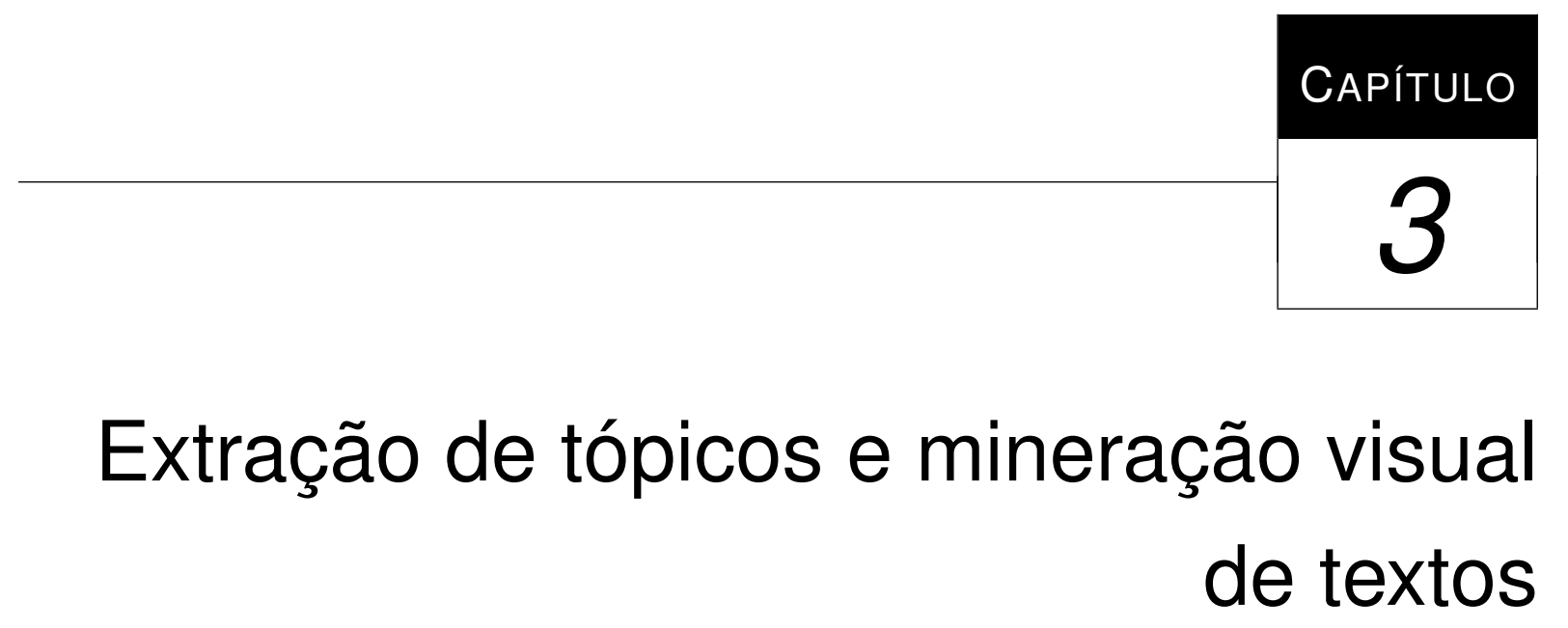

\subsection{Introdução}

Neste capítulo, é abordada a extração de tópicos e suas relações com a visualização de informação (Seções $3.5 \mathrm{e}$ 3.6). Antes, é feita uma breve descrição dos processos de mineração de dados (Seção 3.2 e de mineração de textos (Seção 3.4). É dado especial destaque à aplicação de regras de associação para a mineração de textos, discutindo-se também diversos possíveis cenários de integração entre a mineração de dados e a visualização (Seção 3.3), conforme proposto por Oliveira e Levkowitz (2003).

\subsection{Mineração de dados}

A mineração de dados é definida como a extração de padrões ou modelos a partir de repositórios de dados. Ela pode ser situada como parte do processo de descoberta de conhecimento em bases de dados (Knowledge discovery in databases - KDD). KDD é um processo não trivial, cujo objetivo é obter informação potencialmente útil, válida e previamente desconhecida (Fayyad et al., 1996). 
Embora a mineração de dados seja o cerne do processo de KDD, ela representa apenas entre $15 \%$ e $25 \%$ do esforço envolvido neste processo (Goebel e Gruenwald, 1999). Para Goebel e Gruenwald (1999), outras tarefas integrantes do processo são:

1. entender o domínio do problema e estabelecer os objetivos da mineração;

2. adquirir ou selecionar os dados;

3. integrar e verificar diferentes conjuntos de dados;

4. limpar, preprocessar e aplicar transformações sobre os dados;

5. desenvolver modelos e construir hipóteses;

6. selecionar algoritmos de mineração apropriados;

7. interpretar e visualizar resultados;

8. testar e verificar resultados;

9. aplicar e atualizar o conhecimento adquirido.

A mineração propriamente dita ocorre após as tarefas 1 a 6 , e antes das tarefas 7 a 9. Diferentes tarefas de mineração podem ser combinadas para atingir um certo objetivo. Por exemplo, a extração de regras de associação pode ser aplicada sobre diferentes agrupamentos obtidos em uma etapa anterior.

Ainda segundo Goebel e Gruenwald (1999), as tarefas de mineração de dados podem ser classificadas, de acordo com o seu propósito, em: (i) processamento de dados, (ii) predição, (iii) regressão, (iv) classificação, (v) agrupamento (clustering), (vi) identificação de associações relevantes, (vii) visualização de modelos, e (viii) análise exploratória de dados.

\subsection{Mineração e visualização}

As abordagens que utilizam técnicas de visualização em conjunto com a mineração de dados podem ser agrupadas em três categorias (Oliveira e Levkowitz, 2003): (i) exploração visual de dados para a mineração (Visual Data Exploration - VDE for Mining), (ii) visualização de modelos minerados (Visualization of Mining Models), e (iii) mineração visual de dados (Visual Data Mining).

As técnicas de exploração visual tiram proveito da capacidade visual dos seres humanos e de sua habilidade em reconhecer padrões visuais. Técnicas de visualização podem apoiar a 
detecção de agrupamentos, outliers, regras, padrões e classes. Diferentemente da mineração de dados, as técnicas de VDE são inteiramente conduzidas pelo usuário. Elas podem ajudar também nas tarefas auxiliares de manipulação de grandes bases de dados, como filtragem, consulta e seleção de subconjuntos a serem analisados posteriormente com técnicas de mineração.

As técnicas de visualização de modelos minerados aplicam a visualização para apresentar resultados da mineração. Um bom exemplo de visualização de modelos minerados é a visualização de regras de associação. Tipicamente, na indução de regras de associação, uma grande quantidade de regras é extraída. Na visualização proposta por Wong et al. (1999) são destacados cinco atributos principais das regras: (i) conjuntos de itens antecedentes, (ii) conjuntos de itens consequentes, (iii) associação entre consequentes e antecedentes, (iv) suporte, e (v) confiança. Esta visualização apresenta um grande número de regras e metadados associados em um espaço tridimensional, requer pouca interação, minimiza a oclusão e dispensa a navegação por visualizações distintas (Figura 3.1).

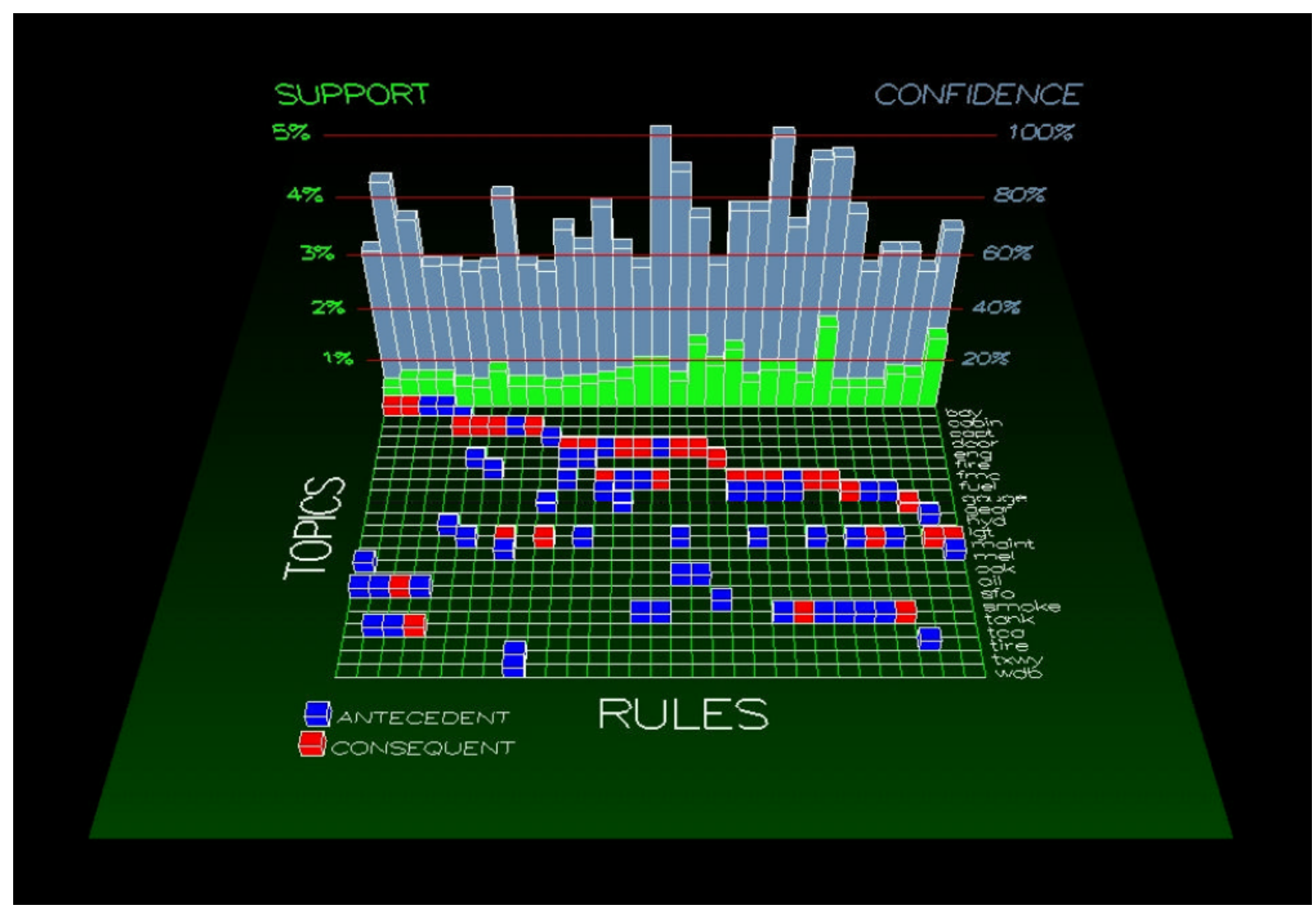

Figura 3.1: Visualização de regras de associação. Extraído de Wong et al. (1999).

A mineração visual de dados pode ser vista como a integração entre a visualização e mineração em um processo unificado, no qual a visualização ajuda os usuários a interagir com o algoritmo de mineração, e a direcioná-lo na busca por uma solução. A mineração de regras de associação, por exemplo, requer o ajuste de limiares para suporte e confiança e a aplicação 
de filtros, a fim de reduzir a quantidade de regras geradas. Em uma abordagem integrada, a visualização pode auxiliar o usuário no ajuste destes parâmetros e no direcionamento do processo de acordo com os seus interesses. Yamamoto et al. (2008) propõem uma solução que agrega técnicas interativas de visualização na condução do processo de descoberta de regras (Figura 3.2). A estratégia busca dar maior controle ao usuário e permitir que ele compreenda melhor o processo e os resultados gerados. A cada passo do processo de extração de regras, quando são extraídos conjuntos de itens (itemsets) de tamanho $k$, o usuário tem a opção de eliminar itemsets considerados não relevantes, que, assim, não darão origem a regras derivadas nas iterações seguintes do algoritmo. A interação com a visualização, em que os k-elementos são posicionados por similaridade, permite aplicar filtros distintos a diferentes agrupamentos de regras. Estes agrupamentos são formados automaticamente, aplicando-se uma técnica de clustering, mas podem ser modificados pelo usuário. No trabalho de Yamamoto et al. (2008), assim como nesta tese, são propostas soluções em que há forte integração entre a visualização e mineração. No entanto, aquele trabalho tem como elemento central um processo de mineração, com apoio da visualização, enquanto que, nesta tese, o elemento central é um processo de visualização exploratória, com apoio de técnicas de mineração. Solução análoga, dada por Schreck et al. (2008), permite que usuários interfiram no processo de treinamento de um Self-Organizing Map - SOM com o apoio de uma ferramenta interativa de visualização.
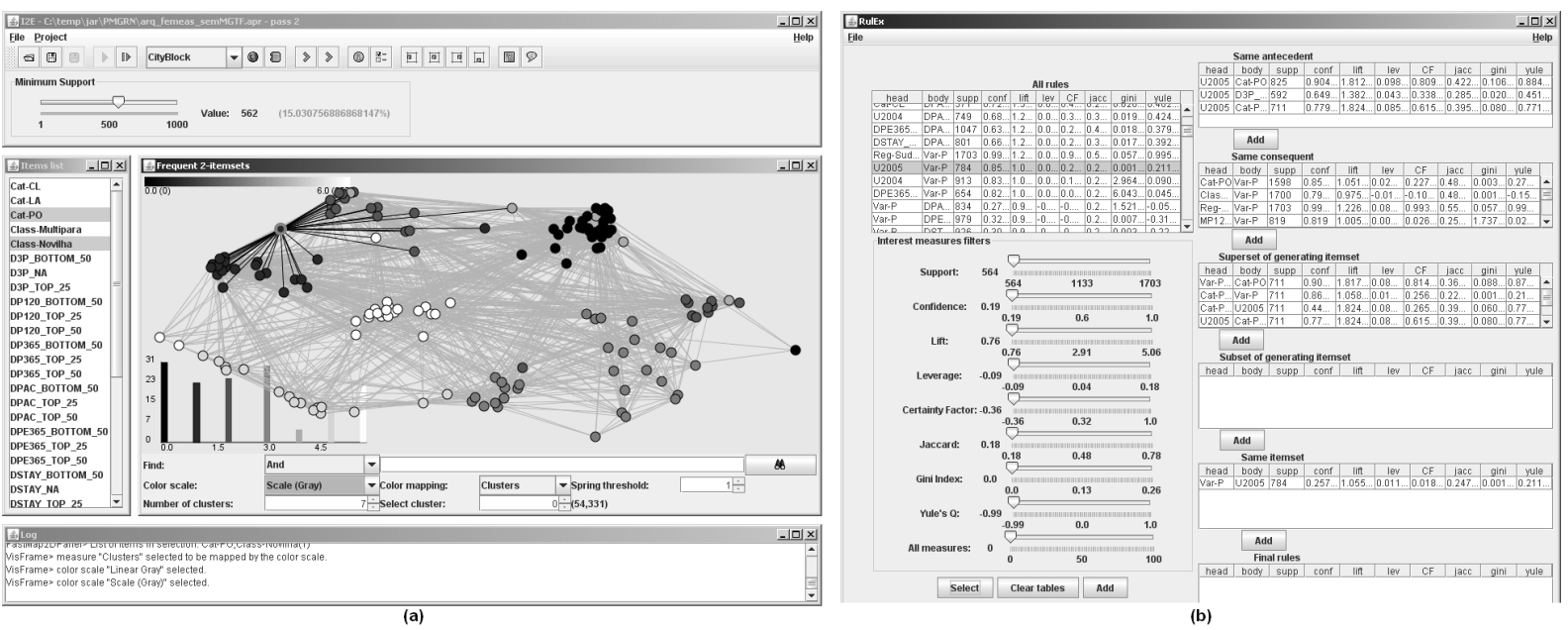

Figura 3.2: Interface da ferramenta I2E : visualização de conjuntos de itens (a) e controles para a exploração de regras (b). Extraído de Yamamoto et al.(2008).

\subsection{Mineração de textos}

A mineração de textos (text mining) ou mineração de dados de texto (text data mining), ou ainda descoberta de conhecimento em bases de dados textuais (knowledge discovery from textual 
databases), tem como objetivo a descoberta de padrões ou de conhecimento não trivial a partir de documentos textuais não estruturados. A mineração de textos é uma tarefa complexa, pois envolve o tratamento de dados que são intrinsecamente difusos e não estruturados. Este é um campo multidisciplinar que engloba a recuperação de informação, análise de texto, extração de informação, visualização, tecnologias em banco de dados, aprendizado de máquina e mineração de dados (Tan, 1999).

Um exemplo de solução de mineração de textos é a aplicação de regras de associação para a classificação de documentos. Uma regra de associação para classificação associa a presença de um conjunto de termos com uma classe de documentos. Na solução proposta por Yoon e Lee (2008), uma técnica, inspirada em abordagens de boosting, é adotada na filtragem das regras que serão usadas na classificação. Uma formalização do problema de indução de regras de associação em conjuntos de documentos e outras soluções em mineração de textos com regras de associação são apresentadas na Seção 3.4.1.

A ferramenta ExperText (Oliveira e Mendonça, 2004) é um exemplo de solução de mineração de textos não baseada na indução de regras de associação. Ela aplica um método de combinação de múltiplos classificadores Bayesianos sobre repositórios de documentos não estruturados. Essa solução permite usar conjuntos de treinamento rotulados por diferentes especialistas de forma distribuída e incremental. Os modelos produzidos por cada conjunto podem ser combinados em um único modelo de classificação. Os autores sugerem a utilização da ferramenta em ambientes empresariais, como apoio à classificação colaborativa de documentos e também na construção de filtros anti-spam, capazes de combinar o julgamento de múltiplos usuários na construção de um filtro único para a identificação de mensagens de correio eletrônico indesejadas.

\subsubsection{Regras de associação e mineração de textos}

Uma regra de associação é uma implicação na forma $T_{i} \Rightarrow T_{j}$, na qual $T_{i} \cap T_{j}=\emptyset$, sendo $T_{i}$ e $T_{j}$ subconjuntos de um conjunto de itens $T=\left\{t_{1}, t_{2}, \ldots, t_{m}\right\}$. Ao extrair regras de associação de conjuntos de documentos, os itens são termos presentes no conjunto de termos $T_{C}$ do corpus $C$ (bag-of-words), e uma transação $T r$ é um conjunto de termos $T_{D_{i}} \subseteq T_{C}$ que representa um documento $D_{i}$. O conjunto $T_{i}$ é o antecedente ou corpo, enquanto o conjunto $T_{j}$ é o seu consequente ou cabeça. A cardinalidade de $T_{i}$ e $T_{j}$ pode variar de $1 \mathrm{a} m-1$. No caso específico da mineração de regras de classificação, o consequente é uma classe, em lugar de um conjunto de itens.

Uma regra $T_{i} \Rightarrow T_{j}$ possui confiança $c \%$ no corpus $C$, se $c \%$ dos documentos que contêm $T_{i}$ também contêm $T_{j}$. O seu suporte será $s \%$ em $C$, se $s \%$ dos documentos do corpus contêm $T_{i} \cup T_{j}$. Usualmente, espera-se encontrar regras de associação que atendam a critérios mínimos 
de suporte e confiança. Além de suporte e confiança, diversas outras medidas objetivas foram definidas para avaliar regras de associação, por exemplo: (i) interesse, (ii) convicção, (iii) dependência, (iv) novidade e (v) satisfação (Geng e Hamilton, 2006).

Dois dos principais problemas na indução de regras de associação são a explosão combinatorial e a identificação de associações raras, portanto, com baixo suporte (Weiss, 2004). De maneira geral, estes problemas são tratados: (i) restringindo-se o espaço de busca da indução, tipicamente estabelecendo limiares relativamente altos para suporte e confiança; ou (ii) filtrando-se o conjunto de regras induzidas, pela aplicação de medidas objetivas ou medidas subjetivas, que consideram intervenções dos usuários. Em ambos os casos, não é incomum que o processo produza, ainda assim, uma grande quantidade de regras, e, não obstante, elimine regras interessantes do ponto de vista da aplicação. Se o objetivo é identificar tópicos em conjuntos de documentos, tais problemas tornam-se particularmente importantes. Um limiar de suporte relativamente baixo deve ser estabelecido para que sejam induzidas regras que incluam termos além daqueles mais frequentes, o que resulta na indução de um grande número de regras, com grande redundância entre elas. Se, por outro lado, o limiar for relativamente alto, regras potencialmente interessantes, porém raras, são completamente ignoradas.

Amir et al.(2005) descrevem uma abordagem para identificar relações relevantes de co-ocorrência de termos em conjuntos de documentos, baseada na indução de regras de associação. Termos com forte relação entre si, que frequentemente aparecem juntos em documentos, podem, eventualmente, mascarar associações menos frequentes de um destes termos com outros. Para descobrir estas associações menos frequentes, associações máximas (maximal associations) são induzidas. Em uma associação máxima, a confiança é computada apenas para ocorrências em que antecedente e consequente são os únicos representantes de suas respectivas categorias. Em um exemplo hipotético fornecido por Amir et al. (2005) sobre notícias acerca de comércio internacional, uma regra de associação 'EUA', 'Canadá' $\Rightarrow$ 'milho' é descartada por não atingir o limiar de confiança estabelecido, já a sua versão máxima, 'EUA', 'Canadá, max 'milho' seria induzida. 'EUA', 'Canadá' $\Rightarrow$ 'milho' teria baixa confiança, devido à abundante presença de artigos sobre o comercio de peixes entre EUA, França e Canadá. Assim, de fato, a presença de EUA e Canadá não implica, necessariamente a menção ao comercio do milho. No entanto, na sua versão máxima, quando são descartados documentos que contêm outros países além de EUA e Canadá, a confiança sobe para 100\%, já que, no conjunto de notícias, o tema prevalecente nas relações comerciais destes dois países seria quanto ao comércio do milho. A regra máxima 'EUA' , 'Canadá' $\stackrel{\max }{\Rightarrow}$ 'milho' pode ser assim interpretada: a presença dos países EUA e Canadá implica a presença do termo milho, se estes forem os únicos países encontrados no documento. A identificação de regras como esta com algoritmos convencionais demandaria a adoção de um limiar relativamente baixo para confiança, e, consequentemente, resultaria na indução de muitas 
regras pouco relevantes. Obter regras máximas é, em geral, mais rápido do que induzir regras de associação típicas, no entanto, requer que sejam estabelecidas previamente categorias de termos fortemente relacionados.

Cherfi et al. (2004) combinam diversas medidas objetivas para filtrar aposteriori regras induzidas a partir de conjuntos de documentos. Eles empregam ferramentas de processamento de linguagem natural para extrair automaticamente termos relevantes de títulos e resumos de artigos científicos. Um especialista no domínio filtra manualmente os termos extraídos, formando um conjunto reduzido de termos. Regras são induzidas considerando o conjunto reduzido de termos e são ordenadas de acordo com o conjunto de métricas definido. A ordenação, seguida de outra etapa de filtragem manual, define o conjunto final de regras extraídas. As regras que satisfazem a uma combinação destas medidas são selecionadas, como ilustrado na Figura 3.3 .

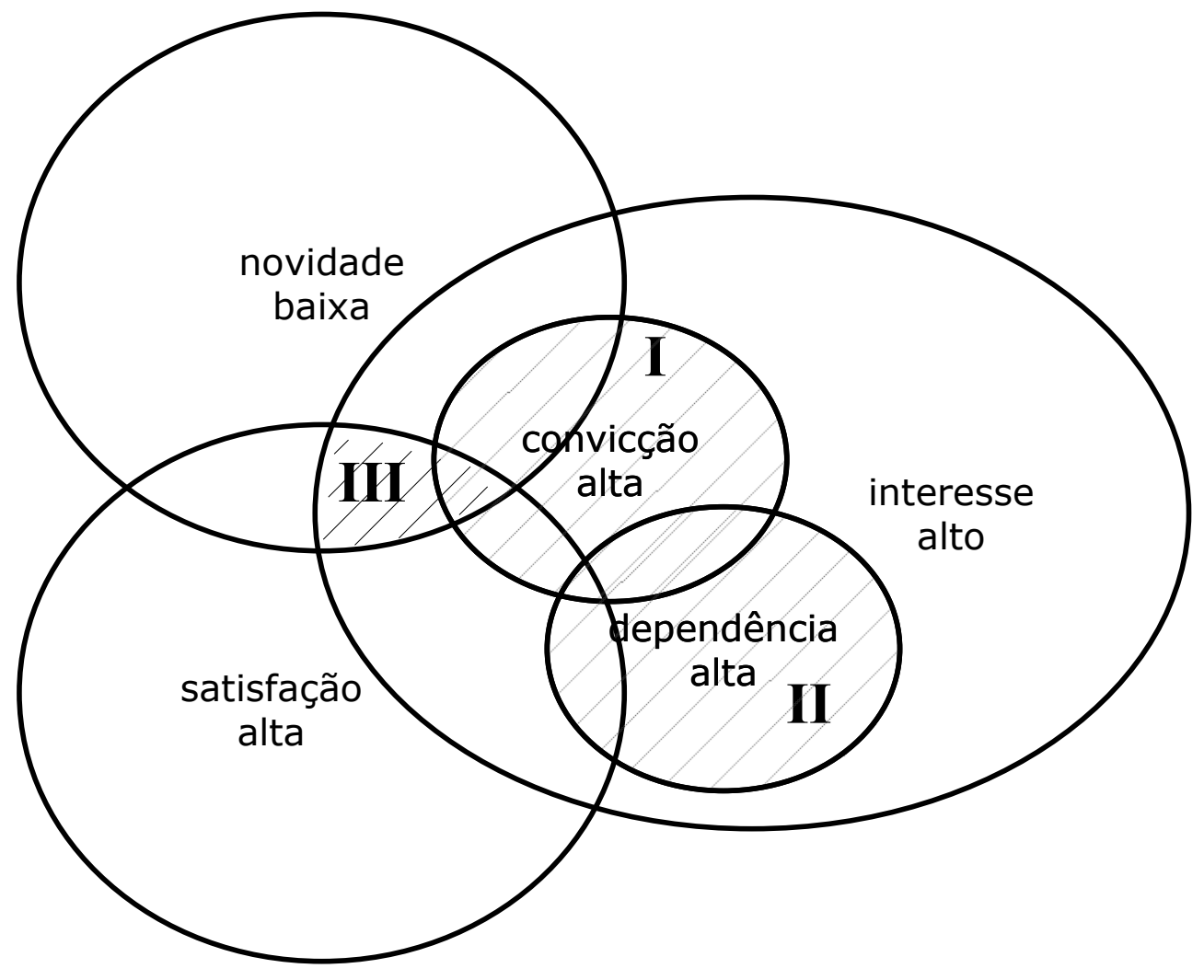

Figura 3.3: Combinação de medidas de qualidade proposta por Cherfi et al. (2004). No diagrama, uma medida alta implica a classificação da regra entre os $k$ maiores valores encontrados para a dada medida. Analogamente, uma medida baixa indica que a regra foi classificada entre os $k$ menores valores encontrados. O conjunto resultado é dado por $I \cup I I \cup I I I$. 


\subsection{Extração de Tópicos}

$\mathrm{Na}$ visualização de conjuntos de documentos, a extração de temas ou assuntos relevantes é um dispositivo frequentemente adotado para apoiar a exploração de mapas, ainda que não identificada como tal. Exemplos de sistemas de visualização que adotam algum procedimento de extração de tópicos são apresentados na Seção 3.6.2.

Um tópico possui diferentes definições a depender da área de pesquisa e do seu uso. Para a Text REtrieval Conference - TREC, importante conferência em recuperação de informação, um tópico é a descrição de um assunto ou necessidade de informação contra o qual documentos podem ser julgados como relevantes ou irrelevantes (Robertson e Callan, 2002). Dado um conjunto de documentos $C$ e um tópico $T p$, um documento $D_{i} \in C$ pode ser considerado relevante, não relevante, ou não ter sido julgado quanto a relevância em relação ao tema. A definição da TREC tem o propósito de avaliar técnicas de recuperação de informação, por meio do cômputo de revocação e precisão e outra medidas derivadas. Neste contexto, o conjunto de documentos relevantes para uma consulta produzido por uma técnica de recuperação de informação é confrontado com os documentos julgados relevantes para o tópico.

Ainda no contexto da recuperação de informação, na ferramenta Scatter/Gather (Hearst e Pedersen, 1996), um tópico é uma lista de termos temáticos (topical terms) que descrevem a essência de um agrupamento de documentos considerados relevantes para uma consulta. A técnica Scatter/Gather e outras técnicas de agrupamento ou classificação de resultados de consultas são detalhadas na Seção 3.5.3.

Para o projeto Topic Detection and Tracking Evaluation - TDT ${ }^{1}$, um tópico é um agrupamento de notícias (stories) que tratam de um mesmo evento.

Nesta tese, conforme discutido na Seção 1.6, define-se tópico como a descrição dada a um conjunto de documentos, usualmente representada por uma lista de termos e ao qual corresponde um conjunto de documentos por ele cobertos.

A extração de tópicos possui, também, relação com a determinação da importância relativa de termos em coleções de documentos, como é feito em Bookstein et al. (1998) e também com a sumarização automática de textos, como em (Pardo et al., 2003).

Diversas abordagens e técnicas são adotadas na extração de tópicos, sendo frequente a utilização de medidas de frequência de termos inspiradas na medida $t f \times i d f$ combinada com outras técnicas ou medidas (Frantzi et al., 1998; Chen et al., 2007; Nagano et al., 2008; Baumer e Fisher, 2008, Chengzhi e Qingguo, 2008).

A abordagem de Frantzi et al. (1998) combina medidas de frequência com a análise do contexto em que são encontradas locuções, i.e. a solução incorpora a análise de termos encon-

\footnotetext{
1 http://www.itl.nist.gov/iaui/894.01/tests/tdt/tasks/detect.html
} 
trados próximos do termo analisado nos documentos da coleção. Nesta abordagem, term context words são termos usualmente encontrados próximos a locuções. Na medida combinada, são privilegiadas as locuções que são frequentemente encontradas em conjunto com term context words. Múltiplas medidas são combinadas por Chengzhi e Qingguo (2008) para a extração de tópicos. Chen et al. (2007) combinam a análise de frequência com a análise da distribuição de termos ao longo do tempo. Nagano et al. (2008) utilizam ontologias para filtrar o conjunto de termos quem serão considerados no processo de extração de tópicos. A extração de conjuntos iniciais de locuções por etiquetadores morfossintáticos (part-of-speech taggers) é utilizada em Frantzi et al. (1998) e por Ibekwe-SanJuan e SanJuan (2002). Em Baumer e Fisher (2008), a extração de tópicos tem o objetivo específico de enriquecer uma lista de blogs relacionados (blog rolls) com os tópicos recém tratados por esses blogs.

A seguir, duas técnicas de extração de tópicos são descritas em detalhe. A primeira dispensa a utilização de contagens de frequência e co-ocorrência, comuns em outras técnicas, apoiando-se na análise de relações léxico-sintáticas entre locuções. A segunda identifica temas emergentes em fluxos de dados analisando alterações na quantidade de novas mensagens ou documentos ao longo do tempo.

\subsubsection{Identificação de temas de pesquisa por agrupamento de lo- cuções}

Um problema para identificar temas de pesquisa em muitas coleções de documentos é a pouca frequência com que locuções específicas do domínio são encontradas. Ibekwe-SanJuan e SanJuan (2002) abordam a questão considerando relações léxico-sintáticas entre locuções em lugar de análises estatísticas apoiadas em contagens de frequência e co-ocorrência de termos.

Inicialmente são extraídas locuções presentes no conjunto de documentos em análise. Para isso, os autores adotam ferramentas existentes ou utilizam um conjunto próprio de expressões regulares para a extração de locuções. O conjunto de locuções extraído pode ser filtrado com base na frequência de ocorrência das locuções, o que é não recomendado pelos autores. Se disponível, recomenda-se a filtragem com base em vocabulário específico do domínio. As locuções são então reduzidas a uma forma composta comum, transformando, por exemplo, a locução 'addition of xanthan gum' em 'xanthan gum addition'.

O próximo passo é estabelecer relações entre as locuções do conjunto por meio da identificação de variantes léxico-sintáticas. Por exemplo, as locuções 'bread manufacture' e 'dietetic bread manufacture' são relacionadas, pois 'dietetic bread manufacture' é uma expansão (à esquerda) de 'bread manufacture'. A Tabela 3.1 traz exemplos para as demais variantes consideradas. As variantes são divididas em duas classes: (i) variantes nas quais há alteração 
do termo cabeça ou principal (variantes CLAS) e (ii) variantes em que não há alteração deste termo (variantes COMP). Há alteração do termo cabeça na variante por expansão à direita e na substituição da cabeça.

Tabela 3.1: Variantes léxico-sintáticas adotadas na identificação de temas de pesquisas. Exemplos extraídos de Ibekwe-SanJuan e SanJuan (2002).

\begin{tabular}{cc} 
Variante & Exemplo \\
\hline Expansão à esquerda & 'bread manufacture' $\mapsto$ 'dietetic bread manufacture' \\
Expansão à direita & 'bakers' yeast' $\mapsto$ 'bakers' yeast preparation' \\
Expansão por inserção & 'bread improvement' $\mapsto$ 'bread quality improvement' \\
Substituição da cabeça & 'frozen dough ingredient' $\mapsto$ 'frozen dough method' \\
Substituição de modificador & 'flour protein content' $\mapsto$ 'bread protein content'
\end{tabular}

Um grafo inicial é construído tendo as locuções como vértices e as variantes COMP como arestas. Cada um dos subgrafos conexos deste grafo contem variantes que compartilham um termo cabeça e, portanto, representam, cada um deles, uma família de conceitos em torno do termo.

Na etapa seguinte, subgrafos são conectados considerando as relações CLAS entre termos. As relações CLAS ligam componentes que potencialmente representam conceitos distintos, já que não compartilham termo cabeça. Os autores justificam a união destes componentes como uma tentativa de associar conceitos que compartilham o mesmo conjunto de modificadores, identificando-se assim associações entre temas de pesquisa.

Uma técnica específica de agrupamento foi desenvolvida a fim de identificar os principais temas de um conjunto de documentos (SanJuan e Ibekwe-SanJuan, 2006). Adota-se uma estratégia de agrupamento hierárquico por single-link, unindo em classes os componentes com ligação mais forte entre si, a cada iteração do algoritmo. A força de uma ligação é dada pela soma dos pesos atribuídos às relações CLAS entre locuções dos dois componentes. O peso atribuído a uma relação CLAS é inversamente proporcional à sua frequência. Assim, se em um conjunto de documentos são identificadas dez variantes do tipo Expansão à esquerda, o peso para este tipo de relação será $1 / 10$. O processo é repetido até que um único componente conexo seja formado. Alternativamente, os usuários podem determinar um limiar mínimo para a força de uma ligação, abaixo do qual ligações são desconsideradas, o que pode resultar em uma rede com diversos componentes.

A rede final é explorada por uma ferramenta de visualização hierárquica de grafos. As classes são identificadas pela locução com maior número de ligações.

A principal vantagem desta técnica é não depender de contagens de frequência ou coocorrência, possibilitando identificar locuções que descrevem temas de pesquisa ainda que 
tais locuções apareçam uma única vez em um corpus. No entanto, a técnica é sensível a características do discurso do domínio em que está sendo aplicada e ao ajuste do parâmetro que impede que todas as classes sejam unidas em um único componente.

\subsubsection{Detecção de Burst}

A técnica de Detecção de Burst (Kleinberg, 2002) tem como objetivo identificar temas emergentes em fluxos de dados, o que seria sinalizado por um aumento súbito de atividade no fluxo. $\mathrm{Na}$ extracão de tópicos a partir de fluxos, a confluência de mensagens ou documentos em um determinado período de tempo pode ser uma informação mais importante do que o conteúdo destas mensagens. Analisando o fluxo de documentos ao longo do tempo, é possível identificar quando tópicos tornam-se salientes e quando deixam de sê-lo.

Kleinberg (2002) propõe uma abordagem baseada em máquinas de estado para modelar fluxos de documentos. Na sua abordagem, aumentos súbitos ou "explosões" de mensagens (bursts) são associados a transições de estado. As máquinas de estado adotadas por Kleinberg para o tratamento de fluxos de mensagens de correio eletrônico contemplam a possibilidade de que, após detectado um aumento súbito na frequência de mensagens (transição do estado inicial dormente $s t_{0}$ para um estado de ocorrência de burst $s t_{1}$ ), ocorram incrementos ainda mais significativos no fluxo de mensagens. Tais bursts de maior intensidade provocam a transição para estados de ordem superior, $\left\{s t_{2}, \ldots, s t_{\infty}\right\}$. A redução na frequência de mensagens provocaria o retorno a estados anteriores. O encadeamento de estados produz uma hierarquia, tendo na base longos períodos de burst de baixa intensidade, que englobam períodos mais curtos de maior intensidade, que, por sua vez, incluem períodos ainda mais curtos e de atividade mais intensa ad-infinitum. Para Kleinberg, tal hierarquia pode ser usada para descrever o comportamento de um fluxo de mensagens.

A técnica fundamenta-se no princípio de que as mensagens são enviadas seguindo um modelo probabilístico, no qual o intervalo $t t$ entre duas mensagens $E_{i}$ e $E_{i+1}$ tem sua distribuição regida por uma função exponencial $f(t t)=\alpha e^{-\alpha t t}$, sendo $\alpha>0$. O valor esperado para um intervalo nesta distribuição é $\alpha^{-1}$, assim, $\alpha$ representa uma taxa de recebimento de mensagens.

Em uma máquina com dois estados, $s t_{0}$ e $s t_{1}$, são definidos dois valores $\alpha_{0}$ e $\alpha_{1}$ que corresponderiam a momentos de baixa e alta atividade, respectivamente, e uma probabilidade $P$ de que ocorra uma transição de estado. É definida uma função de custo $\operatorname{ct}(S T \mid T T)$ para sequencias de transição de estados $S T$ que privilegia sequencias com um baixo número de transições e que melhor se ajustem à sequencia de intervalos de intervalos observada $T T=$ $\left\{t t_{1}, t t_{2}, \ldots, t t_{n-1}\right\}$. Assim, é possível determinar qual a melhor sequencia para um fluxo de dados, minimizando-se $c t(S T \mid T T)$. 
Para contemplar múltiplos estados, é definida uma sequencia infinita de estados $S T_{\infty}$, iniciando em $s t_{0}$. Para $s t_{0}$, o parâmetro $\alpha_{0}^{-1}$ recebe o valor do intervalo médio entre mensagens. Para os estados subsequentes aplica-se um fator de escala $s$ de maneira que o intervalo esperado para cada estado decresce geometricamente: $\alpha_{i}=\alpha_{0} \cdot s^{i}$. Novamente, uma função de custo é definida, desta vez considerando o custo para a transição entre quaisquer dois estados, mantendo-se porém o objetivo de favorecer soluções que tenham poucas transições, ao mesmo tempo em que tenham um bom ajuste ao conjunto de intervalos observados. O fator $s$, ajustável conforme a aplicação, define a resolução da solução encontrada ao controlar a quantidade de estados distintos necessários para modelar toda a faixa de intervalos observados.

Ao filtrar um fluxo de documentos ou mensagens, de acordo com a presença de determinado termo, obtem-se uma distribuição ao longo do tempo da ocorrência de tal termo. A aplicação da técnica de Kleinberg sobre tal distribuição detecta os momentos de burst específicos para o termo. Uma vez que o modelo de transição de estados associa uma medida de custo à adoção de um estado em determinado período de tempo, é possível calcular um peso para um burst st 1 . Esse peso equivale à melhoria obtida na função custo para um período $t t=\left[t p_{\text {início }}, t p_{\text {fim }}\right]$ em que foi detectado burst em relacao ao custo computado caso fosse mantido o estado inicial $s t_{0}$ :

$$
w=\sum_{t p_{j}=t p_{\text {iń́cio }}}^{t p_{\text {fim }}}\left(c t\left(s t_{0} \mid t p_{j}\right)-c t\left(s t_{1} \mid t p_{j}\right)\right)
$$

Tendo cada termo um peso associado, selecionam-se aqueles de maior peso como representativos dos temas do fluxo de dados, relacionando-os com os seus respectivos períodos de ocorrência.

O modelo desenvolvido para tratar fluxos de mensagens, baseado na análise de intervalos, não é adequado para modelar conjuntos de artigos científicos. Ainda que uma data de publicação seja atribuída a cada artigo, a publicação de artigos tipicamente ocorre em lotes, em edições anuais de congressos ou na publicação de uma edição de um periódico. Para modelar a publicação em lotes, considera-se o comportamento de termos específicos. É definido um autômato que responde a alterações na fração de documentos que contem o termo analisado em cada lote. Para a análise de artigos científicos, Kleinberg usa apenas dois estados: (i) o estado $s t_{0}$, no qual espera-se encontrar o termo na mesma proporção em que ele é encontrado no corpus, e (ii) um estado $s t_{1}$, cujo percentual esperado $p e_{1}$ de documentos com o termo é definido em função de $s t_{0}$ e um fator de escala $s: p e_{1}=s \cdot p e_{0}$. Considerando uma distribuição polinomial de probabilidades, define-se uma função de custo para a transição de estados e, a partir daí, é possível identificar os períodos de burst para cada termo na coleção e ordená-los por peso. 


\subsubsection{Classificação e agrupamento de resultados de consultas}

A classificação e o agrupamento (clustering) de resultados de consultas têm aplicação direta na mineração visual de conjuntos de documentos. A separação de um conjunto de documentos em subconjuntos relacionados pode ser útil, tanto para algumas técnicas de projeção quanto para produzir visualizações que ressaltem subconjuntos e/ou hierarquias, como em Andrews et al. (2002). Além de apresentar uma visão global do conjunto sendo examinado, esta separação pode reduzir a complexidade total de alguns algoritmos de mineração aplicados posteriormente ao conjunto de dados.

As técnicas para a apresentação de resultados de consultas que fornecem ao usuário uma descrição de cada conjunto formado são de especial interesse nesta tese. Diferentes abordagens são utilizadas neste sentido. Algumas técnicas trabalham com categorias predefinidas e técnicas de classificação. Outras extraem descrições a partir dos subconjuntos obtidos com a aplicação de algoritmos de agrupamento. Uma terceira abordagem é a utilização de metadados pré-existentes para definir categorias.

Técnicas de agrupamento não requerem categorias predefinidas, como acontece com as técnicas de classificação. Portanto, técnicas que utilizam agrupamento são mais flexíveis para o tratamento de consultas diversas. Elas, no entanto, apresentam maiores desafios, uma vez que operam de maneira não supervisionada (Zeng et al., 2004).

Chen e Dumais (2000) utilizam Support Vector Machines para agrupar resultados de buscas na Web em categorias predefinidas. A técnica de Pratt (1997) utiliza metadados pré-existentes e trabalha com um modelo taxonômico preconstruído do domínio em estudo para associar agrupamentos de documentos a classes.

O sistema Scatter/Gather (Hearst e Pedersen, 1996) apresenta resultados de consultas separados por um algoritmo de agrupamento (clustering). A cada agrupamento é atribuído um sumário descritivo, formado por termos frequentes no agrupamento. Os autores mostram que o sistema produziu melhores resultados com a apresentação de resultados em agrupamentos do que com listas ordenadas de resultados. No experimento conduzido, na grande maioria dos casos (31 em 38), os usuários exploraram em primeiro lugar o agrupamento com maior número de documentos relevantes, que consistentemente apresenta maior percentual de documentos relevantes. Ou seja, ao explorar um agrupamento, em lugar da exploração da lista completa de resultados, os usuários trabalham com um relação menor e mais precisa de resultados.

Em outra abordagem, Zeng et al. (2004) extraem locuções de um conjunto de resultados de uma consulta, com o objetivo de agrupa-los e prover sumários significativos para os agrupamentos. As locuções são ordenadas de acordo com uma combinação de medida extraídas do conjunto de documentos recuperados, por exemplo, a medida $t f \times i d f$. Os agrupamentos são 
obtidos associando os documentos da lista de resultados original a todas as locuções encontradas em cada documento. Agrupamentos que possuam alta sobreposição (>75\%) são mesclados. Por fim, os agrupamentos são apresentados de acordo com a ordem atribuída a cada locução. A ordenação dos documentos, dentro de cada agrupamento, pode refletir tanto a ordem conforme a consulta original, como pode ser escolhida uma medida de similaridade em relação à frase título do agrupamento. A abordagem de Zeng et al. (2004) é similar à utilizada no Grouper (Zamir e Etzioni, 1999), do qual pode ser considerada uma evolução. O Grouper trabalha com locuções extraídas de segmentos de documentos (snippets) retornados por uma ferramenta de busca. Assim como no exemplo anterior, as locuções são avaliadas, os agrupamentos são obtidos por inclusão de documentos nos quais as locuções aparecem, e, em uma etapa final, agrupamentos com alta sobreposição são unidos. No Grouper, a avaliação é mais simples, considerando apenas a quantidade de documentos associados a cada locução e o tamanho das locuções. Outra diferença é quanto à formação do título dos agrupamentos. No Grouper, são utilizadas locuções que aparecem em vários documentos do agrupamento, e não apenas a locução que deu origem a ele.

\subsection{Tópicos e Visualização}

A integração entre tópicos e visualização pode acontecer de maneiras distintas. Uma possibilidade é a visualização de conjuntos de tópicos acabados, produzidos manualmente ou automaticamente, como resultado de uma técnica de mineração. Tal cenário é análogo ao da visualização de modelos minerados e materializa-se na construção de mapas de tópicos (Seção 3.6.1). Uma segunda possibilidade é o enriquecimento de visualizações com o resultado de processos de extração de tópicos, tipicamente exibidos como etiquetas ou rótulos. Se há uma integração maior entre técnicas de visualização e de mineração de textos do que a simples exibição de etiquetas, temos novo um cenário que pode ser descrito como de mineração visual de textos.

A mineração visual de textos, ou Visual Text Mining - VTM, refere-se à analise de documentos textuais não estruturados apoiada por representações visuais interativas capazes de inserir o conhecimento do usuário no processo de mineração. Esta abordagem busca a sinergia entre técnicas de mineração e visualização, aproveitando-se de contribuições do usuário no direcionamento da análise exploratória. A mineração visual de textos segue os princípios da análise visual (Visual Analytics), que defende a associação de representações visuais e interação com abordagens analíticas, com o objetivo de apoiar a detecção de informação relevante e não trivial a partir da análise de grande coleções dinâmicas de dados. 


\subsubsection{Mapas de tópicos}

Mapa de tópicos são um padrão ISO (International Organisation for Standardization (ISO) e International Electrotechnical Commission (IEC), 1999) para a representação de conhecimento e sua associação com recursos de informação (páginas Web, documentos, etc). Eles formam uma rede semântica, possibilitando a navegação sobre um conjunto de recursos em um nível elevado de abstração (Le Grand e Soto, 2002b). Esta possibilidade de navegar um conjunto de dados em diferentes níveis de abstração é desejável na visualização de informação.

Mapas de tópicos são multidimensionais por natureza, e mesmo um mapa de tópicos acerca de um conjunto limitado de documentos pode ser bastante complexo. Assim, a aplicação de técnicas de visualização é essencial para permitir que usuários naveguem e encontrem informação em mapas de tópicos.

Mapas de tópicos permitem a representação de estruturas complexas com base em conceitos simples de: (i) tópicos, (ii) ocorrências e (iii) associações. Neste contexto, um tópico é a representação de um conceito do mundo real em um sistema computadorizado. Um tópico pode estar associado a ocorrências, ou recursos, relacionados de alguma forma com o tópico. Associações, por sua vez relacionam tópicos entre si.

Para Le Grand e Soto (2002b), uma vantagem de mapas de tópicos é que eles adicionam sentido a recursos existentes, sem, no entanto, modificá-los.

Le Grand e Soto (2002a) propõem algumas visualizações interativas com base em mapas de tópicos. Para eles, visualizações com base em grafos e árvores seriam as mais adequadas à visualização de mapas de tópicos. A Figura 3.4 apresenta um exemplo de visualização de mapas de tópicos baseada em grafos, o Topic Navigator (Baudon et al., 2001).

\subsubsection{Tópicos e sistemas de visualização}

Ao explorar um mapa que posicione documentos por similaridade, é importante destacar os temas e subtemas tratados por diferentes grupos de documentos. Em um contexto de mineração visual de textos, a extração automática de tópicos pode suportar: (i) a criação de mapas em vários níveis de abstração, (ii) filtragem e foco com base no refinamento sucessivo de tópicos, (iii) melhoria dos mapas produzidos com anotações (etiquetas) e (iv) exibição de mudanças temáticas para conjuntos em que há uma ordem cronológica entre documentos.

A adição de etiquetas descritivas de temas é uma funcionalidade encontrada em diversos sistemas de visualização de conjuntos de documentos. A visualização ThemeView (Wise, 1999), parto do sistema IN-SPIRE (Seção 2.6.4), apresenta um coleção de documentos como uma superfície, com morros que são formados somando-se a contribuição de termos encontrados no 


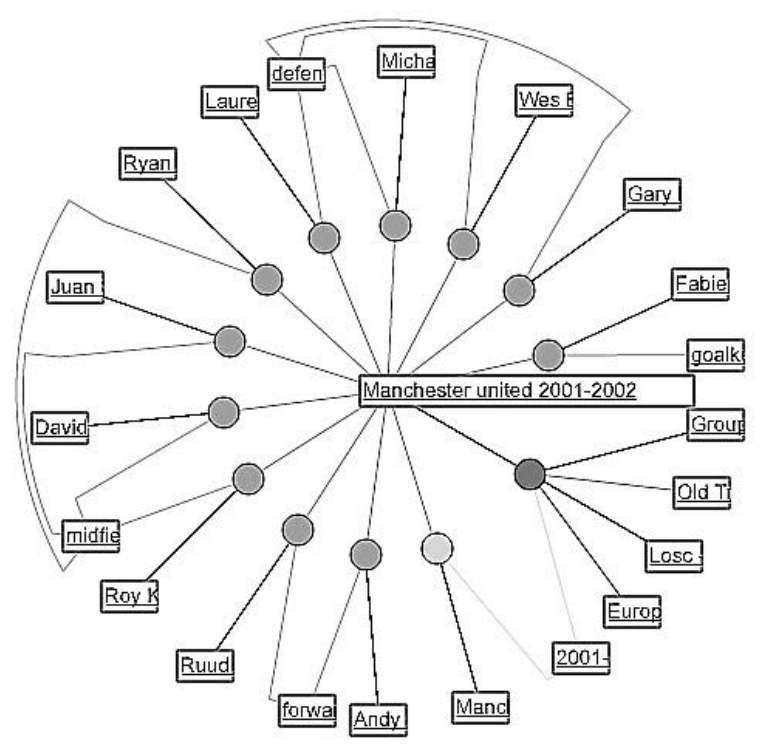

Figura 3.4: Visualização de um mapa de tópicos no Topic Navigator. Extraído de Baudon et al. (2001).

documentos de cada região do mapa. Etiquetas são atribuídas aos topos destes morros, compostas pelo termos que mais contribuem para a altura do morro, i.e. aqueles termos encontrados no maior número de documentos.

Já Chen (2004), que aplica PCA para identificar as três principais especialidades em conjuntos de artigos científicos (ver Seção 2.4.6), adota como descritores destas especialidades os termos mais frequentes encontrados no artigos mais fortemente associados a cada especialidade, i.e. aqueles artigos de maior valor em cada uma das três primeiras dimensões retornadas pela PCA.

Skupin (2002) ordena termos de acordo com a sua frequência para etiquetar regiões em mapas de documentos que assemelham-se a mapas cartográficos (Seção 2.6.1). Múltiplos níveis de abstração, obtidos pela aplicação de um método de agrupamento hierárquico, são destacados. Diferentes variações da contagem de frequência são adotadas na seleção de termos em diferentes níveis. Contagens simples de frequência definem os termos para a agrupamentos no nível mais alto de abstração, enquanto a medida $t f \times i d f$ é adotada para agrupamentos em níveis inferiores.

A visualização ThemeRiver (Havre et al., 2002) mostra mudanças temáticas ao longo do tempo em coleções de documentos com informação temporal associada, como, por exemplo, a data de publicação de artigos científicos. Cada tema, associado a um termo específico, é representado por um rio colorido cuja largura reflete a sua importância nos documentos encontradas em cada período de tempo. A estratégia adotada para determinar o peso, ou importância de cada tema é similar àquela adotada na visualização ThemeView (Wise, 1999). Streamgraphs 
são uma generalização do ThemeRiver, aplicado em domínios além da visualização de mudança temáticas e contando com diversas opções para a sua construção (Byron e Wattenberg, 2008).

Existem ainda visualizações projetadas especificamente para apoiar a identificação de tópicos em um único documento, como, por exemplo, a Topic Islands (Miller et al., 1998). Nesta aplicação, frequências de termos são interpretadas como um sinal e variações temáticas são identificas pela aplicação da transformada wavelet (wavelet transforms).

\subsection{Considerações finais}

Neste capítulo foram discutidas as relações da extração de tópicos com a visualização de conjuntos de documentos, assim como discutidas as relações entre técnicas de mineração de dados e de visualização de informação. Exemplos de técnicas de mineração de textos, extração de tópicos e de soluções que combinam visualização e mineração foram apresentados. Entre os exemplos fornecidos, encontram-se soluções em que o acoplamento é baixo, como na visualização de modelos minerados, e soluções em que há uma forte integração entre a visualização e a mineração. Nestes exemplos, os resultados do processo de mineração são alterados em função de intervenções do usuário, apoiadas pela visualização.

A abordagem de extração de tópicos e visualização exploratória introduzida no Capítulo 5 adota uma técnica de mineração de textos para prover rótulos para regiões de mapas de documentos, como nas soluções apresentadas na Seção 3.6.2. Na abordagem, a extração dos tópicos que servirão de rótulos leva em consideração o posicionamento de elementos no mapa e o usuário, ao selecionar areas de interesse, é capaz direcionar o processo de mineração. Também a lista de tópicos e o próprio mapa de documentos são refinados como resultado de um processo iterativo e interativo de exploração. Portanto, tal abordagem pode ser categorizada como uma abordagem de mineração visual de dados, como definida por Oliveira e Levkowitz (2003). 


\section{Posicionamento incremental de elementos no plano}

\subsection{Introdução}

Uma opção para visualizar conjuntos de dados multidimensionais é posicionar seus elementos em um espaço bidimensional seguindo relações de similaridade. Esta solução é adotada não só na análise exploratória de conjuntos de documentos (ver Capítulo 2), mas também para exibir coleções de imagens (Rodden et al., 1999, 2001) e para visualizar dados multidimensionais em geral, usualmente armazenados em bancos de dados (Barioni et al., 2002).

Neste capítulo, é descrita uma solução incremental para o problema de posicionar elementos de conjuntos dinâmicos de dados multidimensionais no plano. $\mathrm{O}$ algoritmo proposto, denominado Incremental Board ou incBoard, tem baixo custo computacional e é capaz de manter uma disposição coerente de elementos mesmo para conjuntos de dados que sofrem uma total renovação, a medida em que elementos são inseridos e removidos.

Para visualizar um conjunto no qual elementos são constantemente adicionados ou removidos, poder-se-ia (i) tomar como base uma disposição inicial dos elementos, que não seria capaz de refletir grandes mudanças no conjunto de dados, ou (ii) refazer periodicamente todo o mapa, que, neste caso, guardaria pouca ou nenhuma semelhança com o mapa original. Propõe-se aqui uma terceira estratégia que incrementalmente posiciona e reposiciona elementos de dados em 
um espaço análogo a um tabuleiro de xadrez, à medida que estes elementos são adicionados ou removidos do tabuleiro.

Se fôssemos adicionar peças de xadrez a uma posição fixa do tabuleiro, a chegada de uma peça poderia provocar o deslocamento de uma ou mais peças, a fim de acomodar a nova peça. Se tivermos como objetivo posicionar peças similares próximas umas das outras, poderíamos guiar o modo com que deslocamos as peças para atingir tal objetivo.

O problema pode também ser visto como um problema de ordenação de elementos por similaridade, porém utilizando duas dimensões como espaço de trabalho. O tabuleiro de xadrez fornece células onde elementos podem ser posicionados e re-arranjados de modo análogo ao que ocorre em um processo de ordenação por inserção (insertion sort), em que um novo elemento pode deslocar elementos existentes, à medida que o espaço alocado para o conjunto aumenta.

No exemplo do tabuleiro de xadrez, alguém que esteja a organizar as peças talvez não atribua significado explícito aos eixos, i.e., às linhas e colunas. Neste caso, deslocar elementos acima ou abaixo, à direita ou à esquerda, à medida que o conjunto de dados sofre alterações, não carrega, por si só qualquer significado quanto ao conteúdo dos elementos. O significado recai apenas sobre a posição relativa de cada elemento em relação aos demais. O mesmo pode ser dito com relação a distâncias absolutas medidas sobre o tabuleiro.

Tomemos como exemplo um mapa de notícias acerca de diferentes assuntos. Neste mapa, um documento que trate de "eleições" poderia estar a 100 píxeis de distância de um outro, que trata de "economia". No entanto, em um segundo momento, após uma alteração no conjunto de dados, estes mesmos documentos poderiam estar a 300 píxeis de distância um do outro (ver Figura 4.1. Em ambos os casos, pouco pode ser dito sobre a relação entre os artigos, ou mesmo entre os assuntos "economia" e "eleições" com base apenas nas suas posições absolutas. No entanto, se um terceiro documento está presente, pode-se inferir mais a partir da visualização. Um documento que trate de "esportes" poderia, no primeiro mapa, estar distante 150 píxeis do documento sobre "eleições" e 70 píxeis daquele que trata de "economia", como ilustrado no mapa da Figura 4.1(a), Em um segundo mapa, estas distâncias seriam, digamos, 450 e 150 píxeis, respectivamente (Figura 4.1(b)). Com a presença deste novo documento, podemos inferir, a partir de qualquer um dos dois mapas, que artigos que tratam de "eleições" são, em geral, mais relacionados com aqueles que tratam de "economia" do que com aqueles que tratam de "esportes".

Pode-se argumentar, em função do exemplo anterior, que a posição relativa dos documentos é mais significativa do que suas coordenadas $x, y$ específicas no espaço de tela. Ademais, quando se lida com conjuntos de dados ou documentos, o significado de posições absolutas ou distâncias não costuma ser consistente em diferentes momentos, um fato que pode induzir a erro um analista humano. Por exemplo, em uma mapa que inclui notícias sobre política e economia, 


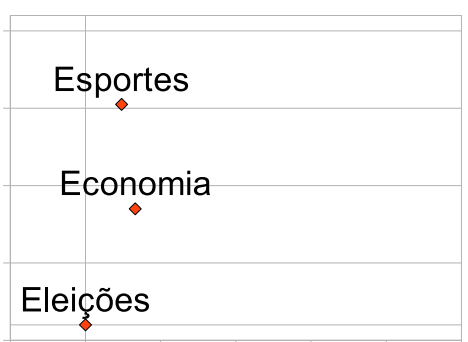

(a)

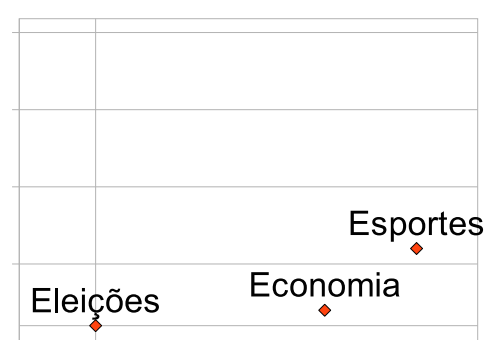

(b)

Figura 4.1: Diferentes versões, correspondentes a instantes distintos, de um mapa de documentos hipotético para um corpus de notícias.

estas podem estar separadas. No entanto, se muitas notícias sobre esportes forem adicionadas a este mapa, talvez durante as Olimpíadas, as notícias sobre política e economia podem ser aproximadas, dando aos usuários, que tenham examinado a primeira versão do mapa, uma impressão potencialmente equivocada de maior similaridade entre dois documentos próximos no novo mapa.

Seguindo este raciocínio, o algoritmo aqui apresentado considera as posições relativas no espaço multidimensional original para posicioná-los (projetá-los) em um espaço bidimensional, como é sugerido no exemplo do tabuleiro de xadrez. A estratégia incremental adotada permite a efetiva exibição de conjuntos dinâmicos de dados. O espaço visual resultante é capaz de manter uma disposição coerente dos elementos de conjuntos em constante mutação, ainda que os eixos não possuam significado explicitamente atribuído no espaço 2D, como discutido na Seção 4.5.1. Adicionalmente, o algoritmo consegue preservar a disposição relativa global das classes ou categorias, ainda que todos os elementos do mapa sejam substituídos em modo contínuo, ao ponto em que nenhum dos elementos correntes do mapa tenham co-existido com aqueles do início (ver Figura 4.7). Uma aplicação de visualização específica para demonstrar do algoritmo foi desenvolvida, e é descrita na Seção 4.4 .

O algoritmo foi comparado com outras estratégias de MDS, com resultados competitivos, mesmo quando lidando com conjuntos estáticos de dados, como descrito na Seção 4.5. A ferramenta de demonstração do algoritmo foi adaptada especificamente para visualizar um conjunto de notícias em constante evolução, cujos elementos são adicionados, removidos, ou substituídos a qualquer tempo, o que não é suportado pelas técnicas correntes. Como na solução proposta apenas um elemento pode ocupar cada célula, não há oclusão no espaço visual. Esta característica é especialmente útil se o objetivo é visualizar um conjunto de imagens, como ilustrado na Seção 4.5 .2 . 
Este capítulo está assim organizado : Na Seção 4.2, são apresentados trabalhos diretamente relacionados à solução introduzida neste Capítulo. A Seção 4.3 (i) detalha o espaço incremental, (ii) apresenta como distâncias são calculadas neste espaço, (iii) descreve como elementos são adicionados, removidos e substituídos no tabuleiro, e (iv) discute a complexidade algorítmica. A visualização associada é apresentada na Seção 4.4. A Seção 4.5 traz estudos de caso com o objetivo de comparar a estratégia proposta com outras técnicas usando medidas quantitativas e de explorar potenciais cenários de aplicação do algoritmo. Finalmente, considerações finais e possíveis extensões das técnicas são encontradas na Seção 4.6 .

\subsection{Trabalhos relacionados}

Nesta Seção, são apresentados trabalhos diretamente relacionados à solução introduzida neste Capítulo, seja por adotarem abordagens similares, compartilhem objetivos em comum, ou apontarem ponteciais cenários para a sua aplicação.

A adoção de um espaço dividido em células para apresentar conjuntos de documentos é similar ao uso de self-organizing maps (SOMs) para visualizar conjuntos de documentos (Kaski et al., 1998), descrito na Seção 2.4.2). No entanto, existem diferenças significativas em relação à estratégia aqui adotada, uma vez que na aplicação de SOMs: (i) as dimensões da grade devem ser fixadas a priori e (ii) uma única célula pode abrigar mais de um documento. As técnicas assemelham-se na medida em que a complexidade algorítmica é uma função da quantidade $V$ de células, e não do número $N$ de elementos analisados (Kaski, 1997). Porém, para exibir um conjunto de dados com grande número de elementos $N$ utilizando um pequeno número de células $V$, um SOM iria encaixar todos os elementos nas células disponíveis, enquanto que a solução aqui proposta apresentaria o conjunto de dados sequencialmente, substituindo elementos até que todo o conjunto fosse apresentado. A primeira opção seria mais indicada para fornecer uma visão geral de um conjunto completo de dados, enquanto a segunda se mostraria mais adequada para dados dinâmicos.

Basalaj (2000) introduz um algoritmo incremental de escalonamento multidimensional, mas que necessita uma árvore geradora mínima computada apriori para o conjunto completo de dados. Ele também defende o uso de grades ou tabuleiros divididos em células para a visualização de elementos dispostos por similaridade, no que ele denomina Proximity Grids. Ele introduz algumas opções para a construção de proximity grids a partir de uma disposição de elementos no plano resultante da aplicação prévia de técnicas de MDS. O seu processo de bump (pancada) de elementos é, em certo grau, similar ao processo de adição de elementos aqui proposto. Porém, a solução proposta por Basalaj não prevê o re-arranjo dos elementos pré-existentes de forma a refletir as mudanças introduzidas pelo elemento recém chegado no 
conjunto de dados, e, não é, portanto, apropriada para a construção incremental, dependendo de uma disposição de elementos previamente computada.

Uma solução análoga de transformação do resultado de um processo de MDS em uma grade é proposta por Schaefer e Ruszala (2006) para a exploração de conjuntos de imagens. Após o processo de posicionamento de elementos por uma técnica de MDS, cada elemento é atribuído à célula da grade onde foi posicionado. Após a atribuição de elementos a células, a grade, cujo tamanho é definido previamente, poderá conter células com diversos elementos e também células vazias. Para preencher células vazias, são buscados elementos de células vizinhas que possuam mais de uma imagem. Células que eventualmente possuam mais de um elemento, mesmo após a redistribuição de imagens para células vazias, são exploradas hierarquicamente, ou seja, ao selecionar uma célula que contenha mais de um elemento, os seus elementos são distribuídos na tela seguindo o mesmo processo adotado no primeiro nível. Este processo é repetido por quantos níveis forem necessários para exibir todo o conjunto de imagens. No entanto, se na distribuição de elementos entre células, apenas um pequeno número de células for ocupado, um processo de deslocamento de elementos, inspirado no método de bump de Basalaj, é adotado. Nos níveis superior, a célula que contem múltiplas imagens exibe a imagem mais similar ao centróide computado para essas imagens.

Estudos desenvolvidos por Rodden et al. (1999, 2001) trazem alguma evidência de que posicionar imagens por similaridade é útil para profissionais de design gráfico em busca por fotografias. Ele indicam também que evitar sobreposição de imagens é um desejo dos usuários. Estes princípios foram aplicados na ferramenta Photomesa (Bederson, 2001) para apresentar agrupamentos e coleções de imagens organizadas hierarquicamente dispostas seguindo a técnica Treemap (Shneiderman, 1992). A ferramenta trabalha também com uma abordagem mais simples de posicionamento de agrupamentos de imagens, denominada Bubblemaps. Ambos os objetivos, posicionar imagens por similaridade e evitar sobreposição, são alcançados com a técnica incBoard, com o benefício adicional de poder gradualmente atualizar uma visualização existente. Uma possível aplicação desta possibilidade é, portanto, a manutenção de uma biblioteca pessoal de imagens, que, pouco-a-pouco, recebe novas contribuições, mantendo, no entanto, um arranjo com o qual o usuário está familiarizado.

Um recurso frequente em páginas de notícias na Internet e em blogs é a exibição de tag clouds - nuvens de marcadores (Seifert et al., 2008). Elas são listas de palavras-chave frequentemente selecionadas por usuários para etiquetar ou marcar (tag) conteúdo. Estas listas de termos são usualmente apresentadas em ordem alfabética ou por frequência. $\mathrm{O}$ seu posicionamento em função de medidas de similaridade foi sugerido. Hassan-Montero e Herrero-Solana (2006), por exemplo, agrupam os termos, exibindo cada agrupamento em uma linha. As linhas são então ordenadas com o objetivo de exibir agrupamentos similares próximos entre si. A utilização de 
um tabuleiro para exibir informação, como é aqui proposto, facilita a sua implementação com marcação HTML típica, sugerindo o uso potencial da técnica incBoard para a apresentação de tag clouds.

\subsection{O espaço incremental}

O espaço incremental (incBoard) é um espaço bidimensional com células dispostas em linhas e colunas, que assemelha-se a um tabuleiro de xadrez. Espera-se que um único elemento (peça do xadrez/documento/item de dados) ocupe uma célula em um dado momento, exceto quando os elementos estão movendo-se (captura de uma peça no xadrez/ adição de elementos). Formalmente:

Um elemento $E_{i}$ posicionado no tabuleiro é representado por um ponto $p_{i}$ com coordenadas $\left(x_{i}, y_{i}\right)$, com $x_{i}, y_{i}$ pertencendo a $\mathbb{Z}$, i.e., $p_{i} \in \mathbb{Z}^{2}$.

O espaço incremental assume dois estados possíveis: (i) estável, quando não há elementos que compartilhem a mesma célula,e (ii) instável, quando dois ou mais elementos compartilham uma mesma célula. Uma intervenção é necessária para levar o espaço de volta à estabilidade uma vez que ele se encontre instável.

Duas alternativas para o cálculo de distância no espaço do tabuleiro foram consideradas. A primeira alternativa considera o uso da distância Manhattan:

$$
d_{m}\left(E_{i}, E_{j}\right)=\left|x_{i}-x_{j}\right|+\left|y_{i}-y_{j}\right|
$$

A outra alternativa para medir distâncias no espaço visual proposto considera o número de passos necessários para que um elemento seja movido de uma célula a outra (distância Chebyshev ou chessboard distance). Assumindo que um elemento pode inicialmente mover-se na diagonal até atingir a linha ou coluna apropriada, e então, se ainda necessário, mover-se horizontalmente ou verticalmente até a célula de destino, a fórmula para a distância no tabuleiro proposto seria:

$$
d_{c}\left(E_{i}, E_{j}\right)=\max \left\{\left|x_{i}-x_{j}\right|,\left|y_{i}-y_{j}\right|\right\}
$$

Seguindo a analogia do xadrez, a distância Manhattan reflete o movimento da torre, enquanto a segunda alternativa reflete o movimento do rei ou rainha.

Afora a aderência à analogia com o jogo de xadrez e suas relações de distâncias, o benefício da adoção da distância de Chebyschev está na obtenção de um comportamento mais consistente quando são computadas as distâncias de uma célula aos seus vizinhos imediatos. Como pode ser observado na Figura 4.2(a), o cômputo da distância Manhattan para as oito células vizinhas de 
uma célula central produz resultados distintos para as quatro células nos cantos se comparados com os demais vizinhos. Ao contrário, a distância de Chebyschev é um para todos os oito vizinhos imediatos de um célula (ver Figura 4.2(b)). Após experimentos preliminares, a distância de Chebyschev foi adotada no algoritmo proposto, por produzir mapas com um melhor aproveitamento do espaço visual. A aplicação da distância Manhattan favoreceria a disposição de elementos em forma aproximada de cruz, com elementos tendendo a posicionar-se ao longos dos eixos principais.

\begin{tabular}{|l|l|l|l|l|}
\hline 4 & 3 & 2 & 3 & 4 \\
\hline 3 & 2 & 1 & 2 & 3 \\
\hline 2 & 1 & 0 & 1 & 2 \\
\hline 3 & 2 & 1 & 2 & 3 \\
\hline 4 & 3 & 2 & 3 & 4 \\
\hline
\end{tabular}

(a)

\begin{tabular}{|l|l|l|l|l|}
\hline 2 & 2 & 2 & 2 & 2 \\
\hline 2 & 1 & 1 & 1 & 2 \\
\hline 2 & 1 & 0 & 1 & 2 \\
\hline 2 & 1 & 1 & 1 & 2 \\
\hline 2 & 2 & 2 & 2 & 2 \\
\hline
\end{tabular}

(b)

Figura 4.2: Comparação entre medidas de distância entre células vizinhas computadas segundo fórmulas de distância Manhattan (a) e de Chebyschev (b), equações (4.1) e (4.2), respectivamente.

O posicionamento de elementos de dados multidimensionais no espaço incremental bidimensional deve refletir o seu posicionamento relativo no espaço original. Assim, para cada elemento $E_{i}$ adicionado ao tabuleiro, um erro pode ser computado que reflita a diferença na classificação (ordenação) dos demais elementos em relação a $E_{i}$ quando consideradas cada uma das distâncias no espaço $2 \mathrm{D}\left(d_{c}\left(E_{i}, E_{j}\right)\right)$ e quando consideradas as respectivas dissimilaridades, $\delta\left(E_{i}, E_{j}\right)$, dadas pelas distâncias medidas no espaço original. No exemplo hipotético apresentado na Tabela 4.1, o erro computado para o elemento $E_{1}$ deveria ser zero, uma vez que a ordenação dos demais elementos, relativa a esse elemento, resultaria sempre no mesmo conjunto ordenado $\left\{E_{3}, E_{2}, E_{4}\right\}$, qualquer que seja a medida utilizada, computada sobre o espaço original ou sobre o espaço bidimensional.

A medida de erro adotada é ponderada: (i) pela diferença entre a posição esperada $\left(R_{m}\right)$ e a posição efetiva $\left(R_{c}\right)$ de cada elemento na lista, e (ii) pela posição esperada, atribuindo maior peso aos erros quem têm origem na vizinhança do elemento de referência. Para um conjunto $L$ 
Tabela 4.1: Exemplo de ordenação por posição relativa. $d_{c}\left(E_{1}, E_{j}\right)$ é a distância computada no espaço $2 \mathrm{D}, R_{c}\left(E_{1}, E_{j}\right)$ é a classificação no espaço $2 \mathrm{D}$ do elemento $E_{j}$ em relação ao elemento $E_{1}, \delta\left(E_{1}, E_{j}\right)$ é a dissimilaridade entre $E_{1}$ e $E_{j}$ computada no espaço $\mathrm{mD}$, e $R_{m}\left(E_{1}, E_{j}\right)$ é a classificação relativa em $\mathrm{mD}$ do elemento $E_{j}$ em relação ao elemento $E_{1}$.

\begin{tabular}{ccccc}
$E_{j}$ & $d_{c}\left(E_{1}, E_{j}\right)$ & $R_{c}\left(E_{1}, E_{j}\right)$ & $\delta\left(E_{1}, E_{j}\right)$ & $R_{m}\left(E_{1}, E_{j}\right)$ \\
\hline D2 & 5 & 2 & 1000 & 2 \\
D3 & 4 & 1 & 850 & 1 \\
D4 & 6 & 3 & 5000 & 3
\end{tabular}

de elementos, o erro ponderado $W_{\text {err }}\left(E_{i}, L\right)$ para um elemento $E_{i}$ em relação a $L$ é dado por:

$$
W_{e r r}\left(E_{i}, L\right)=\sum_{E_{j} \in L}\left|R_{c}\left(E_{i}, E_{j}\right)-R_{m}\left(E_{i}, E_{j}\right)\right| \times\left(|L|-R_{m}\left(E_{i}, E_{j}\right)\right)
$$

Experimentos iniciais mostraram que esta medida de erro produz, com alguma frequência, o mesmo valor para diferentes opções de posicionamento (ver Seção 4.4). Se este for o caso, uma medida ponderada da quantidade de erros é adotada como segundo critério:

$$
C_{\text {err }}\left(E_{i}, L\right)=\sum_{E_{j} \in L} \begin{cases}|L|-R_{m}\left(E_{i}, E_{j}\right) & \text { se }\left|R_{c}\left(E_{i}, E_{j}\right)-R_{m}\left(E_{i}, E_{j}\right)\right| \neq 0 \\ 0 & \text { senão }\end{cases}
$$

Tendo definido estas medidas, é possível perseguir o objetivo de obter uma relação monotônica entre dissimilaridades ou similaridades e as distâncias na projeção, conforme definido por Kruskal (1964b) para o escalonamento multidimensional não métrico (nonmetric multidimensional scaling - MDS).

\subsubsection{Construção dinâmica}

A inclusão de novos elementos no tabuleiro desenrola-se em dois passos: (i) em primeiro lugar, uma célula já ocupada é escolhida como posição inicial do novo elemento, em seguida, (ii) uma vez que a célula escolhida torna-se instável, um processo é iniciado para devolver o espaço ao um estado estável.

Com exceção do primeiro elemento, os novos elementos são sempre adicionados, um por vez, à célula que no momento abriga o elemento mais similar ao novo elemento. A busca deste elemento mais similar pode ser custosa, assim, ela opera em dois modos distintos: (i) completo e (ii) estocástico. No modo completo, o elemento que chega é comparado com todos os demais elementos presentes no tabuleiro, enquanto que no modo estocástico, um conjunto 
limitado de elementos próximos é utilizado na comparação. O modo de amostragem estocástica é derivado de Chalmers (1996) (ver Seção 2.4.3). A amostragem estocástica também é adotada na atualização do erro medido para cada célula, o que é necessário quando elementos são movidos durante os processos de adição ou remoção de elementos. No cálculo do erro, além de um conjunto de elementos próximos, um conjunto de elementos aleatoriamente selecionados também é considerado.

Para uma célula que temporariamente abriga dois elementos, dezesseis soluções são avaliadas para torná-la novamente estável. Oito delas mantêm o novo elemento e move o elemento mais antigo para uma das oito células vizinhas imediatas. As oito soluções alternativas restantes mantêm a posição do elemento mais antigo e movem o elemento mais novo. A opção que possuir o menor erro combinado para os dois elementos é escolhida.

Eventualmente, o elemento movido será deslocado para uma célula também já ocupada. Neste caso, o processo é repetido com os dois elementos que agora compartilham esta nova célula. A fim de evitar ciclos, uma relação de células já visitadas é mantida. Células desta relação não são consideradas quando da avaliação de alternativas de deslocamento de elementos. O processo termina quando um elemento deslocado é movido para uma célula previamente vazia.

Se todas as células vizinhas de uma célula instável estiverem na relação de células já visitadas, o elemento extra fica aprisionado e um procedimento guloso (greedy) é aplicado para movê-lo até uma célula que possua células vizinhas não visitadas. A cada passo, as células vizinhas são avaliadas e aquela que apresenta o menor erro relativo para o elemento aprisionado é escolhida para abrigá-lo. Linhas e colunas descartadas no último movimento não são consideradas no futuro. Por exemplo, se o elemento em questão é movido da linha 5 para a linha 6, apenas as linhas $[6, \infty]$ serão consideradas a partir de então. Quando um célula vazia ou com vizinhos não visitados é encontrada, o procedimento especial é encerrado, e o processo usual é retomado. A relação de células visitadas é sempre limpa antes da adição de novos elementos.

Quando elementos são removidos, a disposição de elementos é ajustada perseguindo-se dois objetivos: (i) melhor refletir as posições relativas dos elementos em função da ausência do elemento removido e, (ii) manter o tabuleiro tão denso quanto possível, evitando que os elementos fiquem dispersos. Portanto, tenta-se mover elementos em direção ao centro do tabuleiro. Se uma célula recém esvaziada está acima e à direita do centro do tabuleiro, ela é preenchida com um elemento escolhido entre as três células acima e à sua direita. A opção com o menor erro relativo computado é escolhida. O processo é repetido com a nova célula vazia até que as três opções disponíveis sejam células vazias. 
A operação mais custosa no processo de adicionar ou remover elementos é a atualização de medidas de erro para todas as alternativas de posicionamento consideradas. Para tratar eficientemente este cálculo, o cômputo do erro pode tanto considerar todos os elementos do tabuleiro (modo completo), quanto apenas um subconjunto dos elementos (modo estocástico), similarmente ao que é feito na busca pelo elemento mais próximo.

O modo completo adota todo o conjunto $B$ de elementos no tabuleiro como o conjunto $L$ utilizado para o cômputo dos erros relativos. Esta opção é adequada para mapas com um pequeno número de elementos, ou para conjuntos de dados que sofrem alterações com pouca frequência, havendo tempo suficiente para alterar a disposição de elementos pelo modo completo. Neste modo, foi possível obter desempenho satisfatório em mapas com até quatrocentos elementos no tabuleiro, com o tempo de resposta degradando rapidamente após este número.

No modo de amostragem estocástica, os cálculos do erro ponderado para cada elemento consideram apenas os conjuntos de elementos próximos e de elementos aleatórios, ambos de tamanho fixo, como proposto por Chalmers (1996). Ambos os conjuntos iniciam vazios e são povoados com elementos aleatoriamente selecionados. Os elementos mais similares ao elemento de referência são mantidos no conjunto de elementos próximos. Toda vez que um elemento é candidato a ser movido, isto é, toda vez que ele encontra-se em uma célula com dois elementos, ou que é considerado para ocupar um célula que tornou-se vazia, o seus dois conjuntos, de elementos próximos e de elementos aleatórios, são atualizados. O conjunto de elementos aleatórios é esvaziado e repovoado. Se quaisquer dos elementos sorteados para o conjunto de elementos aleatórios for mais similar ao elemento de referência do que um ou mais elementos do conjunto de elementos próximos, este novo elemento é adicionado ao conjunto de elementos próximos, que, por sua vez, perde o elemento menos similar entre eles, a fim de manter fixo o tamanho do conjunto. O conjunto de elementos próximos de um elemento recém adicionado $E_{i}, L N_{E_{i}}$, é melhorado avaliando-se o conjunto de elementos próximos do atual vizinho mais próximo $E_{j}$. Este processo de melhoria é repetido se um novo vizinho mais próximo de $E_{i}$ for encontrado. Nos exemplos apresentados por Chalmers (1996), os conjuntos de elementos próximos têm tamanho cinco, e o conjunto de elementos aleatórios têm tamanho dez. Chalmers realizou alguns experimentos inicias com valores maiores com resultados similares. Ele também observou que, em certos casos, a utilização exclusiva de elementos aleatórios promovia uma rápida melhoria inicial na medida de estresse (ver Seção 4.5.1), porém evoluindo muito lentamente à medida que o estresse se aproxima do valor obtido com os dois subconjuntos de refêrencia. Para o incBoard, o tamanho dos subconjuntos aleatórios e de elementos próximos foi fixado, após alguns experimentos, em 16 e 24 elementos respectivamente.

A escolha do modo de operação pode ser feita em tempo-real. Para conjuntos dinâmicos de dados, a escolha pode ser feita com base na frequência com que o conjunto sofre alterações. 
Para conjuntos estáticos, a escolha pode se dar com base no tempo necessário para adicionar cada elemento e a tarefa em questão.

Um cenário típico de uso previsto seria a utilização do modo completo para incluir as primeiras centenas de elementos, seguido do uso do modo estocástico para os elementos posteriores. Neste exemplo, o uso do modo completo no início da construção do mapa provê uma base estável para a operação do modo de amostragem estocástica. Pode-se argumentar que, tendo uma distribuição consistente de elementos ao longo da mapa, a escolha de aleatória de elementos de referência que ocorre no modo estocástico não terá um grande impacto.

Adicionalmente, o fato do algoritmo ser incremental reduz, em certos cenários de uso, a necessidade de construção de mapas completos. Por exemplo, para um pesquisador que mantém um mapa de artigos científicos da sua área de interesse, a inclusão dos artigos de uma recente conferência não requer a reconstrução completa do mapa. Assim, ainda que o mapa possua dezenas de milhares de artigos, a adição de alguns poucos elementos poderia ser feita pelo modo completo.

\subsubsection{Complexidade algorítmica}

Todas as operações necessárias à adição ou remoção de elementos consideram apenas os elementos no tabuleiro. Portanto, um conjunto completo de dados de tamanho $N$ pode ser exibido sequencialmente com um custo computacional constante para cada item adicionado ou removido, desde que seja mantida uma janela de visualização (tamanho do tabuleiro, número de células ocupadas) de tamanho fixo $V$. A complexidade algorítmica para a exibição de todo o conjunto de dados seria $O(V \times N)$ ou simplesmente $O(N)$, mantendo-se $V$ constante.

Um caso particular, discutido em detalhe no restante desta seção, é aquele em que o tamanho do tabuleiro $V$ é o mesmo do conjunto de dados $N$, ou seja, quando se deseja a presença simultânea de todos os elementos no mapa.

Quando se adota o modo de amostragem estocástica, cada movimento (seleção de qual dos dois elementos que compartilham uma célula deve ser movido, e para onde) requer um esforço constante $k$, proporcional somente ao número de elementos nos conjuntos de elementos próximos e aleatórios. Para cada elemento adicionado, um certo número de movimentos é necessário até que um elemento desloque-se para um célula vazia. Um maneira alternativa de enxergar o processo é imaginar que o estado de instabilidade está deslocando-se em direção a um espaço vazio. Se o tabuleiro está uniformemente ocupado, aproximando-se da forma de um quadrado, a maior distância entre a célula instável inicial até a borda é $\sqrt{V}$. Isto significa que, em um caso médio, o processo deveria terminar em, no máximo, $\sqrt{V} / 2$ movimentos. Seguindo este comportamento, a complexidade da construção do mapa seria de $O(N \times \sqrt{V} / 2 \times k)$ ou $O\left(N^{3 / 2}\right)$, para exibir todo o conjunto de dados simultaneamente $(N=V)$. 
No entanto, o espaço não é sempre ocupado uniformemente, assim como o movimento da célula instável não está restrito a seguir em direção à borda mais próxima, estando livre para vagar pelo tabuleiro, desde que não retorne a qualquer espaço previamente avaliado. Assim, teoricamente, no pior caso, todas as células poderiam ser visitadas todas as vezes, elevando a complexidade para $O(N \times V \times k)$. Portanto, $O\left(N^{2}\right)$ é a pior complexidade possível, considerando-se o caso particular em que a janela de visualização tem o mesmo tamanho que o conjunto de dados.

Já o limite teórico mínimo para a complexidade seria $O(N \times 1 \times k)$ ou $O(N)$. Neste cenário, cada novo elemento teria como posição inicial uma célula vizinha a um espaço vazio, sendo necessária apenas uma operação de deslocamento para o fim do processo.

Assim, a complexidade algoritmica, quando $N=V$, situa-se entre estes dois limites: $\{O(N)$, $\left.O\left(N^{2}\right)\right\}$. Uma análise empírica usando um corpus de 675 artigos científicos (ver Seção 4.5) mostrou que o número de movimentos necessários a cada inclusão ficou muito abaixo de $V$, que corresponderia a $O\left(N^{2}\right)$, quando $V=N$, situando-se em torno do caso médio $\left(O\left(N^{3 / 2}\right)\right)$, como pode ser observado na Figura 4.3 .

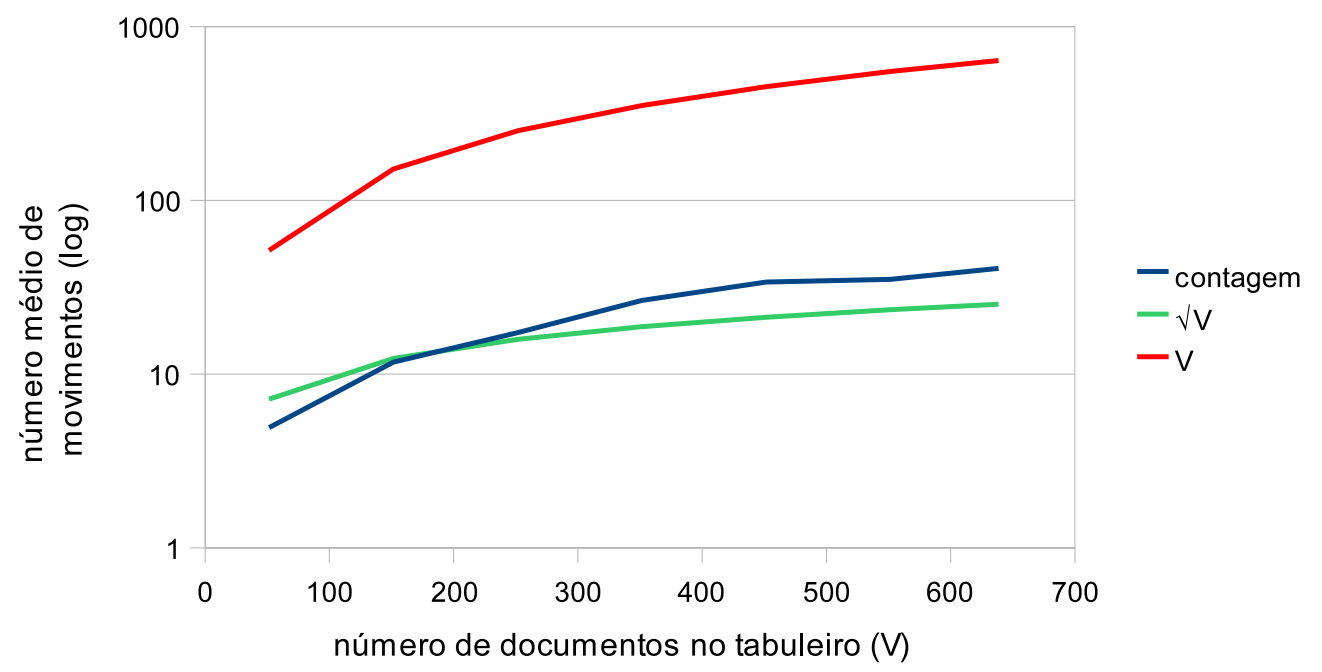

Figura 4.3: Número médio de movimentos necessários para estabilizar o tabuleiro após a adição de um novo documento, versus número de documentos no tabuleiro $(V)$ quando projetando um corpus de 675 artigos científicos (corpus CBR-ILP-IR-SON, apresentado em estudo de caso na Seção 4.5.1. 


\subsection{Visualização incremental}

A analogia com um tabuleiro de xadrez permite a construção de uma visualização incremental não sujeita a problemas de oclusão, e na qual um espaço fixo e predefinido de tela pode ser alocado para cada item de dados apresentado. Glifos ( glyphs) sofisticados podem ser projetados para representar individualmente cada elemento em diferentes níveis de aproximação (zoom). Quando exibindo poucos elementos, os glifos podem mostrar o nome do elemento, seu tamanho ou quaisquer outras informações disponíveis. É possível, por exemplo, exibir uma cópia da página inicial de documentos ou miniaturas de imagens (ver Figura 4.4, na página 91). Quando exibindo uma quantidade maior de elementos, representações simplificadas ou mesmo ícones podem ser utilizados.

Uma ferramenta de visualização baseada no espaço incremental foi desenvolvida como parte deste trabalho. A exibição de elementos adicionados é uma parte importante da visualização. Este processo é animado, possibilitando que os usuários acompanhem a evolução do conjunto de dados. Duas opções estão disponíveis na ferramenta implementada: (i) um modo passo-a-passo, em que o processo sofre uma pausa após a adição ou remoção cada elemento, e (ii) um modo contínuo, sem qualquer pausa entre operações, observe os botões continuar/play, pausa/pause e passo/step na Figura 4.8, na página 95

É possível controlar o tamanho da janela de visualização por tempo decorrido ou por número de elementos no tabuleiro. Assim, elementos mais antigos podem ser removidos uma vez que a sua "idade" ultrapasse o limite estabelecido ou que o tabuleiro contenha mais elementos do que o desejado.

Efeitos de transparência podem ser também aplicados, de modo que elementos possam gradualmente esmaecer até que sejam efetivamente removidos. Na ferramenta, a delimitação das células com linhas de grade é opcional. Esconder estas linhas pode resultar em uma apresentação mais limpa, destacando os elementos de dados apresentados.

Uma versão alternativa da visualização foi desenvolvida que utiliza células em formato hexagonal (Figura 4.5). Nesta nova versão, denominada HexBoard, todos os seis vizinhos de uma célula compartilham uma aresta com ela, ao passo que em uma grade de células retangulares há vizinhos que compartilham arestas e vizinhos que compartilham apenas um vértice. Além de representar uniformemente a vizinhança entre células, atributos das arestas podem ser manipulados para refletir a similaridade entre vizinhos. Por exemplo, arestas espessas ou escuras podem indicar uma grande dissimilaridade entre dois vizinhos. Sem esta modificação, a visualização não fornece qualquer indicação a respeito da similaridade entre vizinhos. Elementos vizinhos são sempre posicionados à mesma distância uns dos outros, ainda que nem todos os elementos vizinhos sejam igualmente similares. Essa versão da visualização supera esta limitação ao 
mesmo tempo em que preserva todas as vantagens da versão original. A representação da similaridade entre vizinhos pode apoiar o usuário na identificação de subconjuntos de elementos semelhantes e fronteiras entre grupos de elementos distintos. O exemplo da Seção 5.5.2 utiliza esta visualização. As alterações necessárias para a implementação da visualização e cenários de uso são relatados em Pinho e Oliveira (2009).

\subsection{Estudos de caso}

Quatro dos estudos de caso realizados são apresentados para avaliar o espaço visual incremental. Os dois primeiros casos comparam, usando medidas quantitativas, o incBoard com outras técnicas de MDS (Seção 4.5.1). Os dois outros estudos de caso aplicam a ferramenta desenvolvida como prova-de-conceito para explorar dois potenciais cenários de uso do algoritmo e da visualização correspondente (Seção 4.5.2).

\subsubsection{Comparação com técnicas de MDS}

Para avaliar incBoard como uma técnica de MDS, a medida quantitativa Estresse (stress), que computa o erro acumulado entre as distâncias observadas no espaço original e no espaço reduzido entre pares de elementos, foi utilizada (Kruskal, 1964ab; Kruskal e Wish, 1978). Na equação de estresse original (4.5), $\hat{d}\left(E_{i}, E_{j}\right)$ é uma medida de distância ajustada dependente da medida de dissimilaridade $\delta\left(E_{i}, E_{j}\right)$. Uma versão simplificada de estresse que assume que $\delta\left(E_{i}, E_{j}\right)=\hat{d}\left(E_{i}, E_{j}\right)$ foi previamente adotada para avaliar técnicas de projeção Chalmers, 1996; Paulovich et al., 2008a). O algoritmo aqui apresentado favorece o posicionamento relativo de elementos ao invés de tentar reproduzir relações exatas de distância. Em outras palavras, trata-se de uma técnica de escalonamento multidimensional não-métrico (nonmetric $M D S)$. Consequentemente, não se pode assumir que $\delta\left(E_{i}, E_{j}\right)=\hat{d}\left(E_{i}, E_{j}\right)$ e deve-se seguir a hipótese original de Kruskal (1964b), segundo a qual $\hat{d}\left(E_{i}, E_{j}\right)$ é uma distorção monotônica desconhecida de $\delta\left(E_{i}, E_{j}\right)$. Adicionalmente, as distâncias no espaço visual resultante encontram-se no intervalo $[1, \infty[$, enquanto que medidas de dissimilaridade são tipicamente normalizadas no intervalo [0,1], logo, uma correspondência direta entre $\delta\left(E_{i}, E_{j}\right)$ e $d_{c}\left(E_{i}, E_{j}\right)$ não é esperada.

$$
\text { stress }=\sqrt{\frac{\sum_{i<j}\left(d_{c}\left(E_{i}, E_{j}\right)-\hat{d}\left(E_{i}, E_{j}\right)\right)^{2}}{\sum_{i<j} d_{c}\left(E_{i}, E_{j}\right)^{2}}}
$$

Assumir que $\delta\left(E_{i}, E_{j}\right)=\hat{d}\left(E_{i}, E_{j}\right)$ também torna a medida de estresse sensível a mudanças de escala: se tomarmos um conjunto de pontos $P S_{1}$, simplesmente aplicarmos uma transfor- 
mação de escala sobre suas coordenadas e chamarmos o novo conjunto de $P S_{2}$, encontraremos estresse entre as distâncias medidas em $P S_{1}$ e $P S_{2}$ para pares correspondentes de elementos. Nas tarefas de visualização, transformações de escala são parte integrantes do processo de exibir imagens em uma dada janela (viewport). Se optamos por aplicar uma operação de ajuste à janela (scale to fit), a visualização dos conjuntos $P S_{1}$ e $P S_{2}$ produziria a mesma imagem, e, ainda assim, elas teriam estresses distintos se comparados a um conjunto de referência.

Além da medida de estresse, a medida nearest neighbors precision metric - nnp também foi utilizada. Paulovich et al. (2008a) defendem que a medida estresse pode não ser adequada para avaliar técnicas para a exibição de dados com alta dimensionalidade. Por este motivo optou-se por também utilizar, nesta comparação, a medida $n n p$ que avalia a vizinhança dos elementos, tal qual foi definida por Paulovich et al. (2008a). Ela computa o percentual de vizinhos que pertencem à mesma classe de cada elemento tomado como referência. Uma maior percentual indicaria uma melhor capacidade de preservar as vizinhanças locais quando comparada a uma outra técnica. Ela pode ser utilizada para verificar se a disposição de elementos produzida pela incBoard é consistente com etiquetas ou classes previamente atribuídas aos elementos de dados. Nesta avaliação os oito primeiros vizinhos de cada célula foram considerados $(8-n n p)$, uma quantidade que corresponde aos vizinhos imediatos de uma célula no tabuleiro.

Os resultados para os mapas finais foram registrados, bem como valores médios computados à medida em que elementos eram adicionados em ordem aleatória ao tabuleiro. Estes valores médios podem indicar como se comporta o algoritmo, com relação ao seu desempenho, à medida que o mapa é gradualmente construído. Sempre que uma das técnicas é sujeita a variância, média aritmética e desvio padrão (std.dev.) foram computados para dez execuções distintas dos algortimos. As projeções utilizadas para a comparação com a incBoard foram feitas com a ferramenta Projection Explorer (Paulovich et al., 2007), aplicando-se os seus parâmetros padrão.

O primeiro conjunto de dados considerado consiste de 675 artigos científicos classificados em uma de quatro áreas do conhecimento: (i) raciocínio baseado em casos (Case-Based Reasoning- CBR); (ii) programação em lógica indutiva (Inductive Logic Programming-ILP); (iii) recuperação de informação (Information Retrieval-IR) e (iv) Sonificação (Sonification-SON). Este mesmo conjunto de dados, daqui por diante denominado CBR-ILP-IR-SON, foi utilizado anteriormente para comparar outras técnicas de projeção (Paulovich et al., 2008a). Ele foi construído agregando-se artigos obtidos de fontes associadas a cada uma dessas áreas, por exemplo, anais de congressos especializados. A dissimilaridade entre documentos foi computada com a distância do cosseno sobre um modelo de espaço vetorial da coleção. Termos frequentes (stopwords) foram removidos e cortes de Luhn foram aplicados para a seleção de termos relevantes. 
A Figura 4.6 mostra estágios intermediários e final de um mapa de documentos do corpus, em que documentos foram coloridos de acordo com suas classes atribuídas. Observa-se que a disposição geral das classes mantém-se globalmente estável à medida que o mapa é construído. Documentos foram adicionados utilizando-se o modo completo (ver Seção 4.3.1) até o 300o elemento, a partir de quando a adição mudou para o modo de amostragem estocástica. Neste momento, cálculos de erro para cada documento passam a utilizar os conjuntos de elementos próximos e aleatórios associados ao documento (modo de amostragem estocástica). O tamanho destes conjuntos foi definido em 16 e 24 elementos, respectivamente. As classes atribuídas aos documentos não assumiram qualquer papel no processo de disposição e re-arranjo dos elementos, sendo usadas exclusivamente para selecionar a cor exibida pelo elemento na tela.

A Tabela 4.2 mostra resultados para estresse e nnp para a disposição final de elementos. As seguintes técnicas foram comparadas com a incBoard: (i) Projection by Clustering - ProjClus (Paulovich e Minghim, 2006b), (ii) Least Square Projection - LSP (Paulovich et al. 2008a), (iii) Principal Component Analysis - PCA (Jolliffe, 2002), e (iv) Sammon's Mapping (Sammon, 1969). A medida de estresse exibida utilizou a distância $\hat{d}\left(E_{i}, E_{j}\right)$ computada conforme o algoritmo de ajuste proposto por Kruskal (1964a). Os resultados para ambas as medidas são encorajadores. O incBoard possui o segundo melhor valor para estresse, muito abaixo do alcançado com técnicas tradicionais como Sammon's mapping e PCA. Embora não tenha tido igual desempenho na medida $n n p$, seu resultado ainda é próximo dos demais. É importante notar também que a variância para os resultados medidos no mapa final são as menores entre as técnicas que estão sujeitas à variação nos resultados.

Tabela 4.2: Resultados para diferentes técnicas de projeção usando o corpus CBR-ILP-IR-SON. Nearest Neighbor Precision ( $n n p$ ) computada para os 8 primeiros vizinhos. Melhores resultados em negrito.

\begin{tabular}{ccccc} 
Técnica & $\begin{array}{c}8-n n p \\
\left(\times 10^{2}\right)\end{array}$ & $\begin{array}{c}\text { std.dev. } \\
\left(\times 10^{2}\right)\end{array}$ & $\begin{array}{c}\text { estresse } \\
\left(\times 10^{2}\right)\end{array}$ & $\begin{array}{c}\text { std.dev. } \\
\left(\times 10^{2}\right)\end{array}$ \\
\hline ProjClus & 67.8 & 8.8 & $\mathbf{1 7 . 6}$ & 0.7 \\
incBoard (mapa final) & 67.8 & 4.3 & 18.2 & 0.6 \\
incBoard (incremental) & 66 & 7.1 & 18.7 & 1.0 \\
PCA & $\mathbf{8 5 . 0}$ & - & 21.6 & - \\
LSP & 70.7 & 5.9 & 22.3 & 2.1 \\
Sammon's & 76.0 & - & 37.7 & -
\end{tabular}

A Tabela 4.3 traz resultados para estresse e $n n p$ computados enquanto documentos são adicionados ao mapa até que todo o corpus, com 675 documentos, tenha sido adicionado. A média aritmética deste resultados é identificada como incBoard (incremental) na Tabela 4.2 . 
Os resultados têm um comportamento consistente ao longo do processo, indicando que mapas obtidos em etapas parciais da construção são também válidos. Há alguma mudança nos valores medidos de estresse, que inicialmente parece aumentar, e, após a inclusão de trezentos documentos, parece reduzir. No entanto, tal variação não parece ser significativa, em nenhum momento mudando a avaliação da técnica em relação aos valores observados para outras técnicas na Tabela 4.2 .

Tabela 4.3: Medidas de estresse e Nearest Neighbor Precision (nnp) computadas ao adicionar gradualmente documentos do corpus CBR-ILP-IR-SON em um tabuleiro usando incBoard, até um número total de 675 documentos.

\begin{tabular}{ccccc}
$\begin{array}{c}\text { Documentos } \\
\text { no tabuleiro }\end{array}$ & $\begin{array}{c}8-n n p \\
\left(\times 10^{2}\right)\end{array}$ & $\begin{array}{c}\text { std.dev. } \\
\left(\times 10^{2}\right)\end{array}$ & $\begin{array}{c}\text { estresse } \\
\left(\times 10^{2}\right)\end{array}$ & $\begin{array}{c}\text { std.dev. } \\
\left(\times 10^{2}\right)\end{array}$ \\
\hline 100 & 55.6 & 5.3 & 18.8 & 1.5 \\
200 & 64.7 & 5.6 & 18.9 & 1.4 \\
300 & 70.7 & 5.5 & 19.1 & 1.2 \\
400 & 67.7 & 5.7 & 18.7 & 0.8 \\
500 & 67.7 & 6.0 & 18.5 & 0.6 \\
600 & 67.8 & 5.2 & 18.4 & 0.6 \\
675 & 67.8 & 4.3 & 18.2 & 0.5
\end{tabular}

Observou-se que mapas com 200 ou menos elementos consistentemente apresentaram resultados piores para a medida $8-n n p$, o que pode ser evidência de viés em relação ao tamanho do conjunto (ver tabelas 4.3 e 4.4). Por exemplo, em um tabuleiro quadrado com 16 elementos pertencentes a duas classes, oito elementos em cada classe, o menor número possível de elementos com um vizinho pertencente a uma classe distinta da sua é 8 , ou $2 \times \sqrt{N}$. Ou seja, metade do total de elementos. Já para um tabuleiro com 100 células, este número é de apenas 20, menos de um quarto dos elementos, ainda que também $2 \times \sqrt{N}$. Em outras palavras, a medida aproxima-se da relação entre perímetro e área de uma forma geométrica, que não é constante para diferentes áreas. Portanto, só é razoável comparar a medida $n n p$ entre mapas com aproximadamente o mesmo número de elementos. Isto implica que também deve-se esperar resultados ligeiramente menores que os demais para as médias dos resultados coletados ao longo do processo, identificados como incBoard (incremental) nas tabelas $4.2 \mathrm{e} 4.5$.

O mesmo corpus, CBR-ILP-IR-SON, foi utilizado em um cenário que melhor se aproxima da visualização de um conjunto dinâmico de documentos.

Neste segundo cenário, documentos foram adicionados até atingir o número de 300 documentos no tabuleiro. A partir deste ponto, um documento era removido sempre que um novo documento era adicionado, até que todos os 675 documentos do corpus tivessem sido exibidos. A Figura 4.7 apresenta três momentos distintos do processo. 
De fato, ao inspecionar os mapas produzidos ao longo do processo, é possível notar que a disposição geral das classes é preservada todo o tempo, ainda que, entre os 300 documentos presentes no mapa ao final da exibição do conjunto, não encontre-se nenhum documento que tenha estado presente no tabuleiro no mesmo momento que qualquer um dos 300 documentos iniciais.

Também neste caso, os resultados quantitativos (ver Tabela 4.4) foram consistentes, destacando a aplicabilidade da técnica incBoard para a apresentação de conjuntos dinâmicos de documentos. O estresse, com um valor mínimo de 18,49 e máximo de 19,44, permanece dentro dos limites estabelecidos pelas demais técnicas avaliadas (Tabela 4.2), tendo ProjClus como limite inferior $(17,6)$ e, como limite superior, a técnica PCA, com estresse 21,6, i.e., tomando-se qualquer um dos valores de estresse computados ao longo da construção incremental do mapa, o seu desempenho não varia o suficiente para alterar a sua posição em relação à demais técnicas. Os valores observados para $n n p$ são relativamente baixos, como esperado, embora ainda situem-se próximos ao valor 67,8 observado para o mapa do corpus completo. A variância, em ambas as medidas, é um pouco mais alta do que o observado anteriormente para a construção do mapa completo, talvez reflexo da escolha aleatória na ordem de adição dos documentos ao tabuleiro.

Tabela 4.4: Medidas de estresse e Nearest Neighbor Precision (nnp) computadas ao substituir documentos do corpus CBR-ILP-IR-SON usando o incBoard em um tabuleiro com 300 células.

\begin{tabular}{ccccc}
$\begin{array}{c}\text { Documentos adicionado/ } \\
\text { Documentos no tabuleiro }\end{array}$ & $\begin{array}{c}8-n n p \\
\left(\times 10^{2}\right)\end{array}$ & $\begin{array}{c}\text { std.dev. } \\
\left(\times 10^{2}\right)\end{array}$ & $\begin{array}{c}\text { estresse } \\
\left(\times 10^{2}\right)\end{array}$ & $\begin{array}{c}\text { std.dev. } \\
\left(\times 10^{2}\right)\end{array}$ \\
\hline $100 / 100$ & 56.92 & 4.56 & 18.56 & 1.09 \\
$200 / 200$ & 65.58 & 3.12 & 19.11 & 1.19 \\
$300 / 300$ & 69.86 & 2.71 & 19.44 & 1.35 \\
$400 / 300$ & 64.68 & 2.89 & 19.26 & 1.08 \\
$500 / 300$ & 64.42 & 4.65 & 18.91 & 0.66 \\
$600 / 300$ & 66.61 & 4.59 & 18.49 & 0.6 \\
$675 / 300$ & 68.45 & 4.84 & 18.51 & 0.71
\end{tabular}

O segundo estudo de caso utilizou o conhecido conjunto de dados de flores Iris Asuncion e Newman, 2007), com um total de 150 itens pertencentes a uma de três espécies. Este segundo conjunto de dados foi escolhido para avaliar o comportamento da solução proposta ao tratar um conjunto de dados que é mais facilmente apresentado em duas dimensões. A distância euclidiana foi adotada para calcular a similaridade entre os elementos do conjunto.

Neste segundo estudo, os resultados para estresse foram razoáveis (ver tabela 4.5), segundo o padrão definido por Kruskal (1964b), porém não tão bons como no caso anterior. A partir 
destes resultados, pode-se argumentar que existe uma solução em 2D para a projeção deste conjunto de dados (o estresse para a técnica PCA foi $0,1 \times 10^{-2}$, que também apresentou o melhor resultado para $n n p$ ). Portanto, as outras técnicas se beneficiam por não estarem sujeitas às mesmas restrições que o algoritmo incBoard, uma vez que elas são livres para posicionar cada elemento em sua coordenada ideal, definida em $\mathbb{R}^{2}$ e não em $\mathbb{Z}^{2}$. No entanto, para conjuntos de dados mais complexos, tais coordenadas ideais podem não existir, e então a possibilidade de utilizar coordenadas em $\mathbb{R}^{2}$ torna-se menos relevante. De qualquer forma, o resultado obtido pelo incBoard para nnp é muito próximo dos melhores resultados, possivelmente implicando que mesmo que uma disposição ideal de elementos não seja possível, a distribuição geral dos elementos é boa. O resultado para nnp foi melhor que o resultado da técnica ProjClus, ainda que o estresse tenha sido pior. Adicionalmente, da mesma forma como ocorreu com o corpus CBR-ILP-IR-SON, as medidas de estresse e nnp comportaram-se consistentemente ao longo do processo de construção do mapa (ver incBoard (incremental) na Tabela 4.5). Foram comparadas com a incBoard as técnicas: (i) Projection by Clustering - ProjClus (Paulovich e Minghim, 2006b), (ii) Least Square Projection - LSP (Paulovich et al., 2008a), (iii) Principal Component Analysis - PCA (Jolliffe, 2002), e (iv) Sammon's Mapping (Sammon, 1969).

Tabela 4.5: Resultados para diferentes técnicas de projeção com o conjunto de dados Iris. Nearest Neighbor Precision ( $n n p$ ) computada para os 8 primeiros vizinhos. Melhores resultados em negrito.

\begin{tabular}{ccccc} 
Technique & $\begin{array}{c}8-n n p \\
\left(\times 10^{2}\right)\end{array}$ & $\begin{array}{c}\text { std.dev. } \\
\left(\times 10^{2}\right)\end{array}$ & $\begin{array}{c}\text { Stress } \\
\left(\times 10^{2}\right)\end{array}$ & $\begin{array}{c}\text { std.dev. } \\
\left(\times 10^{2}\right)\end{array}$ \\
\hline PCA & $\mathbf{9 3 . 6}$ & - & $\mathbf{0 . 1}$ & - \\
LSP & 91.8 & 2.6 & 3.0 & 1.1 \\
ProjClus & 83.6 & 6.3 & 10.2 & 1.7 \\
incBoard (mapa final) & 86.4 & 2.5 & 14.3 & 2.5 \\
incBoard (incremental) & 81.9 & 5.4 & 14.5 & 2.6
\end{tabular}

\subsubsection{Cenários potenciais de uso do algoritmo}

Os próximos dois estudos de caso apresentam duas aplicações em potencial do algoritmo de disposição de elementos e da visualização correspondente, como prova de conceito.

O primeiro cenário de uso trabalha com o corpus Reuters (Lewis et al., 2004), uma coleção de notícias com marcação de data de publicação que cobrem um ano de notícias da Agência Reuters. Estas notícias são classificadas em categorias pela própria agência, no entanto, escolheu-se não exibir quaisquer informações quanto à classificação dos documentos, a fim de manter o foco nas funções desenvolvidas. 
A ferramenta de visualização (Seção 4.4) foi adaptada para exibir sequencialmente as 800 mil notícias do corpus em um tabuleiro com 500 células. Uma linha de execução (thread) dedicada foi criada para extrair sequencialmente notícias do corpus, em lotes de um dia, e as inserir em uma fila para tratamento pelo sistema de visualização. Quando a fila é esvaziada, a thread processa um novo lote de notícias para alimentá-la. São utilizados apenas os campos título (headline) e corpo (text) das notícias para construir o espaço vetorial. Adotou-se uma solução simplificada para criar o modelo de espaço vetorial, computando a frequência dos termos utilizando-se os primeiros 50 mil documentos do corpus, apesar de existirem soluções mais adequadas para a medir a similaridade de documentos de conjuntos dinâmicos. Esta abordagem simula a utilização de um modelo global de linguagem, embora deva-se reconhecer que um conjunto inicial de 50 mil documentos, similar ao que está sendo analisado, não estivesse disponível em um cenário real de uso. No entanto, tratar esta questão e possíveis soluções está além do escopo desta tese. A similaridade entre documentos é medida com a distância do cosseno. Termos frequentes (stopwords) são removidos e cortes de Luhn aplicados para a seleção de termos relevantes.

Uma ferramenta de busca foi acrescentada à ferramenta de visualização. Ela computa a distância do cosseno entre uma consulta fornecida pelo usuário (query string) e os documentos do tabuleiro, exibindo uma relação com os documentos encontrados (ver painel inferior à esquerda na Figura 4.8). Documentos adicionados ao tabuleiro são também comparados com a consulta ativa.

A ferramenta provê também a possibilidade de "travar" documentos no tabuleiro: quando ativa, esta função mantém documentos similares à consulta no tabuleiro. Ou seja, quando um documento $E_{1}$ é similar a uma consulta $Q$, isto é , quando $\delta\left(E_{i}, Q\right)<1$, ele não é selecionado no processo de remoção, sendo outros documentos escolhidos quando é necessário remover elementos para manter o número desejado de documentos no tabuleiro.

$\mathrm{Na}$ execução do estudo de caso foram inicialmente adicionados em torno de 500 documentos ao tabuleiro. O processo foi então interrompido e foi feita uma busca por "Brazil". Alguns grupos de artigos foram encontrados que tratam de uma nova fábrica da Chrysler no Brasil (ver Figura 4.8). O termo "Chrysler" foi então adicionado à consulta ativa. Na visualização, documentos que possuem "Brazil" e/ou "Chrysler" são exibidos com uma borda vermelha. O documento que encontra-se abaixo do cursor do mouse em um determinado momento é exibido com um fundo amarelo, com o seu conteúdo exibido no painel superior direito, permite o exame do conteúdo dos documentos pelos usuários.

Em seguida, a função "trava" foi ativada e novos documentos foram adicionados ao tabuleiro em modo contínuo (botão play). Quando o número de documentos adicionados aproximava-se de mil, isto é, quando aproximadamente 500 documentos já haviam sido removidos para manter 
o número de documentos exibidos constante, observou-se o surgimento de mais alguns documentos relevantes para a consulta ativa (ver Figura 4.9). O novo agrupamento continha notícias do mercado financeiro a respeito do Brasil. O agrupamento de notícias a respeito da fábrica da Chrysler ainda estava presente, não conectado com o agrupamento de notícias financeiras.

Posteriormente, após a marca de 1.800 documentos adicionados, documentos relevantes para a consulta passaram a ser encontrados juntos, à medida que representavam uma porção significativa do conjunto visualizado (ver Figura 4.10). Ainda assim, o agrupamento de notícias acerca da Chrysler é preservado (à esquerda na Figura 4.10). O documento selecionado nas proximidades, destacado em amarelo, não contém "Brazil" ou "Chrysler", mas trata do preço da gasolina, sendo então razoável que se encontre próximo a artigos que tratam dos planos de investimento de um fabricante de automóveis. Em contrapartida, artigos relacionados com a consulta, mas encontrados distantes do agrupamento maior de artigos acerca do Brasil, mencionam apenas brevemente o Brasil. Por exemplo, o artigo iniciando com "Nigeria" (canto superior esquerdo na Figura 4.10 relata a interrupção de um vôo entre a Nigéria e a Índia, mencionando que o mesmo havia acontecido com uma rota para o Brasil.

O último estudo de caso ilustra a aplicabilidade do algoritmo de disposição para exibir uma coleção de imagens, obtendo benefício direto da não ocorrência de oclusão e da possibilidade de dispor imagens de acordo com o seu conteúdo (ver Figura 4.4). Este caso usa um coleção de 1.109 imagens etiquetadas manualmente (Li et al., 2005). As etiquetas descrevem objetos e características encontradas nas imagens. A similaridade foi computada usando o coeficente de Jacquard sobre o conjunto de etiquetas das imagens. Alguns agrupamentos de imagens podem ser identificados na Figura 4.4(b), embora nenhum atributo visual tenha sido usado na comparação. Ainda assim, é possível notar algumas áreas onde algumas cores são predominante, talvez refletindo alguma relação entre etiquetas e cores.

Um vídeo demonstrando a aplicação está disponível ${ }^{1}$.

\subsection{Considerações finais}

Neste capítulo foi apresentada uma técnica para a exibição de elementos de um conjunto dinâmico de dados em um tabuleiro, dispostos de acordo com a sua similaridade. No centro da técnica está um algoritmo incremental de posicionamento que se apoia na posição relativa entre os elementos apresentados. Posições absolutas ou distância possuem pouco significado no espaço visual resultante, no entanto, a disposição de elementos tenta seguir o ordenamento relativo de elementos encontrado no espaço original ou conceitual.

\footnotetext{
${ }^{1}$ http://infoserver.lcad.icmc.usp.br/infovis2/incBoard
} 
O algoritmo é particularmente adequado para a exibição de conjuntos de dados dinâmicos ao prover mecanismos intrínsecos para adicionar e remover elementos, ao mesmo tempo em que mantém um arranjo compacto de elementos, a um baixo custo computacional. Ademais, a adição de um novo elemento não requer um re-arranjo completo do mapa. Em média, apenas 2,6\% (desvio padrão de 0,1 , computado em 10 execuções diferentes) do elementos foram deslocados após a adição de um elemento durante a construção de mapas para o corpus CBR-ILP-IR-SON. Esta é uma característica especialmente interessante, pois torna possível aos usuários acompanhar mudanças na disposição dos elementos à medida que o mapa é gradualmente alterado.

Apesar de não serem consideradas durante o processo de disposição dos elementos, classes manualmente atribuídas a itens de dados mantiveram-se nas mesmas posições relativas na tela, tanto durante a construção gradual de um mapa de um conjunto estático de documentos, e também em um cenário de visualização de um corpus dinâmico, com documentos antigos substituindo mais novos. Um arranjo consistente de classes foi preservado mesmo quando houve a completa renovação do conjunto exibido, ao substituir elementos até que nenhum elemento do conjunto original estivesse presente. Apesar do algoritmo não atribuir qualquer significado para os eixos do espaço visual, esta característica auxilia os usuários a manter uma representação mental da disposição dos elementos.

A visualização provida pelo algoritmo incBoard não sofre de oclusão. A alocação de espaços predefinidos para cada célula permite o uso de representações sofisticadas e informativas. O usuário é capaz de ajustar, a qualquer momento, o número de elementos que deseja exibir a cada momento. A visualização poderia ser facilmente integrada a um sistema de recuperação de imagens, mantendo sua interface padrão, porém dispondo os resultados por similaridade.

No próximo capítulo, o algoritmo é integrado a um algoritmo de extração de tópicos para auxiliar a identificação de agrupamentos e subconjuntos de interesse quando não existem classes predefinidas, ao contrário do que ocorre com os exemplos dos conjuntos CBR-ILP-IR-SON, Iris e Reuters aqui apresentados. Para tanto, o mapa é enriquecido com a apresentação de termos descritivos de tópicos e delimitadores de classes, automaticamente extraídos do conjunto de dados e constantemente atualizados no processo de construção incremental do mesmo. 


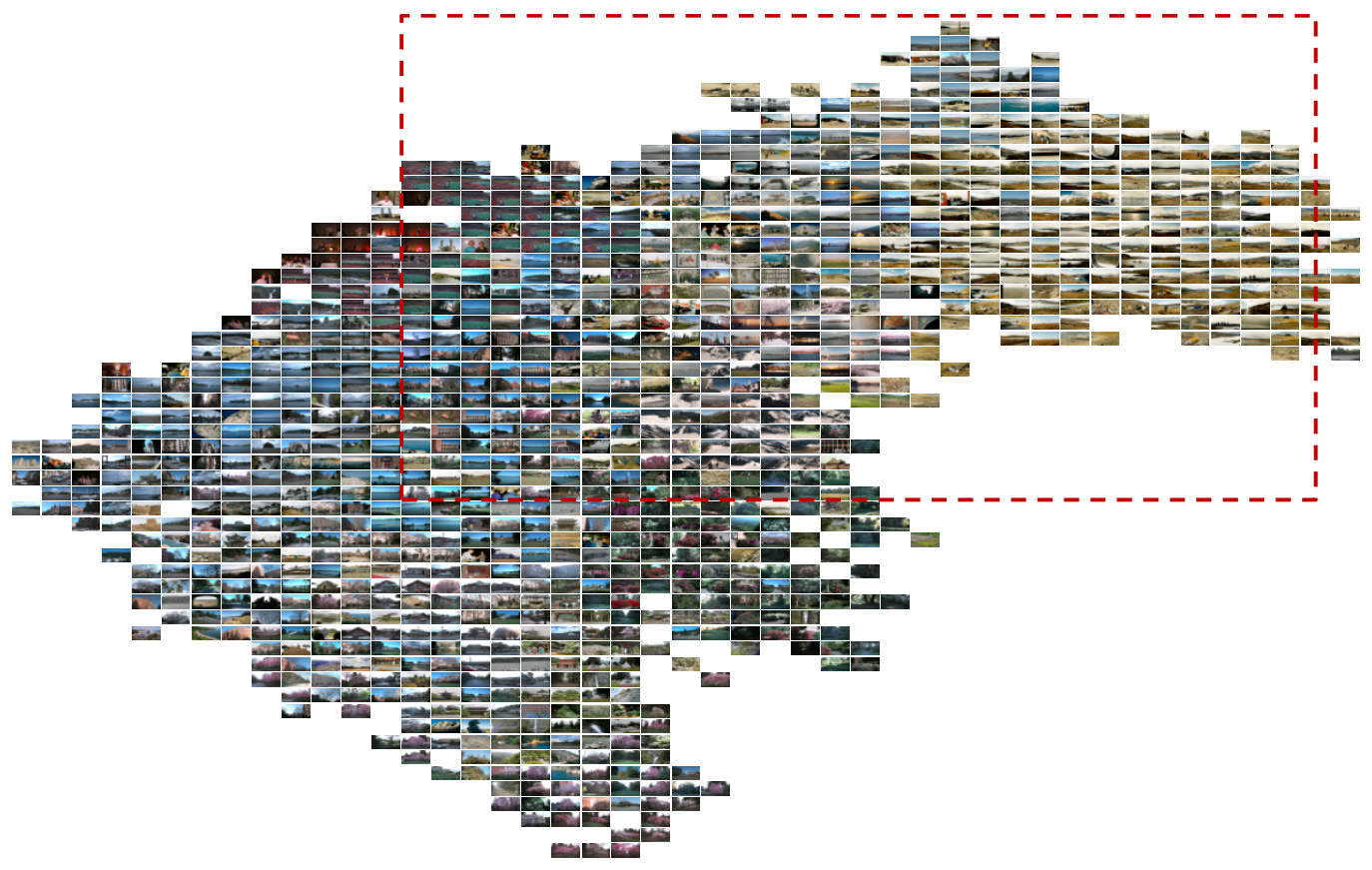

(a)

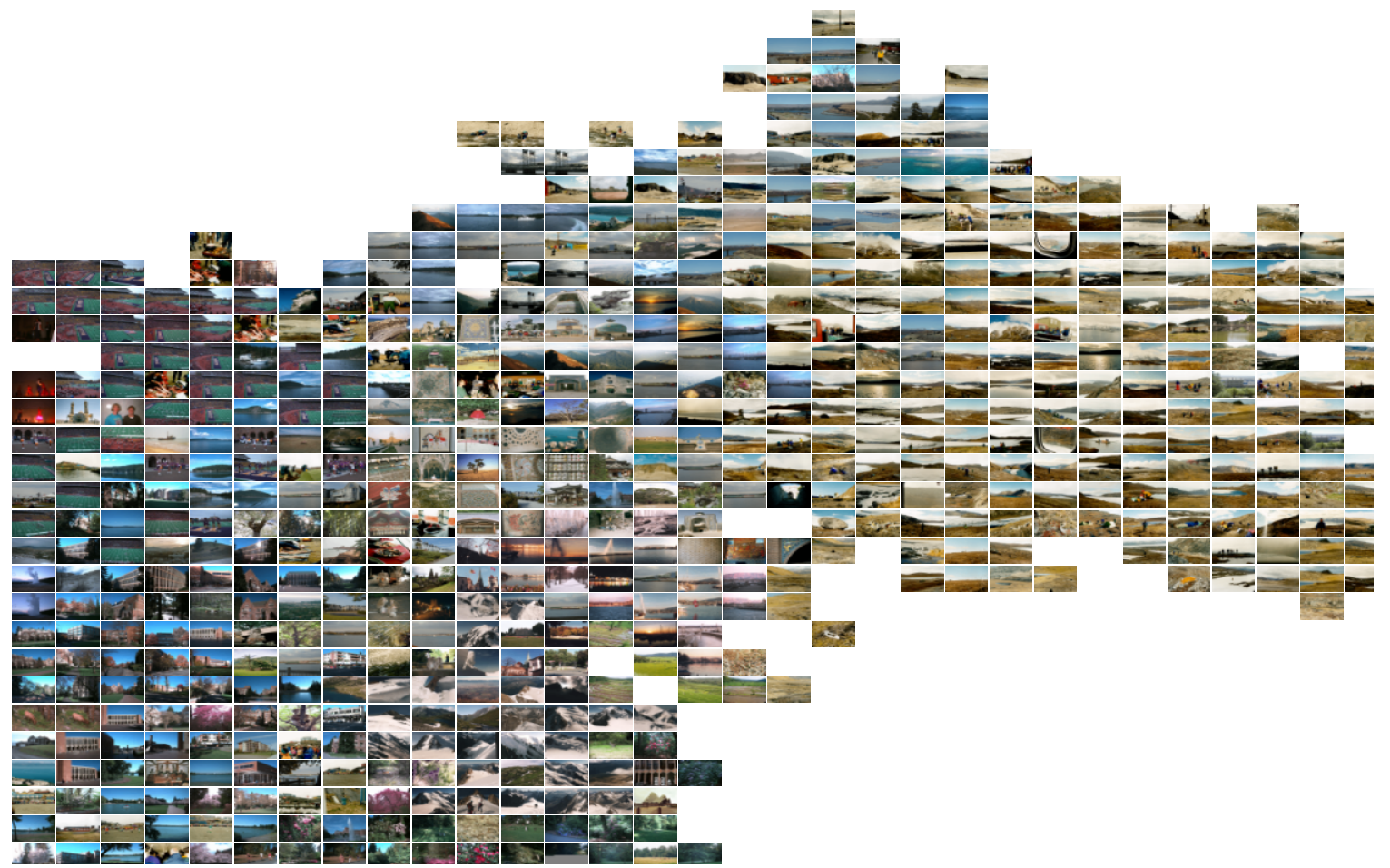

(b)

Figura 4.4: Visualização de 1109 imagens etiquetadas manualmente. A similaridade entre imagens é determinada pela comparação entre etiquetas manualmente atribuídas às imagens.

Mapa completo (a) e detalhe (b). 


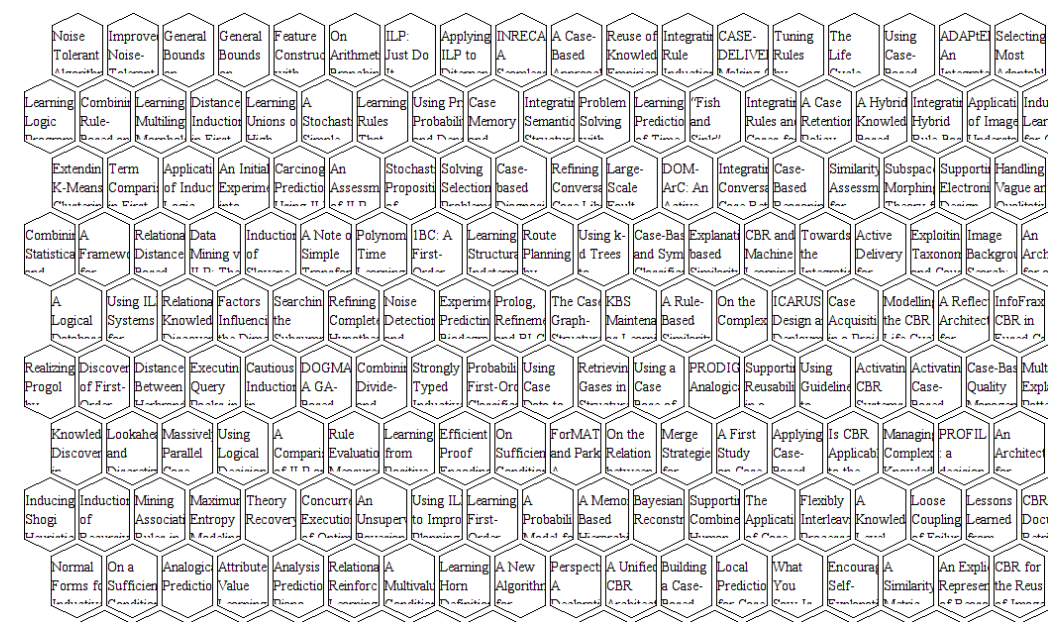

(a)

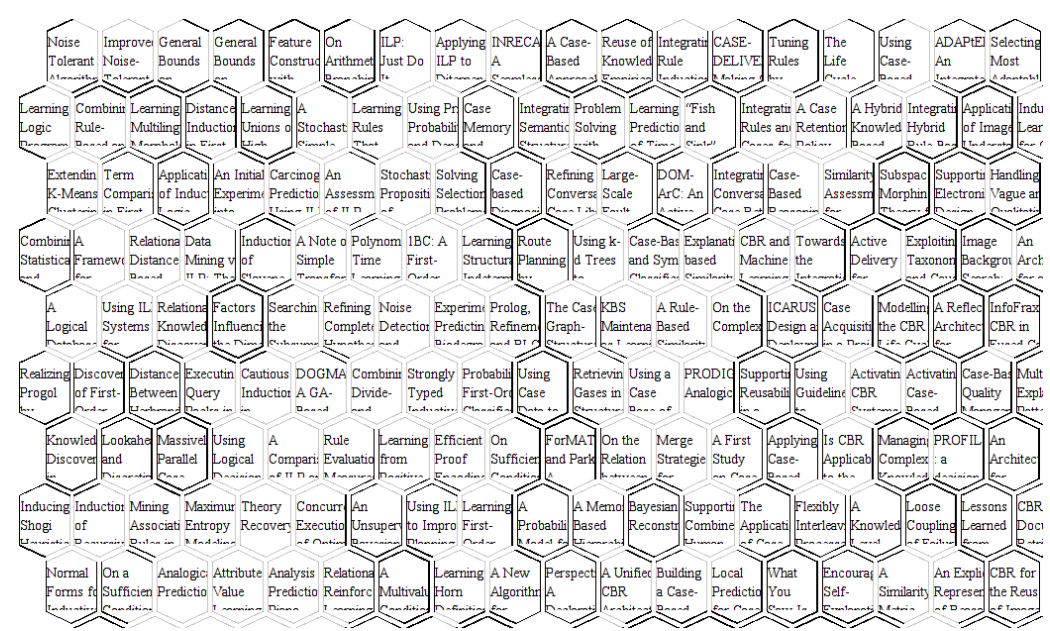

(b)

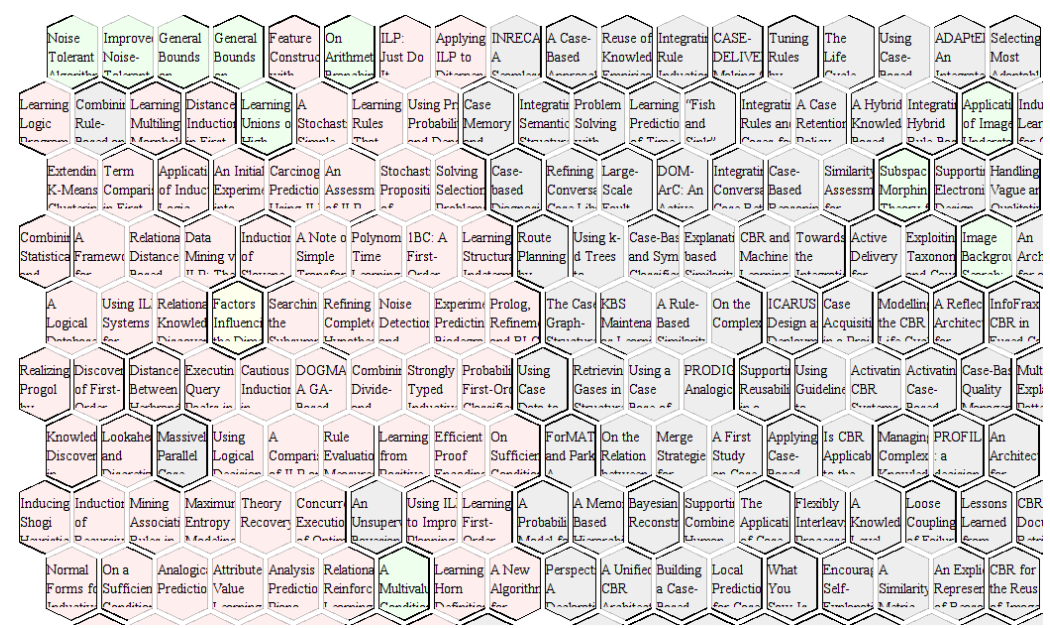

(c)

Figura 4.5: Parte de um mapa com 675 artigos científicos. Versões com bordas simples (a), bordas destacando a similaridade entre pares (b), cores representando classes manualmente atribuídas (c). Bordas mais finas denotam maior similaridade. Artigos classificados como Case-Based Reasoning (CBR), Inductive Logic Programming (ILP) e Sonification (SON) são mostrados em azul, vermelho e verde, respectivamente, em (c). 


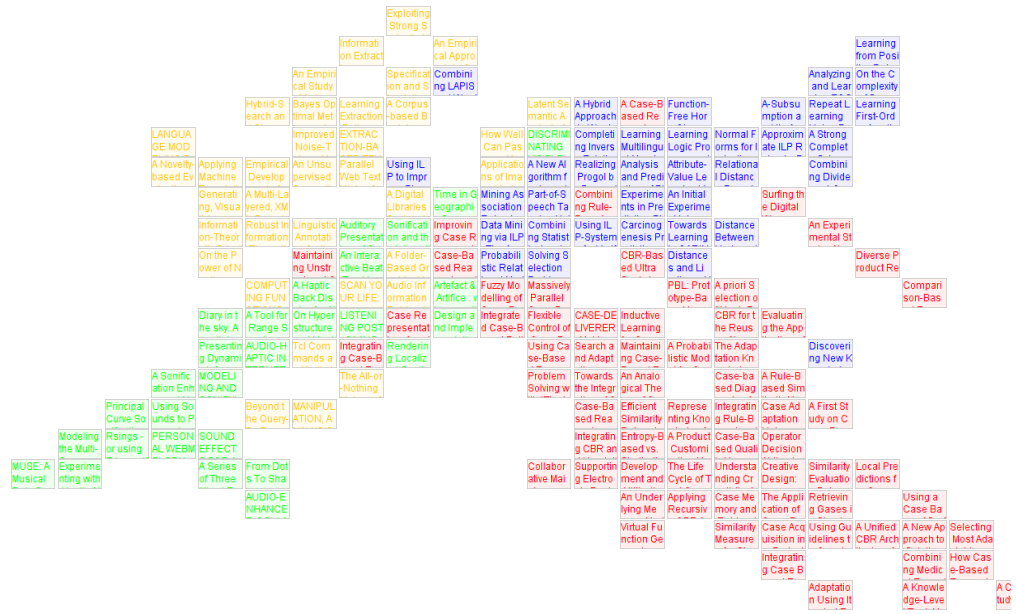

(a) 178 documentos

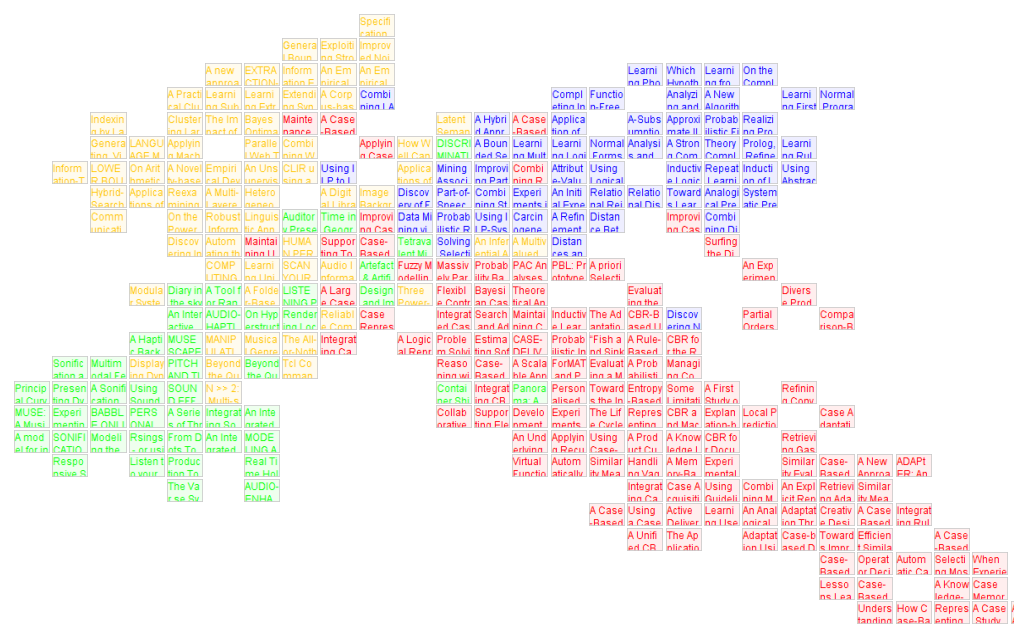

(b) 294 documentos

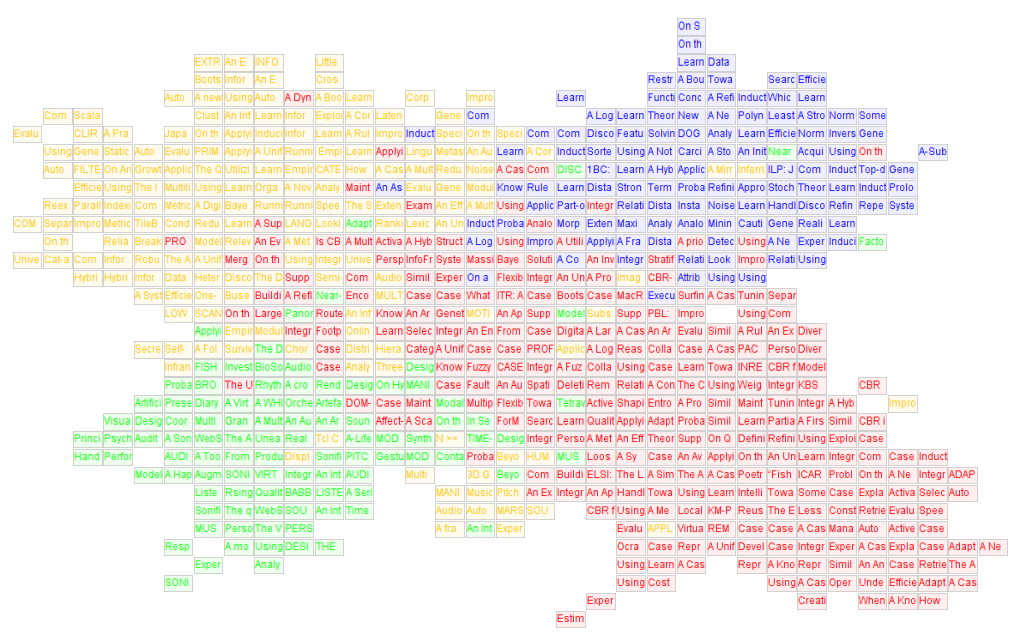

(c) 675 documentos

Figura 4.6: Três momentos na construção incremental de um mapa do corpus CBR-ILP-IR-SON. A cor denota classes manualmente atribuídas aos elementos. 


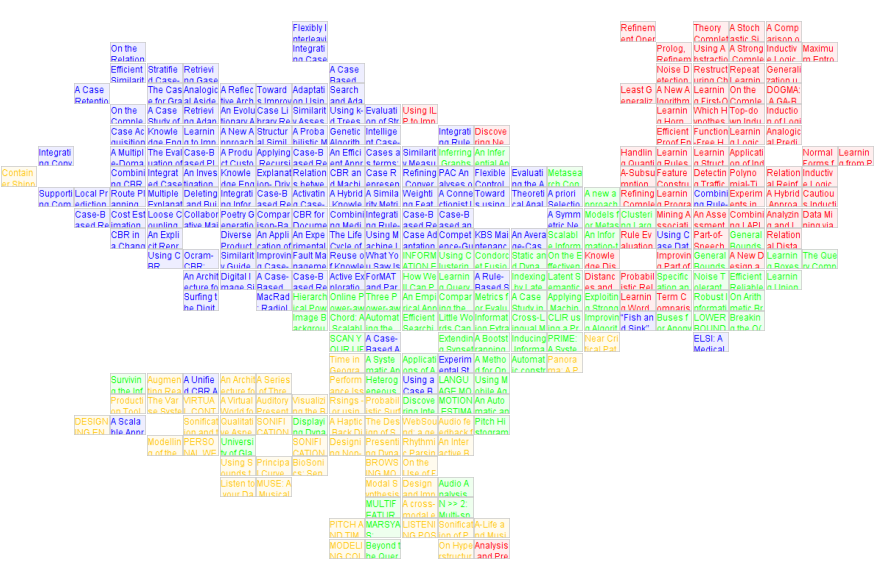

(a) conjunto inicial, com 296 documentos.

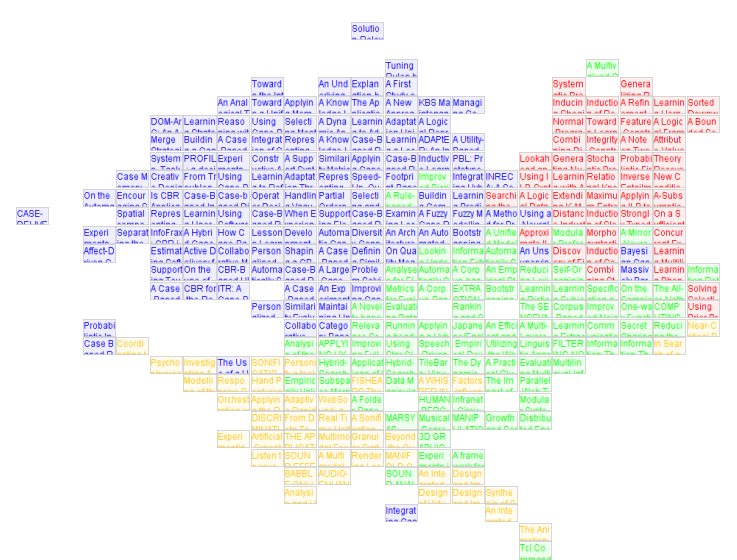

(b) conjunto intermediário, com 300 documentos.

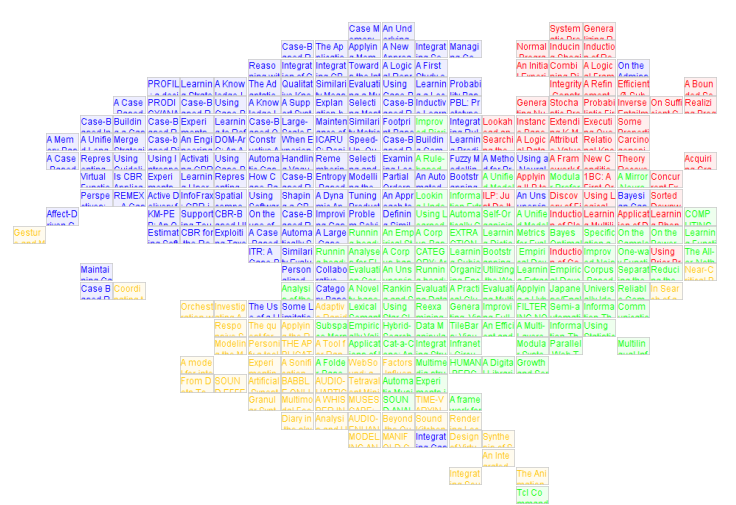

(c) conjunto final, com 300 documentos.

Figura 4.7: Três momentos da visualização do corpus CBR-ILP-IR-SON em que no máximo 300 documentos são mantidos no tabuleiro. A cor dos elementos denota classes manualmente atribuídas. 


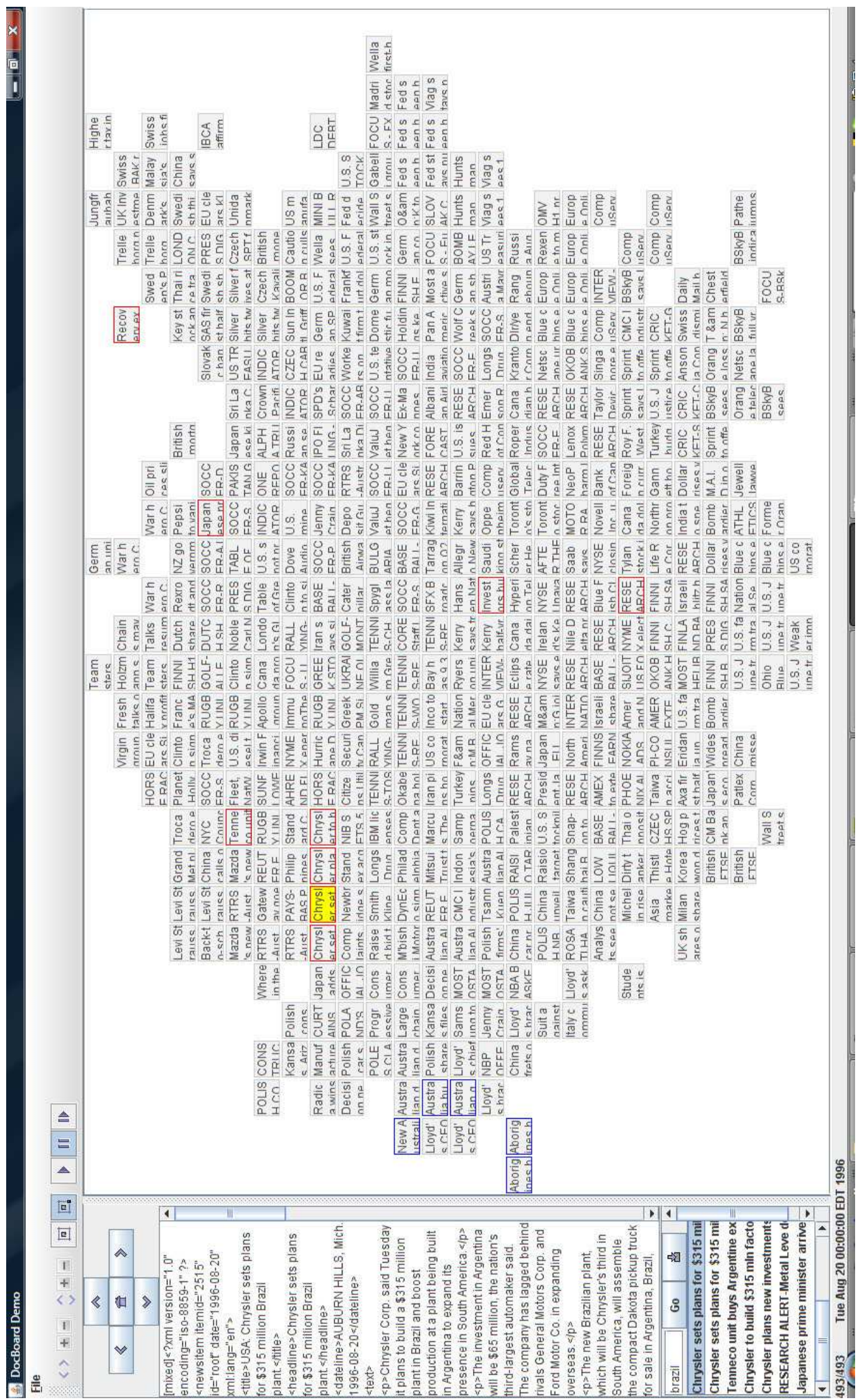

Figura 4.8: A ferramenta de visualização incBoard, exibindo 493 documentos do corpus Reuters. 


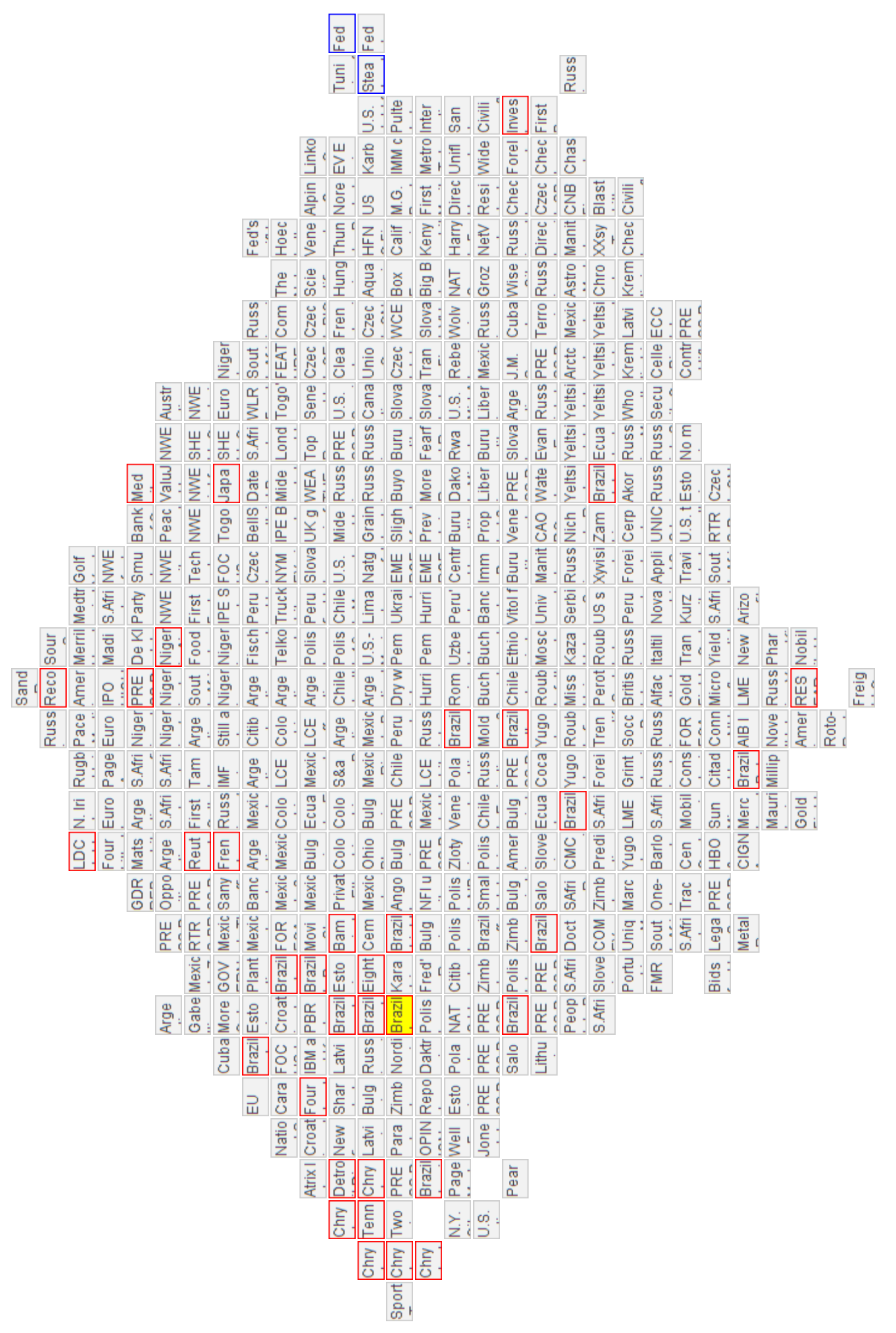

Figura 4.9: Visualização de 500 documentos do corpus Reuters, tendo 'Brazil Chrysler' como consulta ativa. Aproximadamente mil documentos adicionados desde o início do processo. 


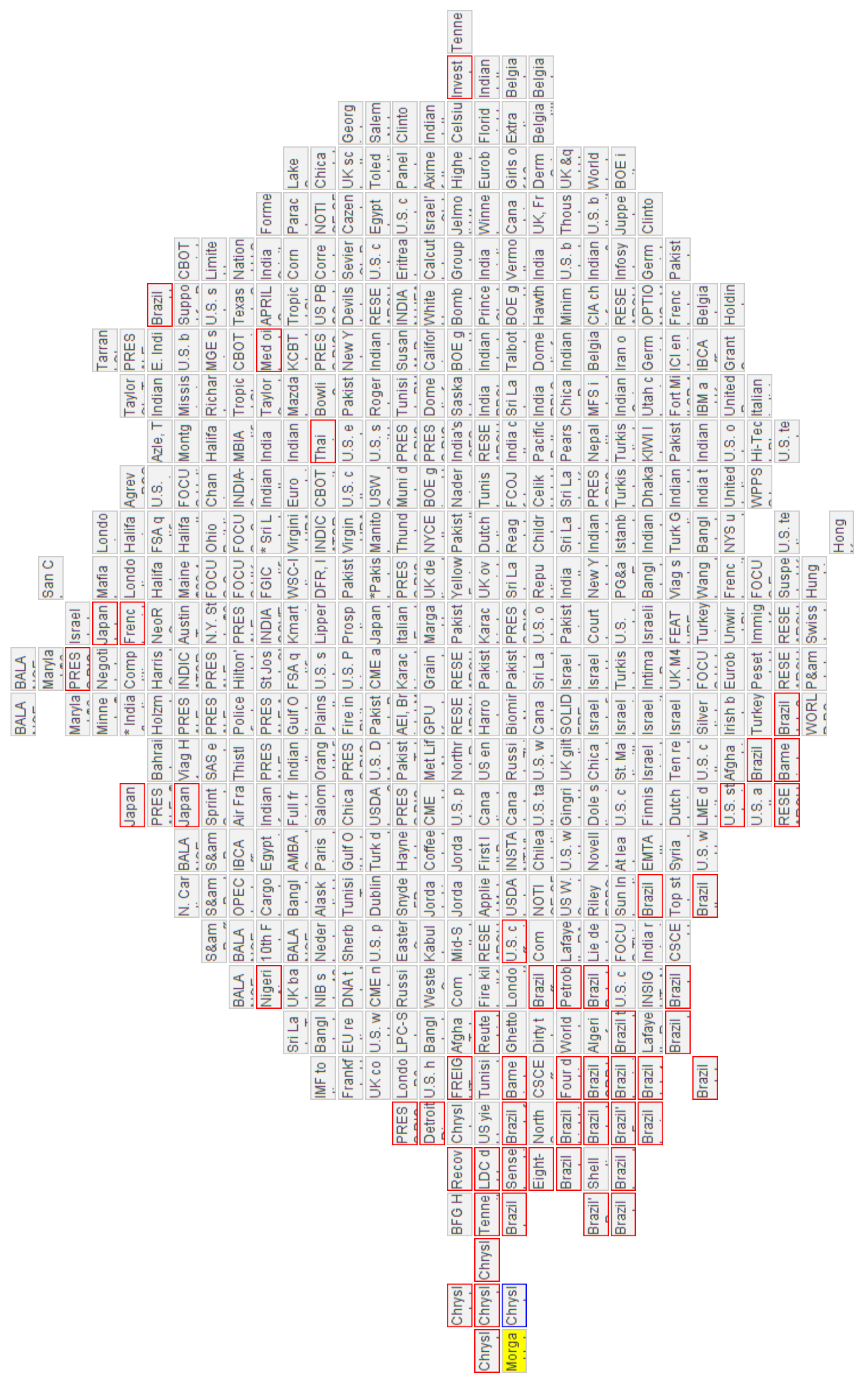

Figura 4.10: Visualização de 500 documentos do corpus Reuters, tendo 'Brazil Chrysler' como consulta ativa. Aproximadamente 1.800 documentos adicionados desde o início do processo. 


\section{Regras de associação com peso local para identificar tópicos em mapas de documentos}

\subsection{Introdução}

Neste capítulo, é introduzida uma abordagem que combina a extração de tópicos com a exploração de conjuntos documentos assistida por mapas visuais (mapas de documentos). É definido um processo iterativo e interativo de mineração visual de textos centrado na indução seletiva de regras de associação. Nele, (i) tópicos são extraídos da coleção, (ii) os usuários exploram o mapa de documentos e os tópicos extraídos, ao mesmo tempo em que refinam a lista de tópicos, e (iii) a qualidade do mapa e da lista de tópicos é melhorada com base na interação do usuário.

Os mapas de documentos utilizados são obtidos a partir da projeção, em duas dimensões, de representações multidimensionais destes documentos, em que procura-se preservar as relações de distância (dissimilaridade) presentes no espaço conceitual definido por estas representações, como visto em exemplos do Capítulo 2 e na solução apresentada no Capítulo 4. Ao explorar tais mapas, a seleção de um agrupamento de elementos do mapa provavelmente corresponderá à seleção de um conjunto de documentos de conteúdo similar ou que abordam temas em comum ou relacionados entre si. Identificar (rotular) os documentos no mapa de acordo com os temas a 
que se referem é importante para apoiar o usuário na análise de grandes coleções de documentos, sendo esta funcionalidade encontrada em diversos sistemas de visualização de documentos. $\mathrm{Na}$ técnica proposta, a extração de tópicos beneficia-se do agrupamento por similaridade para identificar os tópicos relevantes em documentos posicionados em regiões demarcadas do mapa.

Partindo da hipótese de que a co-ocorrência de termos relevantes embute conteúdo semântico que permite identificar tópicos relevantes, um algoritmo seletivo de indução de regras de associação, descrito na seção 5.2 , é proposto para gerar somente regras que incluam pelo menos um termo relevante para um dado subconjunto de documentos. Termos são considerados relevantes se são frequentes no subconjunto, em comparação à sua frequência no conjunto de documentos como um todo. Técnicas convencionais de extração de regras, quando aplicadas à extração de tópicos, deparam-se com problemas que são frequentes na indução de regras: (i) explosão combinatorial e (ii) dificuldade para identificar associações pouco frequentes ou raras. A redundância das regras extraídas é também uma preocupação, uma vez que eventualmente um grande número de regras ligeiramente diferentes são induzidas, potencialmente referindo-se a um mesmo tema. Assim, uma solução específica é necessária para lidar com estes problemas.

Os tópicos extraídos são apresentados em uma árvore de tópicos (Topic Tree Control) que auxilia os usuários a (i) identificar, no mapa, documentos relacionados com tópicos específicos, (ii) remover documentos indesejados, com base nos tópicos a que estão relacionados, (iii) comparar tópicos e documentos similares, (iv) extrair novos tópicos a partir de áreas do mapa selecionadas pelo usuário ou de todo o mapa, (v) construir novos mapas, derivados do mapa corrente, e, (vi) eventualmente exportar conjuntos de documentos classificados por tópico.

À medida que os usuários interagem com o mapa, a lista de tópicos é refinada. O próprio mapa também pode ser objeto de intervenções dos usuários, com a construção de mapas derivados. Mapas derivados herdam tópicos, beneficiam-se da remoção de documentos indesejados, e, opcionalmente, do uso dos termos descritivos dos tópicos para computar a similaridade entre documentos na composição do novo mapa.

Para ilustrar o processo proposto, e demonstrar sua aplicabilidade à exploração de conjuntos de documentos, dois estudos de caso são apresentados. Em um deles, uma coleção de notícias curtas retiradas da Internet é analisada, no outro, trata-se uma coleção de artigos científicos.

Foi desenvolvida uma aplicação que combina o posicionamento incremental de documentos no plano e a extração, também incremental, de tópicos. Para isto, foi necessário adotar estratégias para (i) manter atualizados subconjuntos de documentos, uma vez que o algoritmo de extração de tópicos deve ser aplicado sobre subconjuntos, e (ii) manter o conjunto de tópicos atualizado, sem, no entanto refazer todo o processo. A técnica de extração, entretanto, não se aplica somente a abordagens incrementais ou às técnicas de projeção utilizadas nos estudos de 
caso, quaisquer técnicas que garantam a formação de agrupamentos de documentos similares podem ser adotadas.

Na Seção 5.2 é detalhado o algoritmo de extração de tópicos. A navegação e interação sobre os tópicos extraídos com o Topic Tree Control são descritas na Seção 5.3. A seguir, na Seção 5.4. são discutidos os estudos de caso realizados com o intuito de ilustrar o processo iterativo de análise. Na Seção 5.5, são discutas as alterações necessárias para aplicar a técnica de extração de tópicos proposta em um cenário de visualização de conjuntos dinâmicos de documentos, conforme apresentado no Capítulo 4 . Na Seção 5.5.1 é apresentada a estratégia de atualização incremental de agrupamentos. Intervenções feitas no algoritmo $L W R$ para adequá-lo a aplicação a conjuntos dinâmicos de dados são descritas na Seção 5.5.2. Por fim, considerações finais e uma breve discussão sobre a integração entre os algoritmos de posicionamento e de identificação de tópicos são feitas na Seção 5.6 .

\subsection{Visualização e regras de associação com peso lo- cal para extração de tópicos}

\subsubsection{Extração de tópicos em áreas selecionadas pelo usuário}

Para a extração de tópicos de uma coleção de documentos, uma primeira solução consiste em um algoritmo cujo objetivo é detectar os principais temas tratados por um subconjunto de documentos selecionado pelo usuário em um mapa de documentos. Segundo esta proposta, publicada em Lopes et al. (2007), o usuário demarca uma região do mapa a fim de selecionar um subconjunto de documentos, e tópicos são extraídos em tempo real, sendo exibidos como etiquetas posicionadas sobre o mapa, como ilustrado na Figura 5.1. Esta abordagem extende o clássico algoritmo Apriori (Agrawal e Srikant, 1994) para realizar, seletivamente, a extração de regras de associação, cujos termos serão adotados e exibidos como descritivos dos tópicos.

A lógica do algoritmo (Algoritmo 1) consiste em restringir o espaço de busca para capturar as regras de maior significado, sem, no entanto, descartar associações raras, porém relevantes. O processo inicia com a identificação de termos relevantes para a seleção feita pelo usuário, denominados sementes. As sementes são termos relativamente mais frequentes na seleção do que na coleção de documentos como um todo. O peso aqui adotado para a escolha dos termos semente é, em alguma medida, análogo ao Tf-Idf como definido por Salton e Buckley (1988), e também inspirado nas ideias apresentadas por Bookstein et al. (1998). Intuitivamente, termos muito frequentes em um subconjunto de documentos serão provavelmente mais representativos do seu conteúdo do que termos que encontram-se uniformemente distribuídos nos documentos da coleção. O peso $w_{t_{j} S_{k}}$ de um termo $t_{j}$ em uma seleção $S_{k}$ de documentos contidos em um 


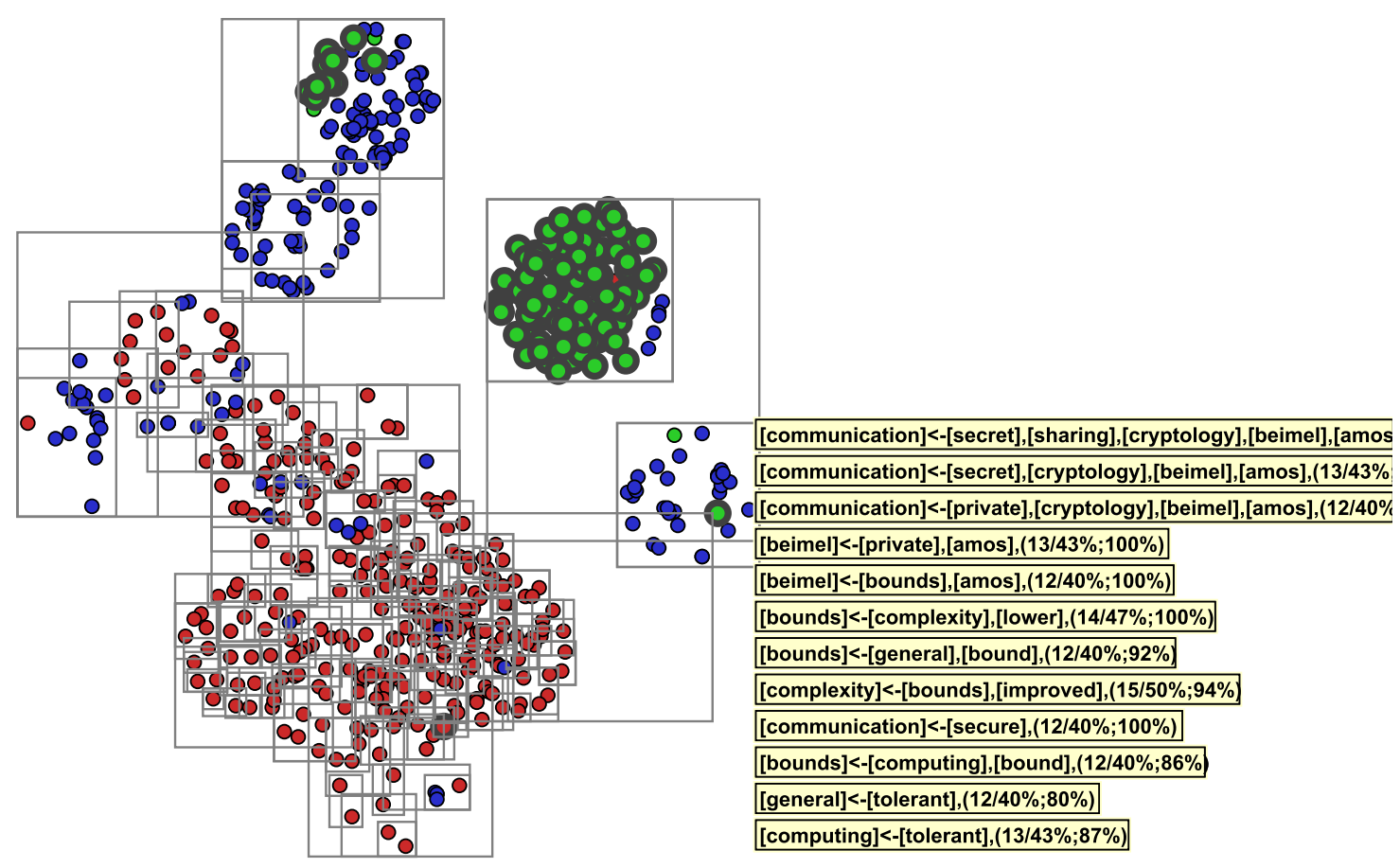

Figura 5.1: Mapa de 574 artigos científicos. Glifos vermelhos, verdes e azuis representam artigos em raciocínio baseado em casos (Case based reasoning - CBR), Programação Lógica Indutiva (Inductive logic programming - ILP) e recuperação de informação (Information retrieval - IR), respectivamente. Bordas em cinza delimitam áreas demarcadas automaticamente para extração de tópicos.

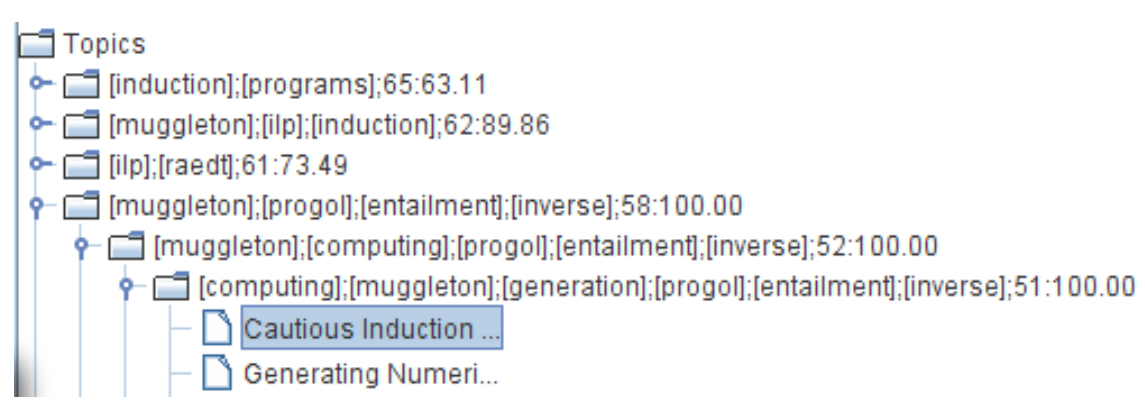

Figura 5.2: Exemplo da árvore de navegação por tópicos - Topic Tree Control. Os números que acompanham cada tópico indicam suporte e confiança, respectivamente para a regra de associação que deu origem ao tópico. O suporte é expresso em número de documentos que suportam a regra e a confiança em expressa em valores percentuais. $\mathrm{O}$ primeiro termo de um tópico é a cabeça (consequente) da regra original.

corpus $C$ é dado pelo somatório das suas frequências $t f_{t_{j} D_{i}}$ nos documentos da seleção, $D_{i} \in S_{k}$, 
dividido pelo somatório das suas frequências $t f_{t_{j} D_{i}}$ em documentos de toda a coleção $D_{i} \in C$ :

$$
w_{t_{j} S_{k}}=\frac{\sum_{D_{i} \in S_{k}} t f_{t_{j} D_{i}}}{\sum_{D_{i} \in C} t f_{t_{j} D_{i}}}
$$

Para evitar a indução de grandes quantidades de regras, ao invés de podar o conjunto de regras induzidas a posteriori, são geradas apenas regras que possuam pelo menos um termo que satisfaz o conceito de semente, i.e., possuem o maior peso na seleção. O número de termos semente foi fixado em dez, valor este estabelecido de forma ad-hoc, após inúmeros experimentos. O suporte mínimo inicial adotado para a chamada do Apriori, no Algoritmo 1 é $50 \%$. Este (relativamente) alto suporte inicial também limita o número de regras produzidas pelo Apriori, priorizando os termos mais representativos da seleção. Uma vez que nem todo subconjunto selecionado de documentos contêm documentos similares em quantidade suficiente para gerar regras com o suporte mínimo inicialmente definido, o valor do suporte mínimo é iterativamente reduzido até que pelo menos uma regra de associação seja induzida. Eventualmente, nenhuma regra é induzida, mesmo definindo um suporte mínimo muito baixo. Nos estudos de caso realizados, um limite inferior de suporte igual a três documentos foi estabelecido. Ou seja, se um conjunto de termos não é suportado por pelo menos três documentos, as regras correspondentes não serão induzidas. Considera-se que se não encontramos um conjunto de termos em pelo menos três documentos, ele não denota um tema comum entre documentos, sendo específico de um ou dois documentos, e portanto não é um tópico representativo da seleção.

Em seguida, um número variável de regras pode ser induzido para cada conjunto de termos frequentes retornado pelo Apriori, escolhendo-se subconjuntos diferentes como cabeça da regra de associação. Com o objetivo de minimizar a redundância entre regras, somente uma regra de associação é induzida para cada conjunto de termos frequentes, tendo apenas um dos termos como cabeça. Assim, por exemplo, para um conjunto composto por cinco termos, cinco diferentes opções existem, escolhendo-se, alternativamente cada um dos termos como cabeça da regra. Todas estas potenciais regras possuem o mesmo suporte, i.e., são encontradas no mesmo número de documentos, no entanto, a sua confiança pode variar. A opção efetivamente escolhida é aquela que possui a maior confiança. Por exemplo, a regra de associação 'Mozart' $\Rightarrow$ 'Música' provavelmente teria uma confiança maior que a regra 'Música' $\Rightarrow$ 'Mozart'.

O próximo passo é ponderar e ordenar as regras. Para isto, o somatório dos pesos dos seus termos é considerado como indicativo da relevância da regra. Dessa maneira, a medida de relevância de uma regra tem uma base comparativa, que contrasta a frequência de ocorrência dos seus termos nos documentos selecionados com a frequência desses termos encontrada no conjunto total de documentos. Portanto, o agrupamento por similaridade de conteúdo perse- 
guido pelos mapas de documentos, ou por qualquer solução de agrupamento por similaridade, é fundamental para o bom funcionamento da técnica. É o conteúdo similar dos documentos do grupo que favorece a extração de tópicos representativos.

Tendo um conjunto de regras ordenado por peso, um número arbitrário de regras podem ser escolhidas para descrever o conjunto selecionado de documentos, sendo exibidas no mapa como etiquetas da seleção original. O algoritmo descrito na Seção 5.2.2 incorpora um mecanismo para seleção de regras que dispensa o estabelecimento deste número arbitrário de regras a serem exibidas.

De certa forma, esta abordagem aproxima-se das estratégias de indução de regras propostas por Liu et al. (1999) e também por Freitas (2000), que também evitam restringir o espaço de busca por um valor único de suporte mínimo. Este último aplica múltiplos valores de mínimo suporte ao induzir regras de associação a partir de transações armazenadas em bancos de dados.

\subsubsection{Extração de tópicos representativos do corpus}

A mesma estratégia de indução seletiva de regras pode ser aplicada sobre todo um mapa de documentos para identificar os tópicos de todo um corpus. Isto requer que o mapa seja particionado em grupos de documentos similares entre si, o que pode ser alcançado, na solução proposta, de duas maneiras: (i) subdividir o mapa em células de tamanho fixo, formando uma grade, e extraindo regras dos documentos encontrados em cada célula, ou (ii) aplicar uma técnica de agrupamento (clustering) considerando a proximidade dos documentos no mapa, utilizando os diferentes grupos como entrada para a indução de regras. Ambas as estratégias introduzem uma variância não desejada no processo, pois diferentes escolhas para a grade ou resultados distintos da técnica de agrupamento produzem conjuntos de regras diferentes. Este problema é tratado repetindo-se o processo de indução com pequenas variações na grade utilizada ou com diferentes soluções de agrupamento. Esta abordagem, de múltiplo reinício (multiple restart), corresponde ao laço externo no Algoritmo 2. Novas regras obtidas a cada iteração são adicionadas ao conjunto de regras previamente induzidas. As iterações são repetidas até que o número de documentos que passam a ser cobertos por uma ou mais regras seja menor que um valor mínimo determinado, i.e., até que as novas regras não cubram novos documentos em quantidade suficiente para que se considere uma nova execução do algoritmo.

O particionamento por grade inicia com a subdivisão do mapa em $l$ linhas e $c$ colunas. A cada iteração do Algoritmo 2 os valores de $l$ e $c$ tanto podem ser incrementados (tipicamente acrescidos de um) quanto a grade pode ser deslocada. Deslocar a grade requer como parâmetro o número de deslocamentos des a serem realizados. Neste caso, a posição inicial da grade é então deslocada em $\frac{\text { des }}{\text { tamanho da célula }}$ em ambos os eixos. O deslocamento requer a inclusão de uma linha e uma coluna extras para garantir que a partição cubra todo o mapa. Quando adotado o 


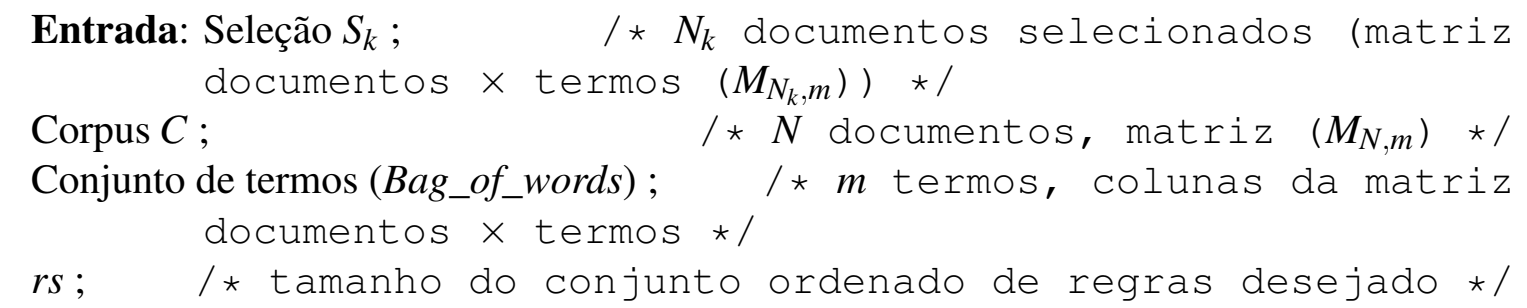

Saída: conjunto ordenado de regras $(S R)$

início

para cada termo $t_{j} \in$ Bag_of_words faça

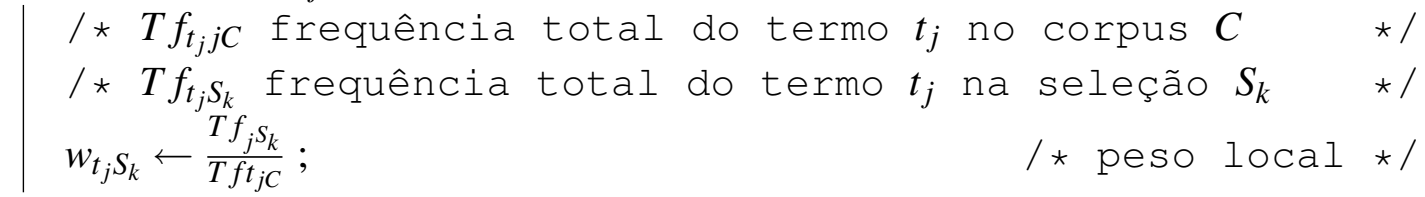

fim

Minsup $\leftarrow 50 \%$;

$S R_{S_{k}} \leftarrow \emptyset$;

I* subconjunto de regras */

$S D \leftarrow \emptyset ;$

I* sementes */

1 itemsets $\leftarrow \emptyset$;

2 itemsets $\leftarrow \emptyset$;

$n S D \leftarrow 10 ;$

I* número de sementes */

faça

para cada $t_{j} \in S_{k}$ faça

/* $\operatorname{Sup}\left(t_{j}\right)$ suporte de $t_{j}$ em $S_{k}$

1_itemsets $\leftarrow$ 1_itemset $s \cup\left\{t_{j} \in\right.$ Bag_of_words $\left.\mid \operatorname{Sup}\left(t_{j}\right)>\operatorname{MinSup}\right\}$;

fim

/* Selecione $n S D$ sementes ( $n S D$ termos $t_{j}$ entre os

1_itemsets com o maior $w_{t_{j} S_{k}}$ )

$S D \leftarrow\left\{t_{1}, \ldots, t_{n}\right\} ;$

2_itemsets $\leftarrow 2$ itemset $s \cup\left\{\left(t_{i}, t_{j}\right), i \neq j \mid\left(t_{i}, t_{j}\right) \in S D \times 1 \_i t e m s e t s\right\}$;

$S R_{S_{k}} \leftarrow$ Chamar Apriori para gerar regras com $2<$ número de termos $\geq m$;

se $S R_{S_{k}}=\emptyset$ então

MinSup $\leftarrow 0.75 *$ MinSup;

$n S D \leftarrow n S D+1$;

fim

enquanto $S R_{S_{k}}=\emptyset$ e MinSup $>=0.01$;

$S R \leftarrow \emptyset$;

para cada $A R_{i}=\left(t_{j 1} \leftarrow t_{j 2}, t_{j 3}, \ldots, t_{j m}\right) \in S R_{S_{k}}$ faça

$w_{A R_{i}} \leftarrow \sum_{t_{j} \in A R_{i}}\left(w_{t_{j} S_{k}}\right)$; / Peso da regra */

fim

$\operatorname{Sort}\left(S R_{S_{k}},-w_{A R}\right) ; \quad / \star$ Ordene $S R_{S_{k}}$ em ordem descrescente de $w_{A R}$ $* 1$

$S R \leftarrow\left\{A R_{1}, \ldots, A R_{r S}\right\} ;$

fim

retorna $S R$

Algoritmo 1: Geração e ordenação iterativa de regras de associação com peso local. 
deslocamento da grade como solução para o múltiplo reinício, o processo é necessariamente interrompido se o número selecionado de deslocamentos for atingido, já que novas grades seriam compostas de células coincidentes com células já antes analisadas. O algoritmo de agrupamento por $k$ médias ( $k$-means clustering) (Witten e Frank, 1999) foi adotado para particionar o mapa por agrupamento. Ele requer a definição de um valor inicial para o número de agrupamentos e o valor do incremento nesse número a cada iteração do Algoritmo 2. Em ambas as abordagens, um número máximo de agrupamentos é também definido. A definição de subconjuntos por um algoritmo de agrupamento é capaz de aproveitar a solução de posicionamento encontrada no mapa, como pode ser observado na demarcação dos dois agrupamentos isolados à direita na Figura 5.1. A divisão do espaço por uma grade, entretanto, tem baixo custo computacional.

Com o propósito de capturar não só os temas mais representativos do conjunto selecionado, mas também temas subjacentes, peculiares a alguns subgrupos de documentos, a seleção de regras considera também o conjunto de documentos cobertos, e não apenas a ordenação pelo somatório do peso local dos seus termos. Simultaneamente, a redundância no conjunto de regras é reduzida pois mantem-se apenas aquelas regras que proveem cobertura adicional, i.e., se duas regras cobrem o mesmo subconjunto de documentos, somente aquela com maior peso é mantida.

A seleção de regras no Algoritmo 1 resumia-se à seleção das $r s$ regras de maior peso. No Algoritmo 2, a seleção de regras inicia pela escolha da regra de maior peso. As demais regras são consideradas, em ordem decrescente de peso. Se a regra em questão cobre algum documento não coberto por quaisquer das regras previamente selecionadas, ela é também selecionada. Ao final deste passo, podem restar documentos não cobertos por quaisquer das regras. Neste caso, a extração de regras é repetida (laço interior no Algoritmo 2) tendo como entrada os documentos remanescentes, produzindo um conjunto diverso de regras, já que as sementes não devem ser as mesmas. A repetição acaba quando não restam documentos não cobertos ou nenhuma nova regra é extraída. Em seguida, o conjunto de regras induzidas para o subconjunto de documentos $S_{k}$ é acrescentado ao conjunto agregado de regras $A R S$. A função cobertura $\left(A R_{i}, U n\right)$ no Algoritmo 2 computa o número de documentos de $U n$ que suportam a regra $A R_{i}$.

A Figura 5.3 mostra parte de um mapa gerado para um corpus de 2.684 artigos jornalísticos disponibilizados na Internet em formato RSS pelas agências de notícias Reuters, BBC, CNN, e Associated Press. Estes artigos foram coletados durantes dois dias em Abril de 2006, e o conjunto de documentos resultante foi denominado corpus RSS. Tópicos foram extraídos dividindo-se o conjunto em agrupamentos e aplicando-se a técnica de indução seletiva de regras de associação. Termos dos tópicos foram adotados como etiquetas e exibidos no mapa.

Um cenário no qual muitas regras cobrem apenas uma pequena fração dos documentos pode indicar que estas regras estão redundantemente descrevendo alguns poucos temas. A 


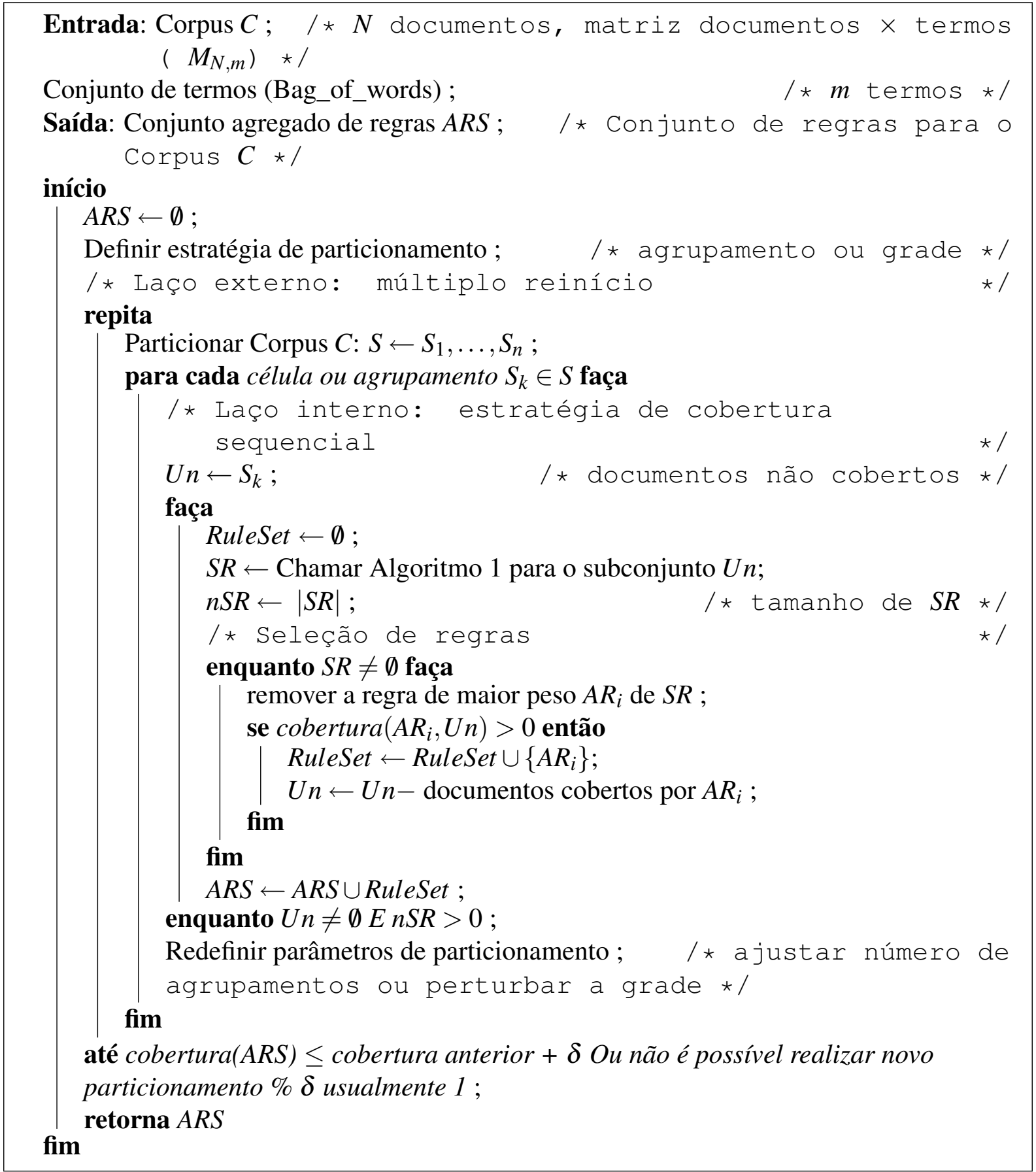

Algoritmo 2: Cobertura sequencial com múltiplos reinícios. 
Capítulo 5. Regras de associação com peso local para identificar tópicos em mapas de

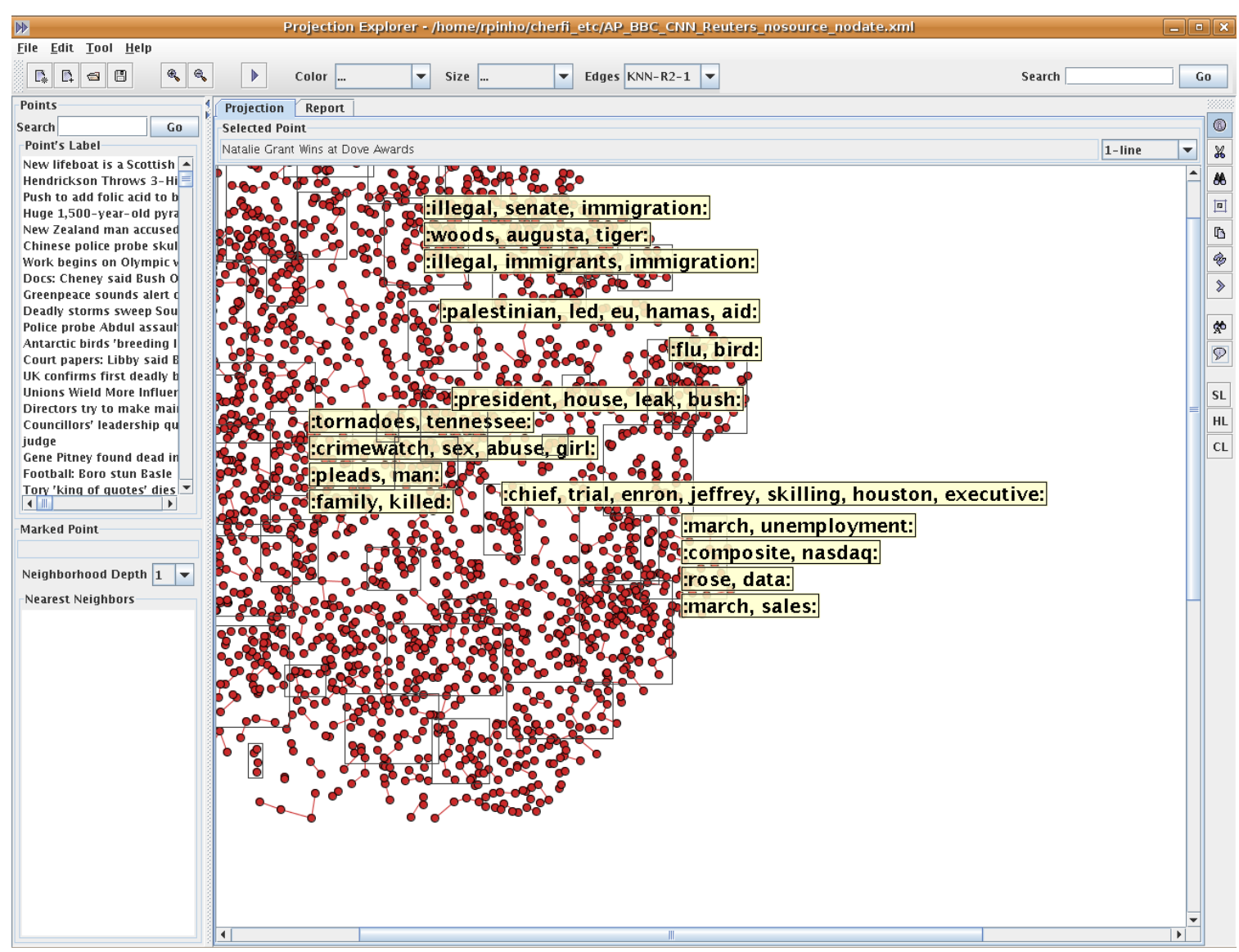

Figura 5.3: Visão parcial de um mapa de documentos para o corpus RSS, gerado no Projection Explorer e exibindo etiquetas com termos descritivos de tópicos.

redundância pode também ser percebida pela diversidade de termos contidos nas regras: poucos termos para um grande conjunto de regras indicaria alta redundância. Procura-se um conjunto reduzido de regras, com diversidade de termos e que seja capaz de descrever boa parte do conjunto de dados.

$\mathrm{Na}$ aplicação do Algoritmo 2, foram feitas três iterações, dividindo-se o corpus em 10, 60 e 110 agrupamentos, respectivamente. Na primeira iteração, 223 regras foram induzidas. A segunda interação somou 180 novas regras. A interação final adicionou 137 regras, totalizando 532 regras distintas. A cobertura do corpus acumulada para cada iteração foi de 47,2\%; 53,9\% e 55,6\%; respectivamente (Figura 5.4(a) . O conjunto completo de regras foi composto por 542 termos distintos.

O resultado da aplicação da técnica neste corpus foi comparado com o resultado da aplicação do algoritmo Apriori não modificado. Observou-se o total de regras geradas, o percentual de documentos do corpus cobertos por estas regras e o número de termos distintos encontrados nas regras. 
Ao aplicar o algoritmo Apriori não modificado, a confiança mínima foi fixada em $80 \%$ e o suporte mínimo foi variado, sendo reduzido para obter diferentes níveis de cobertura (Figura 5.4(b)]. A primeira extração, com suporte mínimo fixado em 13 transações, produziu 1.158 regras, cobrindo apenas $21,1 \%$ do corpus e incluindo apenas 113 termos distintos. Já a última extração, com suporte mínimo fixado em 3 transações, produziu 9.108.828 regras (2.028.917 conjuntos distintos de termos frequentes), cobrindo 72,6\% do corpus e incluindo 2.209 termos distintos. Obviamente, tal abordagem seria inadequada para rotular os mapas, em vista da qualidade e quantidade de regras.

A extração inicial induziu aproximadamente o dobro de regras que a indução seletiva, atigindo, porém, menos da metade da cobertura e incluindo um quinto da quantidade de termos distintos obtidos com a indução seletiva. Comparando os gráficos (a) e (b) da Figura 5.4, é possível notar que são necessárias em torno de 100 mil regras extraídas com o algoritmo clássico para atingir uma cobertura equivalente às 532 regras selecionadas pelo Algoritmo 2 . A Tabela 5.1 resume estes resultados.

Tabela 5.1: Tamanho, termos distintos, cobertura e suporte mínimo para conjuntos de regras extraídos do corpus RSS.

\begin{tabular}{|c|c|c|c|c|}
\hline Processo & Tamanho & Termos distintos & Cobertura & Suporte Mínimo \\
\hline Alg. 2 & $\mathbf{5 3 2}$ & 542 & $55,6 \%$ & n/a \\
\hline Apriori & 1.158 & 113 & $21,1 \%$ & 13 \\
\hline Apriori & 9.108 .827 & $\mathbf{2 . 2 0 9}$ & $\mathbf{7 2 , 6 \%}$ & 3 \\
\hline
\end{tabular}

Uma relativamente alta cobertura, como a obtida, poderia ser também atingida por tópicos compostos por termos genéricos, pouco descritivos dos temas, como, por exemplo, "referências" e "resumo" em uma coleção de artigos científicos. Porém, uma inspeção manual dos 532 tópicos extraídos não encontrou casos como este, com exceção de [percent, rate], que não aponta para nenhum tema específico e pode cobrir parte das notícias de economia. No entanto, apenas dez dos mais de dois mil documentos do corpus RSS incluem os termos percent e rate.

\subsection{Exploração de mapas com base em tópicos}

Para apoiar a exploração do mapa de documentos pelo usuário, os tópicos são exibidos como etiquetas que identificam áreas do mapa, sendo também exibidos em uma árvore (Figura 5.2). Os tópicos são derivados das regras de associação extraídas, cada um deles composto por um conjunto de termos que o descreve, e por um conjunto de documentos que o suporta, ou seja, documentos nos quais o conjunto de termos ocorre. Duas hierarquias alternativas são adotadas para a árvore. Uma reflete a generalização de conceitos por cobertura, i.e., um tópico 


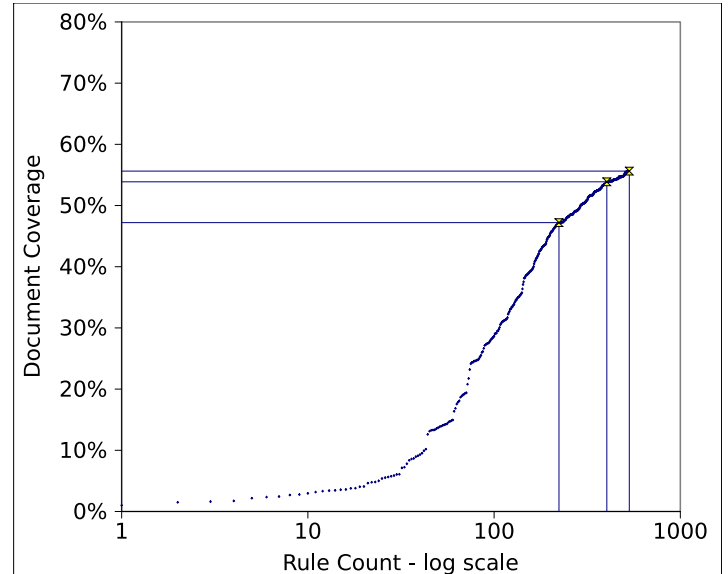

(a)

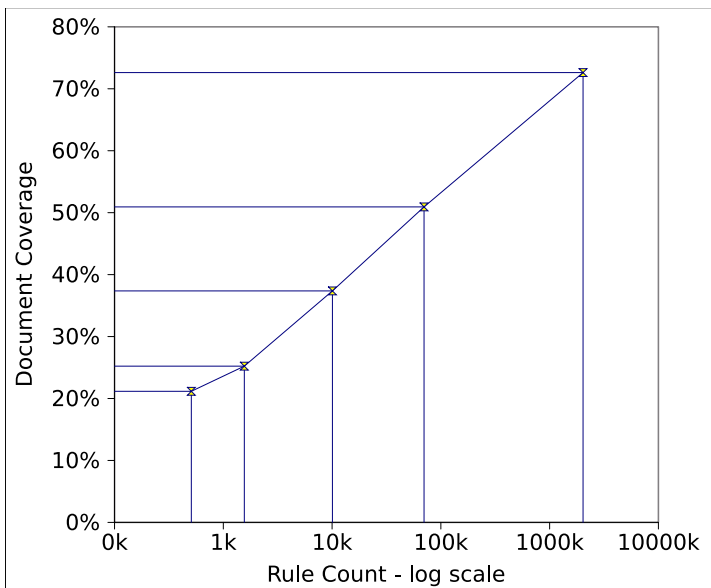

(b)

Figura 5.4: (a) Quantidade acumulada de regras $\times$ percentual de documentos cobertos para 3 iterações do Algoritmo 2 com 10, 60 e 110 agrupamentos. Marcadores foram adicionados no início e final de cada iteração. (b) Quantidade de regras induzidas $\times$ percentual de documentos cobertos na indução de 9.108 .828 regras (2.028.917 conjuntos distintos de termos frequentes) com diferentes valores de suporte mínimo usando o algoritmo Apriori sem modificações e confiança mínima fixada em $80 \%$. Marcadores indicam resultados para diferentes valores de suporte mínimo.

$T p_{B}$ associado ao conjuntos de documentos $D S_{T p_{B}}$ aparece como filho de um tópico $T p_{A}$ se $D S_{T p_{B}} \subseteq D S_{T p_{A}}$. A hierarquia alternativa reflete uma relação de generalização entre tópicos dada pela relação entre os conjuntos de termos que os descrevem, i.e., um tópico $T p_{B}$ descrito por um conjunto de termos $T_{T p_{B}}$ é filho de um tópico $T p_{A}$ se $T_{T p_{B}} \supseteq T_{T p_{A}}$, sendo $T_{T p_{B}}$ mais específico que $T_{T p_{A}}$. Em ambos os casos, tópicos que cobrem mais documentos, tipicamente mais genéricos e com menos termos, aparecem mais próximos à raiz da árvore, conquanto tópicos mais específicos são posicionados mais abaixo na hierarquia. Documentos associados aos tópicos são acrescentados como folhas na árvore, abaixo dos respectivos tópicos.

Os usuários podem ordenar os nós da árvore tanto por suporte quanto alfabeticamente, neste caso considerando o primeiro termo do tópico. A ordenação se dá independentemente a cada nível da árvore. Também está disponível a possibilidade de localizar tópicos por termos e exportar a árvore de tópicos para um arquivo em formato XML. Quando o usuário seleciona um tópico ou grupo de tópicos na árvore, documentos relacionados são destacados no mapa de documentos, o que auxilia a identificar áreas de interesse no mapa. Um duplo clique sobre um tópico abre uma janela mostrando o conteúdo de todos os documentos que o suportam. Documentos que suportam tópicos selecionados também podem ser exportados para que sejam analisados manualmente ou por outras ferramentas. 
Também é possível remover do mapa alguns tópicos e/ou documentos relacionados. Uma vez que tópicos/documentos indesejados tenham sido removidos, é possível construir um novo mapa com os documentos remanescentes. Opcionalmente, a construção pode utilizar o conjunto de termos dos tópicos como a bag-of-words do modelo de espaço vetorial usado para determinar a similaridade entre documentos. A utilização destes termos, considerados relevantes, pode melhorar o processo de construção mapas, como ilustrado nos estudos de caso apresentados na Seção 5.4

Duas visualizações complementares, em formato de matriz de similaridade, apoiam a comparação e a análise de tópicos pelos usuários. Na visualização de similaridade entre tópicos (Figura 5.5), cada célula da matriz, identificada por uma linha $l$ e coluna $c$ representa o grau de sobreposição entre os conjuntos de documentos relacionados com dois tópicos $T p_{l}$ e $T p_{c}$. A cor da célula reflete o coeficiente de Jacquard para o conjuntos $D S_{T p_{l}}$ e $D S_{T p_{c}}$ que suportam os tópicos $T p_{l}$ e $T p_{c}$, i.e., conjuntos de documentos cobertos pelas respectivas regras:

$$
j \operatorname{coef}\left(T p_{l}, T p_{c}\right)=\frac{\left|D S_{T p_{l}} \cap D S_{T p_{c}}\right|}{\left|D S_{T p_{l}} \cup D S_{T p_{c}}\right|}
$$

Já a visualização de similaridade por documentos (Figura 5.6) compara diretamente o conteúdo de cada documento dos conjuntos que suportam os tópicos em análise. A diferença em relação à visualização anterior é que uma célula na linha $l$ e coluna $c$, associadas aos tópicos $T p_{l}$ e $T p_{c}$, respectivamente, ao invés de apresentar um único valor $\left(j \operatorname{coe} f\left(T p_{l}, T p_{c}\right)\right.$ ), contém uma submatriz. Esta submatriz traz os documentos $D S_{T p_{l}}$ associados ao tópico $T p_{l}$ como linhas e os documentos os documentos $D S_{T p_{c}}$ associados ao $T p_{c}$ como colunas. Assim, uma célula de uma dessas submatrizes apresenta a dissimilaridade entre o conteúdo de dois documentos $\delta\left(D_{i}, D_{j}\right), D_{i} \in D S_{T p_{l}}, D_{j} \in D S_{T p_{c}}$. Nesta visualização, documentos podem aparecer mais de uma vez, .i.e., em mais de uma linha ou coluna, se eles suportam múltiplos tópicos. Agora, a cor da célula reflete a similaridade entre o conteúdo dos dois documentos, de acordo com a mesma medida de similaridade adotada na construção do mapa.

Apesar de visualmente similares, estas representação se complementam. A células da diagonal são sempre pretas na visualização de similaridade entre tópicos ( $j \operatorname{coe} f\left(T p_{l}, T p_{c}\right)=$ $1 \mid l=c$ ), uma vez que avalia-se a sobreposição de um conjunto de documentos com ele mesmo. No entanto, na visualização de similaridade por documentos, a comparação se dá documento a documento, e uma diagonal em preto ocorre em cada submatriz da diagonal principal, quando documentos são comparados com eles mesmos. No entanto, estas submatrizes que comparam os documentos de um tópico com eles mesmos podem apresentar-se como uma região mais escura, se os documentos que relacionam-se com o tópico são altamente similares em conteúdo, mas também podem resultar em uma região mais clara. Resultados empíricos mostraram que tópicos 
compostos por termos genéricos ou pouco informativos são frequentemente representados por áreas bem claras. Adicionalmente, pode-se eventualmente encontrar dois tópicos que compartilham poucos documentos, e portanto têm um baixo coeficiente de Jacquard quando comparados, mas cujo conteúdo dos seus respectivos documentos associados é de fato semelhante. Tais casos seriam representados por uma célula branca ou muito clara na primeira visualização, enquanto a segunda mostraria algumas áreas ou faixas escuras na submatriz, na qual conjuntos de documentos similares relativos a cada tópico se encontrassem.

\subsection{Estudos de caso}

São descritos dois estudos de caso que ilustram como a solução proposta pode apoiar um processo de análise de coleções de documentos centrado no usuário.

O primeiro estudo foi conduzido sobre o corpus RSS. Palavras comuns (stop words) foram removidas e foram aplicados cortes de Luhn para selecionar termos relevantes com base na sua frequência no conjunto.

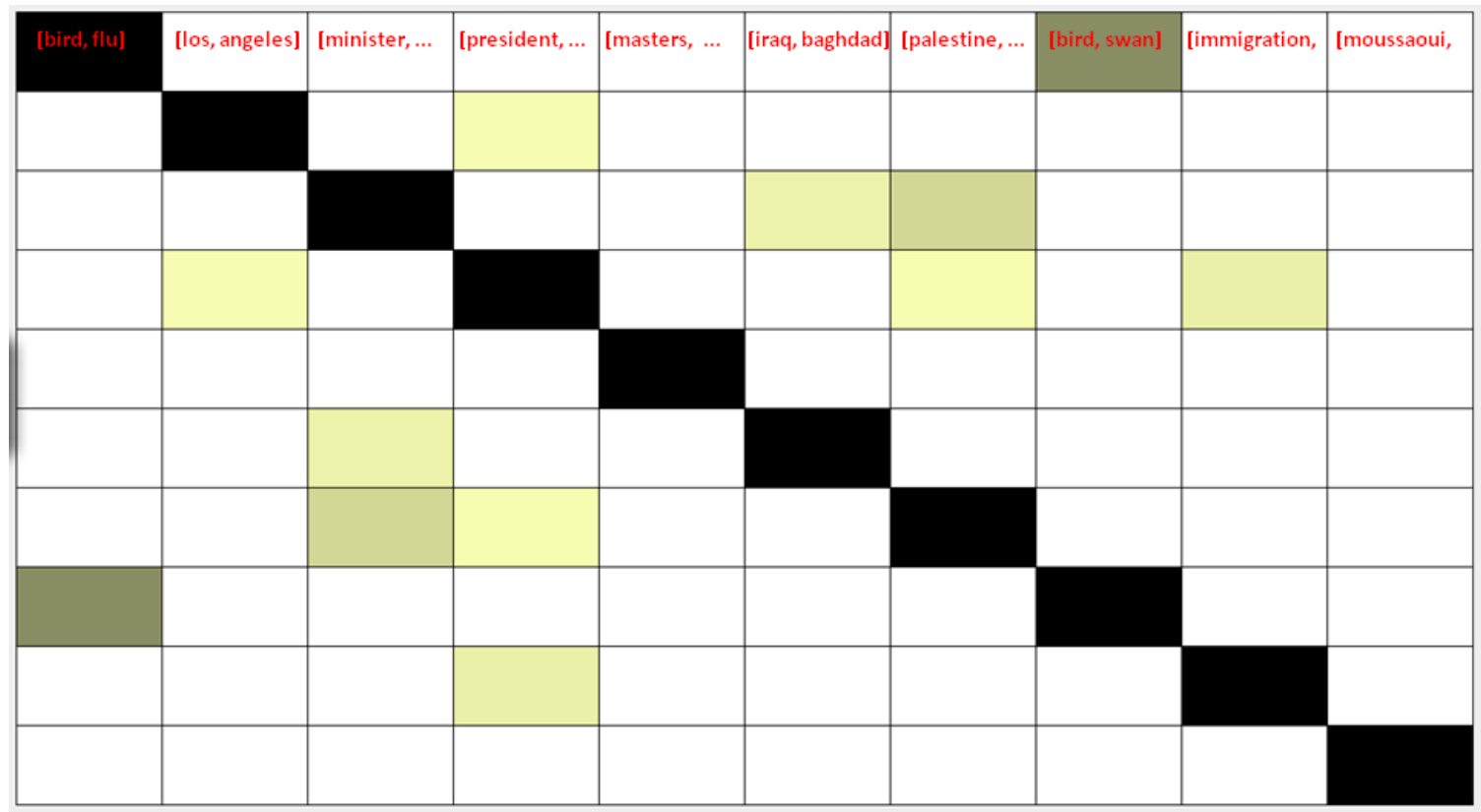

Figura 5.5: Visualização de similaridade entre tópicos para os tópicos [bird, flu] até [moussaoui, zacarias] da Figura 5.7. Cores mais escuras denotam maiores coeficientes de similaridade, e, portanto, maior compartilhamento de documentos entre tópicos.

Ilustramos uma tarefa de usuário em que o objetivo é identificar os três eventos noticiádos de forma mais intensa neste bastante diverso conjunto de documentos. A exploração seguiu os seguintes passos: 


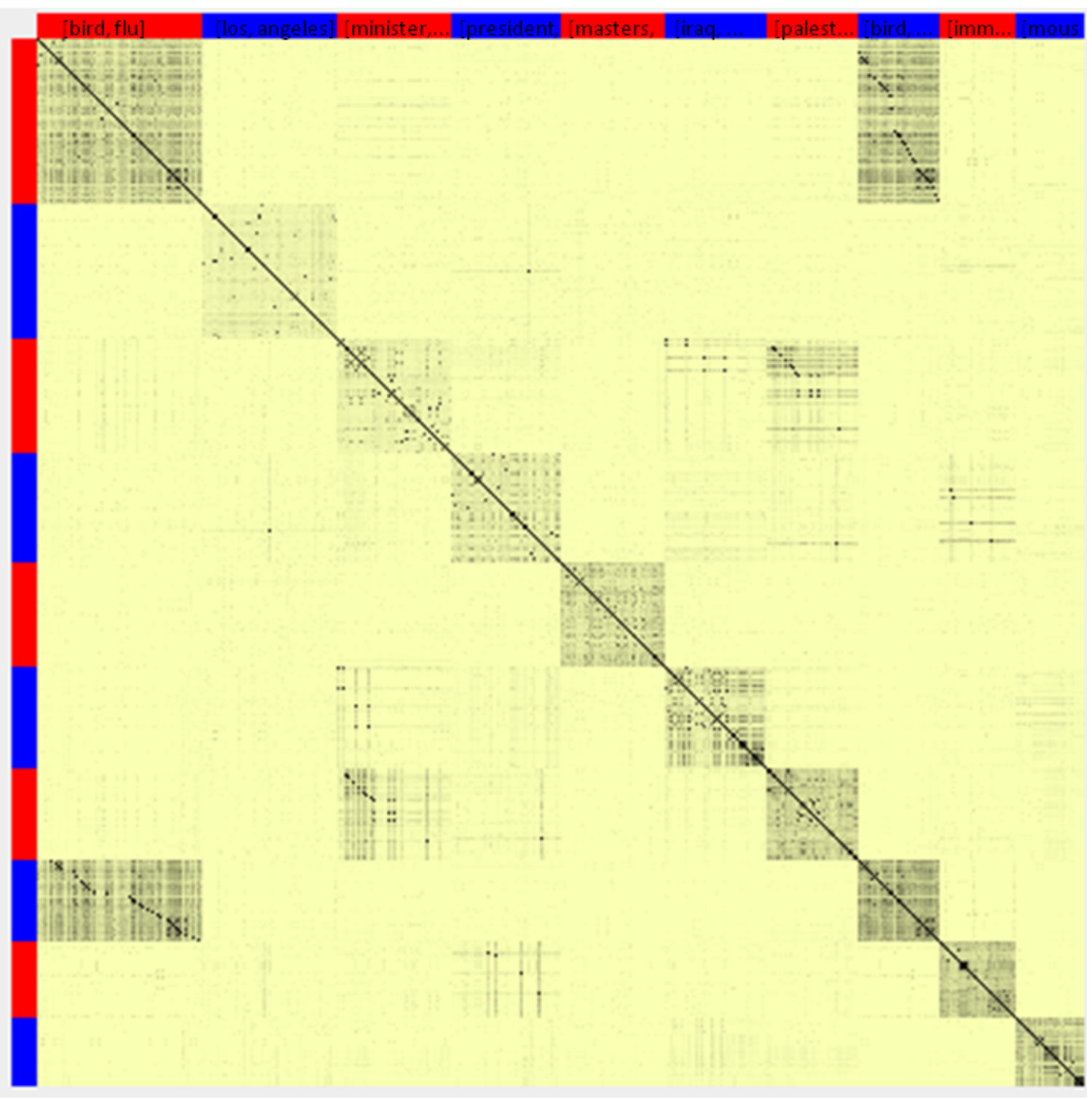

Figura 5.6: Visualização de similaridade por documentos para os tópicos [bird, flu] até [moussaoui, zacarias] exibidos na árvore da Figura 5.7. Cores mais escuras denotam maior similaridade entre documentos.

1. Construção do mapa, usando a medida de distância por cossenos e a projeção ProjClus;

2. Extração de tópicos. Tópicos foram induzidos para todo o mapa com o algoritmo $L W R$ descrito na Seção 5.2, tendo sido selecionada a técnica de agrupamento para a aplicação da estratégia de múltiplo reinício (resultados parciais na Figura 5.7). Os números inicial e máximo de agrupamentos foram fixados em 17 e 189, respectivamente, com um incremento de 86. Estes valores foram escolhidos com base em estudos anteriores, em que notou-se que valores próximos a $\sqrt{N}$ usualmente produziam bons resultados. O processo 


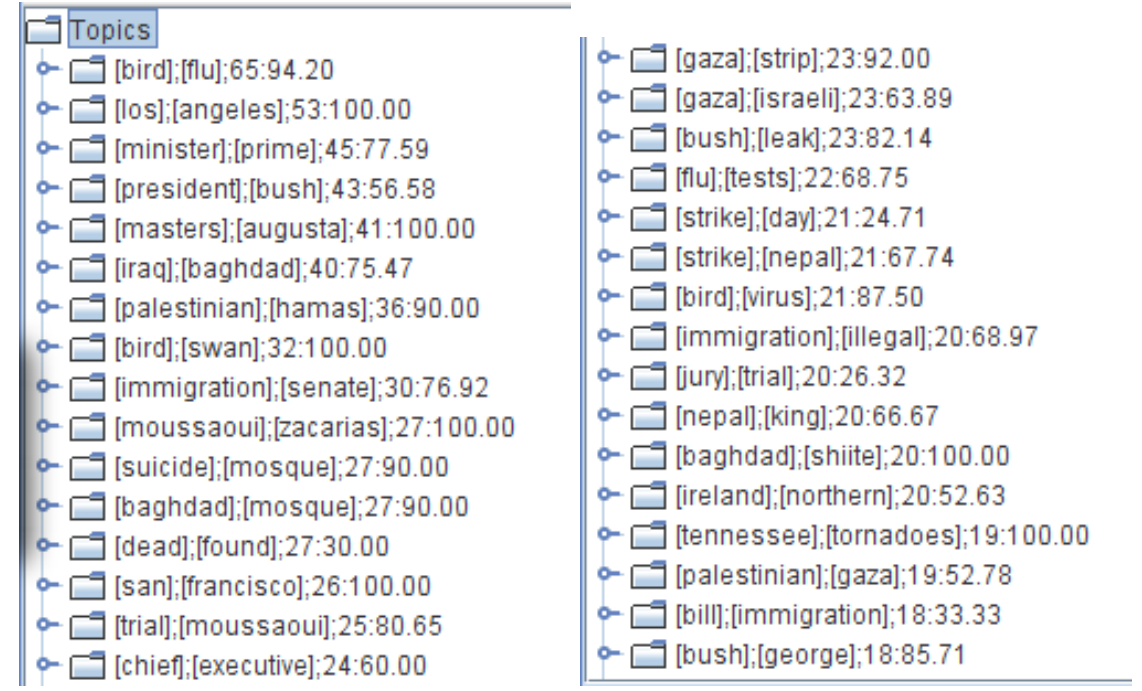

Figura 5.7: Visão parcial da árvore de tópicos do corpus RSS, ordenada por suporte. Os primeiros elementos são mostrados.

teve 3 iterações. Um total de 552 tópicos foram extraídos e exibidos na topic tree. 1.317 documentos (49\%) não foram cobertos por nenhum dos tópicos identificados. O valor mínimo absoluto de suporte foi definido em três documentos;

3. Análise de tópicos centrada no usuário. Esta tarefa foi dividida em duas: (i) remoção de tópicos irrelevantes, e, em alguns casos, dos documentos relacionados e (ii) generalização de tópicos por meio da fusão de tópicos similares. Na fusão de tópicos, um novo tópico é gerado, em substituição a tópicos selecionados. O conjunto de documentos associados ao novo tópico é formado pela união dos conjuntos de documentos associados aos tópicos selecionados. O mesmo ocorre com o conjunto de termos do tópico resultante;

4. Reconstrução do mapa. Um novo mapa é gerado apenas com os documentos relacionados aos tópicos selecionados.

A análise de tópicos centrada no usuário seguiu o seguinte rotina: iterativamente, foram inspecionados os 10 ou 20 tópicos de maior suporte, analisando as matrizes de similaridade e verificando a distribuição de documentos relacionados no mapa - documentos espalhados pelo mapa sinalizariam tópicos pouco informativos. Após cada inspeção, tópicos poderiam ser fundidos, se similares, ou simplesmente removidos, se considerados pouco significativos. Em alguns casos, títulos de artigos associados ao tópicos foram inspecionados.

A figuras 5.5 e 5.6 apresentam as matrizes de similaridade para os dez tópicos de maior suporte inicialmente extraídos (Figura 5.7). Na visualização de similaridade entre tópicos, é possível observar que os tópicos [bird, flu] $\left(1^{\circ}\right)$ e [bird, swan] $\left(8^{\circ}\right)$ são fortemente relacionados, 
o que é confirmado na visualização de similaridade por documentos pela presença de linha diagonal de píxeis pretos nas submatrizes que comparam os dois tópicos, indicando a presença de muitos documentos em comum. Sendo assim, os dois tópicos foram fundidos, gerando o tópico [bird, flu, swan]. Também na visualização de similaridade por documentos é possível observar que documentos que suportam o tópico [los, angeles] $\left(2^{\circ}\right)$ não são tão similares entre si quanto aqueles que suportam [bird, flu] $\left(1^{\circ}\right)$, uma vez que a área resultante da comparação dos documentos relacionados ao tópico [los, angeles] com eles mesmos é mais clara que a área que compara os documentos de [bird, flu] entre si. Uma inspeção dos títulos dos documentos mostrou que "Los Angeles" é meramente o local de ocorrência de muitos eventos desconexos, assim, o tópico foi removido.

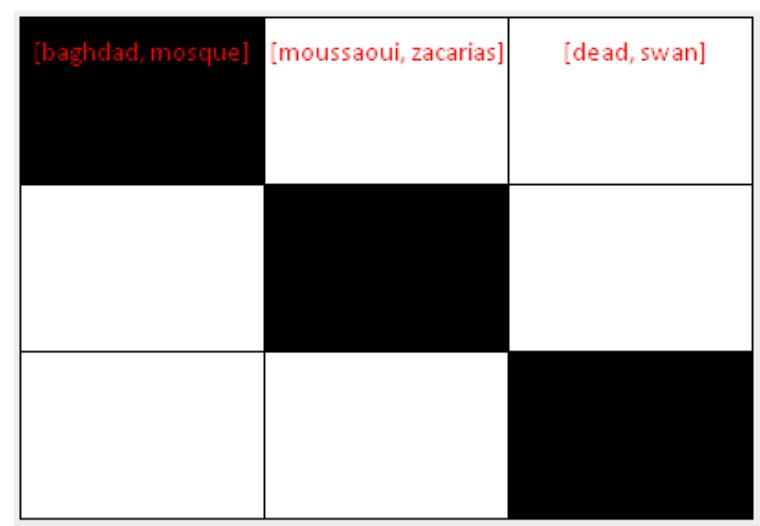

(a)

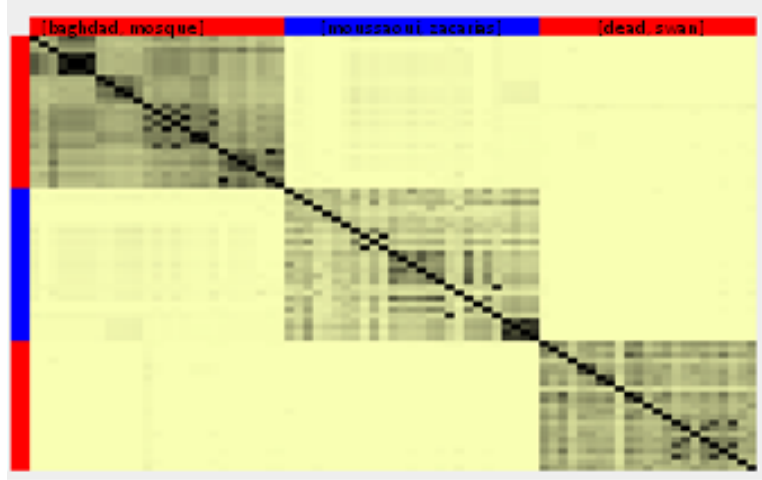

(b)

Figura 5.8: Comparação entre os tópicos [baghdad, mosque], [moussaoui, zacarias] e [dead, swan]

Os tópicos [baghdad, mosque] e [moussaoui zacarias] não cobrem nenhum ou cobrem muito poucos documentos em comum (Figura 5.8(a)], ainda assim são, de certa forma, relacionados, e seus respectivos documentos têm conteúdos similares. Nota-se, na Figura 5.8(b), como as células que comparam os conjuntos de documentos destes dois tópicos (células $(1,2)$ ou $(2,1)$ ) possuem áreas mais escuras do que as células que comparam estes dois tópicos com [dead, swan] (células $(3,1),(3,2),(1,3),(2,3)$ ). Após algumas fusões e remoções, o três tópicos de maior suporte passaram a ser [bird, flu, swan, dead, found,tests], [palestinian, hamas, gaza, strip, israeli], e [iraq, baghdad, suicide, mosque]. Para encontrar outros tópicos relacionados, tópicos que compartilhassem pelo menos um termo com um destes três foram comparados usando as matrizes de similaridade. Novamente, se similares na avaliação do analista, eles foram combinados, resultando nos seguintes tópicos: [bird, flu, swan, dead, found, tests, virus], [palestinian, hamas, gaza, strip, israeli, shot, murdered, soldier, cameraman, jury, british], e [iraq, baghdad, suicide, mosque, shiite, affiliated, bomb, bombers]. 
Finalmente, um novo mapa foi produzido, contendo apenas documentos relacionados aos tópicos principais, no qual os documentos relacionados com cada tópico foram naturalmente posicionados em diferentes regiões. Um novo conjunto de tópicos foi extraído, revelando outros aspectos dos tópicos principais. Por exemplo, o subtópico [mosque,bombers,women] reportava-se ao fato de que um ataque suicida a uma mesquita no Iraque, evento central do terceiro tópico principal, foi realizado por terroristas disfarçados de mulher. A Figura 5.9(a) mostra o mapa original, mantidos apenas os documentos relacionados aos tópicos principais. Os agrupamentos destacados em amarelo contêm notícias acerca da gripe aviária. Os documentos relacionados com o Iraque (verde) e a Palestina (cinza) também encontram-se espalhados pelo mapa. Já no novo mapa (Figura 5.9(b)), documentos sobre a gripe aviária encontram-se no canto inferior direito (amarelo), documentos sobre o ataque suicida no Iraque concentram-se no topo do mapa (em verde), e documentos sobre a Palestina estão posicionados à esquerda (em cinza). No segundo mapa, as arestas ligam os vizinhos mais próximos de cada elemento. Analisando-se as arestas e o posicionamento de elementos no novo mapa, é possível notar que: (i) entre o agrupamento mais ao topo (Iraque) e o agrupamento mais à esquerda (Palestina), existe uma série de documentos interconectados, formando uma gradual passagem de um tema ao outro, o que é esperado, já que ambos, Iraque e Palestina, estão localizados no Oriente Médio, apresentam problemas semelhantes e são frequentemente associados na mídia; (ii) existem alguns poucos documentos aparentemente mal posicionados, como os documentos relacionados ao Iraque que encontram-se entre os documentos relacionados com a gripe aviária (pequeno agrupamento em verde, próximo às áreas amarelas, ligado a documentos no topo do mapa); (iii) há melhoria expressiva no agrupamento das notícias relacionadas à gripe aviária (em amarelo).

O segundo estudo foi realizado com uma coleção de 574 artigos científicos, utilizando apenas títulos, resumos e referências. Ele é um subconjunto do corpus CBR-ILP-IR-SON apresentado no Capítulo 4. Os artigos foram manualmente classificados em uma de três categorias: raciocínio baseado em casos (Case based reasoning - CBR), Programação Lógica Indutiva (Inductive logic programming - ILP) e recuperação de informação (Information retrieval - IR). Este corpus foi denominado CBR-ILP-IR e foi processado da mesma maneira que o corpus RSS.

Como pode ser notado na Figura 5.1, o mapa é capaz de separar visualmente os documentos de cada classe. No entanto, a classificação manual dos documentos foi uma tarefa árdua, que, sem o auxílio de ferramentas automatizadas, requer a leitura de todos os documentos e a atribuição de uma classe a cada um deles.

Este segundo caso ilustra como a aplicação do processo de exploração baseado em tópicos aqui proposto pode permitir ao usuário capturar o conteúdo de um conjunto de documentos, ao mesmo tempo que produz uma relação de tópicos da coleção que aproxima-se de classes que 


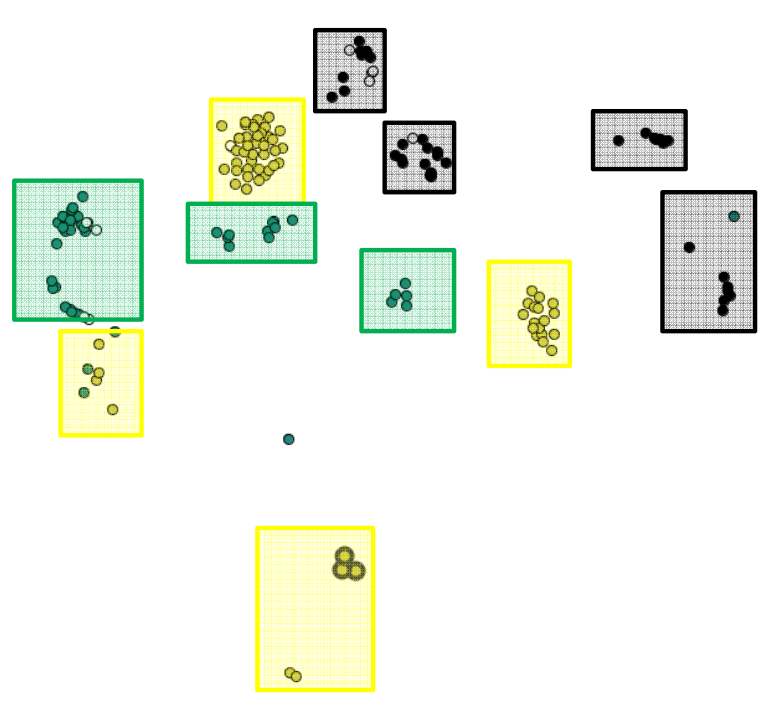

(a)

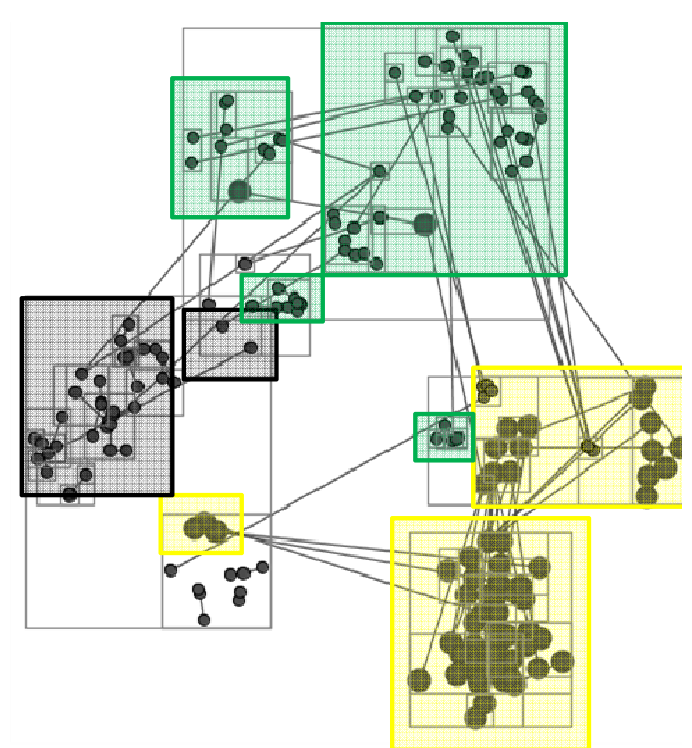

(b)

Figura 5.9: Exemplo de construção de novo mapa com documentos remanescentes após a exploração com base em tópicos. Mapa original incluindo apenas os documentos remanescentes (a) e novo mapa, gerado com o esse mesmo conjunto de documentos (b). As areas destacadas em vermelho contêm notícias relacionadas com o tópico $[$ bird, flu].

foram manualmente elaboradas, sem o esforço de examinar cada um dos artigos. Durante a realização da tarefa, ao contrário do que ocorre na Figura 5.1. os glifos não foram coloridos por classe, a fim de reproduzir um cenário em que uma classificação prévia não estivesse disponível.

Um usuário familiarizado com as áreas de pesquisa cobertas pelo corpus explorou o conjunto seguindo o mesmo processo desenhado para o estudo de caso anterior, embora ele estivesse livre para concentrar-se em tópicos da árvore que chamassem a sua atenção. Seguindo evidências da visualização de similaridade entre tópicos, ele notou que os tópicos [muggleton, raedt], [muggleton, ilp], [muggleton, entailment], e [muggleton, order] cobriam conjuntos similares de documentos. Assim, ele os combinou no tópico [muggleton, ilp], nome com o qual decidiu etiquetar o novo tópico. A comparação deste novo tópico com os tópicos [ilp, raedt], [induction, raedt] e [raedt, dzeroski] levaram à formação de um novo tópico agregado, a que ele deu o nome [inductive logic programming], sabendo que Raedt, Muggleton e Dzeroski são importantes autores desta área de pesquisa e após a inspeção de alguns dos documentos.

Este tópico de alto nível foi, então, comparado com a classificação manual existente, com resultados bastante satisfatórios: o tópico é suportado por 116 documentos, 114 dos quais previamente classificados como ILP. A classe ILP tem um total de 119 documentos. Apenas 5 documentos da classe não foram cobertos pelo tópico. Na Figura 5.1 documentos cobertos 
pelo tópico agregado [inductive logic programming] são mostrados com bordas mais largas, praticamente sobrepondo-se aos documentos pertencentes à classe ILP ( em verde).

\subsection{Mineração visual e identificação de tópicos em ma- pas dinâmicos de documentos}

A integração dos algoritmos de posicionamento incremental de elementos e de extração de tópicos reque mais do que a simples aplicação de ambos a um mesmo conjunto de dados. Adaptações foram introduzidas no algoritmo $L W R$ que viabilizam uma solução em que ambos os algoritmos operam sobre o mesmo espaço. A solução apresentada neste capítulo representa um esforço preliminar, de natureza exploratória, cuja principal contribuição é fornecer uma perspectiva para a construção de uma solução mais robusta.

Tais adaptações têm como foco contemplar a natureza dinâmica dos dados. O algoritmo $L W R$ opera sobre subconjuntos de dados, assim, neste novo contexto, soluções de agrupamento voltadas para o tratamento de fluxos de dados (data streams), como, o algoritmo GenIc (Gupta e Grossman, 2004), são candidatas naturais para a tarefa. No entanto, sem a pretensão de desenvolver uma solução de aplicação geral, propõe-se uma estratégia de atualização incremental para agrupamentos que tem como principal viés a distribuição de elementos no mapa. Embora a adoção de soluções previamente desenvolvidas e validadas requeira menos esforço, a solução adotada investiga potenciais caminhos para integrar os algoritmos de posicionamento e de identificação de tópicos.

Uma vez que a extração de tópicos é tarefa custosa, torna-se inviável refazer todo o processo sempre que o conjunto de dados é alterado. Assim, são adotadas medidas que permitam uma atualização gradual da lista de tópicos associada um mapa.

Por outro lado, deixa de ser necessário construir mapas derivados com elementos que tenham sobrevivido ao processo de análise por tópicos descrito na Seção 5.3, uma vez que a atualização do mapa a fim de refletir a eliminação de elementos já está contemplada pelo próprio algoritmo de posicionamento, o incBoard.

\subsubsection{Estratégia de atualização incremental de agrupamentos}

Agrupamentos são necessários ao processo de extração de tópicos. Em um cenário de análise exploratória de um conjunto dinâmico, dada uma solução inicial de agrupamentos, busca-se atribuir novos elementos aos agrupamentos existentes, e, eventualmente, redistribuir elementos entre agrupamentos, levando em consideração a distribuição de elementos no mapa. 
Inicialmente, tanto elementos quanto células são associados a um agrupamento. Sempre que um elemento é movido, sua atribuição é re-avaliada, bem como o agrupamento da célula para a qual o elemento foi movido.

Se tanto o elemento movido quando a célula de destino pertencem ao mesmo agrupamento, nada é feito. Neste caso, considera-se que houve apenas um re-arranjo no interior do agrupamento. Se, no entanto, eles pertencem a agrupamentos distintos, compara-se o elemento com as duas opções de agrupamento, selecionando-se a mais adequada. Esta avaliação é dependente da solução inicial de agrupamento escolhida. Na aplicação desenvolvida, que utiliza o $k$-means para gerar uma solução inicial de agrupamento, os centróides são atualizados a cada alteração na composição dos agrupamentos e a distância entre centróides e elementos é adotada quando é preciso decidir o agrupamento mais adequado para um dado elemento.

Elementos recém adicionados ao conjunto de dados, no entanto, não possuem um agrupamento associado. Neste caso, avalia-se o agrupamento da célula na qual o elemento é inserido e também os agrupamentos de suas células vizinhas.

Tanto em um caso como no outro, o agrupamento escolhido passa a ser associado tanto com o elemento como com a célula destino. Para escolha do agrupamento é calculada a distância (dissimilaridade) entre o elemento inserido e o centróide do agrupamento. Sempre um elemento é inserido ou removido de um agrupamento, seu centróide é atualizado.

Esta estratégia claramente associa a solução de atualização de agrupamentos com o posicionamento de elementos no mapa. Por exemplo, se um elemento é adicionado em uma região do mapa onde só se encontram elementos de um único agrupamento, este agrupamento será o único considerado. A mudança de uma célula de um agrupamento a outro se dá em duas ocasiões: (i) ela assume o agrupamento de um dos seus vizinhos, como resultado da chegada de um elemento sem atribuição, ou (ii) ela assume o agrupamento de um elemento que foi para ela movido. Em ambos os casos, a célula adota o agrupamento de um de seus vizinhos, favorecendo a atribuição de agrupamentos de acordo com a distribuição de elementos no mapa. Na Figura 5.10, elementos do agrupamento denotado pelos triângulos amarelos encontram-se inicialmente espalhados pelo mapa, porém, no mapa final notam-se que os documentos dos quatros agrupamentos concentram-se em regiões específicas do mapa.

A adoção de tais restrições, por um lado, faz com que eventuais soluções ótimas sejam desconsideradas, por outro, leva em consideração a solução encontrada pelo algoritmo de projeção. Seria, portanto, uma solução híbrida de agrupamento dos elementos projetados, que tanto considera o espaço conceitual original, ao comparar elementos com centróides usando medidas de similaridade definidas neste espaço, como também considera a configuração do espaço projetado para restringir as possíveis escolhas. 


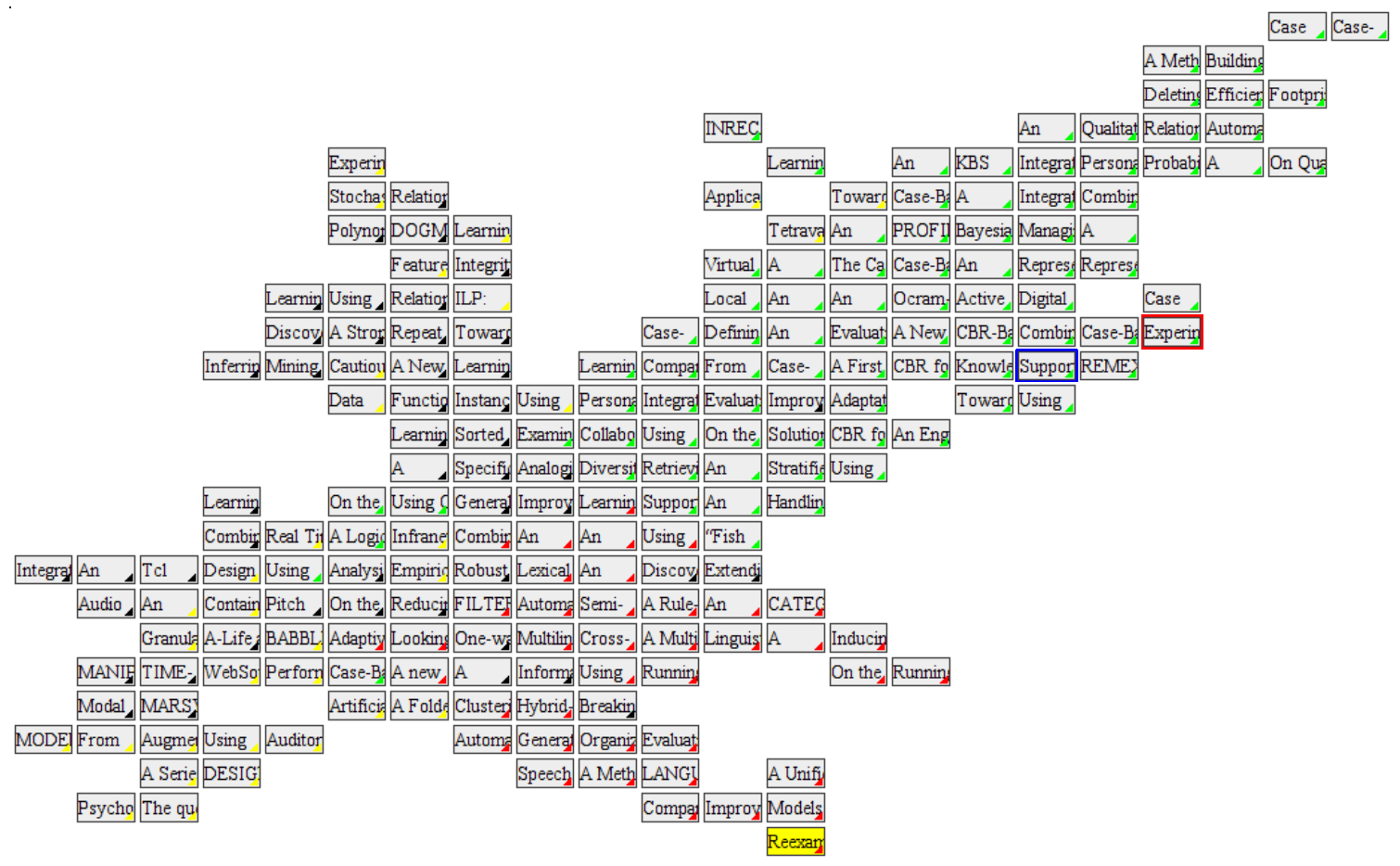

(a)

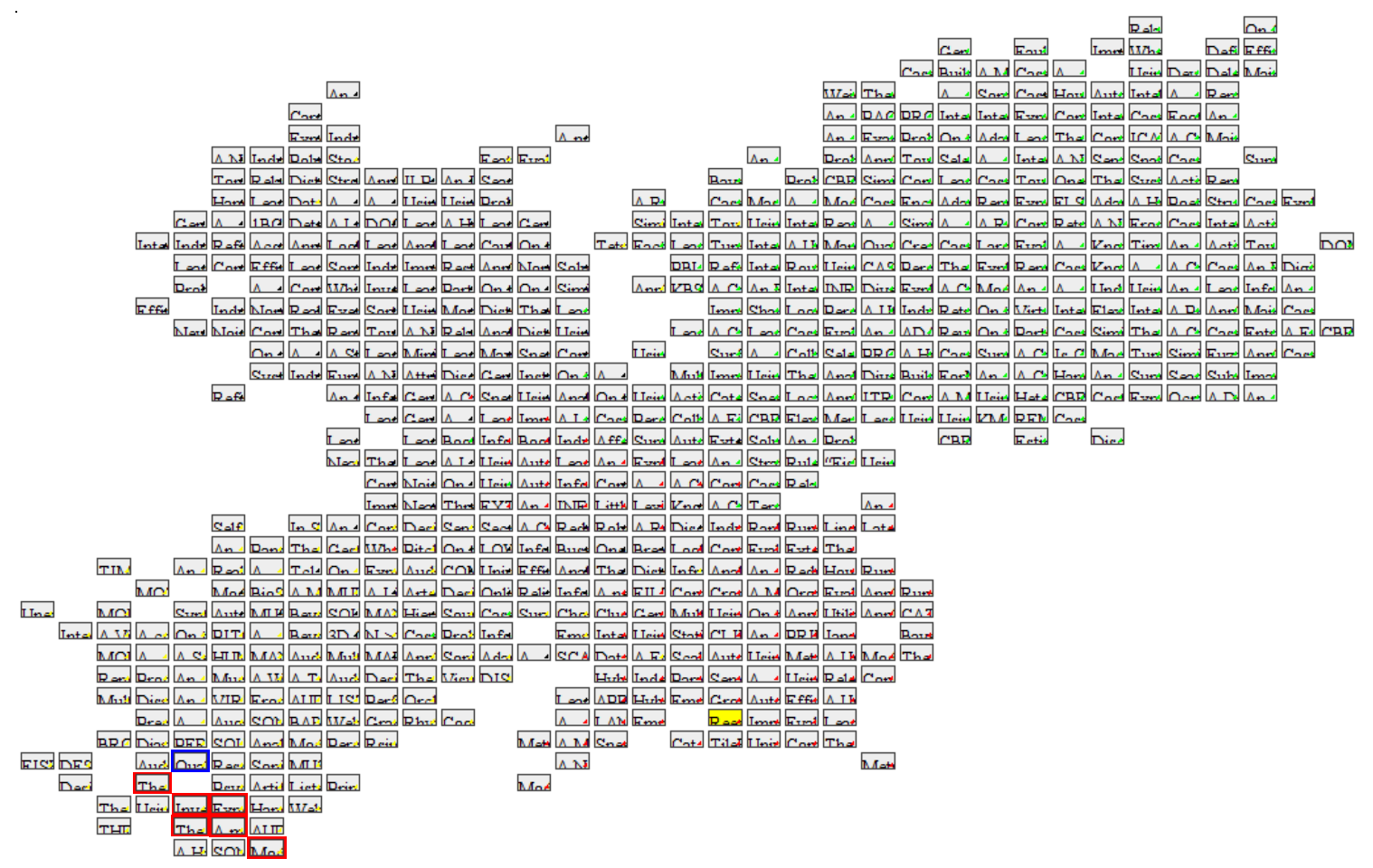

(b)

Figura 5.10: Exemplo de resultado de atualização incremental de agrupamentos para o corpus

CBR-ILP-IR-SON. O triângulo colorido no interior de cada célula denota o resultado do agrupamento. Agrupamento inicial, obtido por k-means sobre 207 documentos (a) e mapa final com 675 (b). 


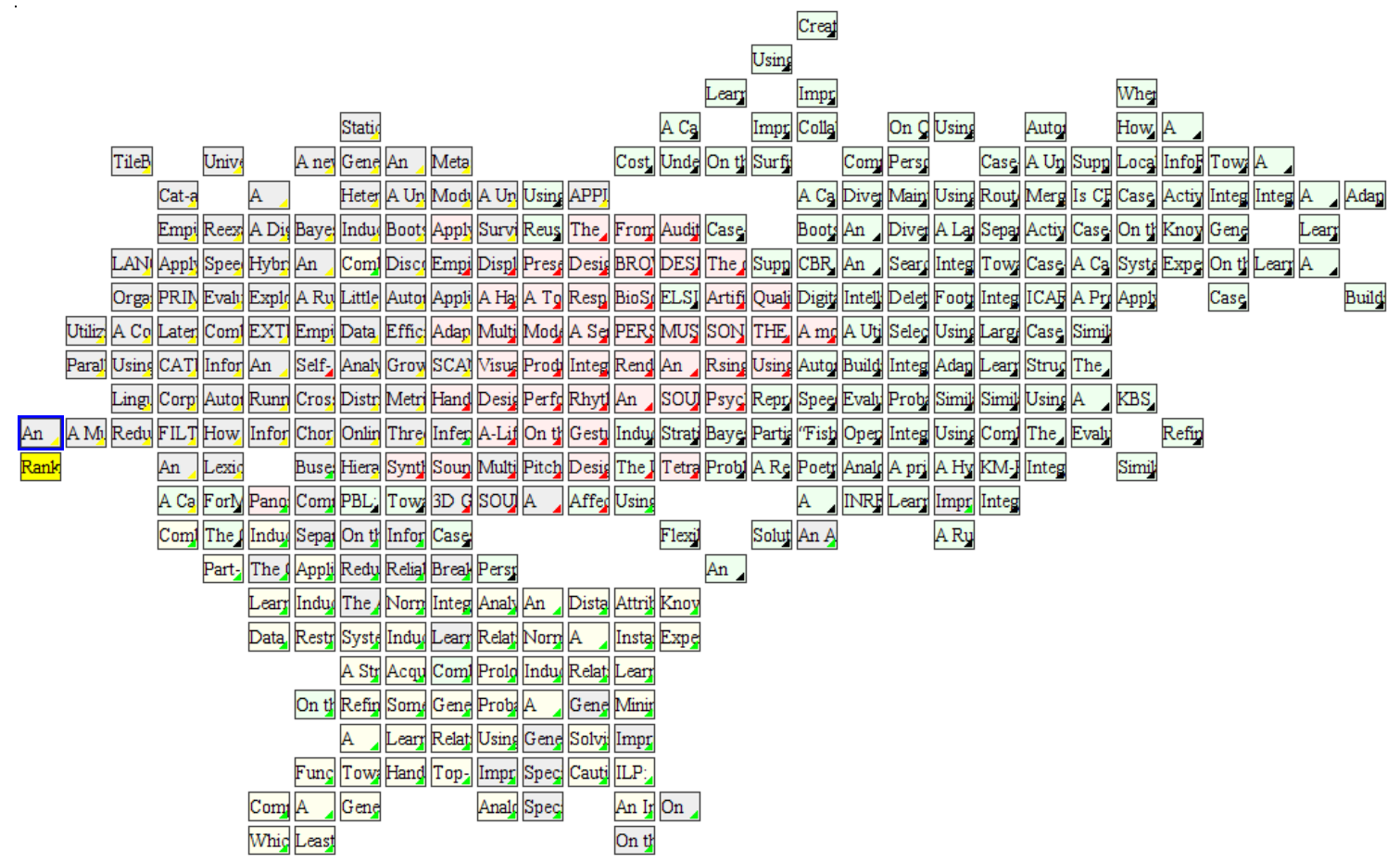

(a)

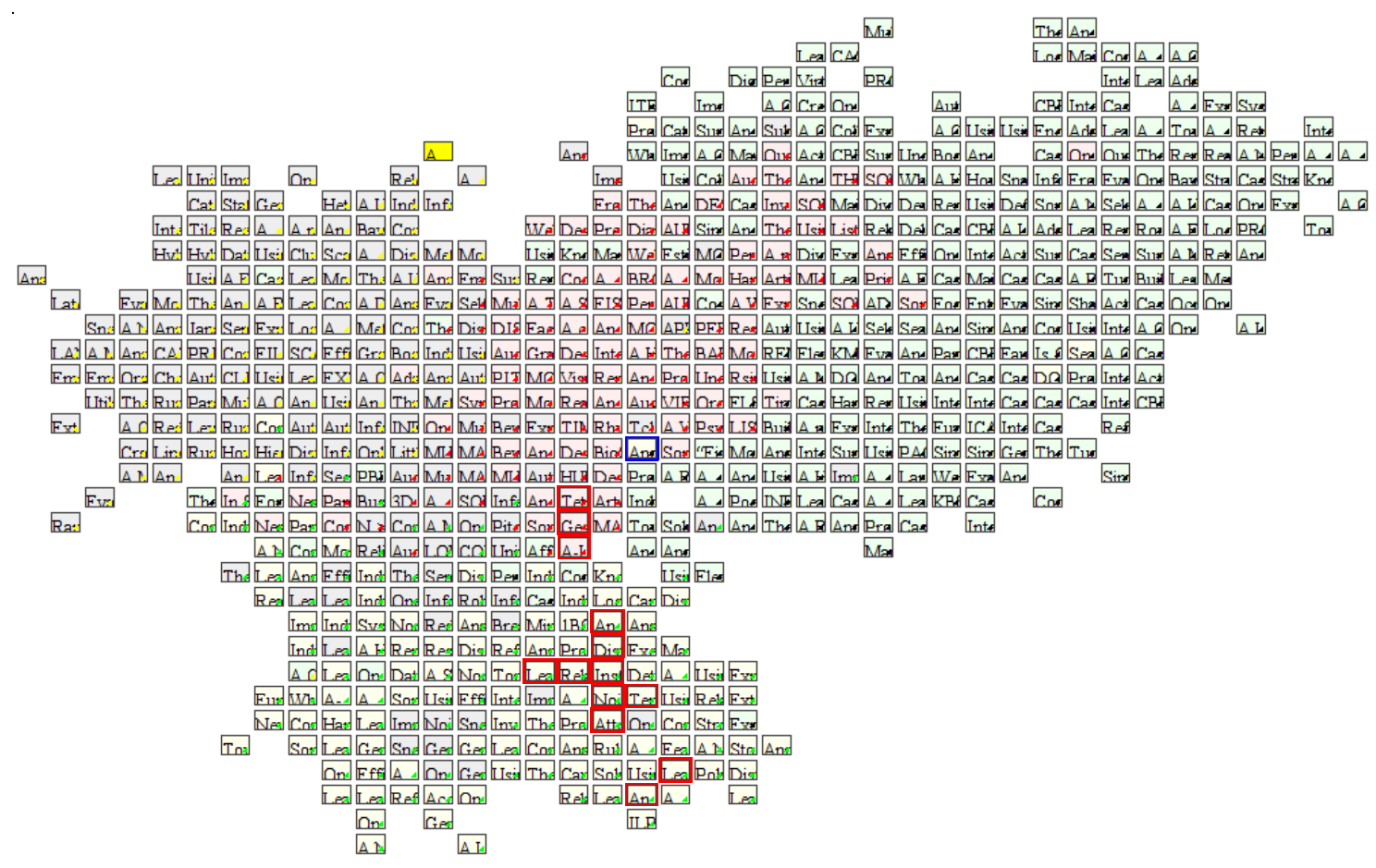

(b)

Figura 5.11: Exemplo de resultado de atualização incremental de agrupamentos para o corpus CBR-ILP-IR-SON. A cor de fundo de cada célula denota classes manualmente atribuídas aos elementos. O triângulo colorido no interior de cada célula denota o resultado do agrupamento. Agrupamento inicial, obtido por k-means sobre 340 documentos (a) e mapa final com 675 (b). 
No exemplo apresentado na Figura 5.11, foram inicialmente projetados 340 documentos do corpus CBR-ILP-IR-SON e aplicado o algoritmo $k$-means com número de agrupamentos fixado em quatro, número equivalente à quantidade de classes da classificação manual disponível para o corpus. Em seguida, o restante dos documentos foi adicionado ao mapa, mantendo-se atualizados os agrupamentos. A fim de avaliar o desempenho do algoritmo, cada um dos agrupamentos foi associado à classe a qual pertecem a maioria dos seus documentos. Quando da aplicação do algoritmo $k$-means, 134 dos documentos do primeiro agrupamento pertenciam à classe CBR, de um total de 140 documentos na classe. Ou seja, o agrupamento recupera (recalls) $96 \%$ dos documentos da classe. Os valores para as classes ILP, IR e SON foram, respectivamente, $100 \%, 70 \%$ e 93\%. Após a inclusão dos demais documentos, o percentual recuperado pelos agrupamentos para as classes CBR, ILP, IR e SON foram, respectivamente, 97\%, 96\%, 68\% e 93\%. Os valores permanecem praticamente estáveis, repetindo no mapa final as características do agrupamento inicial. Na Figura 5.11, as cores de fundo das células, que representam as classes manualmente atribuídas, não têm correspondência direta com as cores do triângulos que representam os agrupamentos, embora observe-se uma prevalência de certa associações, como triângulos pretos em células verdes, reflexo dos valores de recall apresentados. A não correspondência direta entre cores é resultado da aplicação independente do algoritmo de agrupamento, quen desconsidera as classes, e a respectiva atribuição de cores.

Eventualmente, observa-se uma degeneração da solução de agrupamento, com um ou mais agrupamentos desaparecendo e/ou com um dos agrupamentos predominando sobre os demais. A solução para este problema passaria por estratégias para a criação e eliminação de agrupamentos com base em uma ou mais medidas. Gupta e Grossman (2004) periodicamente eliminam centróides levando em conta o número de novos elementos associados ao mesmo, selecionando elementos aleatórios como novos centróides. O algoritmo leader (Hartigan, 1973), por sua vez, cria um novo agrupamento sempre que a distância de um ponto ao centróide supera um limite pré-estabelecido. Já o algoritmo Cobweb (Fisher, 1987) usa uma medida de ganho de informação. A adoção de uma dessas estratégias poderia resolver o problema. Outra possibilidade, além dos objetivos imediatos desta tese, seria o desenvolvimento de uma solução alternativa, que estenda a solução proposta nesta seção. No contexto da exploração realizada, considerou-se suficiente a possibilidade de, periodicamente ou por intervenção do usuário, refazer a solução inicial de agrupamento.

\subsubsection{Estratégia de atualização incremental de tópicos}

A construção da solução incremental para identificação de tópicos adotada considera a resposta a duas perguntas: (i) quando deve um tópico ser eliminado da relação de tópicos ? e (ii) quando devem ser novos tópicos acrescentados à relação de tópicos a fim de refletir alterações 
no conjunto de documentos. Descartou-se, de antemão, a possibilidade de refazer, a cada passo, todo o processo de extração de regras, tal qual descrito na Seção 5.2.2.

Seguindo os parâmetros de indução seletiva de regras de associação definidos no algoritmo $L W R$, a eliminação de regras não mais relevantes é simples: se, no algoritmo original, são apenas induzidas regras que possuem ao menos um termo entre os termos semente (Seção 5.2.1), devem ser eliminados todos os tópicos que não possuam entre seus termos ao menos um termo que ainda seja considerado semente.

A implementação de tal rotina requer, a cada alteração nos agrupamentos que dão origem aos tópicos, a atualização da lista de termos semente. Se há alteração nesta lista, os tópicos previamente extraídos devem ser verificados e eliminados, se necessário.

Por oposição, sempre que um novo termo semente é identificado, a extração de regras deve ser refeita. Neste caso, restringindo-se a indução de regras àqueles que possuam o novo termo semente. Assim, a indução de inicial de conjuntos de dois termos (2_itemsets), que considera o produto cartesiano do conjunto de termos semente $\left\{t_{1}, \ldots, t_{k}\right\}$ com o conjunto de todos os termos encontrados na seleção 1_itemsets, passa a considerar apenas o produto cartesiano dos novos termos semente com o conjunto de todos os termos encontrados na seleção (Algoritmo3).

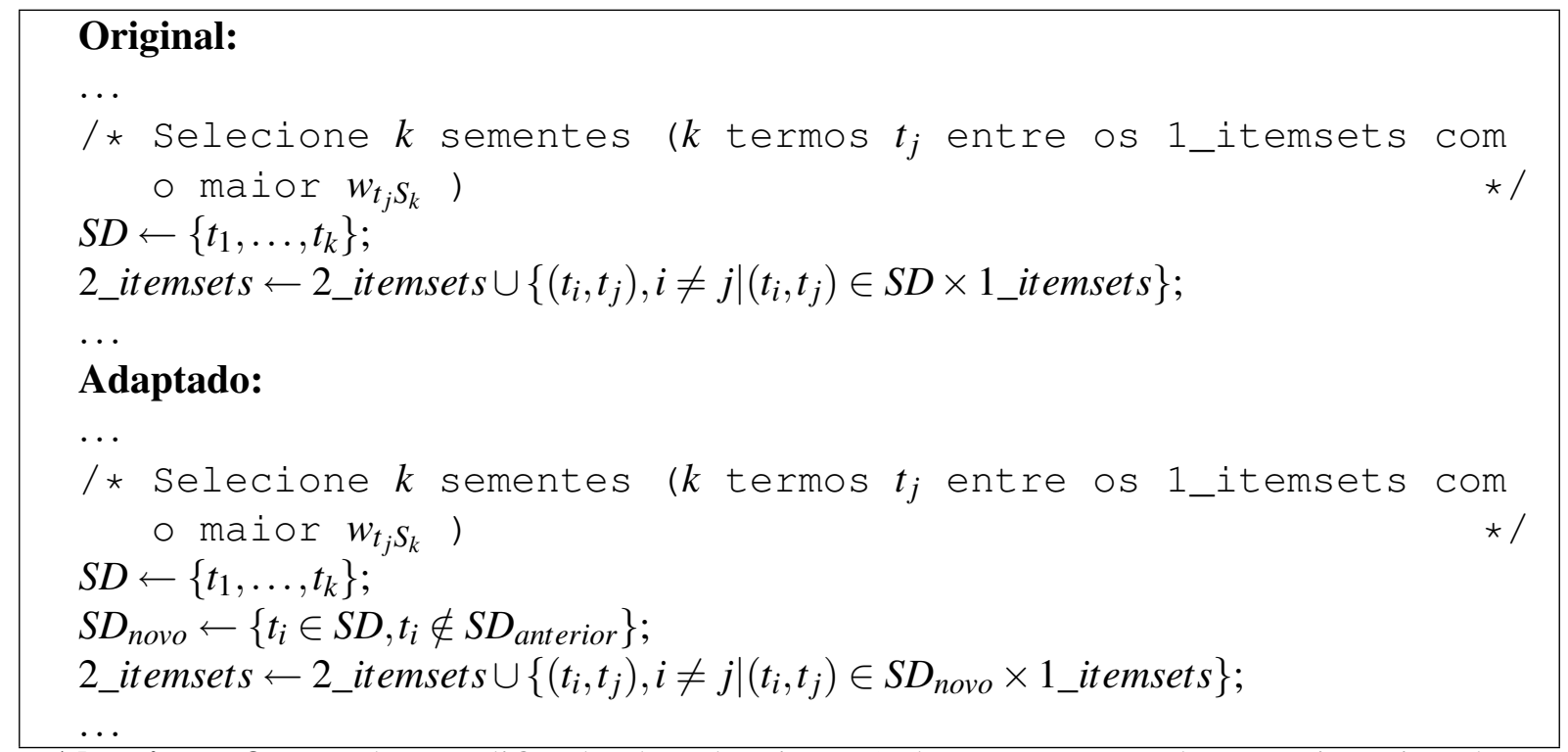

Algoritmo 3: Trecho modificado do Algoritmo 1 de geração e ordenação iterativa de regras de associação com peso local do Capítulo 5. $S D_{\text {anterior }}$ representa o conjunto de termos semente adotados na última execução do algoritmo.

A adoção dessas duas estratégias, que consideram alterações na lista de termos semente, ignora o eventual surgimento de novas relações para termos já presentes na lista. Por exemplo, na análise, em tempo real, de um fluxo de notícias, se um desportista vence uma competição importante, seu nome pode entrar na lista de termos e ser associado, em uma regra, a esta 
competição. Se, daí a pouco tempo, seu nome aparece em algum outro contexto, esta nova relação seria ignorada, caso o atleta ainda se mantivesse na lista. A fim de capturar situações como esta, adota-se a seguinte heurística: para cada termo semente, é mantida uma contagem da variação no seu suporte desde que foram induzidas regras para aquele termo. Sempre que forem induzidas regras para novos termos semente, o que indicaria uma mudança significativa no subconjunto de dados, seriam também induzidas regras para o termo semente cujo conjunto de documentos associados sofreu maior variação, recebendo ou perdendo elementos, ou seja, se o conjunto perdeu um documento, mas recebeu outro, é considerada uma variação de dois elementos (um perdido + um inserido).

Quatro opções de configuração foram introduzidas na aplicação a fim de limitar o custo computacional da atualização de tópicos : (i) utilização de rotina externa para extração de regras, desenvolvida em linguagem $\mathrm{C}$, cuja performance é superior ao Java, linguagem utilizada no desenvolvimento do restante da aplicação, (ii) limite máximo para o número de termos em uma regra, (iii) limite para o número de conjunto de termos frequentes extraídos, interrompendo o processo uma vez que uma quantidade mínima é extraída, e (iv) filtragem de termos por peso local. Esta última opção utiliza o mesmo peso adotado na seleção de termos semente, mantendo no processo de extração apenas aqueles termos que são proporcionalmente mais frequentes na seleção do que seria esperado se houvesse uma distribuição uniforme do termo ao longo da coleção. Em outras palavras, são mantidos os termos $t_{j}$ cujo peso $w_{t_{j} S_{k}}$ no subconjunto em questão $S_{k}$ é maior do que o tamanho relativo da seleção no corpus $C$ : $\left|S_{k}\right| /|C|$. Se, por exemplo, $80 \%\left(w_{t_{j} S_{k}}=0,8\right)$ das ocorrências de um termo aparecem em um subconjunto que representa apenas $20 \%$ do corpus, ele é mantido. Se o peso fosse inferior a $20 \%$, ele seria ignorado.

A adoção de uma versão paralela do algoritmo de extração de tópicos é outra alternativa para acelerar o processo. Almeida et al. (2008) desenvolveram uma versão paralela do algoritmo LWR (Algoritmo 1) que poderia ser adotada.

A Figura 5.12 apresenta a árvore de tópicos implementada na ferramenta incBoard. A principal diferença em relação a versão implementada no PEx é a presença, no primeiro nível da árvore, de nós representativos dos agrupamentos dos quais são extraídos os tópicos. Tais nós são identificados por ícones coloridos conforme a cor dos respectivos agrupamentos no mapa e acompanhados dos respectivos termos semente.

No exemplo da figura, tópicos foram extraídos em etapas intermediárias da formação de um mapa de documentos para um subconjunto do corpus Reuters (Lewis et al., 2004). Este subconjunto inclui parte dos documentos julgados como relevantes para pelo menos um dos temas, ou necessidades de informação, do conjunto de treino da tarefa de filtragem de conjuntos de documentos da conferência Text Retrieval Conference (TREC) de $2002{ }^{1}$. Para um

\footnotetext{
${ }^{1}$ http://trec.nist.gov/data/t2002_filtering.html
} 
tema específico, foram acrescentados documentos extraídos do conjunto de teste, totalizando quarenta documentos relativos ao tema. Este tema, Effects of global warming, foi selecionado por um pesquisador não relacionado a este trabalho, a quem foi solicitado que escolhesse um tema que despertasse a sua curiosidade. O corpus resultante contem 1.125 notícias, associadas a temas conhecidos, conforme julgado para a tarefa da TREC, e, para um destes temas, tem-se a garantia da presença de quarenta documentos. Espera-se que qualquer processo de extração de tópicos seja capaz de recuperar este tema específico, além de outros relacionados à tarefa da TREC.

Logo no primeiro mapa (Figura 5.12(c)), que adotou células em formato hexagonal (HexBoard), gerado com 70 documentos, destacam-se as notícias relacionadas com sequestros de crianças ocorridos na Bélgica. O tema Rescue of kidnapped children, ao qual estão associadas as notícias do caso belga, é o tema dominante do subconjunto de notícias selecionado, somando 120 notícias em um total de 1.125. Neste momento, um único tópico, [belgian, girl,kidnap], é capaz de cobrir os 20 documentos relacionados ao tema. Em seguida, novas notícias foram sendo adicionadas ao mapa, atualizando-se a árvore de tópicos a cada dez documentos adicionados. À medida que novas notícias foram sendo agregadas, outros aspectos do caso foram cobertos por novos tópicos, como, por exemplo, o tópico [scandal,belgian, sex], que refere-se a relação entre os casos de sequestro de crianças reportados e uma rede de pedofilia descoberta na Bélgica.

O tema Effects of global warming, menos frequente, aparece na árvore de tópicos (Figura 5.12(b) quando o número de documentos no mapa chega a 230 (Figura 5.12(d)), com o tópico [greenhouse, propos, emission], relacionado diretamente a uma proposta de redução na emissão de gases causadores do efeito estufa. Com a adição de mais notícias, quando o mapa conta com 650 documentos, surge o tópico [greenhouse,emission,warming], com o suporte de 27 notícias.

\subsection{Considerações finais}

Dois elementos, (i) a extração de tópicos sobre mapas de documentos e (ii) a exploração e refinamento de mapas com base em tópicos, combinam-se para permitir que os usuários capturem o conteúdo de uma coleção e extraiam informação relevante de coleções complexas de documentos.

O processo tem como ponto central um algoritmo de indução de regras de associação projetado para extrair tópicos de conjuntos de documentos eficientemente. Como ele explora os documentos com base na sua similaridade de conteúdo e adota um critério compatível para a identificação de termos relevantes em grupos de documentos similares, o algoritmo é capaz de 


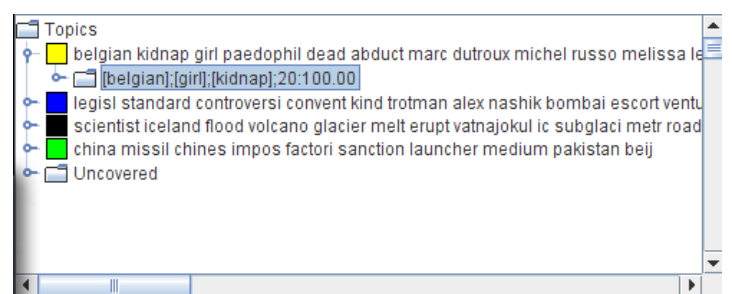

(a) 70 notícias

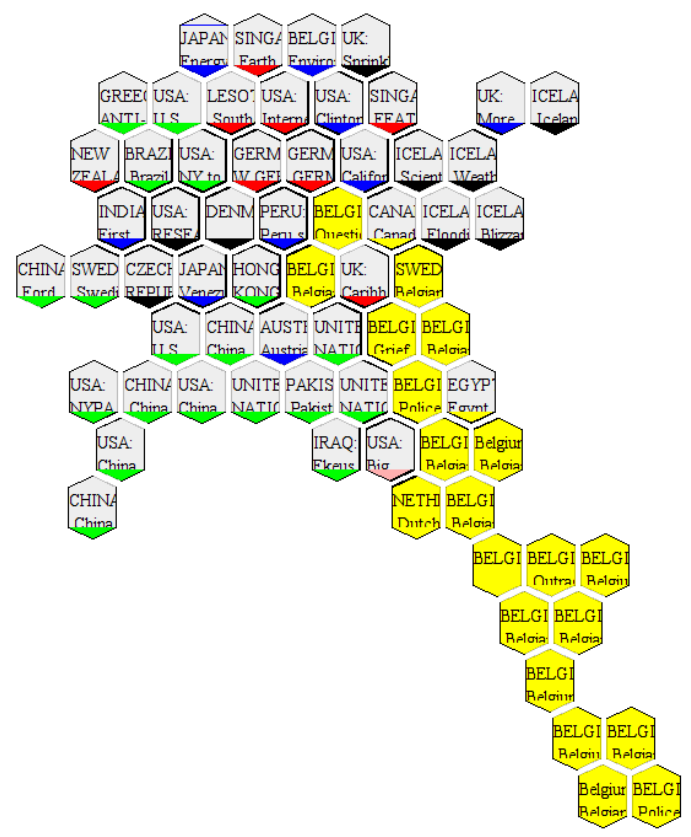

(c) 70 notícias

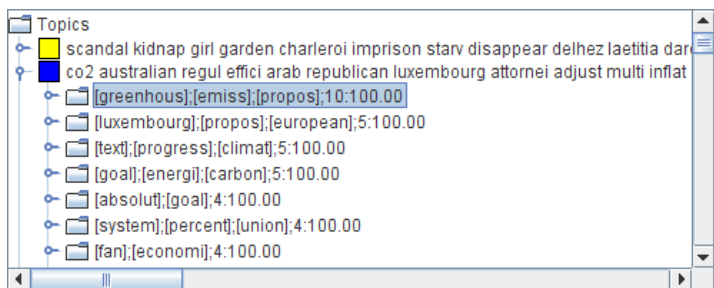

(b) 230 notícias

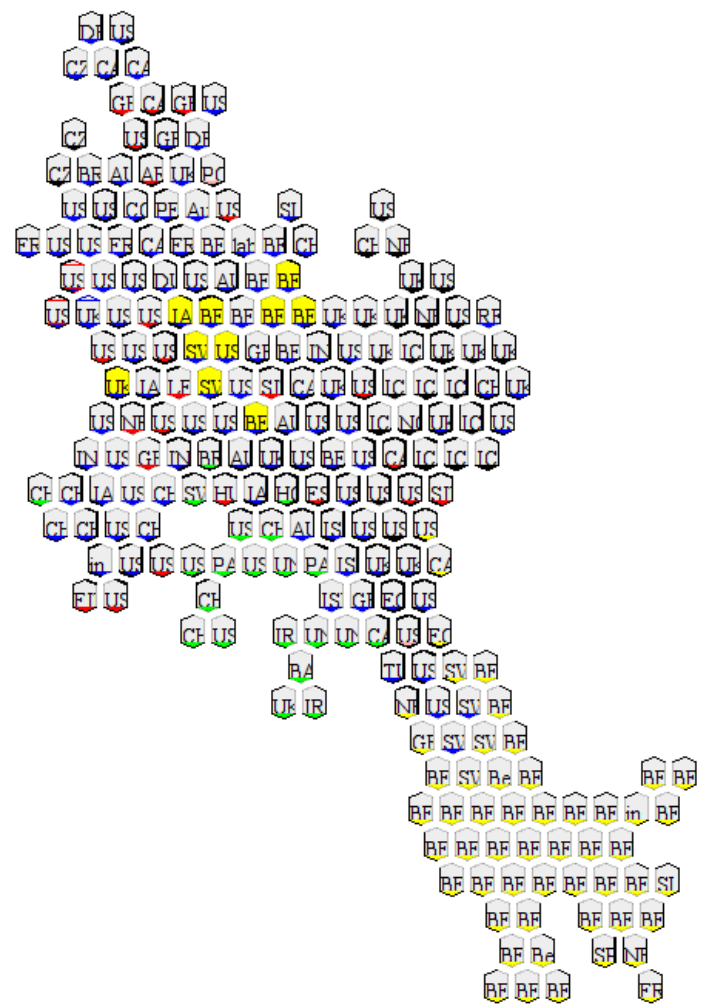

(d) 230 notícias

Figura 5.12: Árvores de tópicos - (a) e (b) - e respectivos mapas - (c) e (d) - para os primeiros documentos de um subconjunto do corpus Reuters. Os documentos relacionados aos tópicos selecionados em (a) e (b), são destacados em amarelo nos mapas (c) e (d), respectivamente.

encontrar associações de termos que descevem tópicos, sejam elas frequentes ou raras. Além disto, ele é capaz de retornar um conjunto de regras representativo dos temas abordados em todo o corpus. A cobertura do conjunto completo de documentos é alcançada com adoção de uma estratégia de particionamento e múltiplos reinícios que trata o problema da variância que pode ocorrer quando adota-se uma estratégia de cobertura sequencial para a indução.

Foram introduzidas ferramentas, adicionadas à plataforma PEx e também na ferramenta de visualização incremental incBoard, que auxiliam na exploração de coleções de documentos em 
mapas e possibilitam o refinamento dos tópicos extraídos. Tópicos são exibidos em uma árvore, são coordenados com os elementos do mapa, e podem ser editados, apagados, combinados e comparados enquanto o usuário navega por tópicos e inspeciona documentos relacionados. Os usuários também podem eliminar documentos do mapa em função dos tópicos a que pertencem, e gerar novos mapas que melhor refletem as suas intervenções, tanto no corpus quanto na lista de tópicos. Mapas que, por exemplo, incluem somente documentos relacionados aos tópicos relevantes remanescentes de uma análise podem ser submetidos a um novo processo de extração e exploração de tópicos, em um processo iterativo e interativo de mineração visual que é realimentado por si mesmo e pelas entradas providas pelo usuário para melhorar a sua capacidade de análise. Na ferramenta incBoard, a natureza incremental do algoritmo de posicionamento permite manter o mapa atualizado mesmo quando o usuário decide eliminar documentos não desejados. Isso evita a reconstrução do mapa, que é necessária quando é adotada uma solução não incremental para a projeção.

O desenvolvimento de uma aplicação que combina o posicionamento incremental de documentos no plano e a também incremental extração de tópicos demandou esforços para (i) manter o conjunto de tópicos atualizado, sem, no entanto refazer todo o processo, e (ii) manter atualizados subconjuntos de documentos similares, fundamentais para a aplicação do algoritmo de extração de tópicos adotado. O principal desafio na atualização do conjunto de tópicos foi evitar a repetição de todo o processo a cada novo documento adicionado, mantendo o seu custo computacional em níveis aceitáveis, permitindo a sua aplicação à medida que o mapa é construído. Diversas estratégias foram adotadas neste sentido.

A estratégia de atualização de agrupamento desenvolvida considera tanto o espaço conceitual original, na busca pelo agrupamento mais adequado a um dado elemento, tanto quanto a configuração do espaço projetado, quando restringe as opções de agrupamento consideradas. A solução tende a aproximar o resultado do agrupamento com a distribuição de elementos no mapa. No entanto, ocorre eventualmente uma degeneração da solução, o que não permitiu uma avaliação objetiva da estratégia. Em um cenário de aplicação imediata, propõe-se a adoção de outras abordagens, já estabelecidas, de agrupamento incremental. Acredita-se ser possível, com algum esforço de pesquisa, melhorar a estratégia proposta, incorporando elementos de outros algoritmos de agrupamento incremental, a fim de evitar os casos de degeneração verificados.

Outra possibilidade, sugerida quando da construção de mapas derivados, seria a utilização do conjunto de termos dos tópicos extraídos para gerar uma bag of words mais adequada. Para conjuntos dinâmicos de documentos, o posicionamento de novos elementos poderia ser guiado por novos valores para as medidas de similaridade. O impacto da alteração da medida de similaridade em mapas já parcialmente construídos deve ser investigado a fim de permitir a adoção desta estratégia. 
Capítulo 5. Regras de associação com peso local para identificar tópicos em mapas de documentos 


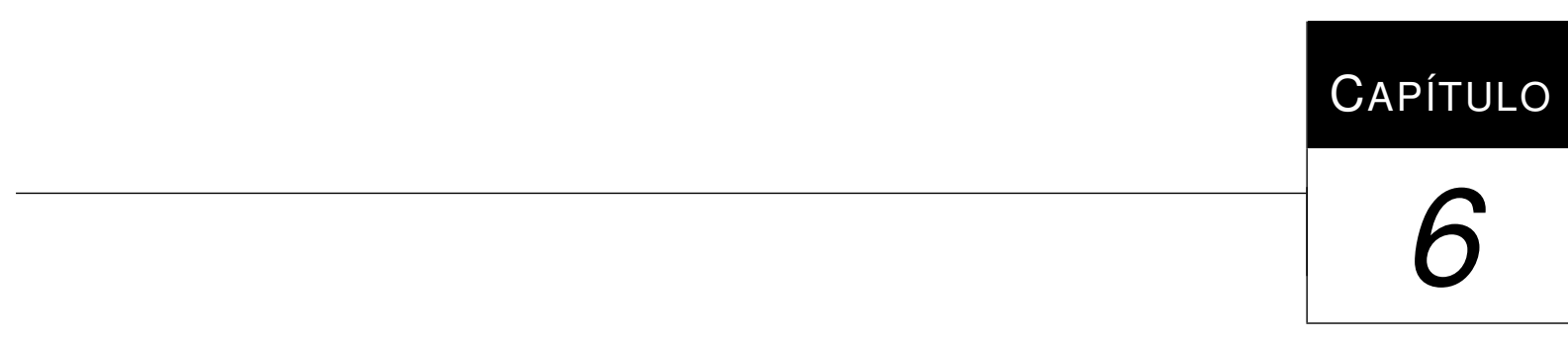

\section{Conclusão}

Neste capítulo são retomadas as contribuições da tese, confrontando-as. Na Seção 6.1 .2 são apresentadas outras contribuições desenvolvidas ao longo da elaboração da tese. Por fim, perspectivas de trabalhos futuros são descritas na Seção 6.2 .

\subsection{Contribuições}

\subsubsection{Contribuições principais}

As principais contribuições desta tese são:

1. Um novo algoritmo para a projeção incremental de conjuntos dinâmicos de dados multidimensionais. O algoritmo é capaz de manter uma disposição coerente à medida que elementos são adicionados ou removidos. O processo, inerentemente incremental e de baixa complexidade, utiliza um espaço dividido em células, análogo a um tabuleiro de xadrez, publicado em Pinho et al. (2009);

2. Uma visualização para conjuntos dinâmicos de dados multidimensionais que não sofre problemas de oclusão; 
3. Um algoritmo seletivo de indução de regras de associação que explora grupos de documentos similares, e, identificando termos relevantes, é capaz de encontrar associações de termos que descevem tópicos abordados em um corpus, sejam elas frequentes ou raras;

4. Um processo iterativo e interativo de mineração visual de textos que combina a extração de tópicos com a exploração de conjuntos documentos assistida por mapas visuais;

5. Um espaço incremental, fruto da união da extração de tópicos com a projeção incremental de dados, no qual tópicos e áreas de interesse são destacados e atualizados à medida que o conjunto analisado é modificado.

As contribuições principais são aplicáveis à visualização de domínios de conhecimento, um dos dez principais problemas não resolvidos em visualização, conforme identificado por Chen (2005), ainda que sua aplicação não esteja restrita a este domínio. Foram realizados estudos de caso que ilustram a sua aplicação na visualização de conjuntos de artigos científicos, principal fonte de informação na visualização de domínios de conhecimento.

A possibilidade de atualizar mapas de documentos, incorporando novos documentos e retirando aqueles que não mais são de interesse é compatível, com a evolução da pesquisa científica, em que novos estudos são constantentemente acrescentados à base intelectual de um domínio, muitos perdendo a relevância em um curto período, enquanto alguns poucos tornam-se refêrencia por um longo período. A implementação de uma visualização que reflita esta dinâmica é possível a partir dos resultados desta tese.

Uma vez que a incorporação e a retirada de elementos têm impacto nos demais elementos do mapa, também o oitavo problema destacado por Chen (2005), a mudança de paradigma, partindo da visualização da estrutura para a visualização da dinâmica de dados abstratos, é tratado. Por exemplo, é possível acompanhar o comportamento de elementos de interesse, como acontece no estudo realizado com o corpus Reuters, na Seção 4.5.2. Nesse exemplo, é possível acompanhar notícias de interesse e sua relação com outros notícias e com o conjunto de notícias como um todo, ao longo do tempo. Outra visualizações podem ser construídas de forma a explicitar aspectos de interesse na dinâmica dos elementos, ou de subconjuntos, o que não foi diretamente explorado nesta tese.

A integração de técnicas de visualização e mineração, como proposto no Capítulo 5, apoia a inferência visual. Ainda no que diz respeito ao suporte à detecção de relações de causalidade, inferência visual e predições (problema 9), uma questão central seria o desenvolvimento de algoritmos altamente sensíveis e seletivos. O algoritmo de indução de regras proposto possui ambas as características, podendo também ser direcionado pelos usuários para a exploração de areas específicas de um mapa de documentos. Outra questão destacada por Chen (2005) 
é a eliminação de ruído de fundo, o que, no cenário descrito no estudo de caso da Seção 5.4 é fruto da sinergia entre mineração e visualização, que culmina na eliminação de elementos indesejáveis.

\subsubsection{Outras contribuições}

As contribuições apresentadas nesta seção podem ser classificadas em duas categorias: (i) ferramentas e aplicações desenvolvidas e com relação direta com as contribuições apresentadas na Seção 6.1.1 e (ii) contribuições cujo tema tangencia os temas principais.

Foi desenvolvida uma interface de programação de aplicativos (Application Programming Interface - API) para o algoritmo incBoard, apresentado no Capítulo 4. A API permite a utilização do algoritmo em outras ferramentas de visualização, seja no domínio da visualização de domínios de conhecimento, seja em outros. Ela foi colocada a disposição em conjunto com exemplos de sua utilização no endereço http://infoserver.lcad.icmc.usp.br/ infovis2/incBoard.

Similarmente, foi também desenvolvida uma API para o algoritmo de indução de regras de associação apresentado no Capítulo 5. A fim de permitir a sua utilização em outros domínios, a API não faz referência a conjunto de termos, trabalhando sobre uma matriz que associa linhas e colunas. Este descolamento do domínio da mineração de textos permite explorar o seu uso em outros domínios. Ela foi colocada a disposição em conjunto com exemplos de sua utilização no endereço http://infoserver.lcad.icmc.usp.br/infovis2/LWR.

O desenvolvimento da ferramenta Voromap e a respectiva avaliação com usuários (Pinho et al. 2006) serviu de inspiração inicial para o desenvolvimento da visualização adotada nesta tese. No artigo, defende-se o uso de áreas para a representação de elementos de dados em oposição à utilização de glifos pontuais. É importante notar que a solução apresentada nesta tese tem uma vantagem adicional com relação àquela adotada na ferramenta Voromap: a utilização de células de Voronoi para a representação de itens de dados tem como desvantagem a criação de elementos de tamanho variado, sem que este tamanho tenha relação direta com propriedades intrínsecas ao elemento relacionado. Na visualização proporcionada pelo incBoard, cada elemento tem tamanho fixo, eliminando-se interferências indesejáveis.

A avaliação com usuários desenvolvida para a ferramenta PEx-WEB (Paulovich et al. 2008b), bem como o conhecimento adquirido durante a sua preparação, testes preliminares e avaliação dos resultados proveu subsídios importantes para o desenvolvimento do processo integrado de mineração aqui proposto, e mostrar que soluções que apresentam mapas de documentos com tópicos: (i) podem ser utilizadas por usuários com pouco treinamento, (ii) documentos são apropriadamente apresentados e (iii) permitem aos usuários inferir tópicos as- 
sociados a regiões do mapa. A avaliação foi realizada através da Internet, pelo endereço http: //infoserver.lcad.icmc.usp.br/infovis2/PExWebUserEvalIntro.

A aplicação do algoritmo de extração de regras de associação a tarefa específica de apoio à realização de uma revisão sistemática foi avaliada no artigo de Malheiros et al. (2007). Também neste artigo, é adotada uma versão preliminar do processo integrado de mineração por tópicos, com a exploração de vizinhanças etiquetadas por tópicos e subsequente eliminação documentos irrelevantes ou identificação de agrupamentos de interesse. $\mathrm{O}$ algoritmo de extração de tópicos foi aplicado no contexto da identificação de variantes temáticas em comunidades de pesquisa e comparado com outra abordagem de extração de tópicos em Chen et al. (2008).

Duas ferramentas foram desenvolvidas especificamente para o desenvolvimento desta tese: (i) TopicPEx e (ii) incBoard. TopicPEx é uma variante da Projection Explorer (PEx) (Paulovich et al., 2007) focada na exploração de conjuntos de documentos por tópicos. Diversas contribuições foram feitas ao desenvolvimento da PEx no decorrer da elaboração da tese. A descrição de algumas destas contribuições pode ser encontrada na monografia de qualificação (Pinho, 2006).

$\mathrm{Na}$ ferramenta incBoard estão implementadas as contribuições descritas nos capítulos 4 e 5. Ela foi totalmente desenvolvida em Java, seguindo o padrão de arquitetura ModelViewController. Foram desenvolvidos elementos distintos para o posicionamento de elementos, exibição do tabuleiro, preprocessamento de elementos e controle da interface. Cada um destes elementos é executado em thread específica, possibilitando melhor desempenho em equipamentos com múltiplos processadores, já que tais tarefas são executadas em paralelo.

Uma versão específica da PEx foi desenvolvida, desta vez como parte do processo de exploração de potenciais cenários de integração entre ferramentas de mineração de textos e visualização, tendo resultado na publicação de um artigo (Ibekwe-SanJuan et al., 2008). Nela, sentenças de resumos de artigos científicos são classificadas quanto à informação que carregam. Tais sentenças são destacadas quando os resumos são visualizados. Nesta versão, também é possível restringir certas operações aos documentos que possuam uma determinada classe de informação. Por exemplo, é possível gerar etiquetas para uma área selecionada pelo usuário, porém considerando apenas aqueles documentos que possuam descrição de trabalhos futuros, uma das classes de informação detectadas pelo sistema.

Uma extensão da ferramenta incBoard foi desenvolvida para destacar a similaridade entre cada par de vizinhos no tabuleiro (Pinho e Oliveira, 2009). Acredita-se que a nova versão auxilie na identificação de agrupamentos e subconjuntos de elementos similares pelos usuários. 


\subsection{Trabalhos futuros}

Entre as possibilidades futuras de investigação, destacam-se (i) a aplicação do algoritmo incremental de projeção em cenários específicos de uso, (ii) a melhoria de pontos específicos do algoritmo e (iii) a investigação de novas possibilidades de interação e visualização.

Um vez definidos cenários específicos de uso, como, por exemplo, a aplicação do processo integrado de mineração no apoio à realização de revisões sistemáticas, avaliações formais devem ser conduzidas com usuários.

Deve ser investigada com maior profundidade a aplicação do algoritmo incBoard em outros domínios que não a análise exploratória de conjuntos de documentos textuais. Cabe também a investigação de um caso particular de conjuntos dinâmicos, em que itens não são adicionados ou removidos, mas cujo conteúdo sofre alteração. Hoje, o tratamento deste tipo de ocorrência se dá pela exclusão da cópia defasada do item e da adição da nova cópia. Talvez seja possível otimizar o processo. Por exemplo, pequenas alterações poderiam ser identificadas, e sendo irrelevantes, decidir-se por dispensar qualquer alteração no mapa.

Existem também oportunidades de melhoria em pontos específicos do processo, como, por exemplo, na escolha de vizinho mais próximo (Seção 4.3.1), que poderia adotar uma melhor estratégia de busca. Da mesma maneira, outras opções para a medida de erro adotada podem ser avaliadas.

O trabalho realizado para integrar a identificação de tópicos em um ambiente de visualização de conjuntos dinâmicos (Capítulo 5) sugere a investigação de uma solução híbrida para a atualização de agrupamentos no mapa, que (i) considere medidas de similaridade definidas no espaço original, (ii) considere a disposição de elementos no mapa, e (iii) adote estratégias para a criação e remoção de agrupamentos, evitando a degeneração da solução.

Termos presentes em tópicos extraídos do mapa poderiam ser usados para a melhoria do cálculo da similaridade entre documentos. Neste sentido, sugere-se a investigação (i) da sua efetividade na melhoria do cálculo de similaridade, e (ii) do impacto da alteração do cálculo de similaridade à medida que o mapa é construído. Esta segunda questão é análoga ao problema, já citado, da atualização do conteúdo de elementos.

O estudo específico do refinamento interativo de mapas de documentos apoiado na extração de tópicos é objeto da dissertação do mestrando Renato Rodrigues Oliveira da Silva sob orientação da Prof. Dr. Maria Cristina Ferreira de Oliveira, ora em curso (da Silva, 2006). Tal investigação poderia considerar também o espaço incremental proposto para a construção de mapas de documentos.

Cogita-se ainda a utilização de tópicos extraídos para dirigir o processo de adição de novos elementos, funcionando como pontos de referência conceituais. Estes pontos de referência 
poderiam ser também criados e posicionados pelos usuários, que assim guiariam o processo de construção do mapa, adequando-o aos seus interesses. A mesma possibilidade se estenderia a manipulação direta de itens presentes no tabuleiro. 


\section{Referências Bibliográficas}

Agrawal, R.; SRIKAnt, R. Fast algorithms for mining association rules. Proceedings of the 20th International Conference on Very Large Data Bases, VLDB, p. 487-499, 1994.

Alahakoon, D.; Halgamuge, S.; Srinivasan, B. Dynamic Self-Organizing Maps with Controlled Growth for Knowledge Discovery. IEEE Transactions on Neural Networks, v. 11, n. 3, p. 601-614, 2000 .

Alencar, A. B.; Paulovich, F. V.; Minghim, R.; Filho, M. G. D. A.; Oliveira, M. C. F. D. Similarity-based visualization of time series collections: An application to analysis of streamflows. In: IV'08: Proceedings of the 2008 12th International Conference Information Visualisation, Washington, DC, USA: IEEE Computer Society, 2008, p. 280-286.

Almeida, M.; Oliveira, M. C. F.; Mello, R. Parallel algorithms for a visual text mining platform. In: Proceedings of the 20th IASTED International Conference on Parallel and Distributed Computing and Systems (PDCS), Orlando, FL, USA, 2008, p. 145-153.

Almeida, M. O. Uma ferramenta para mineração visual de dados usando mapas em árvore e suas aplicações. Dissertação de Mestrado, Universidade Salvador, 2003.

Alvarez, L.; Alvarez, W.; Asaro, F.; Michel, H. Extraterrestrial cause for the Cretaceous-Tertiary extinction. Science, v. 208, n. 4448, p. 1095, 1980.

Amarasiri, R.; Alahakoon, D.; Smith, K.; Premaratne, M. HDGSOMr: A High Dimensional Growing Self-Organizing Map Using Randomness for Efficient Web and Text Mining. Proceedings IEEE/WIC/ACM International Conference on Web Intelligence, p. 215-221, 2005. 
Amir, A.; Aumann, Y.; Feldman, R.; Fresko, M. Maximal association rules: A tool for mining associations in text. Journal of Intelligent Information Systems, v. 25, n. 3, p. 333-345, 2005.

Andrews, K.; Kienreich, W.; Sabol, V.; Becker, J.; Droschl, G.; Kappe, F.; Granitzer, M.; Auer, P.; Tochtermann, K. The InfoSky visual explorer: exploiting hierarchical structure and document similarities. Information Visualization, v. 1, n. 3/4, p. 166-181, 2002.

ASUNCION, A.; NEWMAN, D. UCI machine learning repository. University of California, Irvine, School of Information and Computer Sciences, http://www.ics.uci.edu/ mlearn/MLRepository.html, 2007.

BAeZA-YATES, R.; RibeiRo-Neto, B. Modern information retrieval. Addison-Wesley Harlow, England, 1999.

BAlZER, M.; Deussen, O. Voronoi treemaps. In: INFOVIS '05: Proceedings of the 2005 IEEE Symposium on Information Visualization, Washington, DC, USA: IEEE Computer Society, 2005, p. 7.

Barioni, M.; Botelho, E.; Faloutsos, C.; Razente, H.; Traina, A.; Júnior, C. Data Visualization in RDBMS. In: Proceedings IASTED International Conference on Information Systems and Databases ISDB, 2002, p. 264-269.

Basalaj, W. Proximity visualization of abstract data. Tese de Doutoramento, University of Cambridge Computer Laboratory, 2000.

BAUdon, O.; AUILlans, P.; JARRY, F. Using xml-topic map on a pda. In: XML conference \& exposition, 2001, p. 1.

BAUMER, E.; FisheR, D. Smarter blogroll: An exploration of social topic extraction for manageable blogrolls. 2008, p. 155-155.

Bederson, B. B. Photomesa: a zoomable image browser using quantum treemaps and bubblemaps. In: UIST '01: Proceedings of the 14th annual ACM Symposium on User Interface Software and Technology, New York, NY, USA, 2001, p. 71-80.

Berners-Lee, T.; Hendler, J.; Lassila, O. The Semantic Web:A new form of Web content that is meaningful to computers will unleash a revolution of new possibilities. Scientific American, 2001. 
Bess, C.; Lehmann, J.; Patel, B.; Schmidt, K.; Phifer, W.; Williamson, J. The grand challenges of information technology. Engineering Management Conference, 2003. IEMC'03. Managing Technologically Driven Organizations: The Human Side of Innovation and Change, p. 610-615, 2003.

Blackmore, J.; Mitkkulainen, R. Visualizing high-dimensional structure with the incremental grid growing neural network. In: Proceedings of the 12th International Conference on Machine Learning, San Francisco, CA, USA, 1995, p. 55-63.

Disponível em Citeseer.ist.psu.edu/blackmore95visualizing.html

Bookstein, A.; Klein, S.; Raita, T. Clumping properties of content-bearing words. Journal of the American Society for Information Science, v. 49, n. 2, p. 102-114, 1998.

Borg, I.; Groenen, P. Modern multidimensional scaling: Theory and applications. Springer, 2005.

BÖRner, K.; Chen, C.; BoyACK, K. Visualizing Knowledge Domains. Annual Review of Information Science and Technology ARIST, v. 37, p. 179-255, 2003.

Byron, L.; WATtenberg, M. Stacked graphs Ü geometry and aesthetics. Visualization and Computer Graphics, IEEE Transactions on, v. 14, n. 6, p. 1245-1252, 2008.

Chalmers, M. A linear iteration time layout algorithm for visualising high-dimensional data. In: VIS '96: Proceedings of the 7th Conference on Visualization, Los Alamitos, CA, USA: IEEE Comp. Society. Press, 1996, p. 127-132.

CHEN, C. Information Visualization: Beyond the Horizon. Springer, 2004.

CHEN, C. Top 10 unsolved information visualization problems. IEEE Computer Graphics and Applications, v. 25, n. 4, p. 12-16, 2005.

Chen, C. Citespace II: Detecting and visualizing emerging trends and transient patterns in scientific literature. Journal of the American Society for Information Science and Technology, v. 57, n. 3, p. 359-377, 2006.

Chen, C.; Ibekwe-SanJuan, F.; Pinho, R.; Zhang, J. The impact of the sloan digital sky survey on astronomical research: The role of culture, identity and international collaboration. In: Proceedings of the 10th Conferenceof the International Society for Knowledge Organization (ISKO), 2008, p. 7. 
Chen, H.; Dumais, S. Bringing order to the web: automatically categorizing search results. In: CHI '00: Proceedings of the SIGCHI conference on Human factors in computing systems, New York, NY, USA: ACM Press, 2000, p. 145-152.

Chen, K.-Y.; LuesukPrasert, L.; ChOU, S.-C. T. Hot topic extraction based on timeline analysis and multidimensional sentence modeling. IEEE Trans. on Knowl. and Data Eng., v. 19, n. 8, p. 1016-1025, 2007.

Chengzhi, Z.; Qingguo, Z. Topic navigation generation using topic extraction and clustering. 2008, p. 333-339.

Cherfi, H.; NApoli, A.; Toussaint, Y. Towards a Text Mining Methodology Using Frequent Itemsets and Association Rules. Soft Computing Journal, v. 11, 2004.

Cilibrasi, R.; Vitani, P. Clustering by Compression. IEEE Transactions on Information Theory, v. 51, n. 4, p. 1523-1545, 2005.

Cooke, N. J.; Neville, K.; Rowe, A. L. Procedural network representations of sequential data. Human-Computer Interaction, v. 11, n. 1, p. 29-68, 1996.

DEAN, K. Blogging + Video = Vlogging. Wired News, 2005.

Disponível em http://www.wired.com/news/digiwood/0,1412,68171, 00 . html (Acessado em 2006.08.10)

Dourish, P.; Chalmers, M. Running Out of Space: Models of Information Navigation. In: People and computers IX. Proceedings of Human-Computer Interaction-HCI'94, 1994.

Dumais, S.; Furnas, G.; Landauer, T.; Deerwester, S.; Harshman, R. Using latent semantic analysis to improve access to textual information. Proceedings of the SIGCHI conference on Human factors in computing systems, p. 281-285, 1988.

Egghe, L.; Rousseau, R. Co-citation, bibliographic coupling and a characterization of lattice citation networks. Scientometrics, v. 55, p. 349-361, 2002.

Eler, D. M.; Nakazaki, M. Y.; Paulovich, F. V.; Santos, D. P.; Oliveira, M. C. F.; Espirito Santo Neto, J. B.; Minghim, R. Multidimensional visualization to support analysis of image collections. In: Proceedings of the XXI Brazilian Symposium on Computer Graphics and Image Processing - SIBGRAPI, Campo Grande, Brazil: IEEE Computer Society, 2008, p. 289-296.

Faloutsos, C.; Lin, K.-I. Fastmap: A fast algorithm for indexing, data mining and visualization of tradicional and multidimedia datasets. In: Proceedings of the ACM 
International Conference on Management of Data (SIGMOD), San Jose, California, USA, 1995, p. 163-174.

FAYYAD, U.; PiateTsky-Shapiro, G.; SMYth, P. From data mining to knowledge discovery: an overview. Advances in knowledge discovery and data mining table of contents, p. 1-34, 1996.

FISHER, D. H. Knowledge acquisition via incremental conceptual clustering. Machine Learning, v. 2, n. 2, p. 139-172, 1987.

FRANCHIn, W. J. Adição e avaliação de estímulos sonoros como ferramenta de apoio à exploração visual de dados. Dissertação de Mestrado, Instituto de Ciências Matemáticas e de Computação - Universidade de São Paulo, 2007.

Franchin, W. J.; Watanabe, L. S.; Pinho, R.; Levkowitz, H.; Minghim, R. Development, implementation and evaluation of sonification tools for point- and surfacebased data exploration. In: IV '09: 13th International Conference Information Visualisation (em publicação), 2009.

Frantzi, K. T.; Ananiadou, S.; Tsuji, J.-I. The c-value/nc-value method of automatic recognition for multi-word terms. In: ECDL '98: Proceedings of the Second European Conference on Research and Advanced Technology for Digital Libraries, London, UK: Springer-Verlag, 1998, p. 585-604.

FREITAS, A. Understanding the crucial differences between classification and discovery of association rules: a position paper. ACM SIGKDD Explorations Newsletter, v. 2, n. 1, p. 65-69, 2000.

GARCIA, E. SVD and LSI tutorial 1: Understanding SVD and LSI. 2006.

Disponível em http: //www.miislita.com/information-retrieval-tutorial/ svd-lsi-tutorial-1-understanding.html (Acessado em 2006.08.30)

Geng, L.; Hamilton, H. J. Interestingness measures for data mining: A survey. $A C M$ Computing Surveys, v. 38, n. 3, p. 9, 2006.

Goebel, M.; Gruenwald, L. A survey of data mining and knowledge discovery software tools. ACM SIGKDD Explorations Newsletter, v. 1, n. 1, p. 20-33, 1999.

GRIMES, S. Unstructured data and the 80 percent rule. 2008.

Disponível em http://www.clarabridge.com/default.aspx?tabid=137 $\&$ ModuleID=635 \\&ArticleID=551 (Acessado em 2009.01.05) 
Gupta, C.; Grossman, R. GenIc: A single pass generalized incremental algorithm for clustering. In: SIAM International Conference on Data Mining, SIAM, 2004.

Hand, D. J.; Smyth, P.; Mannila, H. Principles of data mining. Cambridge, MA, USA: MIT Press, 2001.

Hartigan, J. Clustering. Annual Reviews in Biophysics and Bioengineering, v. 2, n. 1, p. 81-102, 1973.

Hassan-Montero, Y.; Herrero-SOlana, V. Improving tag-clouds as visual information retrieval interfaces. In: Proceedings of the I International Conference on Multidisciplinary Information Sciences and Technologies, InSciT2006. Mérida, Spain, 2006.

Havre, S.; Hetzler, B.; Nowell, L. ThemeRiver: visualizing theme changes over time. Information Visualization, 2000. InfoVis 2000. IEEE Symposium on, p. 115-123, 2000.

Havre, S.; Hetzler, E.; Whitney, P.; Nowell, L. ThemeRiver: Visualizing Thematic Changes in Large Document Collections. IEEE Transactions on Visualization and Computer Graphics, v. 8, n. 1, p. 9-20, 2002.

HEARst, M. User interfaces and visualization. In: BAEZA-YATES, R.; RIBEIRO-NETO, B., eds. Modern information retrieval, cáp. User Interfaces and Visualization, Addison-Wesley Harlow, England, p. 257-323, 1999.

Hearst, M. A.; Pedersen, J. O. Reexamining the cluster hypothesis: scatter/gather on retrieval results. In: SIGIR '96: Proceedings of the 19th annual international ACM SIGIR conference on Research and development in information retrieval, New York, NY, USA: ACM Press, 1996, p. 76-84.

HeEr, J.; CARD, S. K.; LAnday, J. A. Prefuse: a toolkit for interactive information visualization. In: CHI '05: Proceedings of the SIGCHI conference on Human factors in computing systems, New York, NY, USA: ACM Press, 2005, p. 421-430.

Hetzler, E. G.; Crow, V. L.; Payne, D. A.; Turner, A. E. Turning the bucket of text into a pipe. In: INFOVIS '05: Proceedings of the 2005 IEEE Symposium on Information Visualization, Washington, DC, USA: IEEE Computer Society, 2005, p. 12.

Holanda Ferreira, A. B. Novo dicionário eletrônico aurélio versão 5.0. POSITIVO INFORMÁTICA LTDA, 2004.

Ibekwe-SanJuan, F.; Chen, C.; Pinho, R. Identifying strategic information from scientific articles through sentence classification. In: (ELRA), E. L. R. A., ed. Proceedings 
of the Sixth International Language Resources and Evaluation (LREC'08), Marrakech, Morocco, 2008.

IBEKWE-SAnJuAn, F.; SAnJuAn, E. From term variants to research topics. Journal of Knowledge Organization (ISKO), v. 29 - special issue on Human Language Technology, p. 181-197, 2002.

International Organisation for Standardization (ISO); International Electrotechnical Commission (IEC) Topic maps. International Standard ISO/IEC 13250:1999, 1999.

JANJUSEVIC, T.; IZQUIERDO, E. Layout methods for intuitive partitioning of visualization space. 2008, p. 88-93.

JOLLIFFE, I. T. Principal component analysis [electronic resource]. Springer, 2002.

Jones, K. S.; Walker, S.; Robertson, S. E. A probabilistic model of information retrieval: development and comparative experiments. Information Processing and Management, v. 36 , n. 6 , p. $779-808,2000$.

KASKI, S. Data exploration using self-organizing maps. Tese de Doutoramento, Finnish Academy of Technology, 1997.

Kaski, S.; Honkela, T.; Lagus, K.; Kohonen, T. WEBSOM-Self-organizing maps of document collections. Neurocomputing, v. 21, n. 1-3, p. 101-117, 1998.

KLEINBERG, J. Bursty and hierarchical structure in streams. In: KDD '02: Proceedings of the eighth ACM SIGKDD international conference on Knowledge discovery and data mining, New York, NY, USA: ACM, 2002, p. 91-101.

KoHonen, T. The self-organizing map. Proceedings of the IEEE, v. 78, n. 9, p. 1464-1480, 1990.

KoHonen, T. Exploration of very large databases by self-organizing maps. In: Proceedings of the IEEE International Conference on Neural Networks, 1997, p. 1-6.

Kruskal, J. Nonmetric multidimensional scaling: A numerical method. Psychometrika, v. 29, n. 2, p. 115-129, 1964a.

Kruskal, J.; Wish, M. Multidimensional Scaling. Sage Publications, 1978.

KRUSKAL, J. B. Multidimensional scaling by optimizing goodness of fit to a nonmetric hypothesis. Psychometrika, v. 29, p. 1-27, 1964 b. 
LAW, M.; JAIN, A. Incremental Nonlinear Dimensionality Reduction by Manifold Learning. IEEE Transactions on Pattern Analysis and Machine Intelligence, v. 28, n. 3, p. 377-391, 2006.

LAW, M.; ZhANG, N.; JAIn, A. Nonlinear Manifold Learning for Data Stream. Proceedings SIAM Data Mining, p. 33-44, 2004.

LE Grand, B.; Soto, M. Topic maps et navigation intelligente sur le web sémantique. In: AS CNRS Web Sémantique, 2002a.

Le Grand, B.; Soto, M. Visualisation of the Semantic Web: Topic Maps visualisation. Proceedings of the Sixth International Conference on Information Visualisation, 2002, p. 344-349, 2002b.

Lewis, D. D.; YAng, Y.; Rose, T. G.; LI, F. Rcv1: A new benchmark collection for text categorization research. Journal of Machine Learning Research, v. 5, p. 361-397, 2004.

Li, M.; Badger, J. H.; Chen, X.; Kwong, S.; Kearney, P.; Zhang, H. An information-based sequence distance and its application to whole mitochondrial genome phylogeny. Bioinformatics, v. 17, n. 2, p. 149-154, 2001.

Disponível em Citeseer.ist.psu.edu/li01information.html (Acessado em 2006.08.10)

Li, Y.; Shapiro, L.; Bilmes, J. A Generative/Discriminative Learning Algorithm for Image Classification. Proceedings 10th IEEE International Conference on Computer Vision ICCV'05, v. 2, p. 1605-1612, 2005.

LIU, B.; HsU, W.; MA, Y. Mining association rules with multiple minimum supports. In: KDD '99: Proceedings of the fifth ACM SIGKDD international conference on Knowledge discovery and data mining, New York, NY, USA: ACM Press, 1999, p. 337-341.

Lopes, A.; Minghim, R.; Melo, V.; PAulovich, F. Mapping texts through dimensionality reduction and visualization techniques for interactive exploration of document collections. Proceedings of SPIE, v. 6060, p. 271-282, 2006.

Lopes, A. A.; Pinho, R.; Paulovich, F. V.; Minghim, R. Visual text mining using association rules. Computers and Graphics, v. 31, n. 3, p. 316-326, 2007.

Luhn, H. A Statistical Approach to Mechanized Encoding and Searching of Literary Information. IBM Journal of Research and Development, v. 1, n. 4, p. 309, 1957. 
Malheiros, V.; Hohn, E.; Pinho, R.; Mendonca, M.; Maldonado, J. C. A visual text mining approach for systematic reviews. In: ESEM '07: Proceedings of the First International Symposium on Empirical Software Engineering and Measurement, Washington, DC, USA: IEEE Computer Society, 2007, p. 245-254.

Miller, N.; Wong, P.; Brewster, M.; Foote, H. TOPIC ISLANDS TM-A Wavelet-Based Text Visualization System. Visualization'98. Proceedings, p. 189-196, 1998.

Minghim, R.; Levkowitz, H.; Nonato, L.; Watanabe, L.; Salvador, V.; Lopes, H.; Pesco, S.; TAVAREs, G. Spider Cursor: a simple versatile interaction tool for data visualization and exploration. Proceedings of the 3rd international conference on Computer graphics and interactive techniques in Australasia and South East Asia, p. 307-313, 2005.

Minghim, R.; Paulovich, F.; Andrade lopes, A. Content-based text mapping using multi-dimensional projections for exploration of document collections. Proceedings of SPIE, v. 6060, p. 60600S, 2006.

Morrison, A.; Chalmers, M. A pivot-based routine for improved parent-finding in hybrid mds. Information Visualization, v. 3, n. 2, p. 109-122, 2004.

Morrison, A.; Ross, G.; Chalmers, M. A Hybrid Layout Algorithm for Sub-Quadratic Multidimensional Scaling. In: INFOVIS '02: Proceedings of the IEEE Symposium on Information Visualization (InfoVis'02), Washington, DC, USA: IEEE Computer Society, 2002, p. 152.

Nagano, S.; Inaba, M.; Mizoguchi, Y.; IIDA, T.; Kawamura, T. Ontology-based topic extraction service from weblogs. 2008, p. 468-475.

Nurnberger, A.; Detyniecki, M. Visualizing changes in data collections using growing self-organizing maps. In: Proceedings of the International Joint Conference on Neural Networks IJCNN'02, 2002, p. 1912-1917.

Ogawa, Y.; Morita, T.; Kobayashi, K. A fuzzy document retrieval system using the keyword connection matrix and a learning method. Fuzzy Sets and Systems, v. 39, n. 2, p. $163-179,1991$.

Oliveira, G. L.; MendonçA, M. G. Expertext: Uma ferramenta de combinação de múltiplos classificadores naive bayes. In: Anales de la 4 a Jornadas Iberoamericanas de Ingeniería de Software e Ingeniería de Conocimiento, 2004, p. 317-332. 
Oliveira, M. C. F.; Levkowitz, H. From visual data exploration to visual data mining: a survey. IEEE Transactions on Visualization and Computer Graphics, v. 9, n. 3, p. 378-394, 2003.

PACIFIC NORTHWESt NATIONAL LABORATORY In-spire visual document analysis. 2006. Disponível em http://in-spire.pnl.gov/(Acessado em 2006.08.30)

PACIFIC NorthWESt NATIONAL LABORATORY In-spire frequently asked questions. 2006. Disponível em http://in-spire.pnl.gov/faq.html (Acessado em 2006.08.30)

Pardo, T.; Rino, L.; Nunes, M. GistSumm: A summarization tool based on a new extractive method. Lecture Notes in Computer Science, p. 210-218, 2003.

Paulovich, F.; Minghim, R. Text map explorer: a tool to create and explore document maps. In: Proceedings of Information Visualization, 2006, 2006a, p. 245-251.

Paulovich, F. V. Mapeamento de dados multi-dimensionais - integrando mineração e visualização. Tese de Doutoramento, Instituto de Ciências Matemáticas e de Computação Universidade de São Paulo, 2008.

Paulovich, F. V.; Minghim, R. Text map explorer: a tool to create and explore document maps. In: Proceedings of the Tenth International Conference on Information Visualization IV '06, Washington, DC, USA: IEEE Comp. Society, 2006b, p. 245-251.

Paulovich, F. V.; Nonato, L. G.; Minghim, R.; Levkowitz, H. Least square projection: A fast high-precision multidimensional projection technique and its application to document mapping. IEEE Transactions on Visualization and Computer Graphics, v. 14, n. 3, p. 564-575, 2008a.

Paulovich, F. V.; Oliveira, M. C. F.; Minghim, R. The projection explorer: A flexible tool for projection-based multidimensional visualization. In: Proceedings of the XX Brazilian Symposium on Computer Graphics and Image Processing - SIBGRAPI, Belo Horizonte, Brazil: IEEE CS Press, 2007, p. 27-36.

Paulovich, F. V.; Pinho, R.; Botha, C. P.; Heiss, A.; Minghim, R. Pex-web: Content-based visualization of web search results. In: IV '08: Proceedings of the 2008 12th International Conference Information Visualisation, Washington, DC, USA: IEEE Computer Society, 2008b, p. 208-214.

PINHO, R. Mineração visual de conjuntos de documentos:regras de associação e identificação de tópicos em mapas. Monografia de Qualificação, Instituto de Ciências Matemáticas e de 
Computação, Departamento de Ciências da Computação e Estatística, Universidade de São Paulo, 2006.

Pinho, R.; Lopes, A.; Oliveira, M. C. F. Incremental board: A grid-based space for visualizing dynamic data sets. In: Proceedings of the 2009 Annual ACM Symposium on Applied Computing, New York, NY, USA: ACM, 2009, p. 1757-1764.

Pinho, R.; Oliveira, M. C. F. Hexboard: Conveying pairwise similarity in a incremental visualization space. In: IV '09: 13th International Conference Information Visualisation (em publicação), 2009.

Pinho, R.; Oliveira, M. C. F.; Minghim, R.; Andrade, M. G. Voromap: A voronoi-based tool for visual exploration of multi-dimensional data. In: Proceedings of Information Visualization, 2006, p. 39-44.

PlatT, J. FastMap, MetricMap, and Landmark MDS are all Nystrom algorithms. In: Proceedings of the 10th International Conference on Artificial Intelligence and Statistics, 2005.

PratT, W. Dynamic organization of search results using the UMLS. American Medical Informatics Association Fall Symposium, v. 480, p. 4, 1997.

Quirin, A.; Cordón, O.; Santamaría, J.; Vargas-Quesada, B.; Moya-Anegón, F. A new variant of the pathfinder algorithm to generate large visual science maps in cubic time. Information Processing and Management, v. 44, n. 4, p. 1611-1623, 2008.

Robertson, S.; Callan, J. Guidelines for the trec 2002 filtering track. 2002. Disponível em http://trec.nist.gov/data/filtering/T1lfilter_ guide.html (Acessado em 2009.04.13)

Rodden, K.; BASAlAJ, W.; Sinclair, D.; Wood, K. Evaluating a Visualization of Image Similarity as a Tool for Image Browsing. Proceedings of the 1999 IEEE Symposium on Information Visualization, 1999.

Rodden, K.; Basalaj, W.; Sinclair, D.; Wood, K. Does organisation by similarity assist image browsing? Proceedings SIGCHI Conference on Human factors in computing systems, p. 190-197, 2001.

Salton, G.; Buckley, C. Term-weighting approaches in automatic text retrieval. Information Processing and Management: an International Journal, v. 24, n. 5, p. 513-523, 1988. 
Salton, G.; Wong, A.; YAng, C. S. A vector space model for automatic indexing. Commun. ACM, v. 18, n. 11, p. 613-620, 1975.

SAmmon, J. W. A nonlinear mapping for data structure analysis. IEEE Transactions on Computers, v. 18, n. 5, p. 401-409, 1969.

SAnJuAn, E.; IBEKWE-SANJuAn, F. Text mining without document context. Information Processing and Management, v. 42, n. 6, p. 1532-1552, 2006.

Schaefer, G.; Ruszala, S. Image database Navigation on a hierarchical MDS grid. Lecture notes in computer science, v. 4174, p. 304, 2006.

Schreck, T.; Bernard, J.; Tekusova, T.; Kohlhammer, J. Visual cluster analysis of trajectory data with interactive kohonen maps. 2008, p. 3-10.

SChVANEVEldT, R. W., ed. Pathfinder associative networks: studies in knowledge organization. Norwood, NJ, USA: Ablex Publishing Corp., 1990.

Secretaria de EducAÇÃo Fundamental, Brasil Parâmetros curriculares nacionais : história, geografia. Secretaria de Educação Fundamental., 1997.

Seifert, C.; Kump, B.; Kienreich, W.; Granitzer, G.; Granitzer, M. On the beauty and usability of tag clouds. 2008, p. 17-25.

Sharma, A.; PALIWAL, K. K. Fast principal component analysis using fixed-point algorithm. Pattern Recognition Letters, v. 28, n. 10, p. 1151-1155, 2007.

SHNEIDERMAN, B. Tree visualization with tree-maps: 2-d space-filling approach. $A C M$ Transactions on Graphics, v. 11, n. 1, p. 92-99, 1992.

Silva, R. R. O. Refinamento interativo de mapas de documentos apoiado por extração de tópicos. Monografia de Qualificação, Instituto de Ciências Matemáticas e de Computação, Departamento de Ciências da Computação e Estatística, Universidade de São Paulo, 2006.

SkUPIN, A. A Cartographic Approach to Visualizing Conference Abstracts. IEEE Computer Graphics and Applications, v. Volume 22, Issue 1, p. 50-58, 2002.

SKUPIN, A. A picture from a thousand words [information visualization]. Computing in Science \& Engineering, v. Volume 6, Issue 5,, p. 84 - 88, 2004.

SKUPIN, A.; FABRIKANT, S. Spatialization methods: A cartographic research agenda for non-geographic information visualization. Cartography and Geographic Information Science, v. 30, n. 2, p. 99-119, 2003. 
Small, H. Visualizing science by citation mapping. J. Am. Soc. Inf. Sci., v. 50, n. 9, p. 799-813, 1999.

Sorkine, O.; Cohen-Or, D. Least-squares meshes. Shape Modeling Applications, 2004. Proceedings, p. 191-199, 2004.

SPENCE, R. Information Visualization. Addison Wesley, 2000.

TAN, A. Text mining: The state of the art and the challenges. 1999.

Disponível em citeseer.ist.psu.edu/tan99text.html (Acessado em 2006.08.10)

TAN, P.; Steinbach, M.; KUmar, V. Introduction to data mining. Addison-Wesley, 2006.

Tejada, E.; Minghim, R.; Nonato, L. G. On improved projection techniques to support visual exploration of multidimensional data sets. Information Visualization, v. 2, n. 4, p. 218-231, 2003.

Telles, G. P.; Minghim, R.; Paulovich, F. V. Visual analytics: Normalized compression distance for visual analysis of document collections. Computers and Graphics, v. 31, n. 3, p. 327-337, 2007.

Thomas, J.; Cook, K. A visual analytics agenda. IEEE Computer Graphics and Applications, v. 26, n. 1, p. 10-13, 2006.

WeISS, G. M. Mining with rarity: a unifying framework. ACM SIGKDD Explorations Newsletter, v. 6, n. 1, p. 7-19, 2004.

WiSE, J. A. The ecological approach to text visualization. Journal of the American Society for Information Science, v. 50, n. 13, p. 1224-1233, 1999.

Witten, I.; Frank, E. Data Mining:: Practical Machine Learning Tools and Techniques. Morgan Kaufmann, 1999.

Wong, P.; Foote, H.; Adams, D.; Cowley, W.; Thomas, J. Dynamic visualization of transient data streams. In: Proceedings IEEE Information Visualization, 2003, p. 97-104.

Wong, P.; Thomas, J. Visual Analytics. IEEE Computer Graphics and Applications, v. 24, n. 5, p. 20-21, 2004.

Wong, P.; Whitney, P.; Thomas, J. Visualizing association rules for text mining. Proceedings of the 1999 IEEE Symposium on Information Visualization (Info Vis' 99), p. 120-123, 1999. 
Wood, J.; DyKes, J. Spatially ordered treemaps. IEEE Transactions on Visualization and Computer Graphics, v. 14, n. 6, p. 1348-1355, 2008.

World Wide Web Consortium Semantic Web. 2005.

Disponível em http://www.w3.org/2001/sw/(Acessado em 2009.01.05)

Yamamoto, C. H.; Oliveira, M. C. F.; Rezende, S. O. Including the user in the knowledge discovery loop: interactive itemset-driven rule extraction. In: SAC '08: Proceedings of the 2008 ACM symposium on Applied computing, New York, NY, USA: ACM, 2008, p. 1212-1217.

Yoon, Y.; LeE, G. Text categorization based on boosting association rules. 2008, p. $136-143$.

ZAMir, O.; ETZIONi, O. Grouper: a dynamic clustering interface to web search results. Computer Networks, v. 31, n. 11-16, p. 1361-1374, 1999.

Zeng, H.; He, Q.; Chen, Z.; MA, W.; MA, J. Learning to cluster web search results. Proceedings of the 27th annual international conference on Research and development in information retrieval, p. 210-217, 2004.

Zhou, X.; Hu, X.; ZhAng, X. Topic signature language models for ad hoc retrieval. IEEE Transactions on Knowledge and Data Engineering, v. 19, n. 9, p. 1276-1287, 2007. 


\section{Apêndice A Trabalhos associados}

- Trabalhos publicados e aceitos para publicação:

Chen, C.; Ibekwe-Sanjuan, F.; Pinho, R.; Zhang, J. The impact of the sloan digital sky survey on astronomical research: The role of culture, identity and international collaboration. In: Proceedings of the 10th Conference of the International Society for Knowledge Organization (ISKO), 2008, p. 7.

Ibekwe-SanJuan, F.; Chen, C.; Pinho, R. Identifying strategic information from scientific articles through sentence classification. In: (ELRA), E. L. R. A., ed. Proceedings of the Sixth International Language Resources and Evaluation (LREC'08), Marrakech, Morocco, 2008.

Franchin, W. J.; Watanabe, L. S.; Pinho, R.; Levkowitz, H.; Minghim, R. Development, implementation and evaluation of sonification tools for point- and surface- based data exploration. in: IV '09: 13th International Conference Information Visualisation (em publicação), 2009.

Lopes, A. A.; Pinho, R.; Paulovich, F. V.; Minghim, R. Visual text mining using association rules. Computers and Graphics, v. 31, n. 3, p. 316-326, 2007.

Malheiros, V.; Hohn, E.; Pinho, R.; Mendonca, M.; Maldonado, J. C. A visual text mining approach for systematic reviews. In: ESEM '07: Proceedings of the First International Symposium on Empirical Software Engineering and Measurement, Washington, DC, USA: IEEE Computer Society, 2007, p. 245-254. 
Paulovich, F. V.; Pinho, R.; Botha, C. P.; Heijs, A.; Minghim, R. Pex-web: Content-based visualization of web search results. In: IV '08: Proceedings of the 2008 12th International Conference Information Visualisation, Washington, DC, USA: IEEE Computer Society, 2008b, p. 208-214.

Pinho, R.; Oliveira, M. C. F.; Minghim, R.; Andrade, M. G. Voromap: A voronoi-based tool for visual exploration of multi-dimensional data. In: Proceedings of Information Visualization, 2006, 2006, p. 39-44.

Pinho, R.; Lopes, A.; Oliveira, M. C. F. Incremental board: A grid-based space for visualizing dynamic data sets. In: Proceedings of the 2009 Annual ACM Symposium on Applied Computing, New York, NY, USA: ACM, 2009, p. 1757-1764. (Best Paper Award in the Information System Theme - Prêmio de melhor trabalho na área Sistemas de Informação).

Pinho, R.; Oliveira, M. C. F. HexBoard: Conveying Pairwise Similarity in an Incremental Visualization Space. In: IV '09: 13th International Conference Information Visualisation (em publicação), 2009.

\section{- Trabalhos em elaboração:}

Pinho, R.; Lopes, A.; Rodrigues, R.; Minghim, R.; Oliveira, M. C. F. Rule-based topic mining to assist user centered visual exploration of document collections.

Pinho, R.; Lopes, A.; Oliveira, M. C. F. Visualizing change in dynamic data sets: the Incremental Board Visualization. In: Convidado para submissão para edição especial do Multimedia Tools and Applications Journal (MTAP) com os melhores trabalhos em Multimídia e Visualização (MMV track) do 2009 Annual ACM Symposium on Applied Computing 
